\title{
DENDROECOLOGY OF FORESTS IN MISSOURI: DISTURBANCE AND INTEGRATION OVER MULTIPLE CENTURIES
}

A Dissertation
presented to
the Faculty of the Graduate School
University of Missouri - Columbia
In Partial Fulfillment
of the Requirements for the Degree
Doctor of Philosophy
Br. Rose-Marie Muzika, Dissertation Supervisor
MAY 2013
CHAD B. KING


The undersigned, appointed by the Dean of the Graduate School, have examined the dissertation entitled:

\section{DENDROECOLOGY OF FORESTS IN MISSOURI: DISTURBANCE AND INTEGRATION OVER MULTIPLE CENTURIES}

presented by Chad B. King

A candidate for the degree of Doctor of Philosophy, and hereby certify that in their opinion it is worthy of acceptance.

Professor Rose-Marie Muzika

Professor Richard Guyette

Professor David Larsen

Professor Candace Galen

Professor Grant Elliott 


\section{ACKNOWLEDGEMENTS}

A dream was fulfilled during the past five years. However, for anyone who has gone through the trials and tribulations as a doctoral student knows that to fulfill this dream takes a village of people committed to helping and supporting this endeavor.

My committee waited patiently and I grew with them over the past five years from a student to a colleague. I greatly enjoyed the conversations we had during this time and I know it made me a better scientist. Most of all, I want to thank Rose-Marie for her energy, guidance, and opportunities to shine during my time at the University of Missouri. She was the best advisor that I could have worked with to complete this dissertation.

My dad demonstrated a strong work ethic for me at an early age. I have to give him credit for teaching me to stay the course during the difficult times. My mom taught me to be vigilant, a trait that is required to be an effective scientist.

Finally, and most importantly, I extend my love to my wife and son. My wife was the rock of the family during the past five years. She fully understood the rigors of a doctoral program and was a sympathetic voice. Thank you to my son for reminding me what was most important and making me laugh. 


\section{TABLE OF CONTENTS}

ACKNOWLEDGEMENTS ...................................................... ii

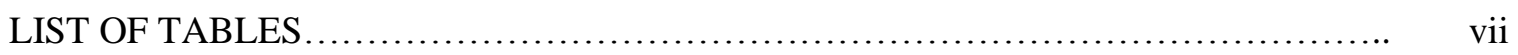

LIST OF FIGURES........................................................... ix

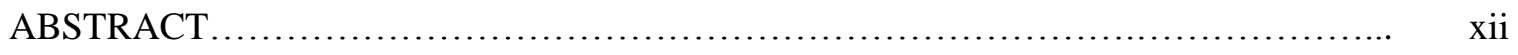

\section{CHAPTER 1}

A REVIEW OF ECOLOGICAL DISTURBANCE THEORY AND

DISTURBANCES IN NORTH AMERICAN FORESTS

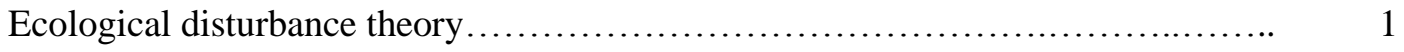

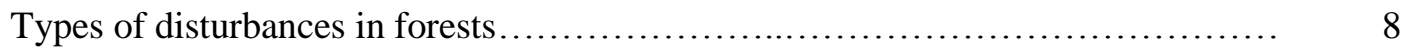

Disturbance interaction.................................................. 21

Dissertation objectives.................................................... 26

\section{CHAPTER 2}

DENDROECOLOGY OF SHADE-INTOLERANT PINUS ECHINATA

(MILL.) INDICATES VARIABLE RESPONSES TO GAP DYNAMICS

OVER 300 YEARS

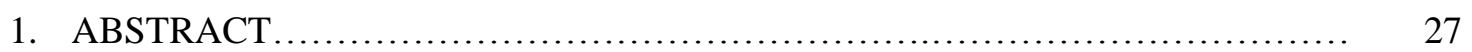

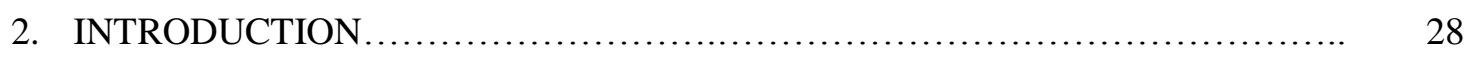

Disturbance in P. echinata forests of Missouri

Study Objectives

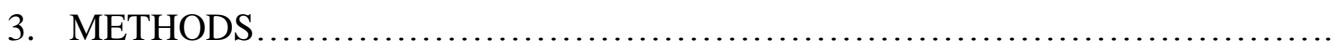

Study sites

Assessing disturbance dynamics

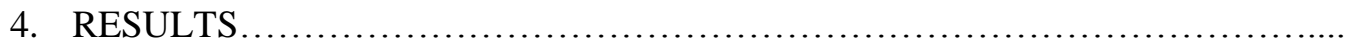

P. echinata release analysis

Growth rates and patterns in $P$. echinata

5. DISCUSSION. 
Canopy disturbance dynamics

Growth rates and patterns in $P$. echinata

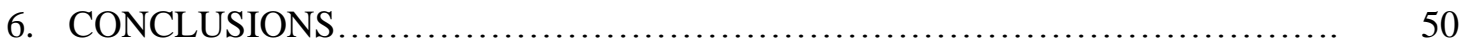

CHAPTER 3

A MULTI-SITE ASSESSMENT OF HISTORIC CANOPY

DISTURBANCE AND CANOPY ACCESSION IN MISSOURI

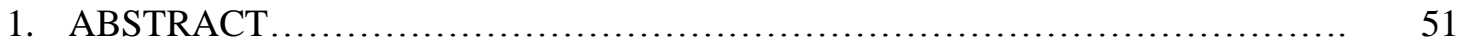

2. INTRODUCTION ...................................................... 52

Using basal area increment to identify disturbance events

Chapter rationale and objectives

3. METHODS

Field Methods

Laboratory Methods

Calculating basal area increment

Regime shift analysis for changes in growth

Analysis of growth changes

4. RESULTS

Descriptive analysis of releases and suppressions

Patterns of growth change and disturbance

MOFEP annual and decadal disturbance

Changes in duration and frequency of disturbance

5. DISCUSSION.

Historic disturbance patterns at sites in Missouri

Assessment of historic disturbance dynamics

6. CONCLUSIONS. 


\section{CHAPTER 4}

DROUGHT, FIRE, AND GROWTH RELEASE: INTERACTIONS

BETWEEN HISTORIC DISTURBANCES AND THEIR EFFECT ON THE

PERSISTENCE OF OAK-PINE FORESTS IN THE MISSOURI OZARKS 1700-1940

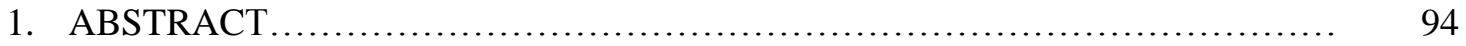

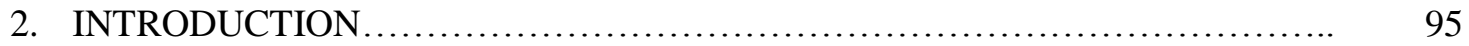

Assessing single disturbance events in forests

Multiple disturbances in oak-pine forest of Missouri

Chapter objectives

3. METHODS

Field and laboratory methods

Disturbance analysis

Disturbance associations

Disturbance, radial growth, and establishment

4. RESULTS

Disturbance analysis

Disturbance associations

Disturbance, radial growth, and establishment

5. DISCUSSION.

Multiple disturbances in oak-pine forests

Associations between disturbance types

Radial growth following discrete fire events

\section{CHAPTER 5}

ASSESSMENT OF DISTURBANCE, TOPOGRAPHY, AND CLIMATE ON TREE GROWTH

1. ABSTRACT 


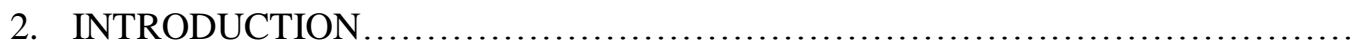

Role of disturbance in forests

Using dendrochronology to study disturbances

Climate and competition in oak-pine forests of Missouri

Chapter objectives

3. METHODS

Study site

Tree-ring series standardization and climate

Drought and growth

Canopy disturbance

4. RESULTS.

ARSTAN statistics for shortleaf pine and white oak

Climate correlation analysis

Drought and growth analysis

Growth release analysis

5. DISCUSSION

Climate variables and growth

Disturbance: drought and growth releases

6. CONCLUSIONS

\section{CHAPTER 6}

SYNTHESIS AND CONCLUSIONS

Effects of multiple disturbances on radial growth in pine and oak

Conceptual synthesis of disturbance in the Missouri Ozarks. 


\section{LIST OF TABLES}

Table

Page

2.1 Descriptive statistics of 367 P. echinata and locations of seven study sites in the Missouri Ozarks....

2.2 Analysis of mean diameter $(\mathrm{cm})$ of $P$. echinata at age 50 in three temporal categories..

3.1 Descriptive statistics of growth change for 14 P. echinata sites in Missouri............. 68

3.2 Descriptive statistics of growth change for 19 Q. alba sites in Missouri....

3.3 Canopy accession of $P$. echinata and $Q$. alba at five sites in the Missouri Ozarks

3.4 Median understory residence time (years) (MRT) and diameter inside bark (cm) for Pinus and Quercus species.

3.5 Decadal analysis of the percentage of P. echinata and Q. alba trees that exhibited releases and suppressions.

3.6 Decadal analysis of the percentage of $Q$. alba trees that exhibited releases and suppressions $1780-1980$.

3.7 Decadal analysis of the percentage of $P$. echinata and $Q$. coccinea/Q. velutina trees that exhibited releases and suppressions 1800-1980.

3.8 Canopy accession of $Q$. alba five sites in Missouri.

3.9 Canopy accession of P. echinata and Quercus species at the nine Missouri Ozark Forest Ecosystem Project.

4.1 Descriptive fire and release statistics of four sites in the Missouri Ozarks during the temporal range of fire events at the four study sites

4.2 Radial growth differences 1,2, and 3 years following a fire in which $>2$ trees were scarred at Mill Hollow using Wilcoxon signed ranks test $(\mathrm{p}<0.05)$.

4.3 Radial growth differences 1,2 , and 3 years following a fire in which $>2$ trees were scarred at Hwy. 19 using Wilcoxon signed ranks test $(\mathrm{p}<0.05)$

4.4 Radial growth differences 1, 2, and 3 years following a fire in which $>2$ trees were

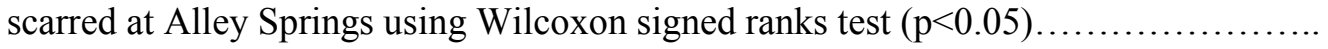

4.5 Radial growth differences 1, 2, and 3 years following a fire in which $>2$ trees were scarred at Eck Tract using Wilcoxon signed ranks test $(\mathrm{p}<0.05)$.

5.1 Descriptive statistics of ARSTAN output for shortleaf pine and white oak at Mill Hollow and Current River Natural Area. 
5.2 Pearson correlation analysis of ring-width indices for shortleaf pine and white oak to

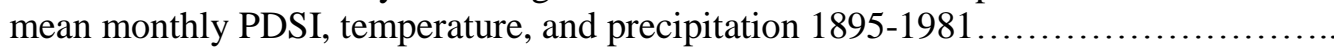

5.3 Mean differences in growth of shortleaf pine and white oak prior and during severe

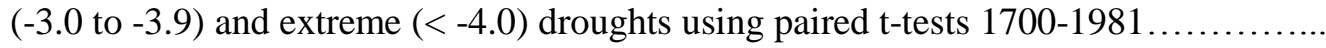

5.4 Mean differences in 5 year mean growth of shortleaf pine and white oak prior and subsequent to extreme $(<-4.0)$ droughts using paired t-tests $1700-1981 \ldots \ldots \ldots \ldots \ldots \ldots$ 


\section{LIST OF FIGURES}

Figure $\quad$ Page

1.1 Conceptual model of system disturbance and the effect of disturbance dynamics (frequency, magnitude)

1.2 The effects of a change in the frequency and/or magnitude of a single disturbance regime on the structure and processes of the system.

1.3 The effects of multiple disturbance regimes on a system and the consequences of changes in one or more disturbance regimes.

2.1 Locations of the seven study sites in Missouri.....

2.2 Examples of growth patterns and regime shift analysis of Pinus echinata in the Missouri Ozarks with known pith dates.

2.3 Release analysis and growth patterns of P. echinata in the Missouri Ozarks....

2.4 Growth patterns of $P$. echinata during the first 50 years of growth at seven sites in the Missouri Ozarks.

3.1 Location of study sites in Missouri

3.2 Example of regime shift analysis for P. echinata \#RTS001 remnant....

3.3 Linear regression models of diameter at breast height and bark width for P. echinata and $Q$. alba.

3.4 Frequency of releases and suppressions - Alley Springs

3.5 Frequency of releases and suppressions - Current River Natural Area....

3.6 Frequency of releases and suppressions - Mill Hollow

3.7 Frequency of releases and suppressions - Eck Tract

3.8 Frequency of releases and suppressions - Hwy. 19

3.9 Frequency of releases and suppressions - Lower Rock Creek.

3.10 Frequency of releases and suppressions - MOFEP Site 2

3.11 Frequency of releases and suppressions - MOFEP Site 3

3.12 Frequency of releases and suppressions - MOFEP Site 4.

3.13 Frequency of releases and suppressions - MOFEP Site 6.

3.14 Examples of canopy accession identified in pine and oak at sites in Missouri 
3.15 Examples of trees that established in the understory and attained the canopy following a release $>100 \%$.

3.16 Canopy accession by decade at oak-pine sites in Missouri.

3.17 Frequency of releases and suppressions - Wegener Woods.

3.18 Frequency of releases and suppressions - Babler State Park.

3.19 Frequency of releases and suppressions - Jack's Fork.

3.20 Frequency of releases and suppressions - Greasy Creek.....

3.21 Frequency of releases and suppressions - MOFEP Site 1.

3.22 Frequency of releases and suppressions - MOFEP Site 5......

3.23 Frequency of releases and suppressions - MOFEP Site 7.....

3.24 Frequency of releases and suppressions - MOFEP Site 8 .

3.25 Frequency of releases and suppressions - MOFEP Site 9.

3.26 Canopy accession by decade at oak sites in Missouri

3.27 Canopy accession by decade at select MOFEP sites in Missouri.

4.1 Superposed epoch analysis of fire year and mean reconstructed PDSI. .

4.2 Superposed epoch analysis for release year and mean reconstructed PDSI

4.3 Superposed epoch analysis for fire year and proportion of releases.

4.4 Disturbance events (fire, drought, proportion of releases) at Mill Hollow 1700-1940.

4.5 Disturbance events (fire, drought, proportion of releases) at Hwy. 19 1800-1940......

4.6 Disturbance events (fire, drought, proportion of releases) at Alley Springs 1750-1940

4.7 Disturbance events (fire, drought, proportion of releases) at Eck Tract 1730-1940....

5.1 Annual and 5 year moving average ARSTAN chronologies for shortleaf pine and white oak.

5.2a,b Five year moving average tree-ring indices and growth release events for Current River white oak

5.3a,bFive year moving average tree-ring indices and growth release events for Mill Hollow shortleaf pine. 
5.4 Five year moving average tree-ring indices and growth release events for

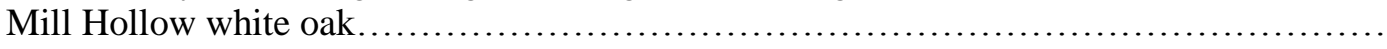




\title{
DENDROECOLOGY OF FORESTS IN MISSOURI: DISTURBANCE AND INTEGRATION \\ OVER MULTIPLE CENTURIES
}

Chad B. King

Dr. Rose-Marie Muzika, Dissertation Supervisor

\begin{abstract}
Disturbances are fundamental components of ecological systems which operate at variable frequencies and magnitudes that affect the structures and processes of the system. Multiple disturbance types have functioned in oak (Quercus)-shortleaf pine (Pinus echinata, Mill.) forests including drought, fire, and canopy disturbances that may be natural (wind, ice, insect defoliation) or anthropogenic (logging). To study historic disturbances, dendroecological methods were used to assess the disturbance dynamics across multiple sites in the Missouri Ozarks in order to better understand multiple disturbances and disturbance integration. Increment cores and remnant wood were collected and ring-widths were measured to analyze the patterns of radial growth, used to identify historic disturbances.

Growth release analysis (a proxy for canopy disturbance) indicated that species responded to gap openings (1-4 releases), but some trees did not exhibit a growth release suggesting these trees established in large gaps and reached the canopy without a release. An assessment of canopy accession strategies indicated the two most common strategies to reach the canopy were gap origin-no release and gap origin-major release. While some trees did not release, others established in gaps, were subsequently overtopped by adjacent canopy trees and required additional gap openings to reach the canopy. Significant associations $(\mathrm{p}<0.05)$ were detected using superposed epoch analysis between
\end{abstract}


drought and fire, drought and growth release, and fire and growth release. This possibly indicates antecedent effects of disturbance. Further analysis of radial growth following fire years showed significant $(\mathrm{p}<0.05)$ increases in growth and release events within three years of a fire. However, there were fire years that resulted in significant $(\mathrm{p}<0.05)$ decreasing radial growth and no release events that may indicate a severe fire that injured trees.

This research demonstrates that frequent, mixed-severity disturbances functioned in promoting the recruitment and canopy accession of oak and shortleaf pine in the Missouri Ozarks. Additionally, there was evidence of disturbance integration that suggests disturbances had both direct and indirect effects on short-term and long-term radial growth of pine and oak. 


\section{CHAPTER 1}

\section{A REVIEW OF ECOLOGICAL DISTURBANCE THEORY AND DISTURBANCES IN}

\section{NORTH AMERICAN FORESTS}

\section{Ecological disturbance theory}

Disturbances are fundamental components of ecological systems which operate at variable frequencies and magnitudes that affect the structures and processes of a system. This variability may affect the successional trajectory of the system by suspending succession, returning the system to a previous state, or changing the trajectory with a possible result of a different system structure (Sousa 1984). The frequency of the disturbance, defined as the number of disturbance events that occur over a given time period, and the magnitude of the disturbance, defined as the strength or force of the disturbance (Romme et al. 1998) are rarely independent of one another. In addition, these two factors of a disturbance (frequency and magnitude) may change across both temporal and spatial scales. The combination of spatial heterogeneity, disturbance frequency, and disturbance magnitude function in creating variability in the effect of the disturbance on a system (Turner 2010). Another possible outcome is a system that exhibits different seral stages across a landscape.

Defining "disturbance" has received attention in order to provide a sound definition that encompasses events that are very frequent and of lower magnitude with those events that are infrequent and of higher magnitude. Rykiel (1985) addressed the lack of a universal definition of disturbance. At the time, Rykiel noted that one of the problems associated with defining a disturbance is that a disturbance can be a cause of ecological change or an effect of ecological change. A forest fire can be a cause of ecological change but can also be the effect of change in

the system. With the ambiguity of the term "disturbance", Rykiel (1985) proposed differentiating disturbance, stress, and perturbation based on cause and effect. He recommended that disturbance be considered a "cause" of a perturbation (the effect of the disturbance) based on the 
magnitude of the disturbance. He went further in differentiating "stress" as a type of perturbation due to a disturbance. Pickett et al. (1989) goes further in that a stress results in changing or interrupting a process of an individual with minimal alteration to its structure while a disturbance results in the structural change of an individual. Based on these definitions, it may be possible for a disturbance event (e.g. ice storm) that results in the death of some individuals to be a stress for other individuals. Therefore, the magnitude of the event (e.g. ice storm) can be variable depending on the spatial extent of the event. Sousa (1984) defined disturbance as any event that results in death, displacement, or injury to an individual or group of individuals that provides for new individuals to become established. In all definitions, the underlying fact is that disturbance is an event that causes some magnitude of change to a system and as such, successional dynamics are altered.

One of the most cited definitions of ecological disturbance in the literature is Pickett and White (1985). In their definition, disturbances are discrete events (cause) that change the structure, resources, or the environment (perturbation/effect). In forest dynamics, the disturbance can result in death of an individual or group of individuals and provides growing space for surviving or new individuals (Oliver and Larson 1996) depending on the frequency and magnitude of the disturbance. While Pickett and White's definition of disturbance is centered on the structural aspects of the effect of a disturbance, the definition makes the assumption of the effect of a disturbance on ecological processes since generally structure and process are linked (Perry and Amaranthus 1997). Processes such as photosynthetic rate or nutrient uptake can be interrupted or suspended due to structural changes to individuals or communities following a disturbance.

Generally, an individual, population, or community has a response following a disturbance that changes the structure and/or processes. Two factors related to a definition of disturbance that affects the response following a disturbance are resistance and resilience. Resistance is defined as a system opposing a perturbation due to a disturbance; resilience, on the 
other hand, is defined as the ability of a system to respond and return to its previous state following the perturbation (Perry and Amaranthus 1997). With these definitions, resistance is a function of the existing structure and process that reduces the potential effect of the perturbation. This represents a system function that exists prior to a perturbation. On the other hand, resilience represents the ability of the system to maintain structure and/or process subsequent to the perturbation (Holling 1973). Romme et al. (1998) suggests that, at some point, an increasing magnitude of a disturbance will result in a perturbation that exceeds the system's resistance threshold and the result is a change to system structure and/or process, much like windstorms in forests resulting in tree stem breakage or windthrow (Quine and Gardiner 2007). The resilience of the forest following the wind disturbance would be the amount of time required for the system to return to the system state that existed prior to the perturbation (Fig. 1.1). Turner et al. (1998) suggests that the resilience of a system to a disturbance is dependent on the biological legacies or residuals following the disturbance. Biological legacies are the surviving individuals following the disturbance and can have a direct influence on the successional trajectory following the disturbance through replacement reproduction and competition with colonizing species.

Systems can experience gradual or abrupt shifts in structure and processes due to changes in the frequency, magnitude, and/or type of disturbance (Scheffer and Carpenter 2003) (Fig. 1.2). Scheffer and Carpenter (2003) argue that shifts do not have to always be abrupt changes that result from factors external to the system but that changes could also be the result of accumulation of internal factors of the system over time. There can be alternative routes to attain a shift in a system ranging from a gradual linear accumulation of changes to changes in the system once a critical threshold is exceeded. Scheffer et al. (2001) argue that changes, either accumulated over time or abrupt, can result in alternative systems existing at different times depending on the shift in the frequency and magnitude of the 
Figure 1.1. Conceptual model of system disturbance and the effect of disturbance dynamics (frequency, magnitude). A system experiences a disturbance in which the resistance of the system to the disturbance minimizes the magnitude of the disturbance on the structure and processes of the system. The resilience of the system determines the response of the system following the disturbance. The response then contributes to the structure and process of the system after the disturbance. In this situation, neither the frequency nor the magnitude of the disturbance overwhelmed the ability of the system to recover. The response of the system provides a feedback mechanism to the system structure and processes that promotes recovery following the disturbance event.

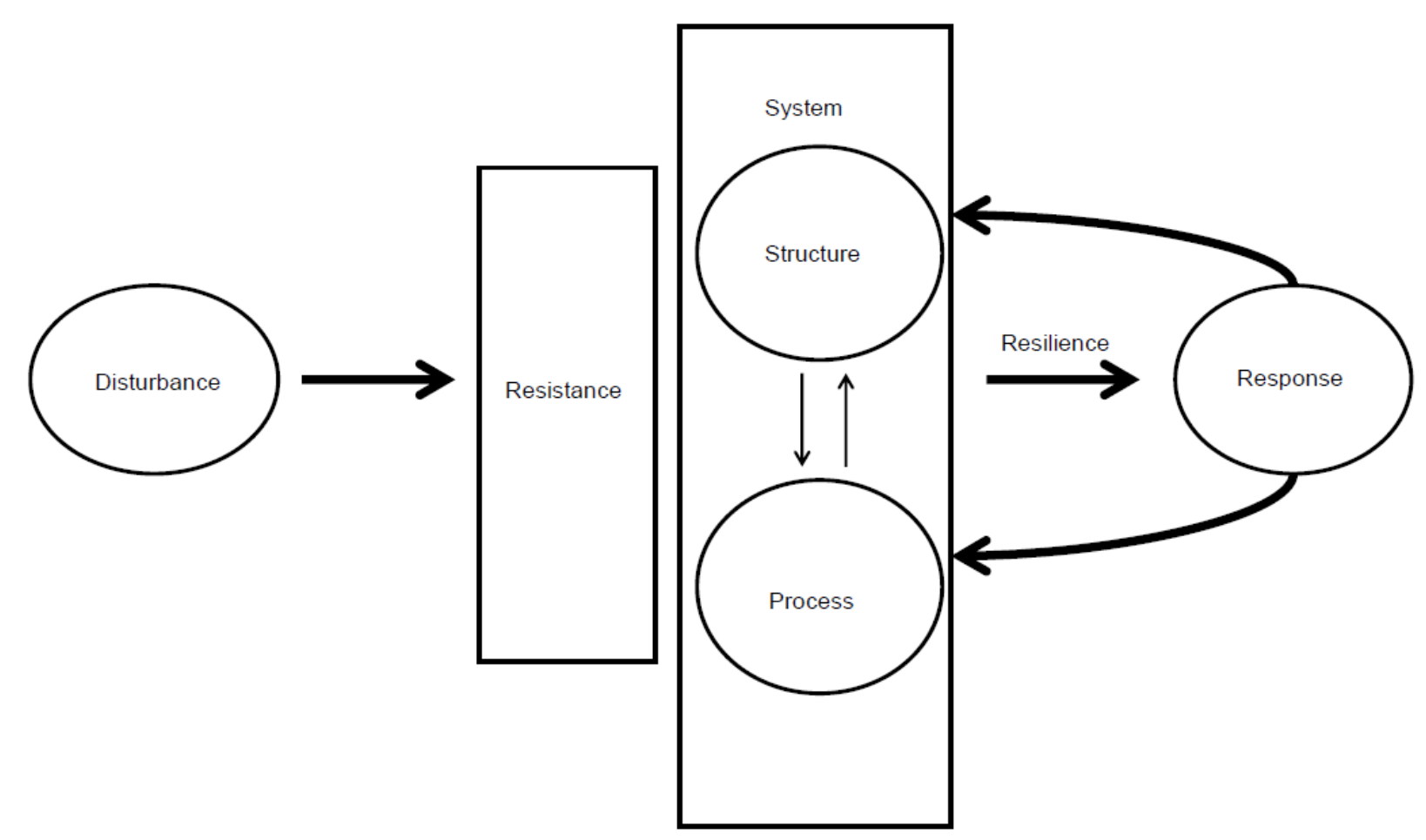


Figure 1.2. The effects of a change in the frequency and/or magnitude of a single disturbance regime on the structure and processes of the system compared to Figure 1. The disturbance is magnified due to a change in the disturbance regime. The resistance of the system to the disturbance is modified due to the change in disturbance; therefore the system becomes less resilient to the change in disturbance dynamics. The response is a feedback mechanism to the system, but because of the disturbance, the structure and processes are disrupted resulting in a shift in the system. Repeated perturbations by the altered disturbance regime lead to either an abrupt or gradual shift in system structure.

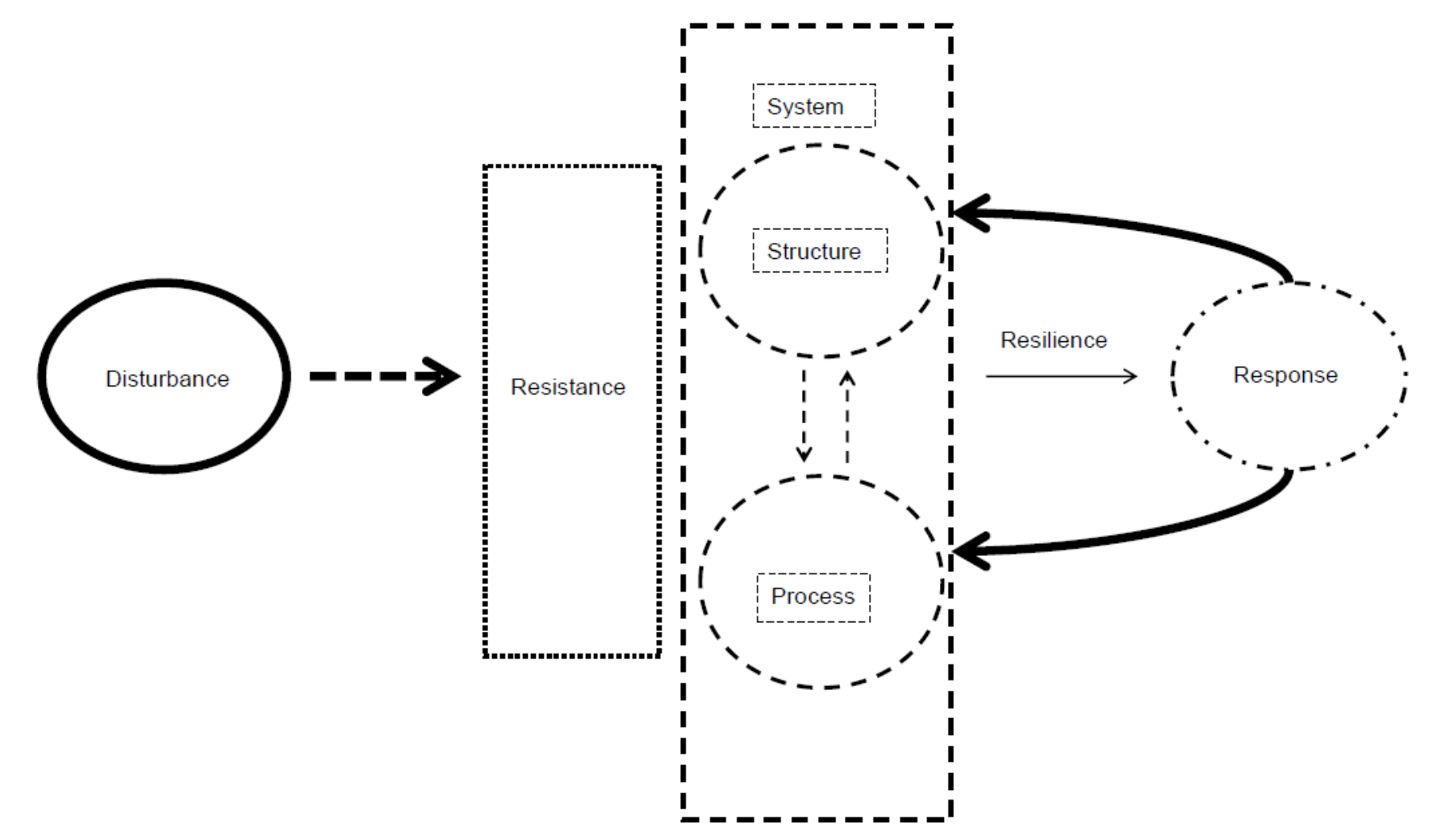


change. While most of Scheffer's examples and applications relate to aquatic ecology and limnology, one cannot entirely eliminate the theoretical approach to other systems. Such shifts have been detected contemporarily in marine systems (Steele 1998) and historically in climate and ecosystems (Foley et al. 2003). Pascual and Guichard (2005) suggest that what contributes to a system exceeding its threshold of a disturbance is a change in the resilience of the system regardless if the shift is abrupt or an accumulation. In a system, it develops towards a state in which the potential of exceeding a threshold increases due to a decreasing resilience to disturbance (Holling and Gunderson 2002) and the result is a shift in the system due to a disturbance. However, Turner et al. (1998) argue that if succession is dictated by abiotic conditions, then a large, infrequent disturbance is likely to have little effect.

One of the limits to the theoretical basis for shifts is its application to ecosystems. Are shifts applicable and can they be detected hierarchically? That is, can an individual or population exhibit a shift that may or may not be exhibited in other individuals or populations within the ecosystem? Folke et al. (2004) note in several ecosystems that changes at the population level of one species in an ecosystem can result in regime shifts of other species with the application of one or more perturbations. In one of the few studies of shifts and disturbance in forests, Frelich and Reich (1999) addressed shifts by modeling the effects of disturbance on forest community structure. In their study, Frelich and Reich considered the neighborhood effect (Frelich and Reich 1995) in concert with variable disturbance frequency and magnitude in three forest types. A neighborhood effect is one in which overstory tree canopy affects the potential of regeneration of the same or different species within the vicinity of the overstory tree (Frelich and Reich 1999). They suggest that neighborhood effects can be positive (processes enhances self-replacement), negative (processes deter self-replacement), or neutral (processes have no effect on selfreplacement). The importance of their model suggests that a tree species' neighborhood effects can affect their canopy status based on the frequency and magnitude of a disturbance. In turn, a 
change in the frequency and/or magnitude of a disturbance can alter a species' ability to retain canopy status in a forest.

Frelich and Reich's (1999) model brings forward an important factor that has remained relatively unstudied in forest dynamics in the changing of the frequency and magnitude of disturbances in systems and the effect of those changes on the structure and dynamics of the system. In their model application to three forest types (northern hardwood, near boreal, tropical), they note that changes in the frequency, magnitude, and type of disturbance contributed to a change in the general forest structure and canopy species composition. While positive neighborhood effects can promote regeneration of the same species following a disturbance, those same neighborhood effects can be overwhelmed in two ways. First can be a compositional catastrophe (Frelich and Reich 1995) due to a change in the frequency of the disturbance that does not allow for positive neighborhood effects. Second, neighborhood effects can be affected by a change in the primary disturbance regime that promoted the initial positive neighborhood effects. These two ways provide an avenue for a change in overstory species composition due to the combined effect of changing neighborhoods and disturbance frequency or regime.

While disturbances are a functional component of affecting systems across the Earth, the focus of this chapter is on the types, role and interaction of disturbances in forests of North America and their relationship to the current disturbance theory. Long-lived species of trees provide long temporal sets of data that allows for the analysis of tree response to various disturbance types in contemporary and historic forests. In addition, it is possible to ascertain changes to the dynamics of disturbance regimes and infer changes to the structure of forests due to the changes in disturbance regimes, whether they are natural changes or anthropogenic induced changes. 


\section{Types of disturbances in North American forests}

Disturbances in North American forests function at varying temporal and spatial scales (Turner et al. 2001; Turner 2010) and affect the existing forest structure and successional trajectory of the forest. If one reconsiders the definition of disturbance proposed by Pickett and White (1985):

"a discrete event in time that disrupts ecosystem, community, or population structure and changes resources, substrate availability, or the physical environment;"

there are several events that occur with variable frequency and magnitude in forests of North America that fit within the previous definition. Previous research on disturbance types, the dynamics of disturbance, and the effect of disturbances on forests have ranged from contemporary studies of disturbances to disturbance reconstructions using dendrochronology.

In North American forests, natural disturbances have been identified and studied including contemporary analysis of disturbance as well as reconstructed historical studies of past disturbance events. Disturbances include insect outbreaks, fire, wind, ice, and drought. While many other disturbances have been studied throughout North American forests (Stoffel et al. 2010), the previous list encompasses the range of disturbance events that will be considered with this dissertation.

\section{Insects as a disturbance agent}

The focus of insects relates to species that have documented cases of reaching outbreak status and contributing to an existing disturbance event or causing the disturbance event. Many species of insects have the potential of reaching outbreak status depending on favorable weather conditions, availability of resources, or following a preceding disturbance event (Schowalter 1985). The exponential growth of native or non-native insect species has the potential of overwhelming host tree species resulting in the death of individual trees or extensive mortality across stands of trees. 
Studies have been conducted to reconstruct historic defoliating insect outbreaks using dendrochronology techniques. Defoliation events typically result in reduced radial growth of the tree for a period of time following the defoliation as the tree recovers foliage. Reconstruction studies have analyzed radial growth of insect host vs. non-host trees because the assumption is that climate signals in tree-rings are similar and residuals represent defoliation events (Swetnam et al. 1995). Reconstructions of defoliating insects such as Pandora moth (Coloradia pandora) (Pohl et al. 2006; Speer et al. 2001), spruce budworm (Choristoneura occidentalis) and Douglasfir tussock moth (Orgyia pseudotsugata) (Swetnam et al. 1995), Choristonuera biennis (Zhang and Alfaro 2003), and jack pine budworm (Choristoneura pinus pinus) (Volney 1988) in western North America forests and eastern spruce budworm (Choristoneura fumiferana) (Morin et al. 1993) in eastern North American forests, suggests that historic outbreaks were highly variable temporally as well as spatially. While, reconstruction of defoliating outbreaks provides a valuable temporal measure of this disturbance, little interpretation has been done in relating this disturbance to the effect on forest structure, succession, and its relation to disturbance theory.

Unlike reconstructed defoliator outbreaks that identified declines in radial growth using dendrochronology, reconstructing past outbreaks of pine beetles were conducted looking for increases in radial growth. The assumption is that these insects select to attack and kill larger diameter, canopy trees that create gap openings for understory, suppressed trees to respond favorably to the gap openings by increasing their radial growth rate. A confounding effect of analyzing increases in radial growth is that many different types of disturbances can promote increases in growth of understory, suppressed trees, including individual tree mortality and windstorm events. In one of the few studies, Campbell et al. (2007) analyzed variations in growth releases in lodgepole pine (Pinus contorta) forests in British Columbia, Canada. Their results suggest that the timing and magnitude of radial growth releases were highly correlated with known areas of mountain pine beetle (Dendroctonus ponderosae) outbreaks. They suggest that growth releases in forest stands with high enough density may be able to be used to 
reconstruct past mountain pine beetle outbreaks. Anderson et al. (2010) reconstructed spruce beetle (Dendroctonus rufipennis) outbreaks using pollen analysis and noted a decrease in Engelmann spruce (Picea engelmannii) pollen and an increase in subalpine fir (Abies lasiocarpa) pollen following the spruce beetle outbreak. They suggest that their methods may be an additional way of documenting historic beetle outbreaks. Veblen et al. (1994) also analyzed historic spruce beetle outbreaks that dated back to the $18^{\text {th }}$ century in Colorado by identifying growth releases using dendrochronology.

In relating the existing knowledge of pine beetles to disturbance theory, one may find a different perspective compared to defoliating insects. These insects are known for killing their host most likely due to multiple stresses already existing in the tree. This suggests that the resistance of the tree is low to a further stress, like insect invasion. Vigorous trees are known to reduce the effect of insect invasion (Coulson 1979) and in some cases survive an attack. In addition, the resilience of trees is likely highly variable depending on the predisposed stresses that the tree is experiencing and vigor of the tree prior to an insect attack. Previous research suggests that trees attacked by this group of insects possess lowered resilience to recover from an attack with the result being widespread mortality. Similar to lowered resistance, the lower resilience of trees may be a product of additional disturbances or stresses on the trees. The lowered resistance and resilience of trees could promote a shift in structure and process within the system but not necessarily species composition. What may change is a seral stage of succession as overstory tree mortality provides an opportunity for advanced regeneration or natural regeneration.

\section{Ice as a disturbance agent}

Ice can be a disturbance agent in North American forests and its effect on forests has long been an interest among researchers (Abell 1934). Generally, freezing precipitation, in the form of freezing rain or drizzle, accumulates on branches and foliage of trees that can result in an addition of weight to the tree's structures resulting in injury or death. The combination of ice accumulation 
on branches and winds contribute the greatest to the loss of tree structure and mortality (Greene et al. 2007).

While icing events can have significant effects on the structure and processes of forests, it has only been in the last 30 years that foresters and other researchers have quantitatively analyzed the post-icing effect to forests. It wasn't until 2002 that the U.S. National Oceanic and Atmospheric Administration (NOAA) created a report detailing the climatology of extreme icing events (Jones et al. 2002). Their report details that areas that generally receive the greatest annual ice loading based on 50 year return period includes eastern Oklahoma, Missouri, Illinois, Indiana, and Ohio. Areas along the Great Lakes and the New England coast also receive high ice loadings. Generally, ice loads in the western United States are lower $(<0.50$ ") than the eastern United States, except for areas of Washington and Oregon. Given the distribution of forests across these regions, ice has the potential of being a disturbance that can function to greatly affect the structure and dynamics of forests.

Research on ice events and forests has largely centered on the structural effect on the forests and species-specific responses to icing. Previous research has estimated that ice storms in Missouri and Virginia have a return interval of 20-25 years (Rebertus et al. 1997; Whitney and Johnson 1984), while during the last 50 years Missouri has experienced approximately 1 ice storm/year. Most research agrees that the damage to trees because of ice storms is species specific and there is a possible topographic influence.

Generally, ice storms and glazing events can cause dramatic effects on pines across eastern North America. Most of the quantitative analysis of ice storm effects on pines has occurred during the last 20 years due to several icing events in eastern North American forests. When compared to hardwoods in the same stand, pines like Virginia pine (Pinus virginiana) and pitch pine (P. rigida) (Warrwillow and Mou 1999), loblolly pine (P. taeda) (Smolnik et al. 2006; Aubrey et al. 2007), Table mountain pine (P. pungens) (Lafon 2003), red pine (P. resinosa) (Boerner et al. 1988), shortleaf pine (P. echinata) (Travis and Meentemeyer 1991), and jack pine 
(P. banksiana) (Yorks and Adams 2005) have all shown high susceptibility to ice damage, exhibited the greatest stem damage following an ice storm, or greatest loss in basal area following an ice storm. Pines can be injured via the loss of canopy stem breakage to the point of mortality if all canopy stems are lost due to ice accumulation. However, some pines can generate epicormic branches following the loss of canopy foliage. If ice accumulation exceeds a threshold, whole stems can snap above the bole of the pine (Bragg et al. 2003). For pines that are injured due to loss of canopy stems or falling neighbor trees following an icing event, the radial growth response is diminished (Travis and Meentemeyer 1991) and recovery is slower than hardwoods (Smolnik et al. 2006).

Hardwoods are also susceptible to damage and mortality due to ice storm events. Previous research that has addressed the effect of icing on hardwoods has demonstrated a high degree of species-specific variability in damage, but that generally mortality of hardwoods was less than pines within the same forest (Lafon 2006). However, Proulx and Greene (2001) determined that the amount of icing and the size of the tree determined the degree of damage in northern hardwoods in Canada. One of the advantages of several hardwood species is the sprouting ability following a disturbance like icing that result in injury (Brommit et al. 2004). Hardwoods are not immune to mortality due to icing events. Turcotte et al. (2012) analyzed longterm mortality of hardwoods in Ohio following an ice storm to determine factors that related to mortality. They determined that amount of canopy damage affected crown dieback and mortality. Epicormic branching was more common in dominant and co-dominant individuals. Trees that showed moderate or heavy crown damage ( $>34 \%$ crown loss) demonstrated no diameter growth, greater crown dieback, and mortality. Authors have also demonstrated topographic variations and tree species composition influence the degree of damage that occurs in a forest (Millward and Kraft 2004; Warrillow and Mou 1999) that results in differences in the amount of damage that occurs at the local scale. 
Several researchers have used dendrochronology techniques to analyze radial growth patterns following ice storm events or to reconstruct past ice storm events. Pisaric et al. (2008) analyzed the response of sugar maple (Acer saccharum) and determined that the rate of canopy recovery was faster than radial growth six years after the icing event. Smolnik et al. (2006) determined that severely damaged trees had the greatest reduction in radial growth with yellow poplar (Liriodendron tulipifera) recovering radial growth the fastest and loblolly pine the slowest in Delaware. This contrasts Lafon (2004) in which he found that yellow poplar had higher variability in radial growth response following an ice storm. Brose and Waldrop (2010) used dendrochronology to date establishment periods of pine-oak forests in the Appalachian Mountains and suggested that frequent ice storm events likely promote hardwoods (oaks) in favor of pines. Based on known ice storm years during the $20^{\text {th }}$ century, Lafon and Speer (2002) determined that chestnut oak (Q. prinus) and black oak (Q. velutina) exhibited increases and decreases in radial growth following ice storms. D'Amato and Orwig (2008) considered the historic disturbance dynamics and attributed changes in radial growth changes as being related to hurricanes or ice storms in western Massachusetts.

Most research related to ice storms and forests consider the damage and response of trees to the icing events with little reference to existing succession and disturbance theory (but see Brose and Waldrop 2010). One factor that complicates ice disturbance and disturbance theory is the perception of the disturbance. Some authors suggest that ice storms are broadscale events (D’Amato and Orwig 2008) while others suggest that ice storms are localized events with different forest responses (Boerner et al. 1988). The research cited in this section demonstrates a high degree of variability between species, tree size, topography, and radial growth following an ice storm disturbance. This suggests a localized effect of ice that does not uniformly affect the disturbed area.

All trees have some degree of resistance to icing events that is dependent upon the type of ice, the rate of ice accumulation, the amount of accumulation, and wind speed (Greene et al. 
2007). However, the research cited within this section suggests that different species likely have different resistance thresholds to ice storms. Pine species retain foliage during winter months which provides additional surface area for ice accumulation (Bragg et al. 2003) unlike hardwood species. This suggests that pines have a lower resistance to icing and the effect of the disturbance is magnified in pine species relative to neighboring hardwoods.

It is likely that resilience differs between pines and hardwoods when exposed to ice storm disturbances. While both pines and hardwoods can experience mortality immediately after or within a few years following an ice storm (Turcotte et al. 2012), hardwoods may respond with sprouting due to canopy damage. Hardwoods can experience damage and mortality due to ice disturbance but lack the additional foliage surface area for ice accumulation like pines.

The frequency of ice storms affecting the same area suggests that these disturbances are infrequent events with high variability in magnitude based on historic reconstructions and contemporary research. Such that, an increase in frequency and/or magnitude of these events may result in a system shift based on the existing resistance and resilience of the species affected by the disturbance.

\section{Fire as a disturbance agent}

One of the most studied disturbance types in North American forests is fire, ranging from the effects of natural (Drever et al. 2008; Fauria and Johnson 2007) and prescribed fire (Boerner et al. 1988; Carter and Foster 2004; Albrecht and McCarthy 2006) to the reconstruction of fire events using dendrochronology and calendar dating using fire scars (Brown 2006; Gray et al. 2004; Iniguez et al. 2008; Stambaugh et al. 2009). It has been the past 30 years that fire has been recognized as an important disturbance agent in nearly all forests in North America and efforts have been made, largely on public lands, to reintroduce fire into the forest system.

The majority of fires in North American forests fall into one of two categories, crown fires and surface fires. Crown fires result in high mortality of overstory trees due to the removal 
of foliage, particularly in evergreen conifers. Surface fires burn the understory of a forest resulting in the removal of leaf litter, herbaceous vegetation, tree seedlings and saplings, and in some cases, cambial injury of larger diameter trees that result in scarring (Frelich 2002; Gutsell and Johnson 2007).

Successional trajectories of a forest can be affected by the type, frequency, and intensity of a fire (Romme 1981). Fires can accelerate the succession of an understory cohort with the mortality of the existing overstory following a crown fire while surface fires may interrupt succession by increasing the mortality of understory cohorts. Studies of the effect of prescribed fire in oak forests of eastern North America suggest that regeneration of oak is greatly affected by the repeated use of fire (Albrecht and McCarthy 2006; Alexander et al. 2008; Hutchinson et al. 2005). This suggests that high frequency surface fires interrupt succession in these oak forests. Repeated prescribed surface fires also reduce fire-sensitive tree species regeneration that affects succession within oak-pine forests in North Carolina (Arthur et al. 1998). In southeastern U.S. pine forests, it is well established that fire was historically an important disturbance event. Fires in these forests have been suggested in promoting and maintaining pines in the overstory of pine, pine-oak, and oak-pine forests. A tremendous research effort has occurred that addresses historic fire regimes across southern pine forests that emphasize the importance of this disturbance in longleaf pine (Pinus palustris) forests (Predmore et al. 2007; Stambaugh et al. 2011) and shortleaf pine (P. echinata) forests (Engbring et al 2008; Guyette and Spetich 2003; Guyette and Dey 1997). The high frequency of fires likely reduced hardwood competition and promoted pine. High historic fire frequencies in eastern North American forests, until the early $20^{\text {th }}$ century fire suppression, were linked with anthropogenic ignition and drought conditions (Guyette et al. 2006). With fire suppression, research has demonstrated the reduced regeneration of pine across southern pine forests and the promotion of hardwoods (Gilliam and Platt 1999) that increases competition between hardwoods and pines that likely has reduced pine regeneration (Abrams 1996). 
In western North American forests, frequent surface fires and infrequent crown fires function in affecting successional trajectories. Romme (1982), in Yellowstone National Park, demonstrated that historic crown fires were a function of 300-350 years of succession that resulted in increased crown density between crown fire events. Surface fires were frequent but generally did not affect large spatial extents. In addition, regional and global climate variables are associated with abundance of fire events across the Colorado Front Range (Kitzberger et al. 2007; Sibold and Veblen 2006), and elevation related variability in fire frequency and severity in the Colorado Front Range (Veblen et al. 2000), southern Cascade Mountains (Bekker and Taylor 2010), and the southern Rocky Mountains (Margolis et al. 2007).

Numerous studies of historic fire regimes have been conducted by either directly identifying years of fire through scarring on trees, timing of fire events using sedimentary charcoal, or indirectly by inferring fires based on cohort establishment. The research consensus suggests that many western forests historically experienced mixed severity fires with some low and high severity fires (Heyerdahl et al. 2012), but the severity is highly variable depending on forest type in western North America (Romme et al. 2009).

Research has emphasized the role of humans in fire disturbance events and the eventual suppression of fire across North America for the past century. The ramification of long-term fire suppression has been the increase in stand densities in western North America and the successional trajectory of late-successional fire-tolerant tree species dominating forests in eastern North America (Nowacki and Abrams 2008). In western forests, the suggested increase in stand densities has been implicated in the potential for more severe fires and interaction with other disturbance processes.

The highly variable fire frequencies and severities that can occur across North America create a challenging component for the application of disturbance theory. While most research only mentions disturbance theory and succession in passing when studying fire effects and fire regimes, there are some exceptions (Romme and Knight 1981; Romme 1982; Stambaugh and 
Muzika 2007). There are several factors that contribute to the challenge of fire and disturbance theory: 1) the variety of forest types across North America; 2) the variability in fire regimes and severities; 3) the change in fire regimes; 4) the fire tolerance of tree species; and 5) the resistance to fire depending on tree size.

It is possible to draw some general conclusions related to fire and disturbance theory.

Fire is one disturbance type that humans can have a direct influence in both ignition and suppression of fire. As such, the scientific literature contends that fire was a frequent occurrence during Euro-American settlement prior to the $20^{\text {th }}$ century and the disturbance regime changed with the advent of fire suppression in the early $20^{\text {th }}$ century. From a disturbance theory view, changes in disturbance dynamics have the potential to cause a shift in forest structure and processes (Frelich 2002; Scheffer et al. 2001). Increases or decreases in the dynamics of the disturbance (fire) likely affect the resistance of species to the disturbance while enhancing the resilience of other tree species. The decrease in fire frequency in eastern North American forests over the past century likely contributed to an increase in abundance of fire sensitive tree species in forests. While these species' resistance to fire is relatively low, the absence of the disturbance has enhanced their success, contributing to a gradual shift in the system structure and dynamics. Tree species that have a relatively high resistance and resilience to fire (pines) are at a competitive disadvantage with a change in fire dynamics that increases the chance of a system shift.

\section{Wind as a disturbance agent}

Another frequently studied disturbance that affects the structure and dynamics of forests across North America is wind. Most studies of wind effects on forests assess the amount of basal area affected and species specific effects and responses while dendrochronology techniques have been developed to identify past canopy disturbance events that could include wind as the disturbance factor. 
While a tremendous body of literature exists related to the effects of wind disturbance on forests, one finds that the current knowledge of wind velocity and turbulence in forests is largely based on theoretical and wind tunnel studies (Finnigan 2007). Multiple factors work together to predispose an individual tree or group to being affected by wind including topography, wind speed, temporal length of wind gusts, height of tree, density of forest, additional stressors or wood defects (e.g. hollow bole), and rooting depth. Many natural phenomena have the potential of producing winds that are destructive to forests including hurricanes, thunderstorm microbursts or macrobursts, and tornadoes (Hjemfelt 2007).

Trees in forests can dampen wind effects for adjacent trees with the greatest wind load on trees along edges of forests and a decreasing load as one moves towards the interior of the forest. In the event a gap is formed within a forest, trees along the edges of the gap become more prone to wind damage and the expansion of the gap. The timing of the wind event can have differing effects on deciduous and coniferous species. In mixed deciduous/conifer forests, winter winds have the potential of increasing wind damage to conifers, while summer winds have the potential of affecting both groups equally. Finally, the combination of additional weight on trees like rain, snow, or ice and wind can increase the probability of tree being snapped or uprooted (Frelich 2002; Quine and Gardiner 2007).

Along the east coast of North America, hurricanes can have large spatial effects on forests. Hurricanes have been inferred to be a large infrequent disturbance that can affect forests from Maine (Fraver and White 2005a) to Georgia (Pederson et al. 2008). Liu and Fearn (2000) calculated that a category 4 or 5 hurricane made landfall once every 280 years based on sediment cores along the Florida Gulf Coast. One of the most studied historic hurricanes was the 1938 event that affected the New England region and Harvard Forest. While hurricane winds affected canopy trees, generally the damage was considered minor based on tree age structures and radial growth rates following the hurricane (Foster 1988; Foster et al. 1992). Other studies of hurricane related disturbance demonstrated that $P$. taeda was more affected by hurricane winds than other 
associated species within the forest (Smith et al. 1997; Battaglia et al. 1999) that reinforces species differences in the effect of wind disturbance (Quine and Gardiner 2007).

While hurricanes are generally considered large, infrequent disturbance events, another group of wind-related disturbances are more frequent but generally affect smaller spatial extents. These disturbances include downbursts, tornadoes, and derechos with wind speeds up to 500 $\mathrm{km} / \mathrm{hr}$ but having localized effects (Fujita 1981). While studies of tornado effects on forests are generally rare, the few that do exist provide important information pertaining to wind disturbance. One of the most consistent findings related to tornado and wind blowdown effects is the relationship between tree size (usually diameter at breast height) and the probability of damage/uprooting/snapping (Peterson 2007; Xi et al. 2008) but there are species differences in the probability (Peterson 2000; Rebertus and Meier 2001; Shirakura et al. 2006).

Another product of wind disturbance in forests can be the formation of gaps. Gap formation is the opening of the canopy due to the death of one or more adjacent individuals that provides growing space for advanced regeneration and neighboring canopy tree canopy expansion. Runkle (1982) defined two gaps: 1) the actual gap that is directly underneath the canopy opening and the expanded gap which includes the ground surface up to the base of adjacent trees to the gap. It should be noted that gap formation does not necessarily have to be associated with wind disturbance. Gaps can form due to individual tree mortality unrelated to wind.

Within gaps, the reduced competition for light, water, and nutrients promotes increases in height growth and radial growth of suppressed understory trees (Runkle 1985). Gap size has a direct influence on the rate of understory radial growth and height growth as these individuals attempt to attain canopy status. In relating sapling height growth to canopy lateral branch expansion within a gap, Hibbs (1982) determined that in gaps <5m radius, saplings would not attain canopy status based on their height growth. As such, it would take these individuals multiple gap opening events to reach the canopy. Larger gap openings may provide the 
opportunity for advanced regeneration of shade-tolerant trees to grow to the canopy, or seed germination of shade-intolerant individuals to grow to the canopy (Runkle 1985).

The rate of disturbance can have direct influence on the sucessional trajectory and species composition of a system. Approximately 1\%/year (ranging between $0.5 \%$ and $2.0 \%$ ) of forested area is affected by disturbance (Runkle 1985). However, there appears to be some variability in the rate of disturbance that may be influenced by the age of the trees (Stambaugh 2001). Generally, older trees that have attained canopy status are more prone to wind disturbance, and therefore the rate of gap formation likely increases with the age of the trees.

Numerous techniques have been developed to identify historic canopy disturbance events using changes in incremental tree-ring growth patterns that involves analyzing average changes in radial growth (Lorimer and Frelich 1989; Nowacki and Abrams 1997), median changes in radial growth (Rubino and McCarthy 2004), regression models (Black and Abrams 2003, 2004), intervention detection (Duckenbrod 2005), and differencing (Fraver and White 2005b). These various approaches use the premise that intra- and interspecific competition for resources between trees is the limiting factor that affects radial growth rates. Gap openings or a severe canopy disturbance that removes overstory competition reduces the effect of the limiting factor that results in increases in radial growth (releases) of surviving trees. However, these approaches cannot differentiate between releases caused by a natural disturbance (wind) and anthropogenic disturbance (logging) unless additional information is available related to the disturbance.

Wind disturbance can be a complex event due to the ability of wind to cause large spatial blowdown events as well as single-tree gap formation. With that, theoretical applications are also complex depending on the frequency and magnitude of the wind event. As with fire disturbance, wind can have differing effects on individual trees ranging from mortality to injury that reduces height and radial growth for a period of time. The resistance of a tree or forest to a wind disturbance can be affected by the size of the tree, density of the forest, location of the tree in the 
forest, and other stressors affecting trees (Hjemfelt 2007). Regardless, there is a resistance threshold for a forest or tree that results in the loss of canopy structure, snapping, or windthrow.

The resilience of the forest to a wind disturbance largely influences the successional trajectory for the forest (Frelich 2002). Gap dynamics of a forest can result in a mosaic of differing tree ages and species compositions within and adjacent to gaps. The severity and magnitude of the wind disturbance can have the consequence of causing a shift in the structure of the forest depending on the species composition of the understory. If the overstory is composed of shade-intolerant species while the understory is composed of shade-tolerant species, a wind disturbance that removes most of the overstory, a shift to a shade-tolerant canopy is likely (Frelich 2002; Runkle 1985).

Another factor that can cause a shift in the structure or dynamics of a system is a change in the frequency or magnitude of a disturbance. The introduction of another canopy disturbance regime has the potential of magnifying the effect of the original disturbance regime. In this case, logging can increase the frequency and magnitude of canopy disturbance in combination with the natural canopy disturbance regime. The result may be a shift to a different canopy structure and species composition because of the reduced resilience of the original canopy to the change in the canopy disturbance regime.

However, it is unlikely that only one disturbance regime functions in affecting the structure and dynamics of a forest system (Frelich 2002). The complex interactions that occur as a forest follows a successional trajectory are usually the result of multiple disturbance regimes and the changes in frequency and magnitude of those disturbance regimes.

\section{Disturbance Interactions}

Disturbances can be a product of inter-related ecological parameters that facilitate particular disturbance events. An example is the relationship between drought (stress) and forest fire regime (perturbation) (Guyette and Dey 1997; Harrod and White 1999; Westerling and 
Swetnam 2003). In most systems, multiple disturbance types function in affecting the structure, resistance, and resilience of the systems. As such, it is important to understand the relationships between disturbances and the potential of one disturbance type facilitating another disturbance type.

Disturbances, such as fire, wind, and herbivory, have historically been the focus of research (Swetnam and Baisan 1996; Frelich and Lorimer 1991; Swetnam et al. 1995; among others) and the effect of the disturbance on forests across North America. However, research that integrates disturbance types and the effect of multiple disturbances on systems are rare (but see, Lorente et al. 2012; Land and Rieske 2006). Different disturbance regimes have the potential of facilitating other disturbance regimes. One geographical area that has received attention in addressing the interaction of disturbances is western North America where insect herbivory, fire, and in some cases, wind disturbance interact to affect forest structure (Hicke et al. 2012; Jenkins et al. 2012; Kulakowski and Veblen 2002; Parker et al. 2006; Veblen et al. 1994). Recently, Schoennagel et al. (2012) analyzed the relationship between mountain pine beetle ( $D$. ponderosae), wind, and fire disturbance in lodgepole pine ( $P$. contorta) stands of Colorado. In categorizing three stages of pine beetle attack on trees, they noted that unattacked trees were more prone to windthrow due to the loss of neighboring attacked trees, and the effect of crown fires were dependent on the stage of pine beetle attack of the tree. DeRose and Long (2012) determined a relationship between drought, fire, and spruce beetle activity in subalpine Englemann spruce (Picea englemannii Parry ex Englm.) forests in Colorado. Their analysis suggested that drought was an antecedent to fire and spruce beetle outbreaks in subalpine forests. In eastern North American forests, the emphasis on disturbance interaction research has focused on the role of climate (particularly drought) and its relationship to other disturbance regimes and tree radial growth response following disturbances (Guyette et al. 2007; Rentch et al. 2002). In other cases, the combination of fire, wind, and anthropogenic disturbance has been studied individually to infer successional patterns of forests (Frelich 2002). With the exception of 
a few studies, most historic and contemporary disturbance studies emphasize one disturbance regime in eastern North American forests. Given that gap dynamics plays a central disturbance regime in eastern North American forests, Rentch et al. (2002) suggests future research address the effect and interaction of gap dynamics and fire regimes to better understand the successional patterns and shifts in forest composition.

Multiple disturbances that function within a forest directly affect the successional trajectory. Changes in the dynamics of one or more of the disturbances can result in alternative successional trajectories and resulting stable states (Turner et al. 1998). This suggests, theoretically, that a system's resistance to a single disturbance may be compromised by the change in the frequency or magnitude of another disturbance. Therefore, a feedback due to the change in disturbance dynamics may result in a shift in the resistance and resilience of the system. The result could be a shift to an alternative successional trajectory that equates to an alternative stable state. The shift to an alternative system may be gradual or abrupt depending on the degree of disturbance regime change.

If multiple disturbance dynamics change in their frequency and magnitude, then the result may be a more pronounced, abrupt shift in system structure and processes. The abrupt shift likely results in a decreasing resistance and resilience of the original system to the change in disturbance dynamics and an increasing resistance and resilience of an alternative system to the prevailing disturbance regimes (Fig. 1.3). 
Figure 1.3. The effects of multiple disturbance regimes on a system and the consequences of changes in one or more disturbance regimes. (A) Disturbance regimes function in overcoming the resistance of a system with the resilience of the system adapted to the disturbance regimes resulting in a stabilizing feedback response that maintains the structure and processes of the system. (B) One of the disturbance regimes is changed in its frequency and/or magnitude that affect the dynamics of other disturbance regimes. The change in one disturbance regime has the potential of shifting the structure and processes of the system. (C) More than one disturbance regime is altered that magnifies the alteration of the system. (D) The result can be a shift in the disturbance regimes of a system that acts as a feedback to an alternative system. This can be accomplished through natural succession (A) or an alteration of the disturbance regimes of the system $(B, C)$. However, this does not indicate that all three results in the same alternative system, rather each can result in different systems following three different trajectories.

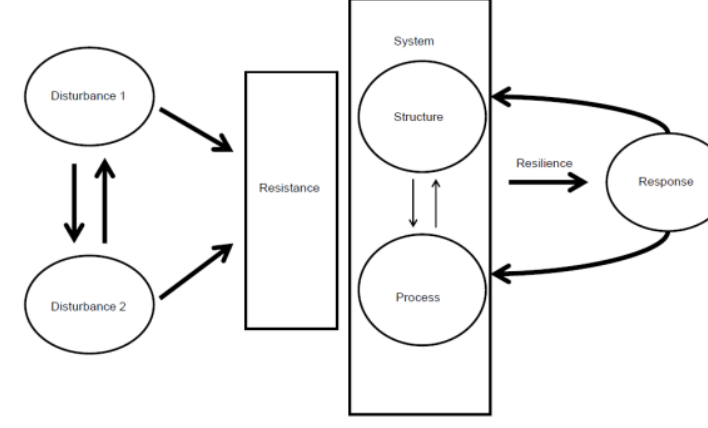

C

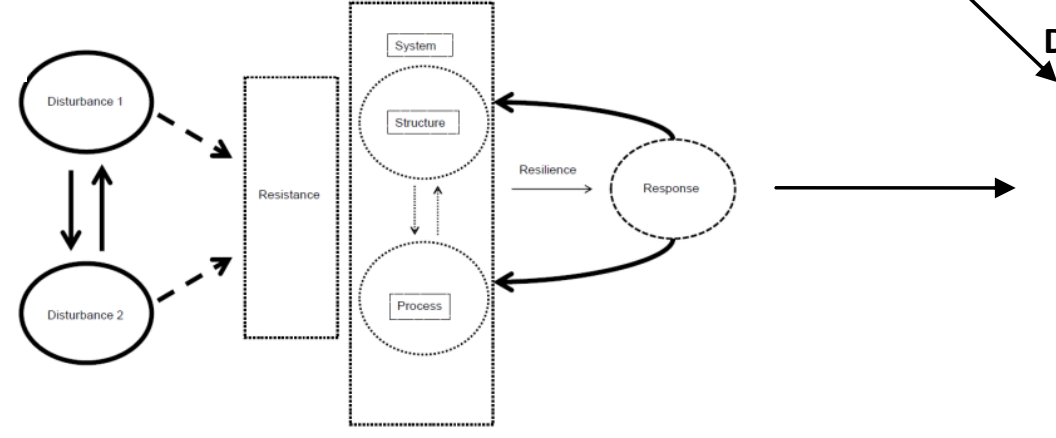

B

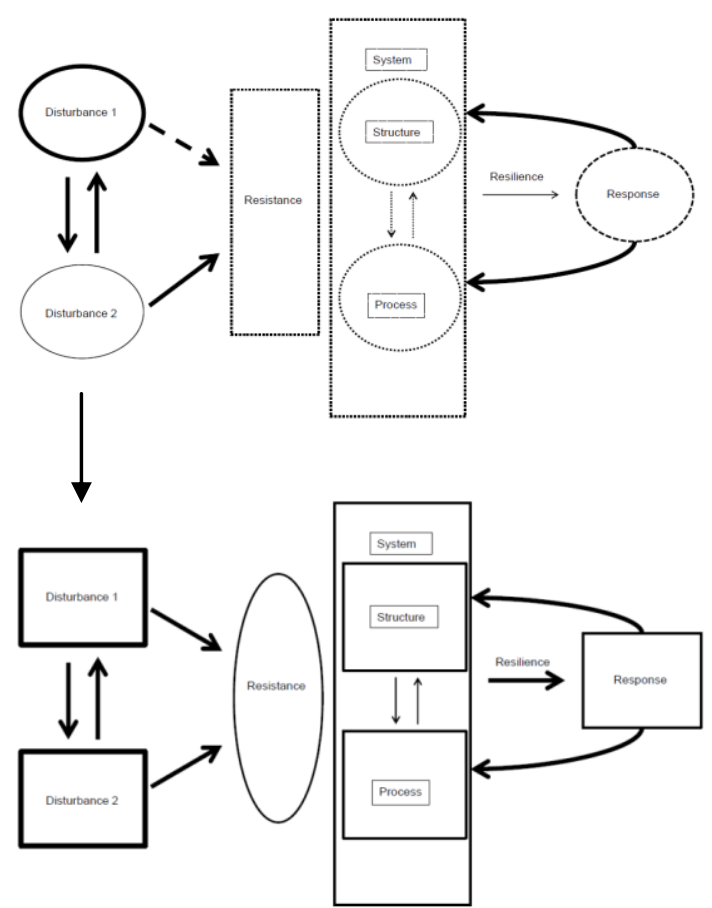




\section{Dissertation Objectives}

This dissertation investigates the disturbance dynamics of shortleaf pine (P. echinata)oak (Quercus spp.) forests in the Missouri Ozark Highlands using dendrochronology techniques. These forests highlight systems that have experienced multiple disturbance regimes along long temporal scales with varying frequencies and magnitudes. Natural disturbance regimes in concert with anthropogenic disturbance regimes emphasize the likely change in disturbance dynamics and shifts in system structure during the past three centuries.

The objectives of the dissertation include:

1) utilizing approaches to identify growth releases to understand the effect of canopy disturbance on long-term growth in shade-intolerant Pinus echinata;

2) analyzing the growth releases and suppressions in radial growth that act as a proxy for canopy disturbance events in Missouri forests; and

3) determining the effects of multiple disturbance regimes (fire, canopy, drought) and the potential interactive effect on pine-oak forests.

Research on fire in the Missouri Ozarks is extensive (Cutter and Guyette 1994; Guyette and Dey 1997; Guyette et al. 2002; Guyette et al. 2003; Stambaugh et al. 2005). While studies of wind disturbance and canopy dynamics have had limited discussion, there are not any known studies that incorporate multiple disturbance regimes in explaining the temporal and spatial variation of disturbance. In addition, the pine-oak systems of the Missouri Ozarks have experienced natural disturbance events and the incorporation of human disturbance regimes that potentially influenced the system's long-term structure and dynamics.

Using dendrochronology provides an opportunity to analyze the long-term changes in radial tree-ring growth patterns in shortleaf pine and oak. While many approaches have been developed to analyze changes in growth patterns of trees, one of the continuing challenges is 
assigning causal factors of the change in growth. However, analyzing the frequency (temporal) and magnitude (spatial) of the changes in growth provides quantitative information to infer the influence of the disturbances that contributed to the changes in growth.

Finally, the investigation of temporal and spatial patterns of multiple disturbance regimes allow for the inference of resilience and resistance of species and sites to the disturbances and changes in the dynamics of the disturbances. Current discussions of disturbance theory suggest that changes in disturbance dynamics may promote shifts in system structure and dynamics and successional trajectories. As such, because of the changes in disturbance dynamics, systems may have alternative successional trajectories that do not allow for the system to revert to a previous state due to changes in disturbance regimes. The intent of this dissertation is to provide information of long-term multiple disturbance regimes and their interaction in explaining the structural patterns of pine-oak forests and the implications for disturbance theory. 


\title{
CHAPTER 2
}

\section{DENDROECOLOGY OF SHADE-INTOLERANT PINUS ECHINATA (MILL.) INDICATES VARIABLE RESPONSES TO GAP DYNAMICS OVER 300 YEARS}

\begin{abstract}
Studies of historic forest disturbances provide an important context for understanding the ecological dynamics that affect forest structure and successional trajectories. I detected release events using growth regime analysis, documented establishment dates, and assessed radial growth rates and patterns over 300 years in shade-intolerant, gap-dependent Pinus echinata (Mill.) at seven sites in the Missouri Ozarks in order to understand historic natural and anthropogenic disturbance dynamics. Euro-American settlement of the region, beginning in the early $19^{\text {th }}$ century, likely changed the canopy disturbance dynamics through logging and land-clearing. Results show that $P$. echinata responded to gap-openings at all sites, but not all trees exhibited release events. Releases prior to 1850 were generally represented by few trees suggesting $P$. echinata was responding to individual tree mortality. Multiple lines of evidence coupled with historical documentation identified possible logging activities during the $19^{\text {th }}$ and $20^{\text {th }}$ centuries. Several release events were documented during the $18^{\text {th }}$ century possibly indicating historical canopy disturbances. Mean radial growth rates and tree diameters increased significantly after 1900 that may relate to large gap formation likely from extensive logging. This research demonstrates that $P$. echinata established and responded to gap openings of varying size and origin in mixed-species forests over the past 300 years in the Missouri Ozarks.
\end{abstract}

Key words: $\quad$ dendroecology; forest disturbance; canopy disturbance; Pinus echinata; shortleaf pine; radial growth; Missouri Ozarks; release; regime shift analysis; tree-ring analysis 


\section{INTRODUCTION}

Various approaches have been developed to ascertain the frequency, magnitude, and spatial extent of historical disturbances using dendrochronology (Black and Abrams 2005; Fraver and White 2005; Lorimer and Frelich 1989; Nowacki and Abrams 1997; among others). Commonly, approaches use long-term changes in radial growth in individual trees to infer changes to the canopy structure of a forest stand or relate the changes in growth to historical documentation. These various approaches to studying historical disturbance have provided valuable insight into stand dynamics, particularly in eastern North American forests where stand replacing events are not common.

In Missouri forests, shortleaf pine (Pinus echinata, Mill.) has a historical as well as contemporary role, both ecologically as well as economically. Pinus echinata became an important economic resource during the $19^{\text {th }}$ century as Euro-Americans began to settle in the Missouri Ozarks. As the only native pine in Missouri, P. echinata has been a focus of research ranging from historic fire regime reconstruction (Guyette et al. 2002) to growth and climate analysis (Stambaugh and Guyette 2004). The presence of remnant wood (snags, stumps) has enhanced the historical studies of $P$. echinata in that these extend tree-ring chronologies several centuries to gather pre-Euro-American data.

During in the $19^{\text {th }}$ century, intensive Euro-American influence became a primary disturbance factor ranging from the use of fire to land-clearing for agriculture and logging practices. Intensive industrial logging occurred during the late $19^{\text {th }}$ and early $20^{\text {th }}$ century (Stevens 1991) and resulted in reduced pine regeneration, a change to the structure of historic oak-pine forests, and a call for changes to logging practices to insure the continuation of the pine resource (Record 1910). However, other natural disturbances are known to occur within the Missouri Ozark region and likely influence the canopy structure of oak-pine forests by either directly affecting the growth of $P$. echinata or indirectly affecting co-occurring species associated with $P$. echinata communities. Drought conditions have been shown to be strongly correlated 
with P. echinata ring-widths (Stambaugh and Guyette 2004) and growth reductions (Guyette et al. 2007). The effect of other regional disturbances that occur in Missouri including ice storms, wind events that result in overstory mortality, and insect outbreaks can be identified using dendrochronology techniques that detect abrupt changes in radial growth of $P$. echinata that survive the disturbance.

Contrastingly, natural disturbances may have the potential of enhancing growth rates of understory $P$. echinata. Any event that results in gap formation can provide an opportunity for $P$. echinata to increase its growth rate. Although pines are not generally considered gap replacement species, Stambaugh and Muzika (2007) demonstrated that $P$. echinata in Missouri Ozark forests can be a gap replacement species. Regional natural disturbances that have the potential of enhancing radial growth of understory $P$. echinata include windstorms such as tornadoes and downbursts and individual tree mortality that create canopy gap openings of varying size.

In this study, I used the historic growth patterns of $P$. echinata in order to quantify canopy disturbance events to further the understanding of the disturbance ecology of P. echinata forests in Missouri. This study compliments the extensive knowledge of historic fire regimes in P. echinata forests of the Missouri Ozarks (Guyette and Cutter 1997; Guyette and Dey 1997a-b; Guyette et al. 2003). By analyzing growth patterns across multiple sites, I can identify common periods of growth change that may be climate related as well as account for differences in growth among sites that may indicate anthropogenic or natural disturbance. Interests in the restoration of P. echinata exist (Kabrick et al. 2007) given the recognition of the decline in abundance of this species in the Missouri Ozarks (Guyette et al. 2007). Yet, little is known concerning the canopy disturbance dynamics in mixed-species forests that include $P$. echinata. I chose to utilize multiple lines of evidence to understand the canopy disturbance dynamics and growth of $P$. echinata at seven sites in the Missouri Ozarks. 
Based on tree-ring chronologies that extend disturbance analysis back multiple centuries, I identified three primary goals of this study. First, I assessed the historic canopy disturbance of P. echinata sites in the Missouri Ozarks by identifying release events using regime shift analysis (Rodionov 2006). Second, I evaluated the early growth rates of trees to understand the structure of forests during three different time periods: pre-1850, 1850-1900, and 1900-1950. Growth patterns can be used to infer the environment (open or closed canopy) that trees were growing at the time of recruitment (Frelich 2002). Lastly, I investigated the median decadal growth rates of individual trees at each site to evaluate the connection between release events and growth rates. 


\section{METHODS}

\section{Study Sites}

I selected seven sites in the historical distribution of P. echinata in Missouri (Fig. 2.1). Liming (1946) estimated that P. echinata was found across 2.7 million ha, or nearly half of the forested area in the State during the pre-settlement period, but now that forest type is a minor component (5\% of total volume of live trees) in Missouri forests (Moser et al. 2011). Sites were selected based on the presence of remnant (stumps/snags) P. echinata and overstory P. echinata. Other overstory species at these sites include white oak (Quercus alba L.), scarlet oak (Quercus coccinea Muench.), and black oak (Quercus velutina Lam.). Elevations of the study sites range from approximately $183 \mathrm{~m}$ to $365 \mathrm{~m}$. Mean annual temperature for the town of Eminence, Shannon County, Missouri that is centrally located among the study sites is $13.5^{\circ} \mathrm{C}$. The mean annual precipitation for Eminence is approximately $114.3 \mathrm{~cm}$ with most precipitation falling March through May (Missouri Climate Center, climate.missouri.edu/modata.php).

Mill Hollow and Highway 19 sites are owned by the L-A-D Foundation (St. Louis, MO) and managed by Pioneer Forest (Salem, MO). Both sites are approximately 70 ha in size and immediately adjacent to the Current River in Shannon County, Missouri. Both sites are located in the Current River Hills ecological subsection (Nigh and Schroeder 2002) known for its rough topography.

Alley Springs is currently managed by the National Park Service and is located within the Ozark National Scenic Riverways. Our site was an approximately 64 ha area adjacent to the Jack's Fork River in Shannon County, Missouri. Alley Springs is also located in the Current River Hills ecological subsection (Nigh and Schroeder 2002).

The Missouri Ozark Forest Ecosystem Project (MOFEP) was established in 1989 to study the effects of forest management on ecosystem attributes in the Missouri Ozarks (Brookshire and Dey 2000). All sites are owned by the Missouri Department of Conservation and are located within an approximately $416 \mathrm{~km}^{2}$ area across three counties. I chose three of the sites in MOFEP 
(Sites 2, 3, and 4) that had both remnant wood as well as increment core data from existing $P$. echinata. The three sites chosen for this study are located near or adjacent to the Current River. All sites are approximately 240 ha in size.

The Eck Tract Conservation Area is a 150 ha site located in Texas County, approximately $70 \mathrm{~km}$ west of the nearest site, Alley Springs. Eck Tract is owned by the Missouri Department of Conservation and is adjacent to the Big Piney River. Eck Tract is within the Gasconade River Hills ecological subsection (Nigh and Schroeder 2002) noted for its slightly dissected plains and more moderate topography relative to the Current River Hills subsection.

\section{Field and laboratory procedures and data sources}

The source of data and samples of $367 P$. echinata from seven sites included collections by me, the Missouri Tree-Ring Laboratory (University of Missouri, Columbia, MO) (MTRL) and data available from the International Tree-Ring Database (ITDRB) (Table 2.1). At Mill Hollow, Hwy. 19, Alley Springs, and Eck Tract I established three $500 \mathrm{~m}$ transects $100 \mathrm{~m}$ apart along the prevailing slope contour at upper slope positions (ridge, shoulder, backslope). Remnant $P$. echinata (stump/snag) wood encountered along each transect was visually inspected for a pith and approximate ring count $>75$ years for cross-dating purposes. Increment cores were collected at breast height $(\sim 1.3 \mathrm{~m})$ on any $P$. echinata $\geq 30 \mathrm{~cm}$ diameter at breast height $(\mathrm{DBH})$ and were in a dominant or co-dominant position and cross-sections of remnant wood were collected with a chainsaw.

Samples that were previously collected from Mill Hollow, Alley Springs, and Eck Tract by the MTRL were used in addition to the samples collected by myself. Ring-width chronologies from MOFEP were accessed via the International Tree-Ring Database and existing samples located at the MTRL were used for disturbance analysis. Additionally, increment cores of 

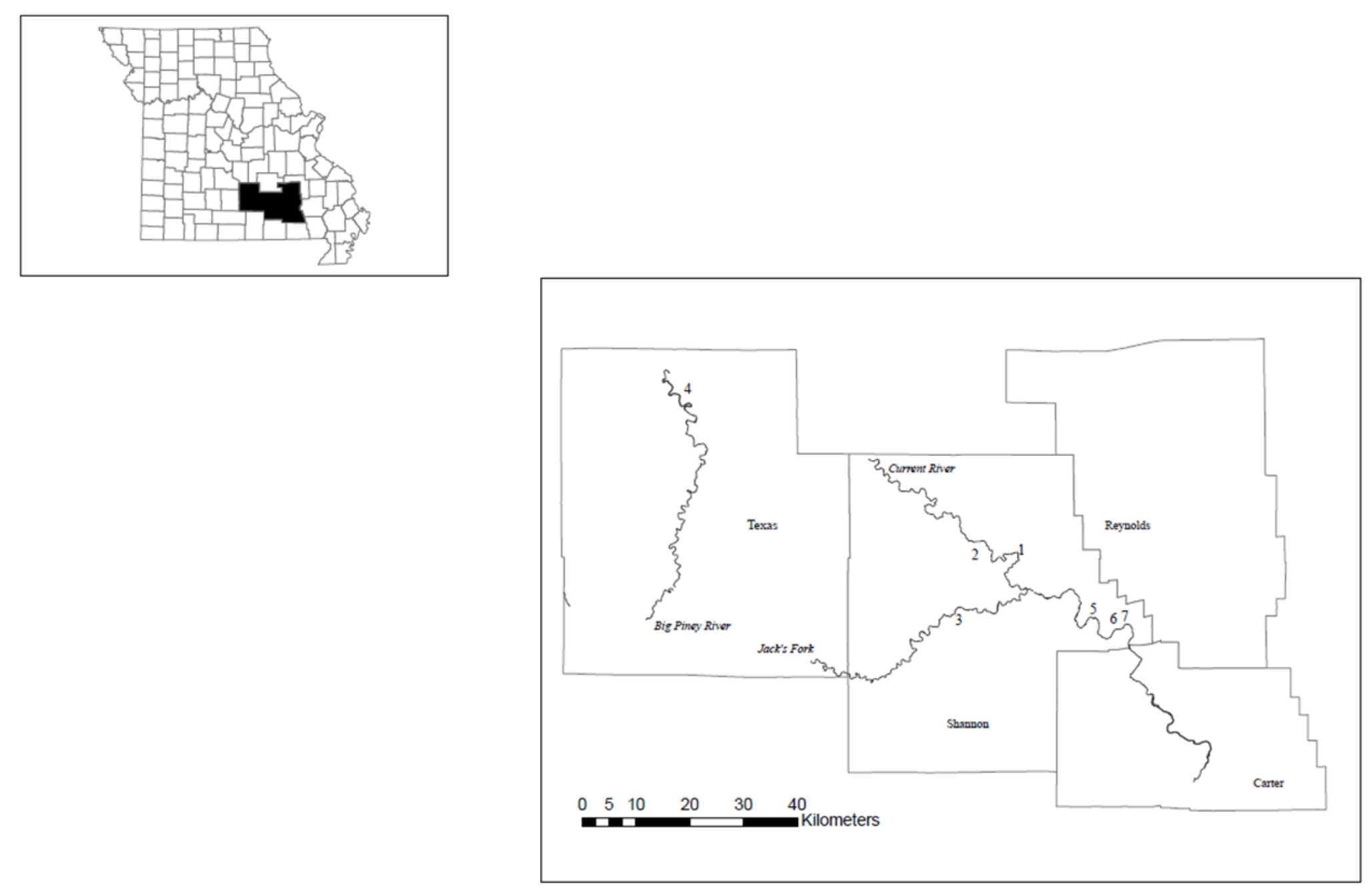

Figure 2.1. Locations of the seven study sites in Missouri. Study sites: 1) Mill Hollow; 2) Hwy. 19; 3) Alley Springs; 4) Eck Tract; 5) MOFEP 2; 6) MOFEP 3; 7) MOFEP 4. 
MOFEP P. echinata collected by Voelker (2004) were incorporated in my study. Wood samples were prepared using the methods of Stokes and Smiley (1996). All samples were cross-dated using visual methods (Yamaguchi 1991) and COFECHA (Holmes 1983, Grissino-Mayer 2001). COFECHA is a computer program that assesses the correlation of ring-width series among samples by site. Visual and computer-based cross-dating increases the accuracy of assigning calendar years to individual ring-widths. Ring-width data obtained via ITDRB historically included data for two or more cores from individual trees for climatic analysis. In the event of multiple cores from single trees, I selected the one ring-width series with the longest chronology.

\section{Assessing disturbance dynamics}

Using radial growth patterns, I applied the regime shift intervention method developed by Rodionov (2006) to identify release events. This approach uses sequential t-test procedures to analyze any time series for significant shifts in the time series. As a new observation is added to a time series, a t-test is performed to determine if it represents a significant deviation from the mean of the current regime. Further analysis of additional observations following a proposed significant change in time series is used to confirm or reject the identified change in the regime (Rodionov and Overland 2005). This approach has been applied largely to the analysis of climate related data (Elliott 2011; Pederson et al. 2012) but provides an adjustable interface for its application to dendroecology. Rauchfuss (2009) assessed the use of the regime shift approach for identifying release and suppression events in forest types of Minnesota. She noted that the regime shift detection was more accurate in identifying abrupt changes in growth to known canopy disturbance events. This was important for my analysis given the limited historical documentation of past canopy disturbance events at the study sites. The regime shift program (http://www.BeringClimate.noaa.gov) allows for the user to change the length of the regimes and determine the a priori significance level. In using the most recent version of the regime shift 
analysis, I accounted for autocorrelation using ordinary least squares and the pre-whitening feature given that tree-ring chronologies are autocorrelated. I used a 0.05 significance level and was interested in identifying abrupt shifts in radial growth that were sustained for at least 15 years.

To support the regime shift analysis, I analyzed the early radial growth rates of trees. In the event of a missing pith in either remnant or increment cores, I used the methods of Duncan (1989) to estimate pith dates. I assigned establishment periods of trees into one of three categories: trees establishing prior to $1850,1850-1900$, or 1900-1950. I chose these three categories of establishment for multiple reasons. Prior to 1850, population density of humans (both Native Americans and Euro-Americans) was low across the Missouri Ozarks (Stevens 1991), transitory, and likely only localized logging and land clearing for agriculture occurred. The period 1850-1900, however, saw a significant increase in Euro-American population growth in the Missouri Ozarks largely due to the Graduation Act of 1854 which increased the number of land entries of settlers and land prospectors (Stevens 1991). Finally, the period 1900-1950 saw the greatest period of logging activity along with logging operations in the Missouri Ozarks (Record 1910, Stevens 1991). Therefore, I expected that early growth rates of trees might reflect changes in the canopy structure over these time periods. I calculated mean radial growth for the first 50 years of growth by time period for each site to assess if trees exhibited different growth patterns following establishment. I calculated inside bark diameter at age 50 for trees in the three time periods to further provide evidence of changes in growth rates for $P$. echinata over the past 300 years. I used a two-factor analysis of variance (ANOVA) to test for differences in mean tree diameter among sites and time periods.

As another source of evidence, I used median decadal growth of each tree compared to the overall median growth rate of all $P$. echinata by site to analyze for changes in disturbance dynamics. I used this in concert with identified releases to corroborate canopy disturbance at the sites and understand the growth of trees that did not exhibit a growth release during the decade. 
Based on the overall median radial growth rate by site, I calculated the $75^{\text {th }}$ and $25^{\text {th }}$ percentiles of overall growth to compare to the median decadal growth for each tree. Trees that had a median decadal growth rate greater than the overall $75^{\text {th }}$ percentile were inferred to be growing in a gap during the decade while trees that had a median decadal growth rate less than the overall $25^{\text {th }}$ percentile were inferred to be growing in a suppressed or non-gap position during the decade due to injury or overtopping. I expected that a change in canopy dynamics may be reflected in the percentage of trees that had a median decadal growth $>75^{\text {th }}$ percentile or $<25^{\text {th }}$ percentile. An increase in the percentage of trees with a radial growth $>75^{\text {th }}$ percentile during the late $19^{\text {th }}$ and $20^{\text {th }}$ century may be a reflection of large gap formation associated with logging activity during this time period. I used SAS version 9.3 (SAS Institute 2011) and SigmaPlot version 11.0 (Systat Software Inc. 2008) for analysis and calculations. 


\section{RESULTS}

\section{$P$. echinata release analysis}

Based on the 367 P. echinata tree-ring series and 38,520 tree-rings analyzed from seven sites, 416 release events were identified using regime shift analysis. This analysis covered approximately the past 250 years with the longest tree-ring chronology (Alley Springs) covering over 300 years (Table 2.1). Figure 2.2 provides an example of the detection of significant shifts in mean radial growth of $P$. echinata using regime shift analysis. Alley Springs trees accounted for approximately $24 \%(n=102)$ of all release events and $20 \%(n=54)$ of all releasing trees across all sites. The MOFEP sites all exhibited the lowest number of release events. The Hwy. 19 site had the lowest percentage of trees that released $(54 \%, \mathrm{n}=44)$ relative to the total trees sampled at the site while $83 \%(n=46)$ of trees at Mill Hollow experienced at least one release event.

Across all sites, $27 \%(\mathrm{n}=98)$ of trees revealed no evidence of a release event. The mean number of releases per tree indicates that trees that did release expressed approximately one release event $(\overline{\mathrm{x}}=1.18$, S.E. $+/$ - 0.16) (Table 2.1). At the site level, 65\% $(\mathrm{n}=35)$ of releasing trees at Alley Springs had more than one release event while only 34\% $(n=15)$ of trees at Hwy. 19 experienced more than one release event. This is additionally reflected in the mean number of release events at each site (Table 2.1). Decadal disturbance chronologies indicate site-specific patterns of disturbance with common regional periods of pronounced release events between 1680 and 1950.

The earliest releases detected occurred at Mill Hollow and MOFEP 2 during the 1710's. Common temporal periods of releases in which sample depth was $>10$ trees and at least $20 \%$ of samples released occurred during 1800, 1840, 1900, 1930, and 1940. Release events during 1750 (Alley Springs), 1800 (Hwy. 19), and 1930-1940 (six sites) corresponded with establishment of P. echinata during those decades. In addition to the notable historic release/establishment events 


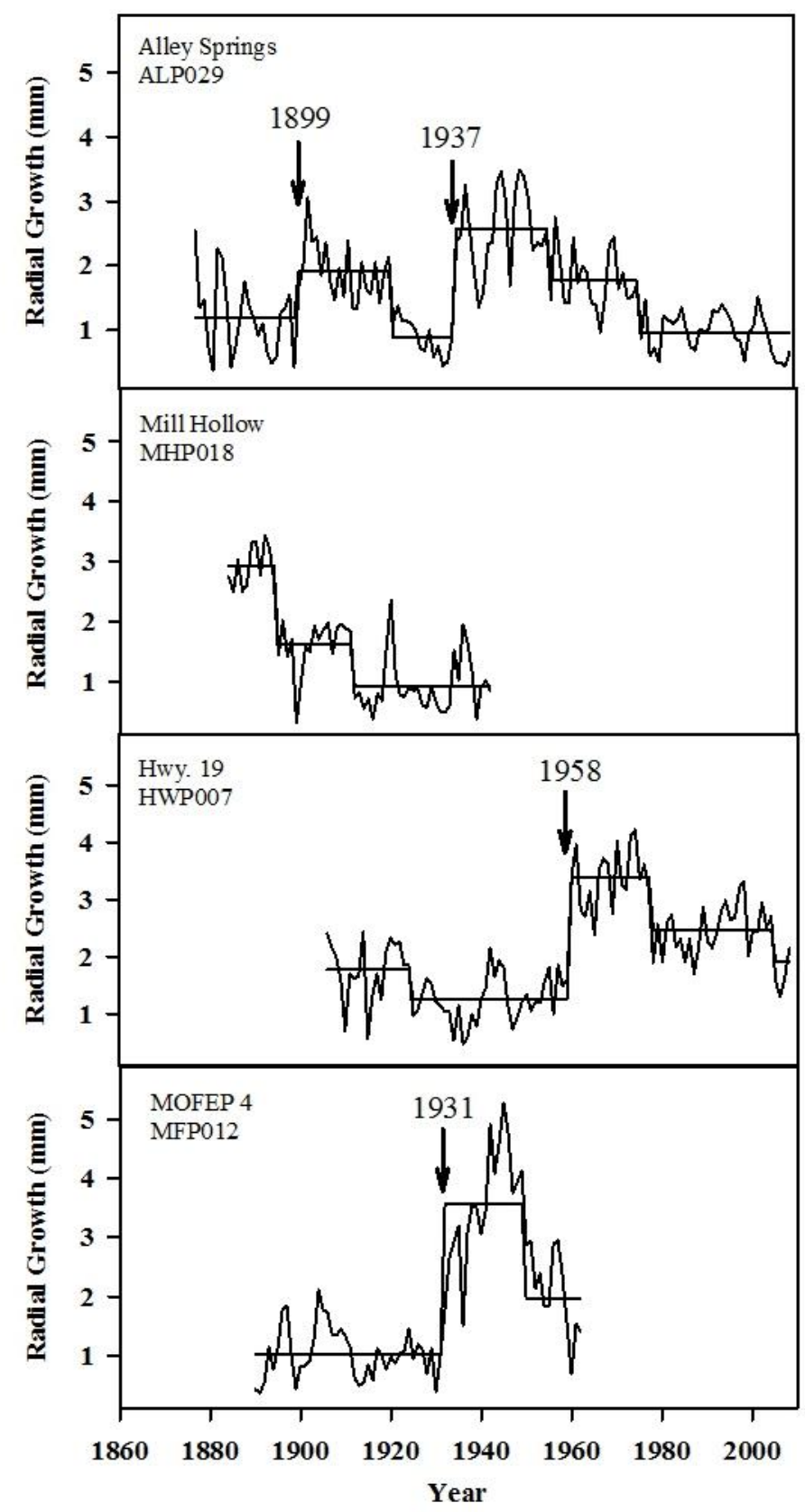

Figure 2.2. Examples of growth patterns and regime shift analysis of individual Pinus echinata in the Missouri Ozarks with known pith dates. Examples demonstrate different growth patterns of $P$. echinata across all sites. Arrows indicate significant increases in growth identified as release events. Trees not exhibiting releases (b) were common at all sites after 1900. 
Table 2.1. Descriptive statistics of 367 P. echinata and locations of seven study sites in the Missouri Ozarks.

\begin{tabular}{|c|c|c|c|c|c|c|c|c|c|}
\hline Site & Collector & ${ }^{1}$ Chronology & Coordinates & $\begin{array}{c}\text { Sample } \\
\text { Depth }\end{array}$ & $\begin{array}{l}{ }^{2} \text { Mean/Media } \\
\text { n \# Releases }\end{array}$ & $\begin{array}{c}\text { Median } \\
\text { Growth } \\
\text { (25th, 75th) }\end{array}$ & $\begin{array}{l}{ }^{3} \% \text { Trees } \\
\text { Shifting } \\
\text { Growth }\end{array}$ & $\begin{array}{c}{ }^{4} \% \text { Trees } \\
\text { with Early } \\
\text { Growth } \\
<\text { Median } \\
\end{array}$ & $\begin{array}{c}{ }^{4} \% \text { Trees } \\
\text { with Early } \\
\text { Growth } \\
>\text { Median } \\
\end{array}$ \\
\hline $\begin{array}{l}\text { Alley } \\
\text { Springs }\end{array}$ & $\begin{array}{l}\text { Author } \\
\text { MTRL }\end{array}$ & $1624-1960$ & $\begin{array}{l}37^{\circ} 08^{\prime} \mathrm{N}, \\
91^{\circ} 27^{\prime} \mathrm{W}\end{array}$ & 68 & $\begin{array}{l}1.52(0.13) \\
2.00(0-4)\end{array}$ & $\begin{array}{c}1.23 \\
(0.79,1.81)\end{array}$ & $31 \%$ & $27 \%(17)$ & $73 \%(47)$ \\
\hline Eck Tract & $\begin{array}{l}\text { Author } \\
\text { MTRL }\end{array}$ & $1701-1960$ & $\begin{array}{l}37^{\circ} 35^{\prime} \mathrm{N}, \\
91^{\circ} 01^{\prime} \mathrm{W}\end{array}$ & 48 & $\begin{array}{c}1.17(0.15) \\
1.00(0-4)\end{array}$ & $\begin{array}{c}0.99 \\
(0.62,1.63)\end{array}$ & $11 \%$ & $26 \%(11)$ & $74 \%(31)$ \\
\hline $\begin{array}{c}\text { Mill } \\
\text { Hollow }\end{array}$ & $\begin{array}{l}\text { Author } \\
\text { MTRL }\end{array}$ & $1670-1960$ & $\begin{array}{l}37^{\circ} 24^{\prime} \mathrm{N}, \\
91^{\circ} 26^{\prime} \mathrm{W}\end{array}$ & 55 & $\begin{array}{c}1.30(0.13) \\
1.00(0-4)\end{array}$ & $\begin{array}{c}1.09 \\
(0.67,1.67)\end{array}$ & $24 \%$ & $19 \%(8)$ & $81 \%(36)$ \\
\hline Hwy. 19 & Author & $1740-1960$ & $\begin{array}{l}37^{\circ} 25^{\prime} \mathrm{N}, \\
91^{\circ} 38^{\prime} \mathrm{W}\end{array}$ & 86 & $\begin{array}{c}0.74(0.09) \\
1.00(0-3)\end{array}$ & $\begin{array}{c}1.46 \\
(0.80,2.32)\end{array}$ & $16 \%$ & $17 \%(9)$ & $83 \%(46)$ \\
\hline $\begin{array}{c}\text { MOFEP } \\
\text { Site } 2\end{array}$ & $\begin{array}{l}\text { MTRL } \\
\text { Voelker } \\
(2004)\end{array}$ & $1700-1960$ & $\begin{array}{l}37^{\circ} 15^{\prime} \mathrm{N}, \\
91^{\circ} 13^{\prime} \mathrm{W}\end{array}$ & 42 & $\begin{array}{c}1.07(0.12) \\
1.00(0-3)\end{array}$ & $\begin{array}{c}1.15 \\
(0.72,1.8)\end{array}$ & $37 \%$ & $11 \%(4)$ & $89 \%(33)$ \\
\hline $\begin{array}{c}\text { MOFEP } \\
\text { Site } 3\end{array}$ & $\begin{array}{l}\text { MTRL } \\
\text { Voelker } \\
(2004)\end{array}$ & $1715-1960$ & $\begin{array}{l}37^{\circ} 14^{\prime} \mathrm{N}, \\
91^{\circ} 09^{\prime} \mathrm{W}\end{array}$ & 35 & $\begin{array}{c}1.29(0.18) \\
1.00(0-4)\end{array}$ & $\begin{array}{c}1.3 \\
(0.79,1.98)\end{array}$ & $21 \%$ & $18 \%(6)$ & $82 \%(28)$ \\
\hline $\begin{array}{c}\text { MOFEP } \\
\text { Site } 4\end{array}$ & $\begin{array}{l}\text { MTRL } \\
\text { Voelker } \\
(2004) \\
\end{array}$ & $1724-1960$ & $\begin{array}{l}37^{\circ} 13^{\prime} \mathrm{N}, \\
91^{\circ} 08^{\prime} \mathrm{W}\end{array}$ & 33 & $\begin{array}{c}1.16(0.31) \\
1.00(0-3)\end{array}$ & $\begin{array}{c}1.54 \\
(1.02,2.21)\end{array}$ & $28 \%$ & $25 \%(8)$ & $75 \%(24)$ \\
\hline
\end{tabular}

${ }^{1}$ For this study, chronologies were restricted to historic time periods up to 1960 .

2 Top value indicates mean (SE); bottom value indicates median (range).

${ }^{3}$ This reflects the percentage of trees in which $10 \mathrm{yr}$ median radial growth rates changed from $<25^{\text {th }}$ to $>75^{\text {th }}$, or vice versa.

${ }^{4}$ Percentages are based 50yr median of trees with actual or estimated pith data. 
at Alley Springs and Hwy. 19, five of the seven sites exhibited growth releases and establishment during the 1930-1940 period. At five of the seven sites, $>70 \%$ of decades examined had at least one tree releasing. Even at those sites with fewer, Eck Tract and MOFEP 2, the percentage of decades showing a release was $>50 \%$ (Fig.2.3).

\section{Growth rates and patterns in $P$. echinata}

Median decadal growth rates of trees that exceeded the $75^{\text {th }}$ percentile corresponded with identified release events across all sites (Fig. 2.3). Trees with median decadal growth $>75^{\text {th }}$ percentile reflect establishment or growth release events. The combination of $P$. echinata establishment, release events, and percentage of trees with growth rates $>75^{\text {th }}$ percentile coincide to reflect a large canopy disturbance event or series of events. In most cases, the percentage of releasing trees was low $(<25 \%)$ while the percentage of trees with a growth $>75^{\text {th }}$ percentile was $>25 \%$.

At the Hwy. 19 site, the release event during 1800 also shows trees with growth rates exceeding the $75^{\text {th }}$ percentile threshold (Fig. 2.3). The same pattern occurs during the release events of 1930-1940. Trees that had growth rates $>75^{\text {th }}$ percentile corresponded to trees that established during the decade. At Eck Tract beginning in 1850 , trees with growth rates $<25^{\text {th }}$ percentile were noticeably rare when compared to growth rates prior to 1850 . This same pattern appears at other sites beginning in decades during the mid $-19^{\text {th }}$ century but is generally not sustained when compared to Eck Tract (Fig. 2.3). Overall, 24\% $(n=88)$ of trees showed a shift in growth rate that resulted in either increasing from a median decadal growth rate $<25^{\text {th }}$ percentile to one $>75^{\text {th }}$ percentile or vice versa. This change in growth occurred more frequently at Alley Springs $(31 \%, \mathrm{n}=22)$ and MOFEP $2(37 \%, \mathrm{n}=15)$ (Table 2.1). 

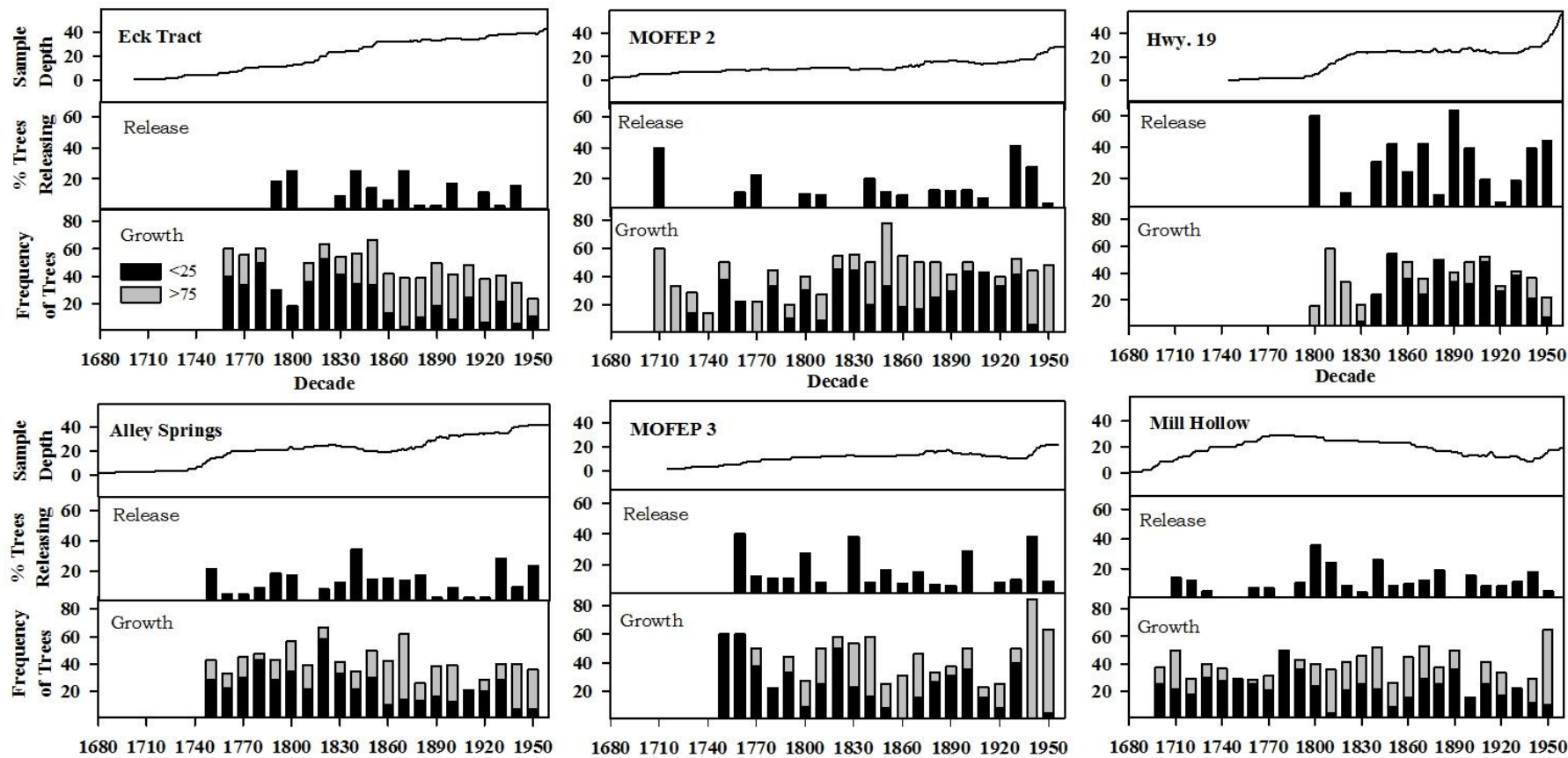

Decade

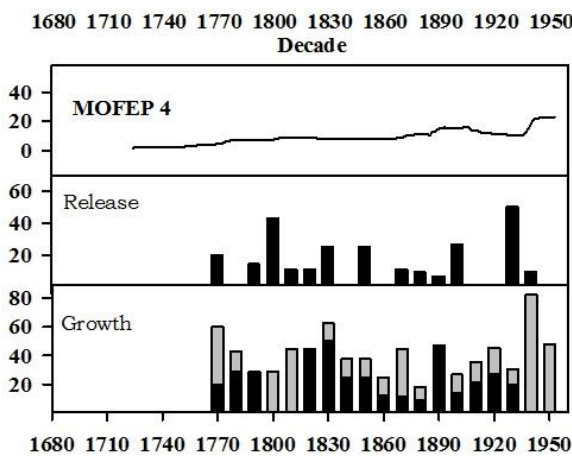

68017101740177018001830
Decade

Figure 2.3. Release analysis and growth patterns of P. echinata at seven sites in the Missouri Ozarks. The top graphs for each site indicates the sample depth (number of trees analyzed during the decade). The center graphs indicate the percentage of $P$. echinata that exhibited a release. The bottom graphs for each site indicates the percentage of trees that exhibited a median decadal growth rate $>75^{\text {th }}$ percentile (grey bars) and $<25^{\text {th }}$ percentile (black bars). 
Mean growth rates of $P$. echinata during the first 50 years exhibit differences during different time periods at the seven sites (Fig. 2.4). The greatest early growth rates appear in trees that established following 1900, while the lowest growth rates of establishing P. echinata occur prior to 1900. An exception to this pattern was at Hwy. 19 in which trees that established prior to 1850 had the highest growth rates during the first 10 years that corresponds to the release event during the 1800 decade (Fig. 2.4). At the MOFEP sites there is a notable negative exponential growth pattern during the $1900-1950$ period. This higher growth rate is sustained for approximately 30-40 years, following that, the mean growth rates of trees across the three time periods were similar. This similar pattern is also found at Mill Hollow and Alley Springs. Differences in early growth were noted at Eck Tract in which the mean early growth of $P$. echinata was higher during the first 50 years (Fig. 2.4).

Analysis of variance of mean diameter indicated significant differences in mean diameter during the first 50 years of growth (Table 2.2). Trees that established after 1900 had a significantly greater diameter than trees that established prior to 1900 . No differences were detected in mean tree diameter among sites $\left(\mathrm{F}_{6,286}=2.070, \mathrm{p}>0.05\right)$. 


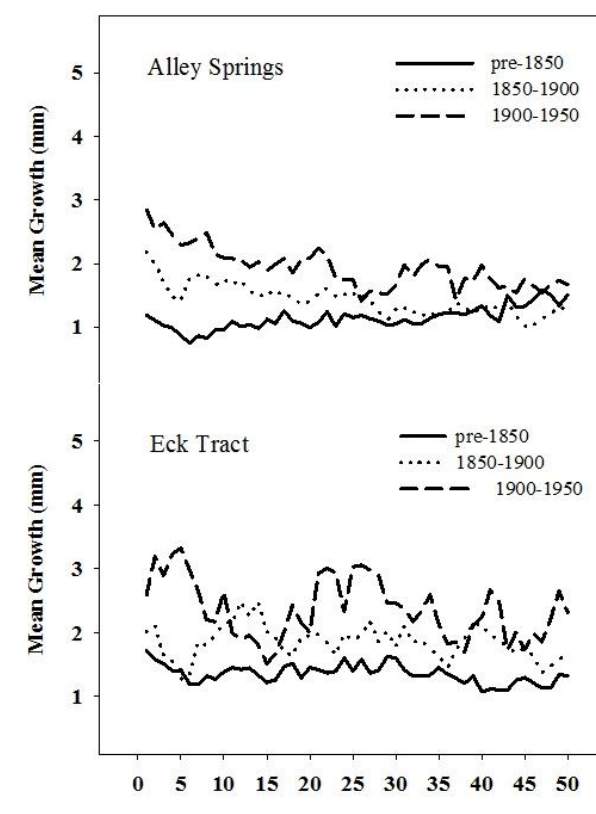

Age
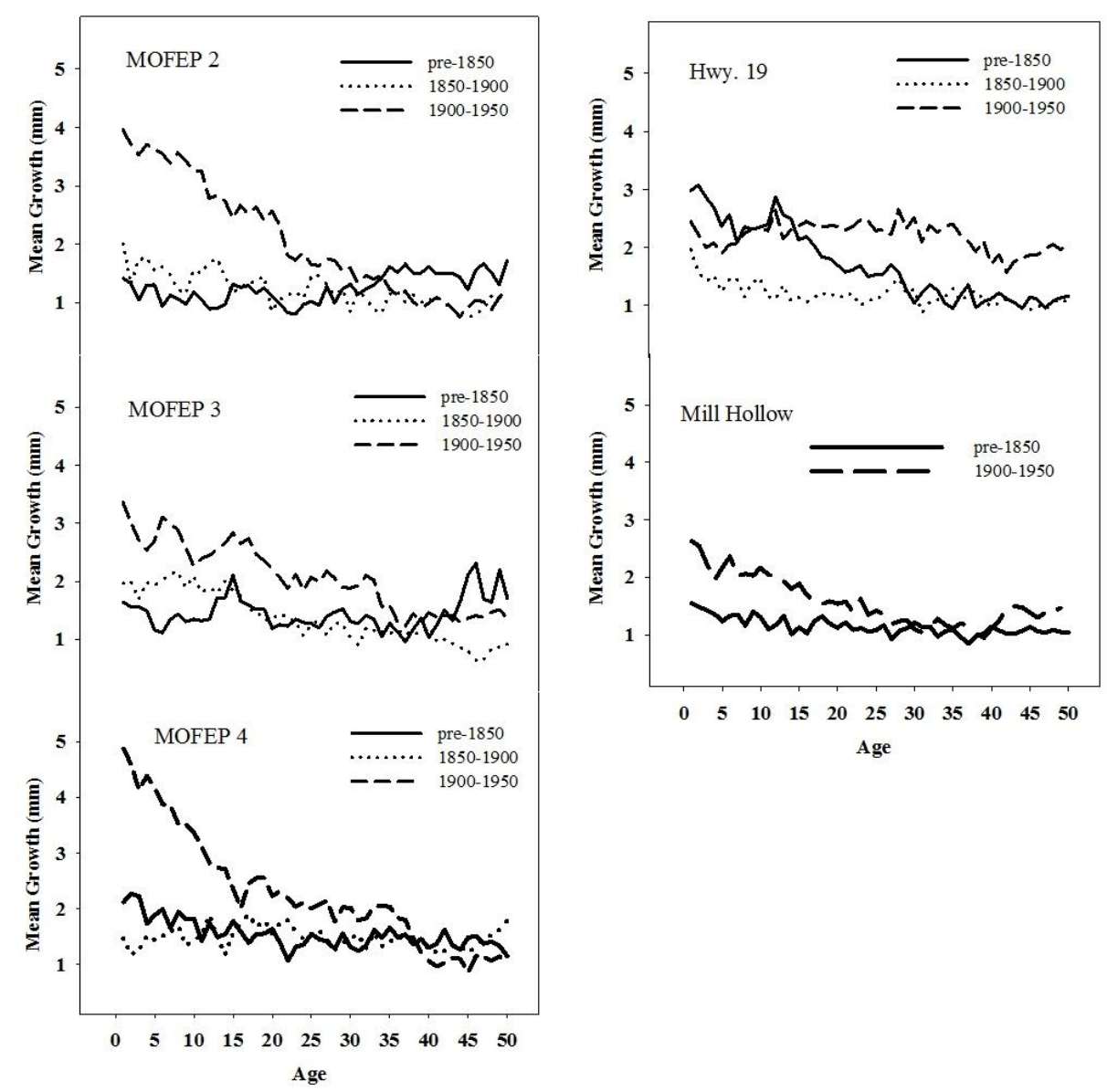

Figure 2.4. Growth patterns of $P$. echinata during the first 50 years of growth at seven sites in the Missouri Ozarks. Graphs are grouped by vicinity of study sites (Alley Springs/Eck Tract); (Mill Hollow/Hwy. 19); (MOFEP 2, 3, 4). Note: There was no P. echinata establishment at Mill Hollow during the period $1850-1900$. 
Table 2.2. Analysis of mean diameter $(\mathrm{cm})$ of $P$. echinata at age 50 based on site and time period. Differences were detected among time periods by site $(\mathrm{p}<0.05)$ using analysis of variance. Values in parantheses indicate $+/$-SE. Same letter superscripts indicate differences detected using Tukey's post-hoc test. No differences in mean diameter were detected among sites $\left(\mathrm{F}_{6,286}=2.070, \mathrm{p}>0.05\right)$. Sample depths are different from Table 2.1 based on the ability to estimate pith dates using Duncan (1989).

\begin{tabular}{cccc}
\hline \hline Site & pre 1850 & $1850-1900$ & $1900-1950$ \\
\hline Alley Springs & $11.41(0.834)^{\mathrm{a}, \mathrm{b}}$ & $14.36(0.726)^{\mathrm{b}, \mathrm{c}}$ & $19.36(0.738)^{\mathrm{a}, \mathrm{c}}$ \\
\hline Eck Tract & $9.64(1.46)^{\mathrm{a}, \mathrm{b}}$ & $16.55(2.13)^{\mathrm{b}}$ & $20.36(1.32)^{\mathrm{a}}$ \\
\hline${ }^{1}$ Mill Hollow & $11.43(0.66)$ & & $15.68(1.1)$ \\
\hline Hwy. 19 & $17.05(1.55)^{\mathrm{b}}$ & $11.94(1.50)^{\mathrm{a}, \mathrm{b}}$ & $21.94(1.57)^{\mathrm{a}}$ \\
\hline MOFEP 2 & $14.92(1.82)^{\mathrm{a}}$ & $13.72(1.19)^{\mathrm{b}}$ & $20.64(1.18)^{\mathrm{a}, \mathrm{b}}$ \\
\hline MOFEP 3 & $12.11(1.28)^{\mathrm{b}}$ & $12.21(1.63)^{\mathrm{a}}$ & $20.45(1.10)^{\mathrm{a}, \mathrm{b}}$ \\
\hline MOFEP 4 & $15.32(1.47)^{\mathrm{a}}$ & $15.94(1.75)^{\mathrm{b}}$ & $22.54(1.12)^{\mathrm{a}, \mathrm{b}}$
\end{tabular}

${ }^{1}$ No analysis was conducted on Mill Hollow 1850-1900 as there were no samples that established during that time period. 


\section{DISCUSSION}

\section{Canopy disturbance dynamics}

My results show that: 1) P. echinata responded to canopy disturbance events as indicated by growth releases over the 300 years of analysis; and 2) growth rates of P. echinata changed during the release events as a response to changing disturbance regime i.e. gap size; and 3) growth rates during the first 50 years differed across time periods, also likely reflecting changes in gap dynamics. This is the first evidence that I am aware of that links multiple lines of support to explain the changes in forest structure in Missouri Ozark forests. While it has been well established that fire was an important historic forest disturbance through the 1930's in Missouri oak-pine forests (Batek et al. 1999; Guyette et al. 2002), canopy disturbance events that had either natural or anthropogenic origin also affected the canopy ascension of P. echinata in these forests. Generally, while fire may be important in establishment of $P$. echinata, canopy disturbance events correspond more closely to stand dynamics.

I identified release events dating to the late $17^{\text {th }}$ century at seven sites in the Missouri Ozarks. Most release events constituted a small number of trees $(<3)$ and $<25 \%$ of trees releasing during a decade and did not appear to coincide with the establishment of P. echinata. One of the earliest large-scale disturbance events, based on the percentage of trees releasing, the establishment of a cohort of P. echinata, and $75^{\text {th }}$ percentile growth, occurred at Hwy. 19 during the period 1800-1810. Likely, this event was associated with a natural disturbance such as a wind-related event, a severe fire event, or a combination of both that removed portions of the overstory canopy. Two fires burned at Hwy. $19(1806,1808)$ based on fire scar analysis of remnant wood (King, unpub. data). A large-scale canopy disturbance event likely occurred at Alley Springs during the 1740's in which releases were identified and a large percentage of my samples established $(16 \%, \mathrm{n}=11)$. This also reflects a wind-related event that removed portions of the overstory and promoted releases of understory $P$. echinata and establishment of P. echinata in newly created gaps. Two fires also burned at Alley Springs $(1744,1747)$ that coincided with 
the canopy disturbance at the site (King, unpub. data). I noted continuous recruitment with pulses of establishment associated with release events that I attribute to minor and major canopy disturbance events, respectively (Fig. 2.3). A similar conclusion was developed in a study of longleaf pine (P. palustris, Mill.) stands in Georgia in which a series of minor and major canopy disturbances led to continuous recruitment of P. palustris (Pederson et al. 2008).

In addition to pre-settlement disturbance patterns, my multiple lines of evidence related to canopy disturbance capture the effect of increased Euro-American settlement and logging after 1850 in the Current River watershed. Release events, increased growth rates, and P. echinata recruitment were apparent in the 1870's (MOFEP 2, 3), 1880's (Alley Springs, MOFEP 4), 1930's (MOFEP 2 and 4, Alley Springs), and 1940's (Mill Hollow, Hwy. 19, MOFEP 3). In a previous study of MOFEP 4, Guyette and Dey (1997a) referenced logging activity during the 1920-1940 period. From the 1880 's, several large sawmills were established within the Current River watershed, including the Grandin Mill which was one of the largest in the United States at the time (Cunningham and Hauser 1989). Record (1910) notes that by the early $20^{\text {th }}$ century, most of the P. echinata stands had been cutover in this region and efforts were underway to harvest Q. alba. The release events during the 1930's and 1940's may reflect this logging of remaining P.echinata or Q. alba.

Eck Tract is located immediately adjacent to the Big Piney River which is part of the Gasconade River watershed. Some of the earliest mill sites and logging of P. echinata occurred within the Gasconade River watershed, dating back to the early $19^{\text {th }}$ century (Morrow 2008). Release analysis of Eck Tract indicates a series of release events beginning in the 1830's with continuous establishment through the 1860's suggesting this site could have been selectively logged during that time period. 


\section{Growth rates and patterns of $P$. echinata}

Pinus echinata is a relatively shade-intolerant species that likely established historically in canopy gaps within these forests. In their analysis of contemporary canopy gaps in $P$. echinata stands in Missouri, Stambaugh and Muzika (2007) found that P. echinata was a common gap replacement tree in pine forests. In addition, the number of established P. echinata seedlings increased by eight times from small gaps $\left(\sim 400 \mathrm{~m}^{2}\right)$ to larger gaps $\left(1700 \mathrm{~m}^{2}\right)$ (Stambaugh and Muzika 2004). I found that $27 \%$ of P. echinata did not experience a growth release that would suggest they were growing in large canopy openings. However, only $23 \%(n=23)$ of the trees that exhibited no release established prior to 1850 . Generally, most trees that did not exhibit a release after 1850 had consistent or declining ring-widths (Fig. 2.2b). These trees may have already been in a dominant overstory canopy position and occurred in a once large canopy gap (Frelich and Reich 1995). In particular, P. echinata that established after 1900 exhibited declining ring-widths indicative of large canopy gap openings that put these trees in a position to ascend to the canopy without a release. The declining pattern of growth was reiterated in the growth rates of trees that established after 1900 (Fig. 2.4).

Releases by $P$. echinata were common in trees that eventually were competitive in the canopy and in some cases required multiple releases to ascend to the canopy. The mean number of releases per tree across most sites was $>1$ (Table 2.1) likely indicating that some $P$. echinata experienced sequences of partial canopy openings and overtopping while growing towards the canopy. Shelton and Cain (2000) report that $P$. echinata can withstand several years of seedling suppression and develop less shade tolerance as they mature. It is likely that $P$. echinata at my study sites established in canopy gaps, but gap size was most likely small gaps or partial gap openings that resulted in periods of suppressed growth and one or more releases (Fig 2.2a, c, d). Multiple growth release episodes is likely given that $P$. echinata historically co-existed in mixed species stands with other species such as $Q$. alba, $Q$. coccinea, and $Q$. velutina at all my study sites (Fletcher and McDermott 1957). Therefore, in order to attain canopy status, understory $P$. 
echinata experienced periods of canopy closure by overstory P. echinata and Quercus species at my study sites prior to 1900 .

Using the $75^{\text {th }}$ and $25^{\text {th }}$ percentile growth rates and P. echinata establishment appears to provide further evidence of canopy disturbance across the sites. My use of the $25^{\text {th }} / 75^{\text {th }}$ percentile thresholds relative to release events at the study sites appears to capture the increase in growth rates due to establishment of $P$. echinata and changes in canopy structure (Fig. 2.3). There were discrepancies in the percentage of trees that had a median decadal growth rate that exceeded the $75^{\text {th }}$ percentile did not match the percentage of trees that were identified as releasing based on the regime shift detection (Rodionov 2006). One possible explanation for this is that the growth rate of some trees already exceeded the $75^{\text {th }}$ percentile and therefore did not reflect a release using the regime shift method. Secondly, trees did not necessarily have to experience a growth rate exceeding $>75^{\text {th }}$ percentile in order to release from a suppressed state.

The $25^{\text {th }} / 75^{\text {th }}$ thresholds also indicate that $P$. echinata median decadal growth rates were widely divergent. It was common for trees to exhibit growth rates that were lower than the $25^{\text {th }}$ percentile. At some sites (Eck Tract, Alley Springs, Mill Hollow) prior to 1850, several trees had growth rates below the $25^{\text {th }}$ percentile. During that same time period, relatively few trees were growing in excess of the $75^{\text {th }}$ percentile. One possible explanation for this is P. echinata trees that were growing $>75^{\text {th }}$ percentile were in single tree-fall gaps while most trees growing $<25^{\text {th }}$ percentile were growing slowly under a closed canopy. Finally, at all sites were patterns of increase in trees growing $>75^{\text {th }}$ percentile followed by decades of trees growing $<25^{\text {th }}$ percentile (Fig.2.3). I attribute these patterns to sequences of canopy openings and closings during the growth of $P$. echinata at these sites.

My analysis also suggests that growth rates of $P$. echinata have increased during approximately 300 years in the Missouri Ozarks. Early growth rates of P. echinata during the first 50 years suggest that radial growth was at its highest in trees that established after 1900 at most sites (Fig. 2.4). Stambaugh and Guyette (2004) also noted increases in radial growth of $P$. 
echinata at sites in Missouri during the $20^{\text {th }}$ century when comparing growth rates pre- and post1880. They attributed the increases in radial growth to extensive logging activity 1880-1940 which provided large gap openings for understory $P$. echinata. In general, the greatest diameters at age 50 were in the $20^{\text {th }}$ century. Voelker et al. (2006) found that while early growth rates were greater after 1850 compared to pre-1850, the increased growth rates were not sustained. My early growth rate data suggests that the pattern of increased growth rate after 1900 was not consistent across all sites. Similar to Voelker et al.'s (2006) analysis, I found high rates of early growth after 1900 at all three MOFEP sites. However, by age 30-40 at the MOFEP sites, the growth rates were similar to the growth rates of 1850-1900 and pre-1850. A similar pattern was seen in early growth rates at Alley Springs and Mill Hollow in which growth rates were different during the first 20 years but became similar by age 30-40 (Fig. 2.4). At Eck Tract, the growth rate of trees after 1900 appeared to be similar to growth rates of trees that established 1850-1900. At Hwy. 19, growth rates of trees post-1900 and pre-1850 were similar during the first 20 years of growth that is explained by the large canopy disturbance that occurred during 1800 that coincided with $P$. echinata establishment during that decade. This pattern of early growth of $P$. echinata during pre-1850 exhibited declining ring-widths similar to patterns found at Alley Springs (post1900), Mill Hollow (post-1900), and MOFEP 2, 3, and 4 (post-1900) that suggests large canopy gap formation at Hwy. 19 during the release event of 1800 . The increase in fire frequency, logging, and land-clearing after 1880 (Guyette et al. 2002) may explain the increase in ringwidths in P. echinata that established after 1900. Record (1910) noted the extensive logging that occurred in the Missouri Ozarks during the late $19^{\text {th }}$ and early $20^{\text {th }}$ century. While I cannot rule out the possibility that increased $\mathrm{CO}_{2}$ may have contributed to changes in early growth of $P$. echinata after 1850, it appears that similar negative exponential early growth patterns were occurring prior to 1850 consistent with growth patterns explained by Frelich (2002) for trees establishing in canopy gaps. 


\section{CONCLUSIONS}

My data provides an analysis of the disturbance history of seven sites in the Missouri Ozarks by using multiple lines of evidence to understand canopy disturbance dynamics and growth of $P$. echinata over 300 years. Forests in Missouri that included $P$. echinata experienced frequent small-scale gap dynamics and infrequent large-scale canopy disturbance over the past 300 years based on release analysis, recruitment patterns, and growth rates prior to 1850 .

Significant increases in diameter at age 50 after 1900 suggests that extensive logging practices between 1880 and 1940 promoted an increase in growth rates during the first 30-40 years of growth in newly established P. echinata. However, growth rates after age 40 were similar to trees that established prior to 1900 . Voelker (2004) confirmed that red oak species (Q. velutina and $Q$. coccinea) generally replaced $P$. echinata following the logging period of the early $20^{\text {th }}$ century, and my data shows that by age 30-40 P. echinata had similar growth rates as trees before 1900 suggesting $P$. echinata became overtopped by oaks.

Pinus echinata in Missouri was historically in some mixed-species stands (Fletcher and McDermott 1957). Guyette et al. (2007) attribute declines in P. echinata abundance in the Missouri Ozarks to changes in fire frequencies, intensive hardwood competition, and selective logging of P. echinata. My data suggests that while P. echinata could historically withstand periods of suppression in the mixed-species forests in Missouri, this species experienced frequent gap openings (indicated by multiple releases in trees) or large gap openings allowed ascendance to a canopy position without an apparent growth release. While my research did not directly address regeneration, establishment success of this species is dependent upon large gap openings (Stambaugh and Muzika 2004) and frequent gap openings to attain canopy status in mixedspecies forests. 


\title{
CHAPTER 3
}

\section{A MULTI-SITE ASSESSMENT OF HISTORIC CANOPY DISTURBANCE AND CANOPY ACCESSION IN MISSOURI}

\begin{abstract}
Historic fire regimes were confirmed to have been a primary disturbance that affected oak-pine forests in the Missouri Ozarks. Other disturbances have the potential of being detected in these forests using dendrochronology. I assessed long-term increases and decreases in basal area increment using regime shift analysis to identify growth regimes (releases and suppressions) and canopy accession of Pinus echinata, Quercus alba, and $Q$. coccinea/Q. velutina at 19 sites in Missouri. Results show that release events were more prevalent than suppression events.

Establishment of all species corresponded with growth release events. The most common canopy accession for all species was originating in a canopy gap with no subsequent major release to attain the canopy. Frequent canopy disturbances, such as wind-related events or logging, occurred historically that likely resulted in large canopy gaps in which trees were able to reach the canopy without a major release. Evidence also suggests that while trees originated in canopy gaps, all species had periods of suppression that required additional gap openings to attain the canopy.
\end{abstract}




\section{INTRODUCTION}

Disturbances that affect the canopy of a forest can range from natural events such as windthrow, climate, insects, fire, and individual tree mortality to anthropogenic events such as logging and fire or a combination of events. The result of these disturbances can be reflected in the radial growth of trees that survive the disturbance. It has been well demonstrated that different disturbance events, either natural or anthropogenic, can be recorded within tree-rings (Abrams and Copenheaver 1999, Bebber et al. 2004, Estes 1970, Lafon and Speer 2002, McEwan et al. 2007, Rentch et al. 2002, Rubino and McCarthy 2004)

While studies of historic canopy disturbance have focused on individual sites with some historic value (Abrams and Copenheaver 1999, Glitzenstein et al. 1986, Hart et al. 2008, Hart et al. 2011, McCarthy and Bailey 1996), few studies have considered more than one site to assess patterns of historic disturbance. Abrams et al. (1997) used dendroecology to study historic disturbance and succession of two oak (Quercus) forests in Virginia. They noted that the two forests exhibited different patterns of disturbance and recruitment. However, they also confirmed that both sites had similar radial growth responses to regional climate. Nowacki and Abrams (1997), in their disturbance analysis of presettlement oaks in Pennsylvania, suggested a change in the forcing factor from natural to anthropogenic following Euro-American settlement of the region as trees were harvested for charcoal production. Orwig and Abrams (1997) studied radial growth responses of multiple tree species during and subsequent to droughts in Virginia. They noted that understory trees following a drought increased their radial growth by an average of $11 \%$. In addition, differences existed in the drought response as a function of canopy position. Rentch (2001) assessed disturbance at five oak sites in the Appalachian plateau and found that a canopy disturbance occurred on average every 3 years and multiple tree disturbance events occurred every 17 years. The results of disturbance and recruitment suggested that these stands were uneven-aged across multiple centuries. 
Regional assessments of canopy disturbance dynamics have the potential of providing analysis on the patterns of disturbances that affect multiple sites during the same time period as well as site-specific history of disturbance. Patterns of disturbance that are similar among sites may indicate a regional disturbance effect such as climate, similar to that suggested by Abrams et al. (1997). Differences in temporal patterns of disturbance among sites may indicate a localized natural disturbance or an anthropogenic effect. Studies that analyze individual site disturbance patterns may conclude that a disturbance was a localized event (logging, windthrow) while additional sites may indicate a regional disturbance (climate) when lacking other lines of solid evidence.

One of the challenges of analyzing historic disturbance events is assigning causal factors of the disturbance with limited historical documentation of the event. The result is that most studies have difficulty in knowing the factors that resulted in releases or suppressions before 1900 unless other historical information can corroborate the event or additional data can be related with the event. A possible way of overcoming this limitation is analyzing disturbance dynamics among multiple sites and using additional site or tree characteristics to corroborate the disturbance chronologies.

The existing scientific literature demonstrates the extensive use of radial growth in the identification of abrupt growth changes that indicate past canopy disturbances (Hart et al. 2011; Lorimer and Frelich 1989; Nowacki and Abrams 1997; Rentch et al. 2002; Rubino and McCarthy 2004). However, there is some argument as to the accuracy of using radial growth patterns from individual trees to assess canopy disturbance events. Copenheaver et al. (2009) analyzed growth release events by comparing changes in radial growth of two increment cores from individual trees. They concluded that differences within-tree release analysis emphasized the need to collect two increment cores rather than the standard one increment core. Their analysis of $Q$. alba indicated that the pairs of cores from individual trees identified identical release events $65 \%$ of the time. 
Most studies of historic disturbance use radial growth patterns to assess responses of trees to canopy disturbance. However, few studies have calculated and analyzed basal area increment (BAI) as a means to assess growth of trees following a disturbance event (Kay et al. 2005;

Pedersen 1998). Basal area increment (BAI) has been used to assess climatic related growth of trees (Pedersen 1998; Rubino and McCarthy 2000) but has rarely been used to study changes in growth related to canopy disturbance (Johnson and Abrams 2009).

Basal area increment is a measurement of annual wood production for an individual tree (Visser 1995). Three measurements are needed to calculate BAI for a stem: annual radial growth, diameter at breast height, and bark width. For radial analysis of growth patterns, only one of the three is used to assess stem growth. However, BAI provides a more accurate measure of wood production on an ever-increasing stem diameter (Pedersen 1998; Rubino and McCarthy 2000).

\section{Canopy Accession}

While long-term changes in basal area increment can be used to infer historic disturbance dynamics in forests, additional lines of evidence can be used to corroborate growth analysis. Canopy accession and radial growth patterns can provide important information that can be used to infer forest stand conditions. Frelich (2002) highlighted three patterns of radial growth that can provide information related to reconstructing forest stand histories.

a. Understory suppressed/major release: Trees establish in closed canopy conditions. Removal of the canopy results in abrupt, sustained increases in radial growth.

b. No release: Trees establish in large gaps in which the trees are in a position to fill the gap before canopy closure. Trees generally have declining, flat, or parabolic growth patterns based on ring-widths. 
c. Irregular growth: Trees may originate in a gap but canopy closure results in suppressed radial growth. Subsequent gap openings result in moderate releases until the tree reaches the canopy.

Rentch et al. (2003) used these three strategies to define establishment and growth patterns in five oak (Quercus spp.) forests in the eastern central hardwoods region. They determined that the most common canopy accession used by four Quercus species was gap origin-no release that suggested large gap openings promoted understory oaks to the canopy. This analysis in combination with release analysis provided strong evidence for reconstructing stand histories of the five Quercus sites.

\section{Rationale and Chapter Objectives}

Two long-lived tree species, Pinus echinata (Mill.) and Quercus alba (L.) in Missouri provide an opportunity to study canopy disturbance dynamics and canopy accession. Additionally, the historic presence of $Q$. coccinea (Muenchh.) and Q. velutina (Lam.) at these sites offer additional tree species to assess responses to gap dynamics and canopy accession.

The chapter objectives include:

1) assess growth regimes (releases and suppressions) possibly due to disturbance across 19 sites in Missouri using basal area increment; and

2) analyze canopy accession of P. echinata and Quercus species in Missouri.

This chapter investigates the within and among site historic canopy disturbance dynamics by analyzing the releases and suppressions of multiple tree species, P. echinata, Q. alba, $Q$. coccinea, and $Q$. velutina. Tree-ring chronologies span multiple centuries providing invaluable information on individual and stand level responses to disturbance. A multi-site analysis provides 
greater clarity of the variability as well as the similarity in disturbance dynamics across eastern Missouri. Canopy accession can corroborate canopy disturbances that are identified based on release/suppression analysis. 


\section{METHODS}

\section{Study Sites}

All sites for this study are located in eastern Missouri (Fig. 3.1). Mill Hollow and Highway 19 sites are owned by the L-A-D Foundation (St. Louis, MO) and managed by Pioneer Forest (Salem, MO). Both sites are approximately 70 ha in size and immediately adjacent to the Current River in Shannon County, Missouri. Both sites are located in the Current River Hills ecological subsection (Nigh and Schroeder 2002) known for its rough topography.

Alley Springs is currently managed by the National Park Service and is located within the Ozark National Scenic Riverways. Our site was an approximately 64 ha area adjacent to the Jack's Fork River in Shannon County, Missouri. Alley Springs is also located in the Current River Hills ecological subsection (Nigh and Schroeder 2002).

The research project Missouri Ozark Forest Ecosystem Project (MOFEP) was established in 1989 to study the effects of forest management on ecosystem attributes in the Missouri Ozarks (Brookshire and Dey 2000). All sites are owned by the Missouri Department of Conservation and are located within an approximately $416 \mathrm{~km}^{2}$ area across three counties. We chose three of the sites in MOFEP (Sites 2,3, and 4) that had both remnant wood as well as increment core data from existing $P$. echinata from the sites. The three sites chosen for this study are located near or adjacent to the Current River. All sites are approximately 240 ha in size.

The Eck Tract Conservation Area is a 150 ha site located in Texas County, approximately $70 \mathrm{~km}$ west of the nearest site, Alley Springs. Eck Tract is owned by the Missouri Department of Conservation and is adjacent to the Big Piney River. Eck Tract is within the Gasconade River Hills ecological subsection (Nigh and Schroeder 2002) noted for its slightly dissected plains and more moderate topography relative to the Current River Hills subsection.

Lower Rock Creek and Greasy Creek are located in the St. Francois Knobs and Basin ecological subsection (Nigh and Schroeder 2002) in Madison and Ste. Genevieve Counties, respectively. Previous collections of increment cores of $P$. echinata and $Q$. alba were done by 
Duvick at these sites (International Tree-Ring Database:

www.ncdc.noaa.gov/paleo/treering.html).

Babler State Park is owned and managed by the Missouri Department of Natural Resources and is located in St. Louis County. Previous tree-ring collections at this site include $Q$. alba by Duvick (International Tree-Ring Database, National Climatic Data Center). This site is located in the Outer Ozark Border ecological subsection, and specifically the wildwood loess woodland/forest breaks landtype association (LTA) known for rugged hills and historically forested with oak and mixed-hardwoods (Nigh and Schroeder 2002). The forest type located at Babler State Park is considered a dry-mesic loess/glacial till forest with trees $>20 \mathrm{~m}$ tall and $>80 \%$ canopy cover (Nelson 2005).

Wegener Woods is located in Warren County, Missouri and is identified as a National Natural Landmark (National Park Service) for its late successional Q. alba forest. This site is also located in the Outer Ozark Border ecological subsection and Holstein mixed-hardwood woodland/forest low strath hills LTA known for deep loess deposits. Historically, this area was oak and mixed-hardwood forests (Nigh and Schroeder 2002). Wegener Woods is privately owned and the only known logging occurred following the drought of the early 1950's.

Jacks Fork Natural Area is located in Shannon County, Missouri and is a representative site for dry-mesic limestone/dolomite forest (Nelson 2005). This forest type has gently sloping north and east-facing aspects with deep gravelly silt loam soils. This site is also located in the Current River Hills ecological subsection (Nigh and Schroeder 2002).

Current River Natural Area was the first designated natural area in Missouri and is currently owned by the L-A-D Foundation (St. Louis, MO). This site is located in Shannon County, Missouri and was identified as a representative of a late-successional $Q$. alba forest in Missouri. Current River Natural Area is located in the Current River Hills ecological subsection as described above. 


\section{Sources of Ring-width Measurements}

Raw ring-width measurements were obtained from multiple sources for identifying canopy disturbance patterns. Ring-width measurements were obtained via the International TreeRing Database (ITDRB: www.ncdc.noaa.gov/paleo/treering.html) for sites that had samples that included P. echinata, Q. alba, or both species. Sites in Missouri available from the ITDRB for this study included Lower Rock Creek (P. echinata and Q.alba), Babler State Park (Q.alba), Current River Natural Area (Q. alba), Jack's Fork $(Q$. alba), Greasy Creek $(Q . a l b a)$, Wegener Woods (Q. alba), and Missouri Ozark Forest Ecosystem Project (P. echinata). Ring-width measurements and the corresponding cross-dating analysis in ITDRB format often include two or more samples from each tree. In order to avoid oversampling growth changes from the same tree, the longer ring-width chronology from each tree was used for growth change analysis.

A second source of ring-width measurements was obtained from Voelker (2004) that were previously collected from the Missouri Ozark Forest Ecosystem Project. These samples include red oak species (Quercus velutina and Q. coccinea).

A third source of ring-width measurements were from samples previously collected by the Missouri Tree-Ring Laboratory. These samples included increment cores and cross-sections of remnant $P$. echinata wood that supplemented samples collected by me. The fourth source of ring-width measurements were obtained by me during 2009-2011. 


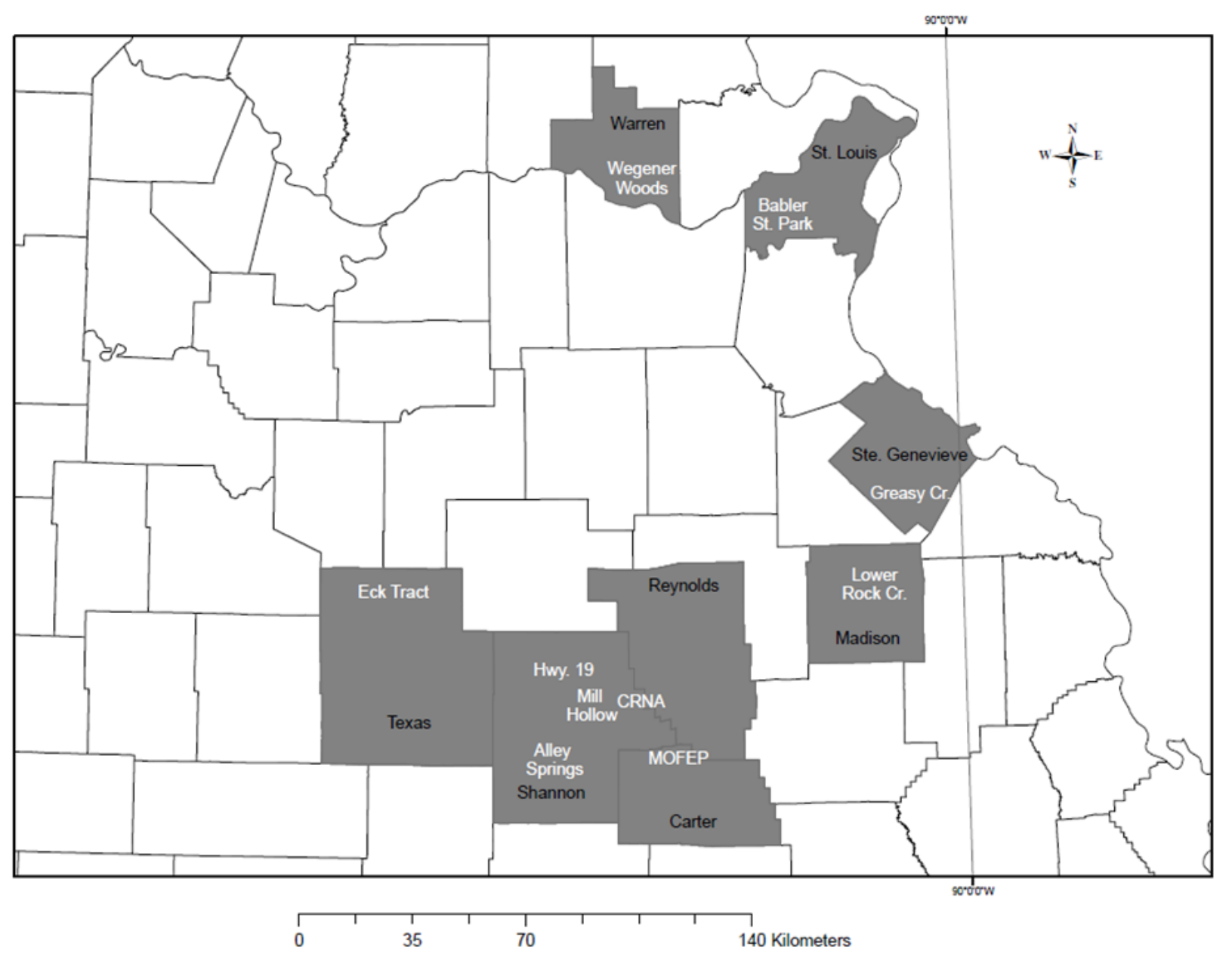

Figure 3.1. Location of 19 study sites in Missouri to assess growth release and suppression events and canopy accession strategies in pine and oak. 


\section{Field Methods}

I collected tree-ring samples for disturbance analysis from Alley Springs, Eck Tract, Mill Hollow, and Hwy. 19 in the Missouri Ozarks. The four sites selected in the Missouri Ozarks included the following criteria:

1. presence of overstory dominant or co-dominant P. echinata and Q. alba; and

2. remnant $P$. echinata stumps or snags.

These sites were selected because they demonstrated contemporary forests that included overstory P. echinata as well as evidence of historic P. echinata.

Individual increment cores were collected from dominant or co-dominant $P$. echinata and Q. alba in order to capture the longest ring-width chronologies and disturbance histories at each site. Increment cores were collected at breast height $(1.37 \mathrm{~m})$. Additionally, cross-sections of remnant $P$. echinata stumps and snags were collected using a chainsaw. Samples were selectively collected in order to obtain cross-sections that provided the longest ring-width chronology and extend the canopy disturbance chronology. A Garmin E-trex GPS unit was used to identify the UTM coordinate point location of each tree or cross-section and diameter at breast height $(\mathrm{DBH})$ measurements $(\mathrm{cm})$ were collected for each tree that was cored.

\section{Laboratory Methods}

All samples were prepared, measured, and cross-dated at the Missouri Tree-Ring Laboratory, University of Missouri, Columbia. Increment cores and cross-sections were sanded with progressively finer sandpaper (up to 1200 grit) in order to differentiate narrow tree-rings (Stokes and Smiley 1996). Tree-ring width measurements to the nearest $0.01 \mathrm{~mm}$ for all samples were collected using a Velmex measuring stage (Velmex, Inc., Bloomfield, NY) and binocular microscope. Standard visual cross dating procedures (Yamaguchi 1991) and the COFECHA quality control program (Holmes 1983, Grissino-Mayer 2001a) were used to crossdate and verify 
the appropriate calendar year for each tree-ring. Additional samples previously collected from these sites were prepared and re-measured and crossdated to include in analysis.

\section{Calculating Basal Area Increment (BAI)}

Basal area increment (BAI) was calculated for individual ring-width series. At Alley Springs and Eck Tract, I collected two bark thickness measurements from opposite sides of the tree using a bark gauge and a diameter at breast height (DBH) measurement on two P. echinata or Q. alba that were closest to either a remnant or cored P. echinata or Q. alba. To calculate BAI, I multiplied the incremental radius by $\pi$ to determine basal area and subtracted the basal area at year X from the basal area at year X-1. In order to account for changing bark thickness during the diameter growth of a tree, I created a linear regression models for P. echinata and Q. alba and applied the resulting regression equations to BAI of the tree.

\section{Shifts in Growth Regimes}

Rodionov's regime shift analysis $(2004,2005,2006)$ is a sequential approach in which the time series analysis is not fixed. Rather, each new observation (ring width value or BAI) requires a new statistical analysis as it is added to the existing group of mean observations. As each observation is added, a statistical test is performed to assess the acceptance or rejection of the null hypothesis or the program continues adding observations. The regime shift approach uses sequential t-test procedures to analyze any time series for significant shifts in the time series. The regime shift is identified when the mean value of a new regime is significantly different from the current regime. Rauchfuss (2009) compared different release detection methods in forests of Minnesota and determined that the regime shift detection method was more accurate with identifying abrupt changes in growth to known disturbance events in those forests. However, she cautions that the regime shift method also identifies shifts in growth that were likely not associated with a canopy disturbance. Based on comparing detected regime shifts, visual 
inspection of ring-width series, and a percent growth change (\%GC) >100\%, Rauchfuss (2011) noted that events that resulted in a regime shift index $(\mathrm{RSI})<0.1$ were considered "false releases" and concluded they were not growth releases due to canopy disturbance.

This approach has largely been applied to the analysis of climate related data (Elliott 2011; Pederson et al. 2012) but provides an adjustable interface for its application to dendroecology (Elliott 2012). The first step in using the regime shift analysis program is determining a priori the length of time to identify a shift in growth. This is similar to the other averaging methods that have been used in canopy disturbance studies. Secondly, the probability level $p$ is adjustable for detecting a significant difference. The most recent version of the regime shift analysis allows for the accounting of autocorrelation in the data using ordinary least squares. Running average approaches to identifying changes in growth do not account for autocorrelation and may result in the identification of growth changes not associated with disturbance events (Druckenbrod 2005). An example of BAI growth regimes using regime shift analysis is shown in Figure 3.2. The graph shows the points in time at which the mean BAI increases or decreases based on a 10 year minimum change at $\mathrm{p}=0.05$. The bar graph indicates the regime shift index (RSI). The RSI is a measure of the confidence of the shift as the sequential analysis continues past the year of the identified change in growth. Higher values (either positive or negative) indicate a greater confidence that a shift in growth has occurred during the year. The regime shift analysis indicates a significant growth regime shift at 1808, 1826, and 1864. A critical component of using the regime shift analysis is the importance of sample replication.

One limitation to the use of regime shift analysis is the decline of statistical power towards the end of a time series (Rodionov 2004). This concern is similar to the use of averaging techniques described previously (Lorimer and Frelich 1989; Nowacki and Abrams 1997; Rubino and McCarthy 2000). Using averaging techniques limits the identification of growth changes by the averaging value. 
I used a 0.05 significance level and was interested in identifying abrupt shifts in mean BAI that were sustained for at least 10 years which likely indicate an event that altered the canopy of the tree or trees nearby. I also used the pre-whitening and autocorrelation features for each tree-ring chronology. Tree-rings are inherently autocorrelated (Fritts 1976). I accounted for autocorrelation using ordinary least squares and the pre-whitening feature programmed within the regime shift detection software (Rodionov 2006).

\section{Analysis of Growth Changes}

I used the regime shift analysis method (Rodionov 2004, 2005, 2006) and averaging technique proposed by Nowacki and Abrams (1997) to identify the year of release or suppression for each tree at each site. Any change in growth that was significant at $\mathrm{p}<0.05$ and exhibited a RSI $>0.1$ was considered a growth change associated with a disturbance. I used the averaging technique to corroborate the releases or suppressions identified by the regime shift analysis. Changes in running mean $\mathrm{BAI}+/->25 \%$ were considered a disturbance event (Nowacki and Abrams 1997). They noted, along with Rentch (2001), that a growth increase of $25 \%$ was associated with $25-49 \%$ canopy removal at oak sites.

\section{Canopy accession and disturbance}

Growth release analysis can provide invaluable information to infer historic canopy disturbance events in forests. However, additional sources of data can provide corroborating evidence of past disturbances. I assessed the canopy accession of P. echinata and Quercus species ( $Q$. alba, $Q$. coccinea, and $Q$. velutina) at sites across Missouri.

I defined canopy accession in a tree as one in which a $>100 \%$ growth change occurred while the tree was $<25 \mathrm{~cm}$ diameter inside bark (DIB). Following the $>100 \%$ growth change, the radial growth of the tree must have been sustained for at least 10 years. While a release $>100 \%$ is

a conservative approach, Rentch et al. (2003) attributed growth releases $<100 \%$ to partial gap 
openings for understory trees and increases in side light in canopy trees. Two sources of data were calculated to compare to release events at each site: 1) diameter inside bark at the time of the first $>100 \%$ growth change (canopy accession); and 2) number of years to first $>100 \%$ growth change that indicates understory residence time.

Trees were categorized based on canopy accession to understand the environment at the time of establishment to canopy accession. Tree strategies included gap origin-no major release indicating the tree established in a dominant position in which the tree was able to attain the canopy without a release. Gap-origin-major release trees established in a gap, were subsequently overtopped (suppressed) by the remaining overstory and a >100\% growth change occurred to attain the canopy. Suppressed-major release trees established in a closed canopy environment and a $>100 \%$ growth change occurred to reach the canopy.

Trees were assigned to one of three categories based on the pattern of growth while in the understory. Inside ring/pith dates and canopy accession were compared to the growth release analysis to corroborate and understand the disturbance dynamics at each site. I restricted my analysis to trees that exhibited historic establishment (pre-1900) and had actual pith dates or pith dates that could be estimated. 


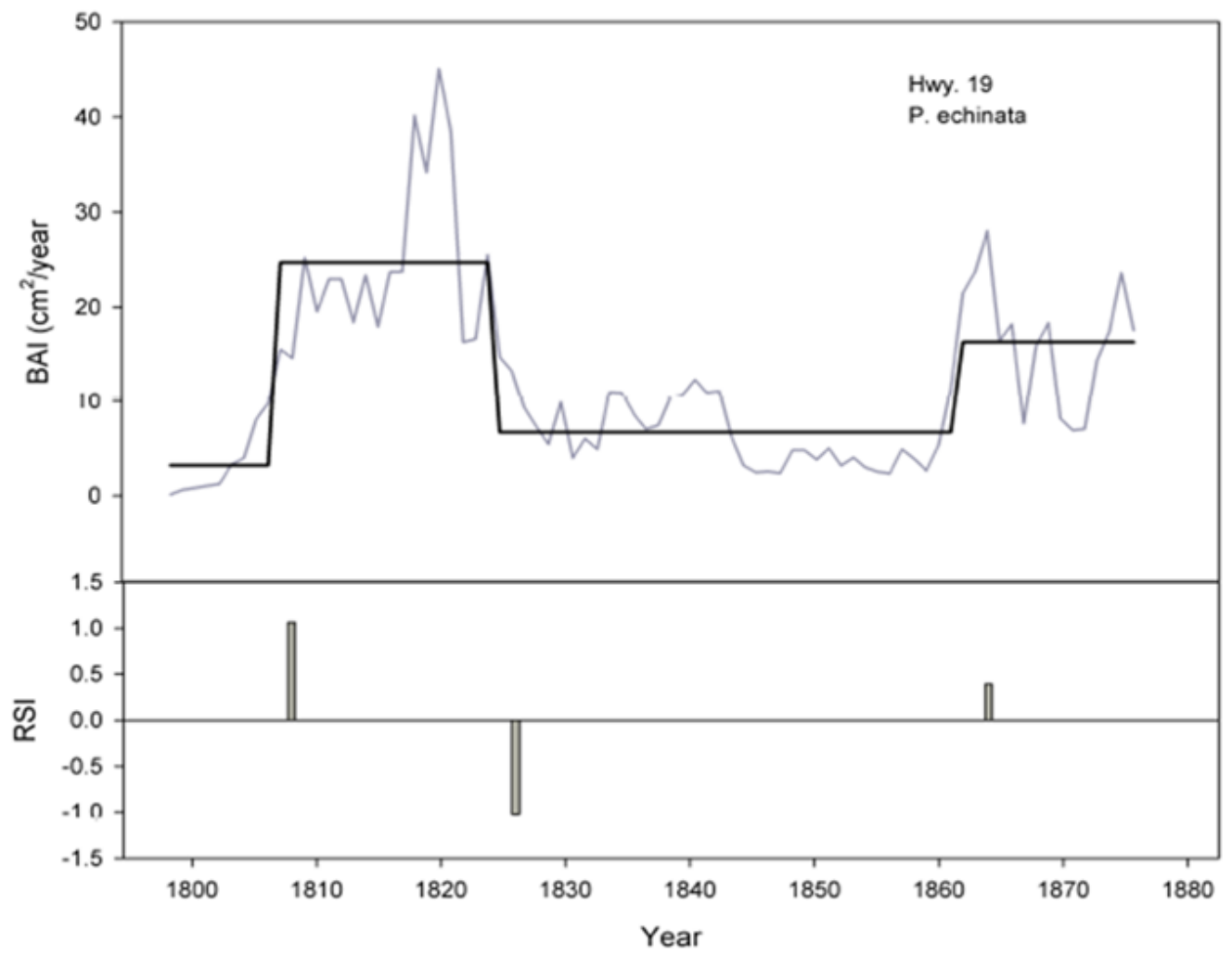

Figure 3.2. Example of regime shift analysis for P. echinata RTS001 remnant. Gray line is the BAI of the tree by year. Black line is the mean BAI using a minimum of 10 year shift identification at $\mathrm{p}=0.05$. The bar graph indicates the RSI values at the year of a growth shift. Higher values indicate a greater confidence in the shift during that year. 


\section{RESULTS}

\section{Descriptive Analysis of Growth Changes}

A total of 19 sites were analyzed for growth regimes using the regime shift analysis (Rodionov 2006). Across these 19 sites was a total of 1524 ring-width series analyzed for changes in BAI (P. echinata $=533 ; Q$. alba $=372 ;$ Q.coccinea/ $Q$. velutina $=619)$. Ring-width series extended from 1588-2010.

Linear regression models were created for $P$. echinata $(\mathrm{n}=160)$ and $Q$. alba $(\mathrm{n}=96)$ samples (Fig. 3.3) to calculate BAI. Regression models were significant $\left(\mathrm{R}_{\text {pine }}^{2}=0.496\right.$; $\mathrm{R}^{2}{ }_{\text {oak }}=0.735$ ), however, the $P$. echinata regression model indicated a higher degree of variability in bark thickness based on DBH.

A total of 942 releases and 475 suppressions were identified from 1616 to 2010 for $P$. echinata. A total of 3124 releases and 494 suppressions were identified from 1588 to 2010 for 991 Quercus trees. All sites exhibited a greater number of releases than suppressions, except for Alley Springs P. echinata (Table 3.1). Approximately $81 \%$ of all growth changes identified were releases compared to suppressions.

All Missouri Ozark Forest Ecosystem Project (MOFEP) sites demonstrated a higher mean number of releases per tree $(\overline{\mathrm{x}}=1.479)$ compared to sites outside of MOFEP $(\overline{\mathrm{x}}=0.498)$ for Quercus species (Table 3.2). However, there was little difference in the mean number of releases per tree when comparing $P$. echinata among MOFEP $(\overline{\mathrm{x}}=0.254)$ and non-MOFEP sites $(\overline{\mathrm{x}}$ $=0.250)($ Table 3.1).

\section{Annual and Decadal Patterns of Growth Changes and Disturbance}

Releases and suppressions were compiled in order to analyze each site and among sites for patterns of common increases and decreases in growth based on regime shift analysis. At sites where more than one species was analyzed, the growth changes were combined into one site disturbance chronology. 
Table 3.1. Descriptive statistics of growth change for 14 P. echinata sites in Missouri. Release frequency and suppression frequency are based on the number of releases and suppressions that occurred within the chronology years at each site.

\begin{tabular}{|c|c|c|c|c|c|c|c|c|}
\hline Study Site & Coordinates & $\begin{array}{c}\text { No. of } \\
\text { samples }\end{array}$ & $\begin{array}{l}\text { Chronolog } \\
\text { y time } \\
\text { span }\end{array}$ & $\begin{array}{c}\text { Years } \\
\text { in } \\
\text { Chronology }\end{array}$ & $\begin{array}{c}\text { No. of } \\
\text { Releases }\end{array}$ & $\begin{array}{c}\text { No. of } \\
\text { Suppress }\end{array}$ & $\begin{array}{c}\text { Release } \\
\text { Frequency }\end{array}$ & $\begin{array}{c}\text { Suppress } \\
\text { Frequency }\end{array}$ \\
\hline Alley Springs & $37^{\circ} 08^{\prime} \mathrm{N}, 91^{\circ} 27^{\prime} \mathrm{W}$ & 68 & $1624-2010$ & 386 & 88 & 96 & 0.228 & 0.249 \\
\hline Eck Tract & $37^{\circ} 35^{\prime} \mathrm{N}, 91^{\circ} 01^{\prime} \mathrm{W}$ & 40 & $1701-2010$ & 309 & 94 & 45 & 0.304 & 0.146 \\
\hline wer Rock Creek & $37^{\circ} 5^{\prime} \mathrm{N}, 91^{\circ} 5^{\prime} \mathrm{W}$ & 15 & $1766-1981$ & 215 & 28 & 15 & 0.130 & 0.070 \\
\hline Mill Hollow & $37^{\circ} 24^{\prime} \mathrm{N}, 91^{\circ} 26^{\prime} \mathrm{W}$ & 55 & $1670-2009$ & 339 & 101 & 38 & 0.298 & 0.112 \\
\hline Hwy. 19 & $37^{\circ} 25^{\prime} \mathrm{N}, 91^{\circ} 38^{\prime} \mathrm{W}$ & 82 & $1630-2010$ & 380 & 110 & 39 & 0.289 & 0.103 \\
\hline \multicolumn{9}{|l|}{ (MOFEP) } \\
\hline Site 1 & $37^{\circ} 09^{\prime} \mathrm{N}, 91^{\circ} 08^{\prime} \mathrm{W}$ & 39 & $1821-2002$ & 181 & 79 & 35 & 0.436 & 0.193 \\
\hline Site 2 & $37^{\circ} 08^{\prime} \mathrm{N}, 91^{\circ} 07^{\prime} \mathrm{W}$ & 42 & $1659-2002$ & 343 & 87 & 33 & 0.254 & 0.096 \\
\hline Site 3 & $37^{\circ} 07^{\prime} \mathrm{N}, 91^{\circ} 05^{\prime} \mathrm{W}$ & 43 & $1715-2002$ & 287 & 90 & 36 & 0.314 & 0.125 \\
\hline Site 4 & $37^{\circ} 08^{\prime} \mathrm{N}, 91^{\circ} 04^{\prime} \mathrm{W}$ & 30 & $1724-2002$ & 278 & 60 & 29 & 0.216 & 0.104 \\
\hline Site 5 & $37^{\circ} 09^{\prime} \mathrm{N}, 91^{\circ} 03^{\prime} \mathrm{W}$ & 22 & $1860-2002$ & 142 & 45 & 34 & 0.317 & 0.239 \\
\hline Site 6 & $37^{\circ} 10^{\prime} \mathrm{N}, 91^{\circ} 03^{\prime} \mathrm{W}$ & 41 & $1724-2002$ & 278 & 74 & 33 & 0.266 & 0.119 \\
\hline Site 7 & $37^{\circ} 00^{\prime} \mathrm{N}, 91^{\circ} 12^{\prime} \mathrm{W}$ & 28 & $1886-2002$ & 116 & 42 & 20 & 0.362 & 0.172 \\
\hline Site 8 & $36^{\circ} 59^{\prime} \mathrm{N}, 91^{\circ} 10^{\prime} \mathrm{W}$ & 19 & $1616-2002$ & 386 & 27 & 14 & 0.070 & 0.036 \\
\hline Site 9 & $37^{\circ} 04^{\prime} \mathrm{N}, 91^{\circ} 09^{\prime} \mathrm{W}$ & 9 & $1646-2002$ & 356 & 17 & 8 & 0.048 & 0.022 \\
\hline
\end{tabular}


Table 3.2. Descriptive statistics of growth change for 19 Q. alba sites in Missouri. Release frequency and suppression frequency are based on the number of releases and suppressions that occurred within the chronology years at each site.

\begin{tabular}{|c|c|c|c|c|c|c|c|c|}
\hline Study Site & Coordinates & $\begin{array}{c}\text { No. of } \\
\text { samples }\end{array}$ & $\begin{array}{c}\text { Chronology } \\
\text { time span }\end{array}$ & $\begin{array}{l}\text { Years in } \\
\text { Chronology }\end{array}$ & $\begin{array}{c}\text { No. of } \\
\text { Releases }\end{array}$ & $\begin{array}{c}\text { No. of } \\
\text { Suppress }\end{array}$ & $\begin{array}{l}\text { Release } \\
\text { Frequency }\end{array}$ & $\begin{array}{l}\text { Suppress } \\
\text { Frequency }\end{array}$ \\
\hline Alley Springs & $37^{\circ} 08^{\prime} \mathrm{N}, 91^{\circ} 27^{\prime} \mathrm{W}$ & 39 & $1730-2010$ & 280 & 153 & 25 & 0.546 & 0.089 \\
\hline Eck Tract & $37^{\circ} 35^{\prime} \mathrm{N}, 91^{\circ} 01^{\prime} \mathrm{W}$ & 31 & $1758-2010$ & 252 & 110 & 26 & 0.437 & 0.103 \\
\hline ower Rock Creek & $37^{\circ} 5^{\prime} \mathrm{N}, 91^{\circ} 5^{\prime} \mathrm{W}$ & 17 & $1728-1982$ & 254 & 87 & 14 & 0.343 & 0.055 \\
\hline Mill Hollow & $37^{\circ} 24^{\prime} \mathrm{N}, 91^{\circ} 26^{\prime} \mathrm{W}$ & 55 & $1836-2009$ & 173 & 68 & 7 & 0.393 & 0.040 \\
\hline Hwy. 19 & $37^{\circ} 25^{\prime} \mathrm{N}, 91^{\circ} 38^{\prime} \mathrm{W}$ & 66 & $1795-2010$ & 215 & 166 & 22 & 0.772 & 0.102 \\
\hline $\begin{array}{l}\text { Current River } \\
\text { Natural Area }\end{array}$ & $37^{\circ} 27^{\prime} \mathrm{N}, 91^{\circ} 27^{\prime} \mathrm{W}$ & 67 & 1588-1992 & 404 & 358 & 83 & 0.886 & 0.205 \\
\hline Babler State Park & $38^{\circ} 6^{\prime} \mathrm{N}, 90^{\circ} 72^{\prime} \mathrm{W}$ & 28 & $1641-1980$ & 339 & 119 & 40 & 0.351 & 0.118 \\
\hline Greasy Creek & $37^{\circ} 72^{\prime} \mathrm{N}, 90^{\circ} 2^{\prime} \mathrm{W}$ & 15 & $1777-1982$ & 205 & 55 & 4 & 0.268 & 0.020 \\
\hline Jack's Fork & $37^{\circ} 12^{\prime} \mathrm{N}, 91^{\circ} 5^{\prime} \mathrm{W}$ & 30 & $1776-1981$ & 205 & 98 & 7 & 0.478 & 0.034 \\
\hline $\begin{array}{l}\text { Wegener Woods } \\
\text { MOFEP }\end{array}$ & $38^{\circ} 65^{\prime} \mathrm{N}, 91^{\circ} 5^{\prime} \mathrm{W}$ & 24 & $1662-1982$ & 320 & 162 & 36 & 0.506 & 0.113 \\
\hline Site 1 & $37^{\circ} 09^{\prime} \mathrm{N}, 91^{\circ} 08^{\prime} \mathrm{W}$ & 82 & $1860-2002$ & 142 & 239 & 22 & 1.683 & 0.155 \\
\hline Site 2 & $37^{\circ} 08^{\prime} \mathrm{N}, 91^{\circ} 07^{\prime} \mathrm{W}$ & 24 & $1828-2002$ & 174 & 62 & 10 & 0.356 & 0.057 \\
\hline Site 3 & $37^{\circ} 07^{\prime} \mathrm{N}, 91^{\circ} 05^{\prime} \mathrm{W}$ & 90 & $1849-2002$ & 153 & 221 & 30 & 1.444 & 0.196 \\
\hline Site 4 & $37^{\circ} 08^{\prime} \mathrm{N}, 91^{\circ} 04^{\prime} \mathrm{W}$ & 22 & $1877-2002$ & 125 & 55 & 1 & 0.440 & 0.008 \\
\hline Site 5 & $37^{\circ} 09^{\prime} \mathrm{N}, 91^{\circ} 03^{\prime} \mathrm{W}$ & 82 & $1863-2002$ & 139 & 236 & 20 & 1.698 & 0.144 \\
\hline Site 6 & $37^{\circ} 10^{\prime} \mathrm{N}, 91^{\circ} 03^{\prime} \mathrm{W}$ & 95 & $1890-2002$ & 112 & 315 & 30 & 2.813 & 0.268 \\
\hline Site 7 & $37^{\circ} 00^{\prime} \mathrm{N}, 91^{\circ} 12^{\prime} \mathrm{W}$ & 74 & $1875-2002$ & 127 & 190 & 40 & 1.496 & 0.315 \\
\hline Site 8 & $36^{\circ} 59^{\prime} \mathrm{N}, 91^{\circ} 10^{\prime} \mathrm{W}$ & 75 & $1880-2002$ & 122 & 215 & 38 & 1.762 & 0.311 \\
\hline Site 9 & $37^{\circ} 04^{\prime} \mathrm{N}, 91^{\circ} 09^{\prime} \mathrm{W}$ & 75 & $1869-2002$ & 133 & 215 & 39 & 1.617 & 0.293 \\
\hline
\end{tabular}



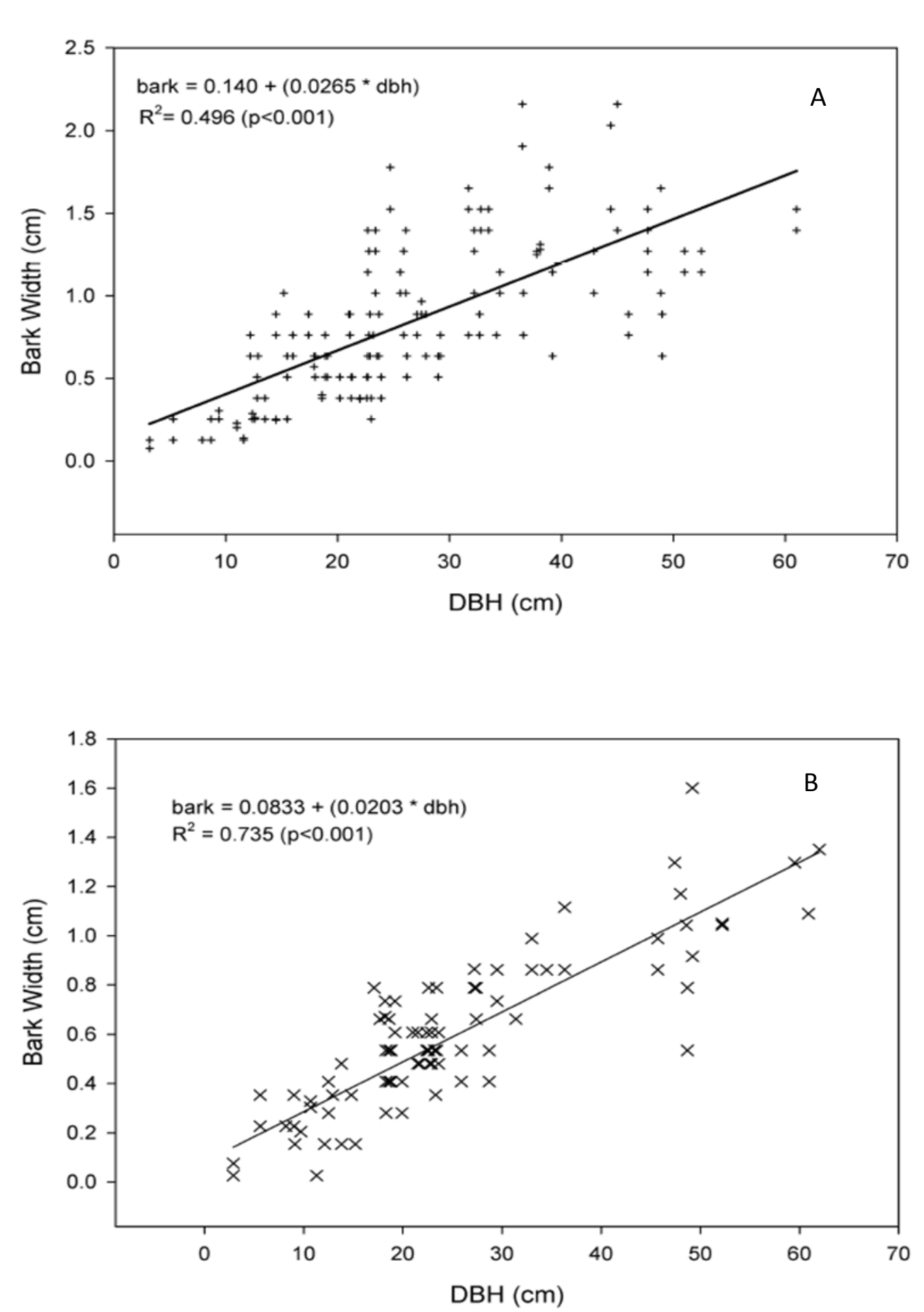

Figure 3.3. Linear regression models of diameter at breast height and bark width for P. echinata (a) and Q. alba (B). All regression models were significant at $\mathrm{p}<0.05$. 


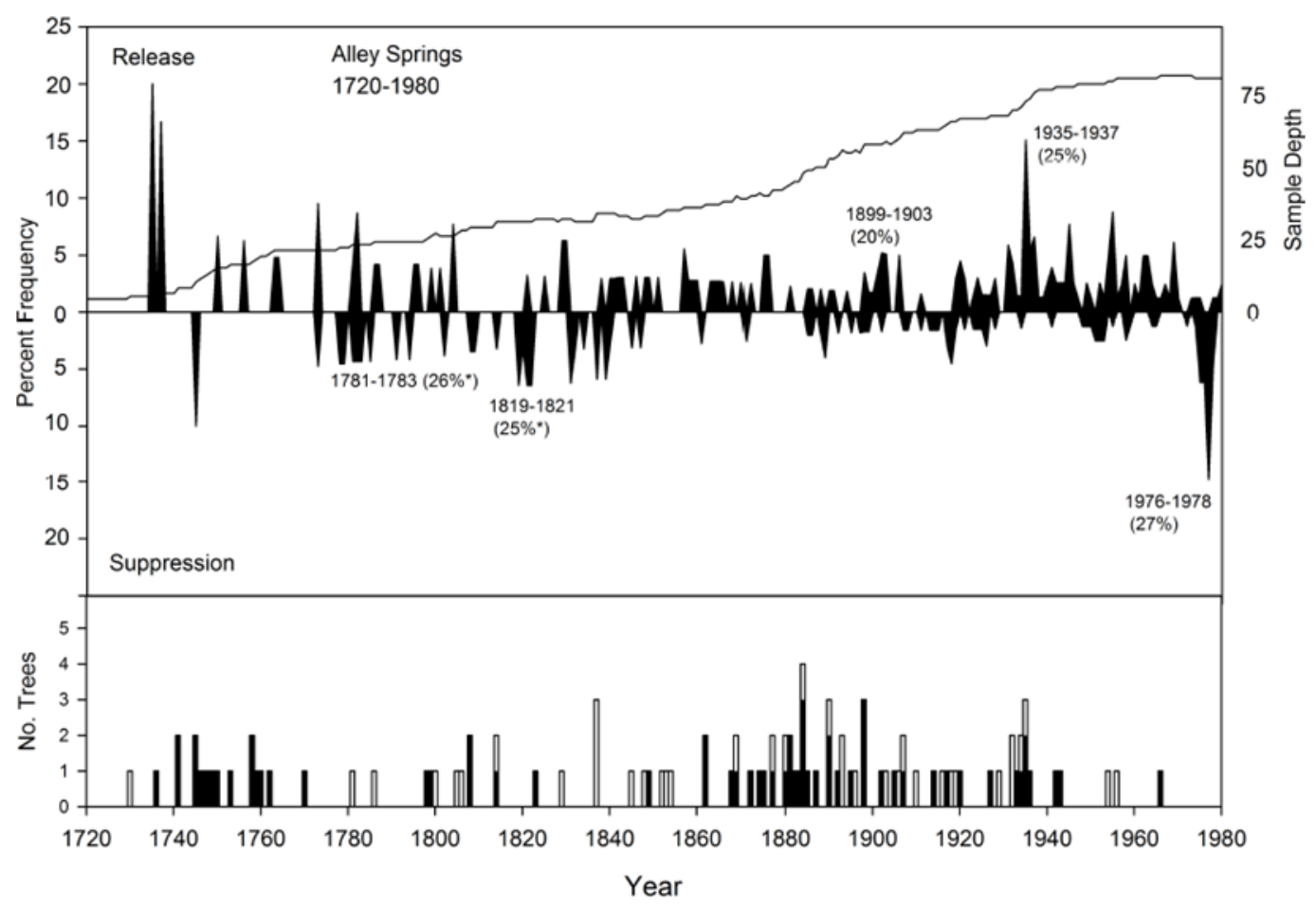

Figure 3.4. Frequency of releases and suppressions at Alley Springs, Shannon County, Missouri 1720-1980. Periods of time are highlighted that include a sample depth $>20$ trees and $>20 \%$ of trees released or suppressed based on mean BAI. Horizontal line indicates the annual number of trees alive in each year (sample depth). Bottom graph indicates pith/inside ring dates for trees. Black bars $=P$. echinata $;$ white bars $=Q$. alba .

The earliest release and suppression detected, across all sites for P. echinata was 1654 and 1640 at Alley Springs, respectively, and 1619 and 1680 for Q. alba at Current River Natural Area (Figs. 3.4 and 3.5). The earliest release event in which the sample depth was $>20$ trees and $>25 \%$ of trees demonstrated a release was 1773-1775 at Mill Hollow (38\% of trees) (Fig. 3.6).

Large suppression events, defined as $>25 \%$ of trees demonstrating a suppression within a five year period, were more rare than large release events. For $Q$. alba at Wegener Woods (Fig. 3.17, Appendix) 27\% of trees showed suppression during 1911-1913 and Q. alba at Babler State Park during 1929-1932 (Fig. 3.18, Appendix). In more contemporary times, suppression events occurred 


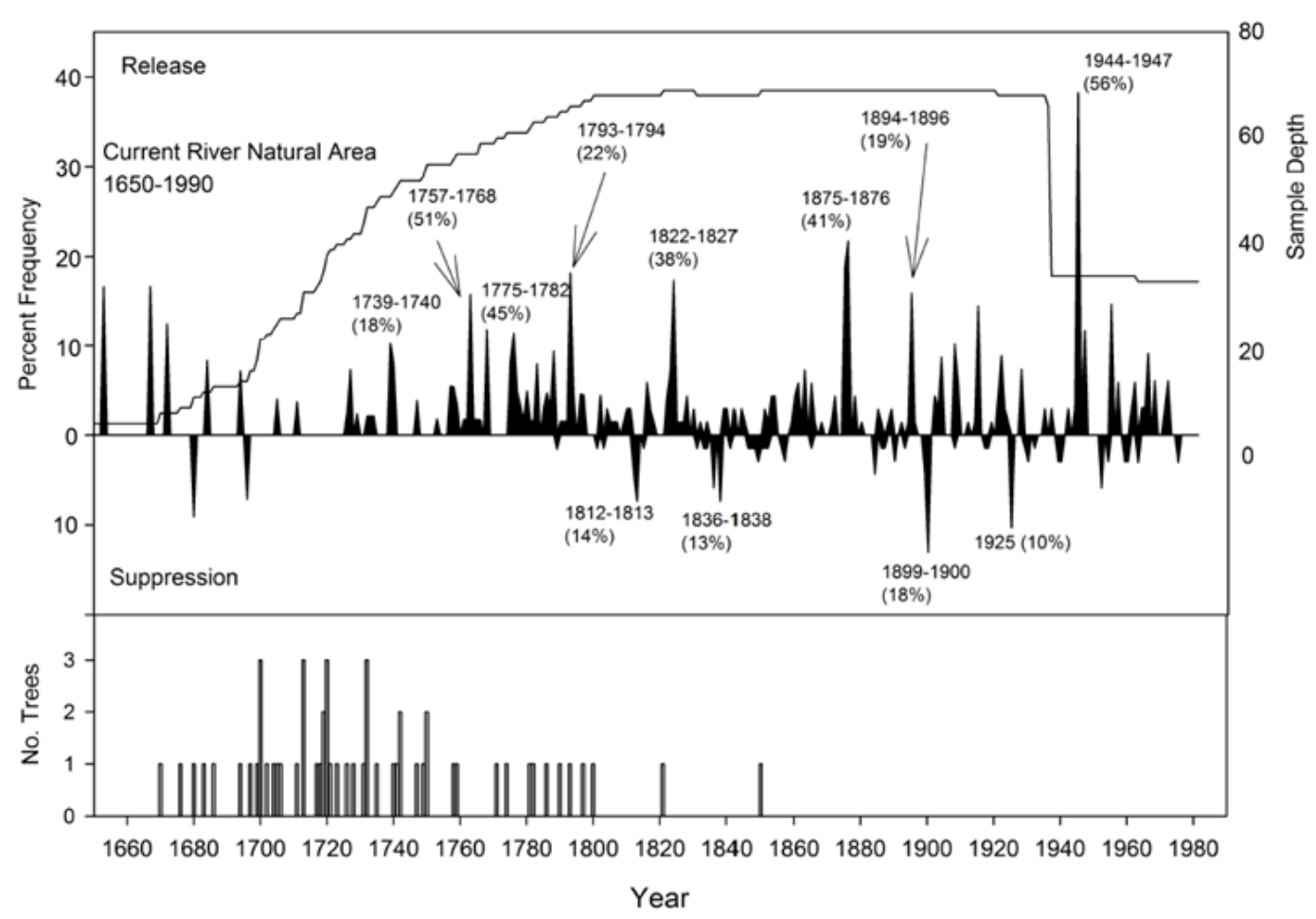

Figure 3.5. Frequency of releases and suppressions in growth at Current River Natural Area, 16501980. Periods of time are highlighted that include a sample depth $>20$ trees and $>10 \%$ of trees released or suppressed based on mean BAI. Horizontal line indicates the annual number of trees alive in each year (sample depth). Bottom graph indicates pith/inside ring dates for trees. White bars indicate inside ring/pith dates of $Q$. alba.

during the 1950's (Wegener Woods, Eck Tract) (3.17-Appendix, Fig. 3.7), the 1960's (Babler State Park) (Fig. 3.18-Appendix), and the 1970's (Alley Springs) (Fig. 3.4). Most suppressions appeared to coincide with release events. However, there were specific decades at some sites where only suppression events occurred including the 1830's at Hwy. 19 (Fig. 3.8), the 1880's and 1920's at Wegener Woods (Fig. 3.17-Appendix), the 1960's at Babler State Park (Fig. 3.18Appendix) and the 1890's at Mill Hollow (Fig. 3.6). While there were common release and suppression events among sites, there were also events that were indicative of localized disturbance. During the late 1920's and early 1930's nearly 50\% of Q. alba trees at Babler State Park were suppressed, a phenomenon that is not repeated at other sites. 


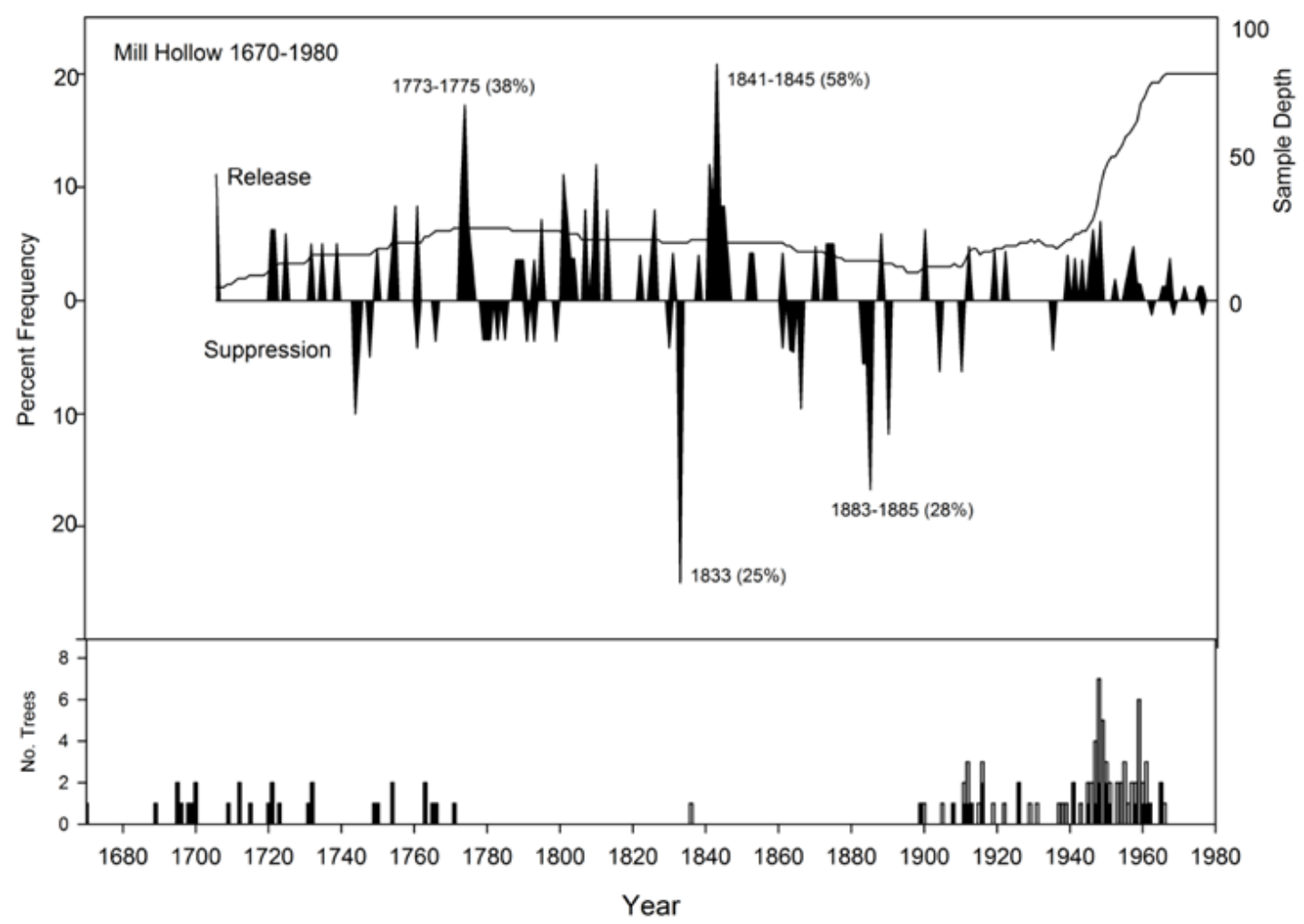

Figure 3.6. Frequency of releases and suppressions at Mill Hollow, Shannon County, Missouri 1670-1980. Periods of time are highlighted that include a sample depth $>20$ trees and $>10 \%$ of trees released or suppressed based on mean BAI. Horizontal line indicates the annual number of trees alive in each year (sample depth). Bottom graph indicates pith/inside ring dates for trees. Black bars $=P$. echinata; white bars $=Q$. alba.

Release events were more prevalent across all sites. All sites indicated releases in which $<5$ trees exhibited increased growth during a year or decade. There were time periods that saw $>25 \%$ of trees releasing when the sample depth was $>20$ trees at all sites at an annual and decadal resolution. Alley Springs had the fewest number of large release events (Fig. 3.4) while Wegener Woods(Fig. 3.17-Appendix), Current River Natural Area (Fig. 3.5), Babler State Park (Fig. 3.18Appendix), Jacks Fork (3.19-Appendix), and Lower Rock Creek (Fig. 3.9) had the greatest number of large release events. 


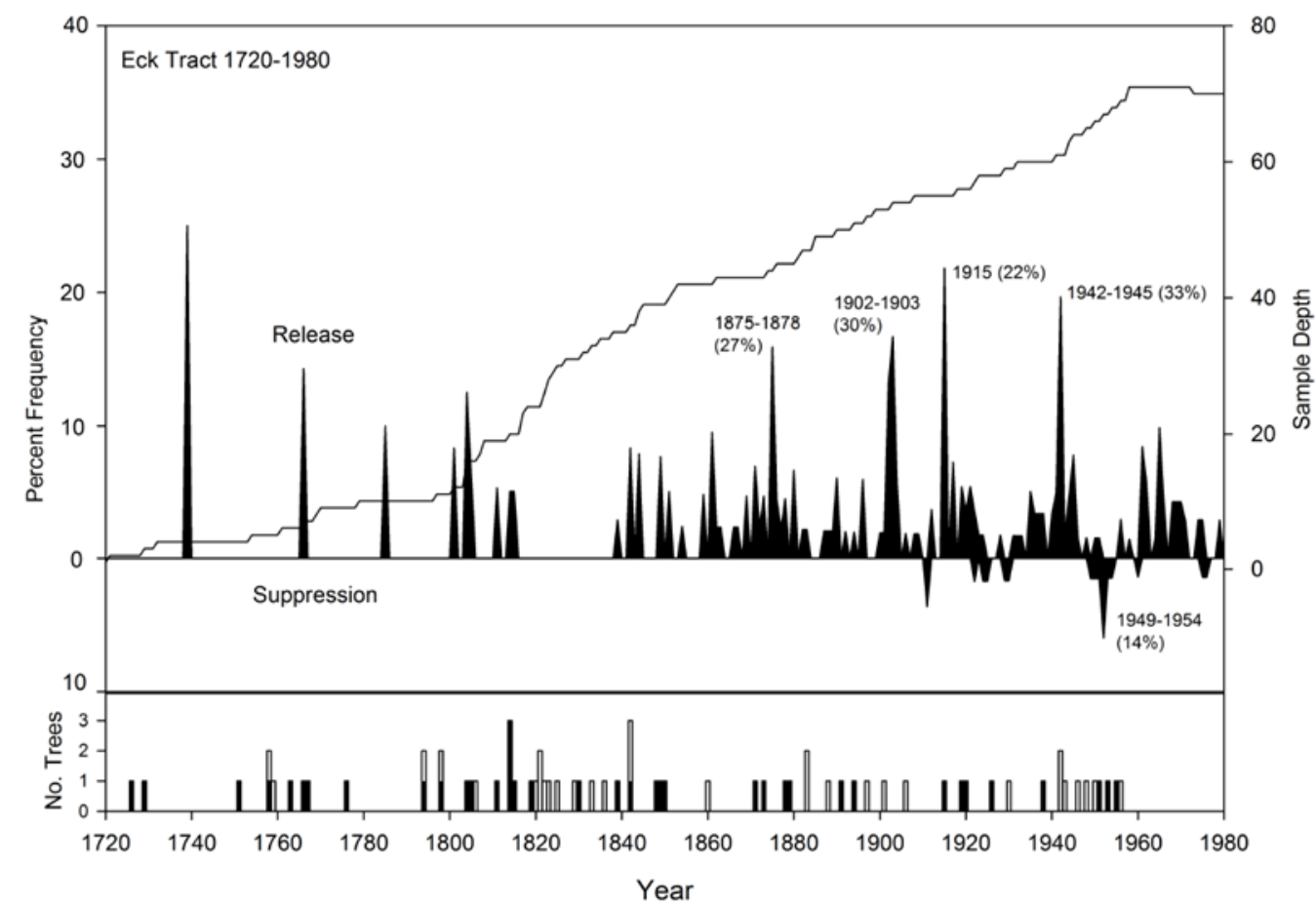

Figure 3.7. Frequency of releases and suppressions of trees at Eck Tract, Texas County, Missouri 1720-1980. Periods of time are highlighted that include a sample depth $>20$ trees and $>20 \%$ of trees released or suppressed based on mean BAI. Horizontal line indicates the annual number of trees alive in each year (sample depth). Bottom graph indicates pith/inside ring dates for trees. Black bars $=P$. echinata ; white bars $=Q$. alba .

Common decadal periods of release include 1870's (4 sites), 1880's (3 sites), 1900's (8 sites), 1930's (3 sites), and 1940's (7 sites) (Tables 3.5-3.6-Appendix). Before 1870, release events were less synchronized among sites. During the 1770's, both Mill Hollow and Current River Natural Area had release events that equated to $38 \%$ and $45 \%$ of trees releasing, respectively. During some time periods no release events were evident at any sites. The period between 1800 and 1820 demonstrated few releases occurring at Mill Hollow, Alley Springs, Eck Tract, and Lower Rock Creek. The lack of releases occurred again 1910-1930 at Highway 19, Wegener Woods, and Mill Hollow. There appeared to be constant recruitment of P. echinata and $Q$. alba at most sites. An exception is Mill Hollow in which only one tree $(Q$. alba $)$ was found to have established during the 1800's (1836). 


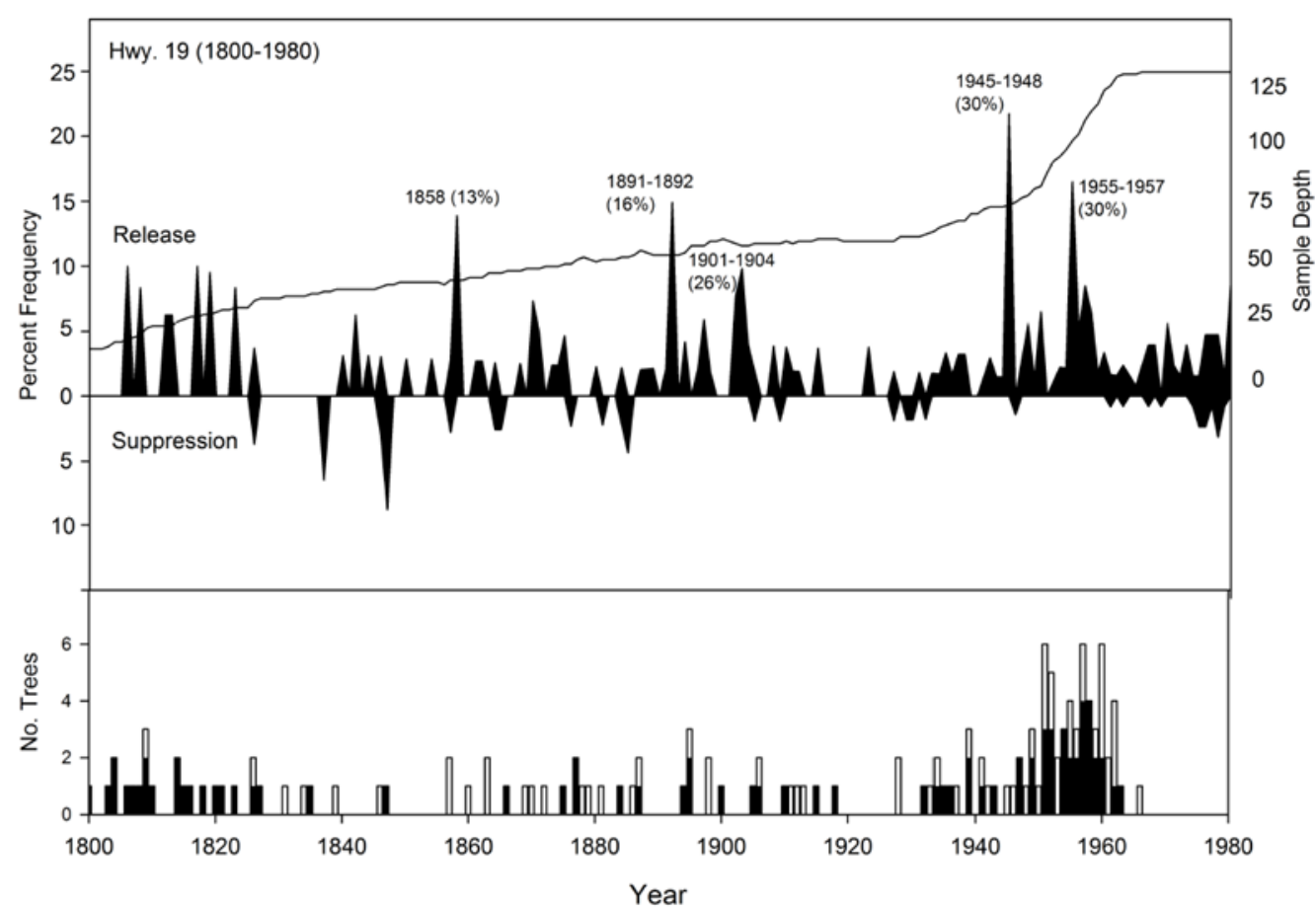

Figure 3.8. Frequency of releases and suppressions at Highway 19, Shannon County, Missouri 1800-1980. Periods of time are highlighted that include a sample depth $>20$ trees and $>10 \%$ of trees released or suppressed based on mean BAI. Horizontal line indicates the annual number of trees alive in each year (sample depth). Bottom graph indicates pith/inside ring dates for trees. Black bars $=P$. echinata , white bars $=Q$. alba

\section{MOFEP Annual and Decadal Disturbance}

Missouri Forest Ecosystem Project disturbance analysis was limited by sample depth and length of ring-width chronologies Nonetheless, MOFEP sites exhibited commonalities in releases and suppressions. Figures 3.11-3.14 in this section provide release and suppression events for $P$. echinata and $Q$. coccinea/ $Q$. velutina. These figures represent the longest disturbance chronologies at MOFEP sites. Additional disturbance chronologies for other MOFEP sites are provided in the Appendix.

Suppression events were common during 1861-1866 for MOFEP sites 3, 4, 6 (Figs. 3.123.14), 1884-1886 (MOFEP 1, 2, 3, 4, 6) (Fig. 3.21-Appendix, Figs 3.12-3.14), 1921-1924

(MOFEP 1, 2) (Fig. 21-Appendix, Fig. 3.12), 1951-1956, and 1976-1980. Most suppression events prior to the 1950's were 


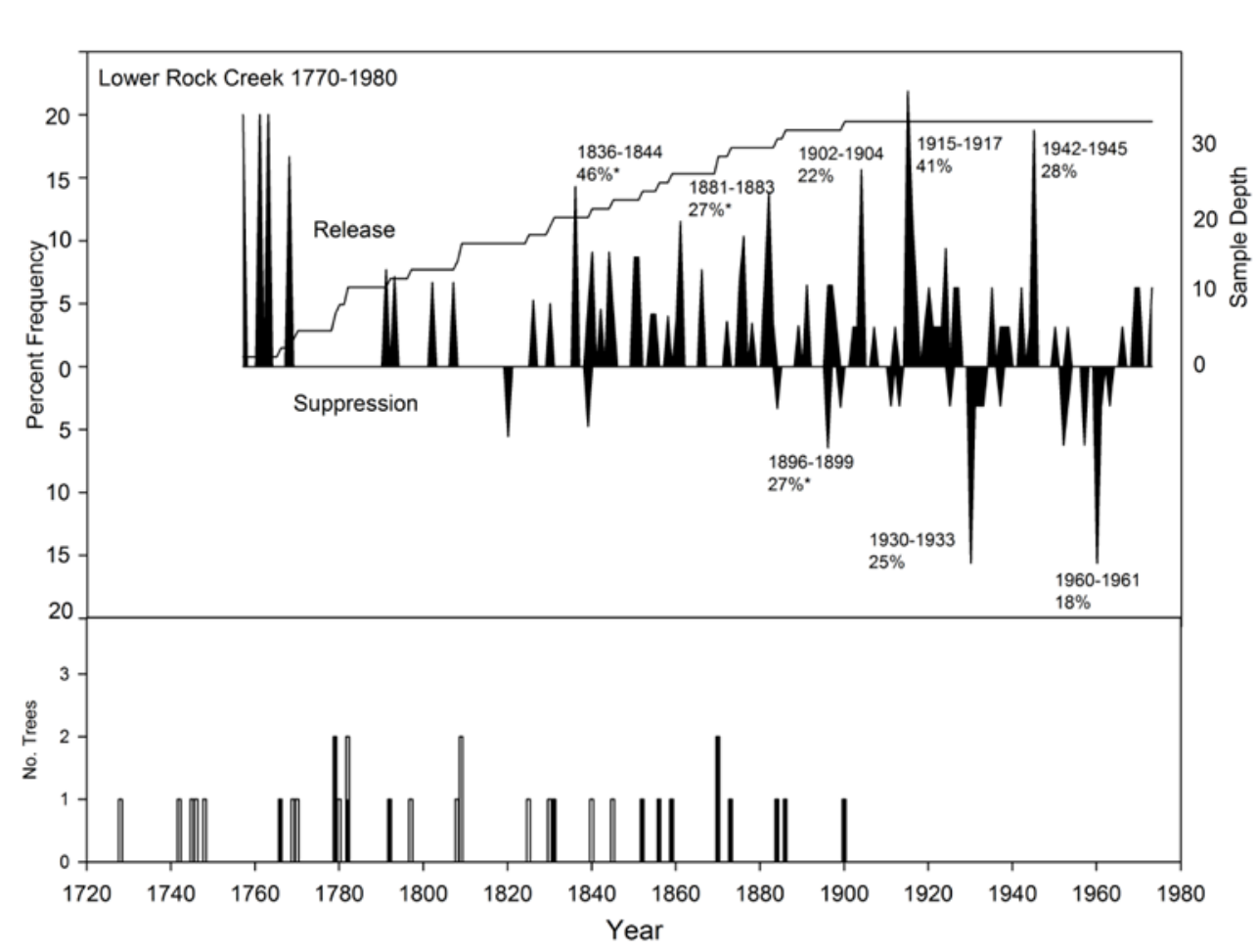

Figure 3.9. Frequency of releases and suppressions at Lower Rock Creek, Missouri 1720-1980. Periods of time are highlighted that include a sample depth $>20$ trees and $>10 \%$ of trees released or suppressed based on mean BAI. Horizontal line indicates the annual number of trees alive in each year (sample depth).Bottom graph indicates pith/inside ring dates for trees. Black bars $=P$. echinata; white bars $=Q$. alba

evident in fewer than five trees. The 1950's and 1970's suppressions occurred to both $P$. echinata and trees of the red oak group with approximately $5 \%$ and $25 \%$ of all trees exhibiting suppression, respectively (Table 3.7).

The earliest release detected was from MOFEP 6 (1759). Release events were common during 1870-1880 (MOFEP 1, 2, 4, 5, 6), 1913-1918 (MOFEP 1, 3, 5, 8, 9), 1920-1928 (MOFEP 1, 6, 7), 1935-1939 (all MOFEP sites), 1940-1945 (MOFEP 7, 8, 9), and 1955-1958 (MOFEP 1, 3, 5, 6, 7, 9). Release events across MOFEP were more synchronous after 1870. As with the other 10 sites across Missouri, there were common temporal periods in which little canopy disturbance was detected at MOFEP sites. The period between 1880 and 1900 saw no detection of disturbance among five of the nine MOFEP sites 


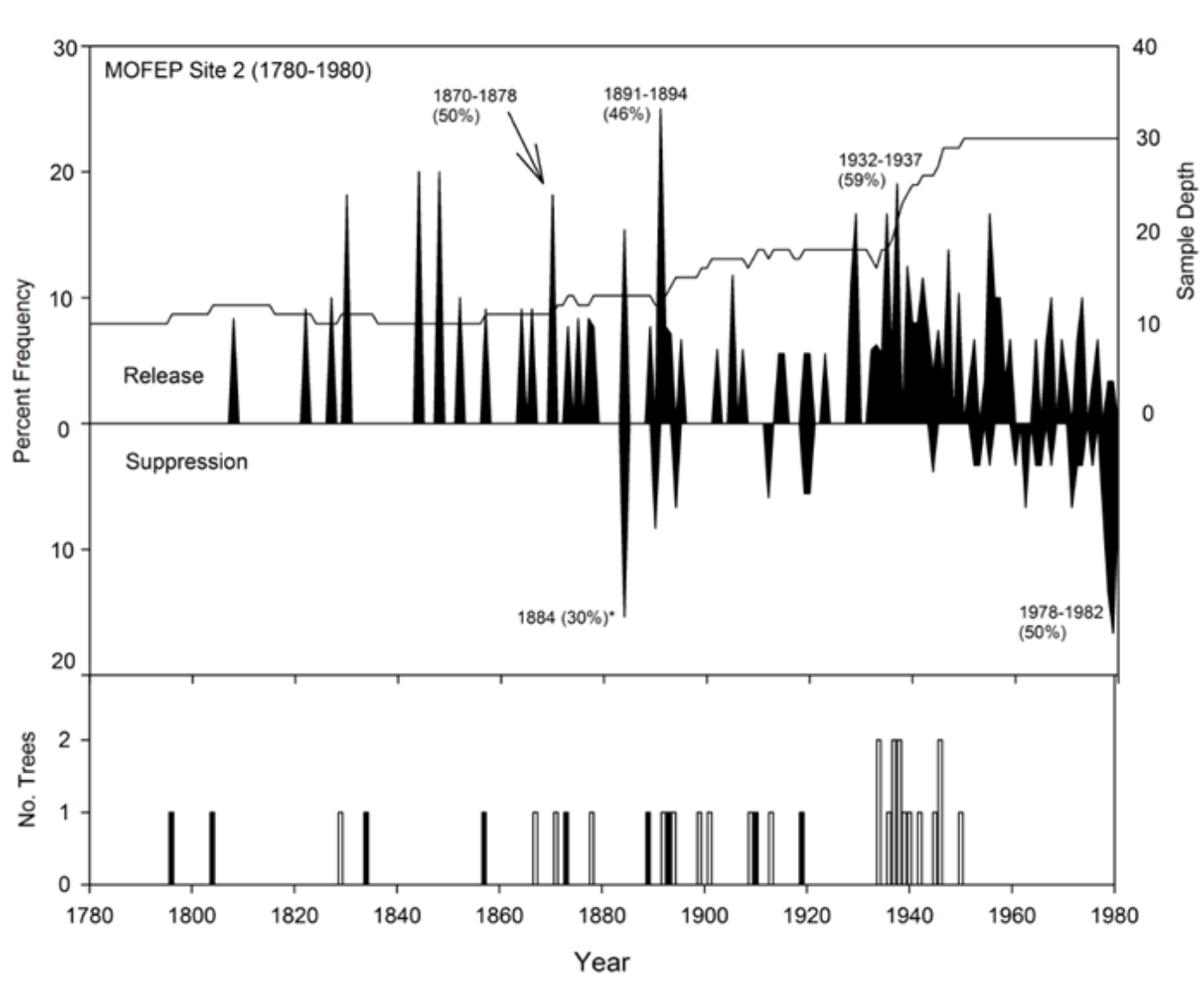

Figure 3.10. Frequency of releases and suppressions in growth of trees at MOFEP 2, Missouri 17801980. Periods of time are highlighted that include a sample depth $>20$ trees and $>10 \%$ of trees released or suppressed based on mean BAI. Horizontal line indicates the annual number of trees alive in each year (sample depth).Bottom graph indicates pith/inside ring dates for trees. Black bars $=P$. echinata , white bars $=Q$. coccinea/ $Q$. velutina .

(MOFEP 1, 3, 4, 5, 6). During the period between 1920 and 1930, there was a lack of release events at four of the nine MOFEP sites (MOFEP 4, 5, 7, 9). Prior to 1880, most sites exhibited an absence of disturbance that may be an artifact of limited samples.

Establishment of $P$. echinata and Q. coccinea/Q. velutina at MOFEP sites appears to correspond with detected release events. At MOFEP sites 1, 2, 4, 5, and 9 there appeared to be limited to no recruitment of trees during the 1920-1930 decade. During the period of 1930 to 


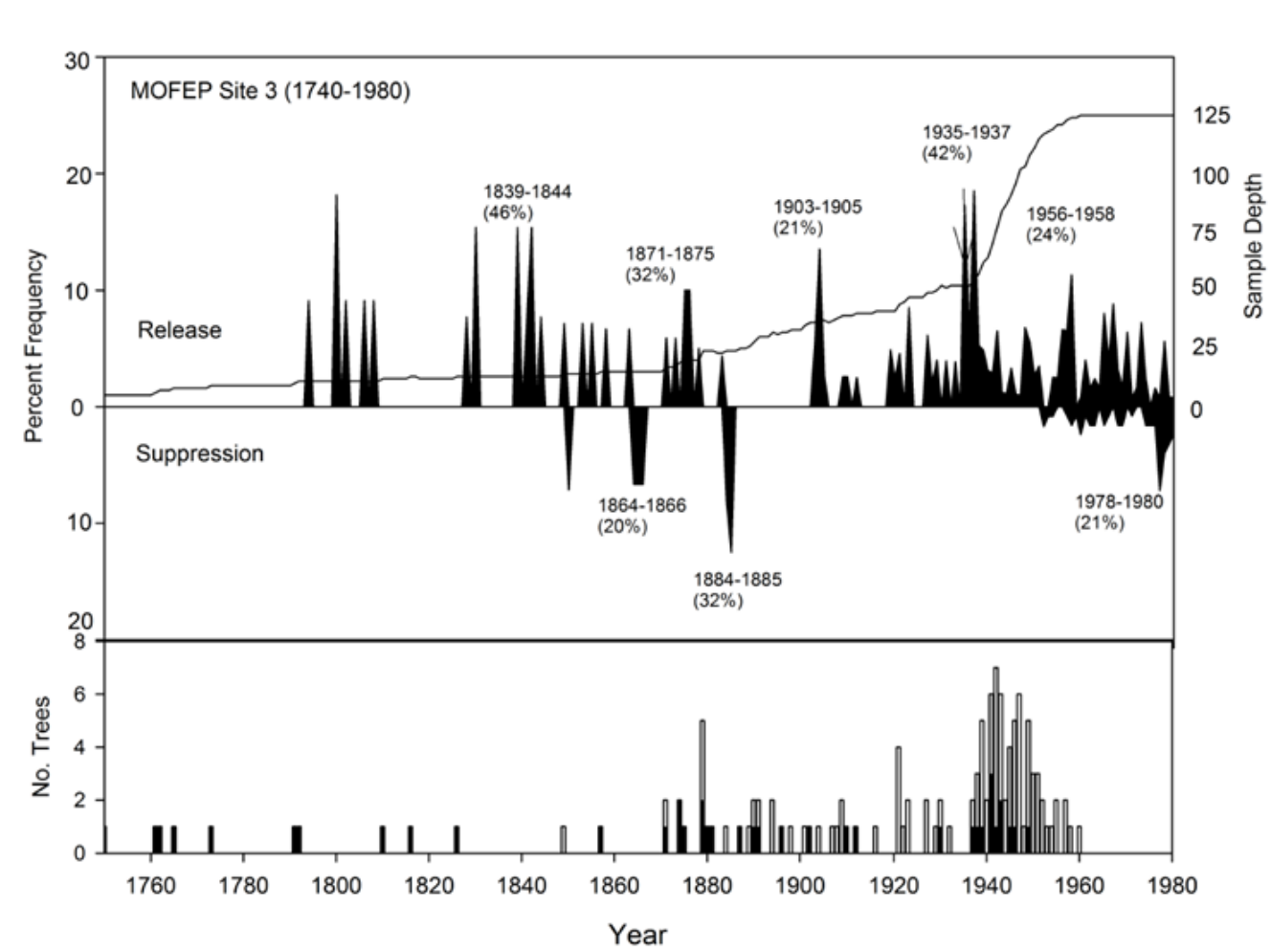

Figure 3.11. Frequency of releases and suppressions in growth of trees at MOFEP 3, Missouri 17501980. Periods of time are highlighted that include a sample depth $>20$ trees and $>10 \%$ of trees released or suppressed based on mean BAI. Horizontal line indicates the annual number of trees alive in each year (sample depth). Bottom graph indicates pith/inside ring dates for trees. Black bars $=P$. echinata; white bars $=Q$. coccinea/ $Q$. velutina

1950 all sites had recruitment pulses, especially during the late 1930's through the 1940's that corresponded with an increase in the percentage of releasing trees. 


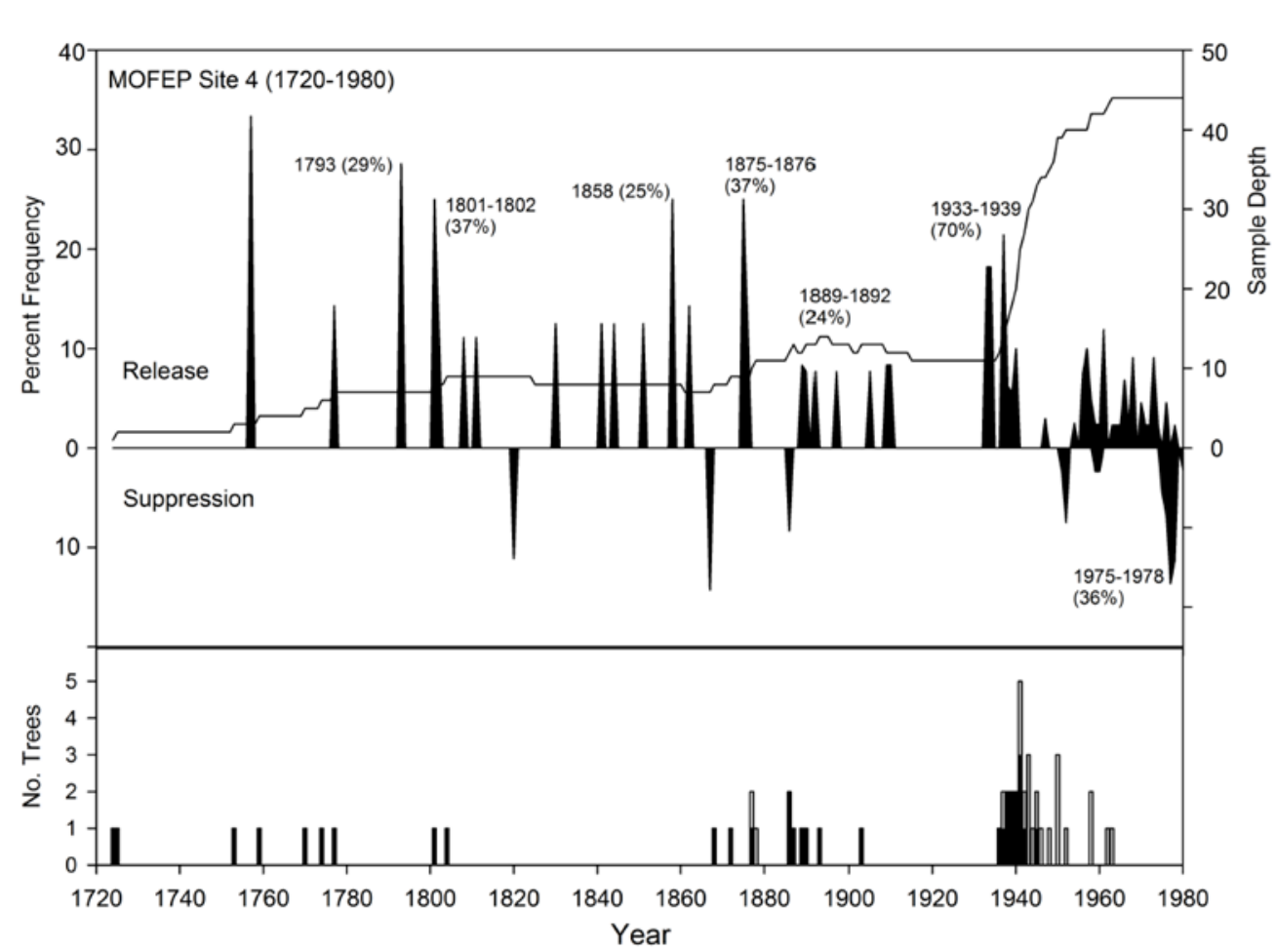

Figure 3.12. Frequency of releases and suppressions in growth of trees at MOFEP 4, Missouri 17101980. Periods of time are highlighted that include a sample depth $>20$ trees and $>10 \%$ of trees released or suppressed based on mean BAI. Horizontal line indicates the annual number of trees alive in each year (sample depth).Bottom graph indicates pith/inside ring dates for trees. Black bars $=P$. echinata $;$ white bars $=Q$. coccinea/ $Q$. velutina 


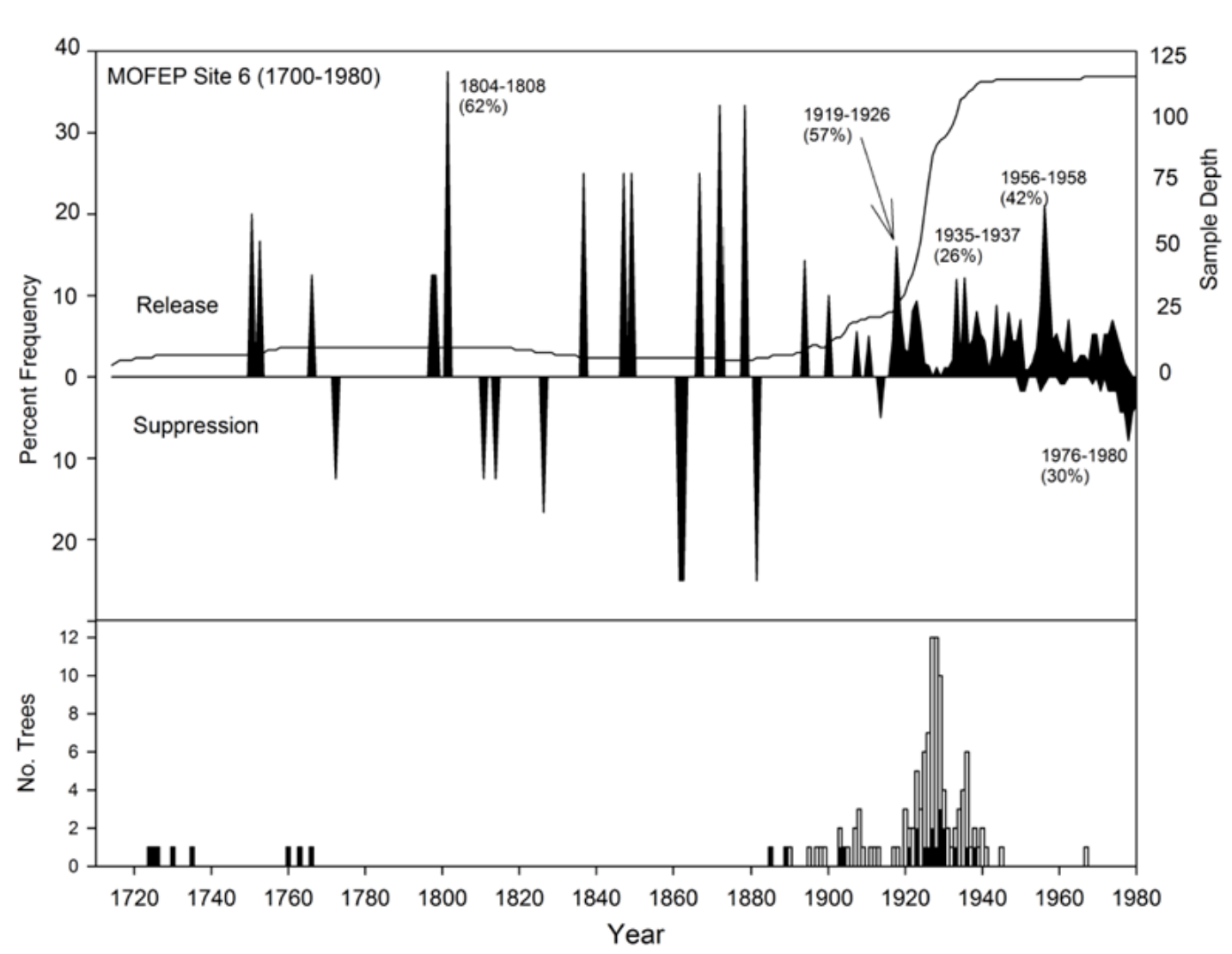

Figure 3.13. Frequency of releases and suppressions in growth of trees at MOFEP 6, Missouri 17101980. Periods of time are highlighted that include a sample depth $>20$ trees and $>10 \%$ of trees released or suppressed based on mean BAI. Horizontal line indicates the annual number of trees alive in each year (sample depth).Bottom graph indicates pith/inside ring dates for trees. Black bars $=P$. echinata $;$ white bars $=Q$. coccinea/Q. velutina 


\section{Canopy accession of Pinus and Quercus}

A total of 538 trees pre-dated 1900 and were analyzed for canopy accession (Tables 3.3, 3.8-Appendix, 3.9-Appendix). Pinus echinata accounted for $46 \%$ of trees analyzed for canopy accession. Canopy accession (Fig. 3.14) most commonly identified was gap-no release (57\% of P. echinata, $59 \%$ of $Q$. alba) but gap-major release was most common in $Q$. coccinea/Q. velutina (47\%). Suppressed-release was most rare among all species (Tables 3.3, 3.8-Appendix, 3.9Appendix).

Trees that exhibited gap-release and suppressed-release strategies were analyzed for the time they spent in the understory (Fig. 3.15) and the diameter inside bark (dib) at the time of canopy accession (Fig. 3.14). Approximately 44\% ( $\mathrm{n}=239)$ of trees had one of the two release strategies. The red oaks ( $Q$. coccinea/ $Q$. velutina) at MOFEP had the shortest median understory residence time while both $P$. echinata and $Q$. alba had the longest median understory residence time (Table 3.4). The longest time to the first release $>100 \%$ growth change in P. echinata was 157 years $(\mathrm{dib}=17.19 \mathrm{~cm})$ and in $Q$. alba was 165 years $(\mathrm{dib}=20.42)$.

Gap-no release and gap-release strategies were common following major release events (>25\% trees releasing) (Fig. 3.16, Figs. 3.26, 3.27-Appendix). This pattern was noted at both $P$. echinata/Q. alba and $Q$. alba only sites. However, these two strategies also occurred during periods when $<25 \%$ trees were releasing in a decade. 
Table 3.3. Canopy accession of P. echinata and $Q$. alba at five sites in the Missouri Ozarks. Percentages are based on total samples analyzed at each site by species.

\begin{tabular}{|c|c|c|c|c|c|c|c|c|c|c|}
\hline \multirow[t]{2}{*}{$\begin{array}{c}\text { Canopy } \\
\text { Accession }\end{array}$} & $\begin{array}{l}\text { Alley } \\
\text { Springs }\end{array}$ & & $\underline{\text { Eck Tract }}$ & & $\underline{\text { Mill }}$ & & $\underline{\text { Rock }}$ & & Hwy. 19 & \\
\hline & $\begin{array}{c}P . \\
\text { echinata } \\
\end{array}$ & Q. alba & $\begin{array}{c}P . \\
\text { echinata } \\
\end{array}$ & Q. alba & $\begin{array}{c}P . \\
\text { echinata } \\
\end{array}$ & Q. alba & $\begin{array}{c}P . \\
\text { echinata } \\
\end{array}$ & Q. alba & $\begin{array}{c}P . \\
\text { echinata } \\
\end{array}$ & Q. alba \\
\hline $\begin{array}{l}\text { Gap - No } \\
\text { Release }\end{array}$ & $\begin{array}{c}25 \\
(50 \%)\end{array}$ & $\begin{array}{c}17 \\
(55 \%)\end{array}$ & $\begin{array}{c}21 \\
(66 \%)\end{array}$ & $\begin{array}{c}12 \\
(52 \%)\end{array}$ & $\begin{array}{c}9 \\
(41 \%)\end{array}$ & $\begin{array}{c}5 \\
(56 \%)\end{array}$ & $\begin{array}{c}10 \\
(77 \%)\end{array}$ & $\begin{array}{c}13 \\
(76 \%)\end{array}$ & $\begin{array}{c}18 \\
(55 \%)\end{array}$ & $\begin{array}{c}14 \\
(46 \%)\end{array}$ \\
\hline Gap - Release & $\begin{array}{c}16 \\
(32 \%)\end{array}$ & $\begin{array}{c}9 \\
(29 \%)\end{array}$ & $\begin{array}{c}8 \\
(25 \%)\end{array}$ & $\begin{array}{c}10 \\
(44 \%)\end{array}$ & $\begin{array}{c}12 \\
(55 \%)\end{array}$ & $\begin{array}{c}3 \\
(33 \%)\end{array}$ & $\begin{array}{c}3 \\
(23 \%)\end{array}$ & $\begin{array}{c}3 \\
(18 \%)\end{array}$ & $\begin{array}{c}12 \\
(36 \%)\end{array}$ & $\begin{array}{c}8 \\
(27 \%)\end{array}$ \\
\hline $\begin{array}{l}\text { Suppressed - } \\
\text { Release }\end{array}$ & $\begin{array}{c}9 \\
(18 \%)\end{array}$ & $\begin{array}{c}5 \\
(16 \%)\end{array}$ & $\begin{array}{c}3 \\
(12 \%)\end{array}$ & $\begin{array}{c}1 \\
(4 \%)\end{array}$ & $\begin{array}{c}1 \\
(4 \%)\end{array}$ & $\begin{array}{c}1 \\
(11 \%)\end{array}$ & $\begin{array}{c}0 \\
(0 \%)\end{array}$ & $\begin{array}{c}1 \\
(6 \%)\end{array}$ & $\begin{array}{c}3 \\
(9 \%)\end{array}$ & $\begin{array}{c}8 \\
(27 \%)\end{array}$ \\
\hline Total & 50 & 31 & 32 & 23 & 22 & 9 & 13 & 17 & 33 & 30 \\
\hline
\end{tabular}




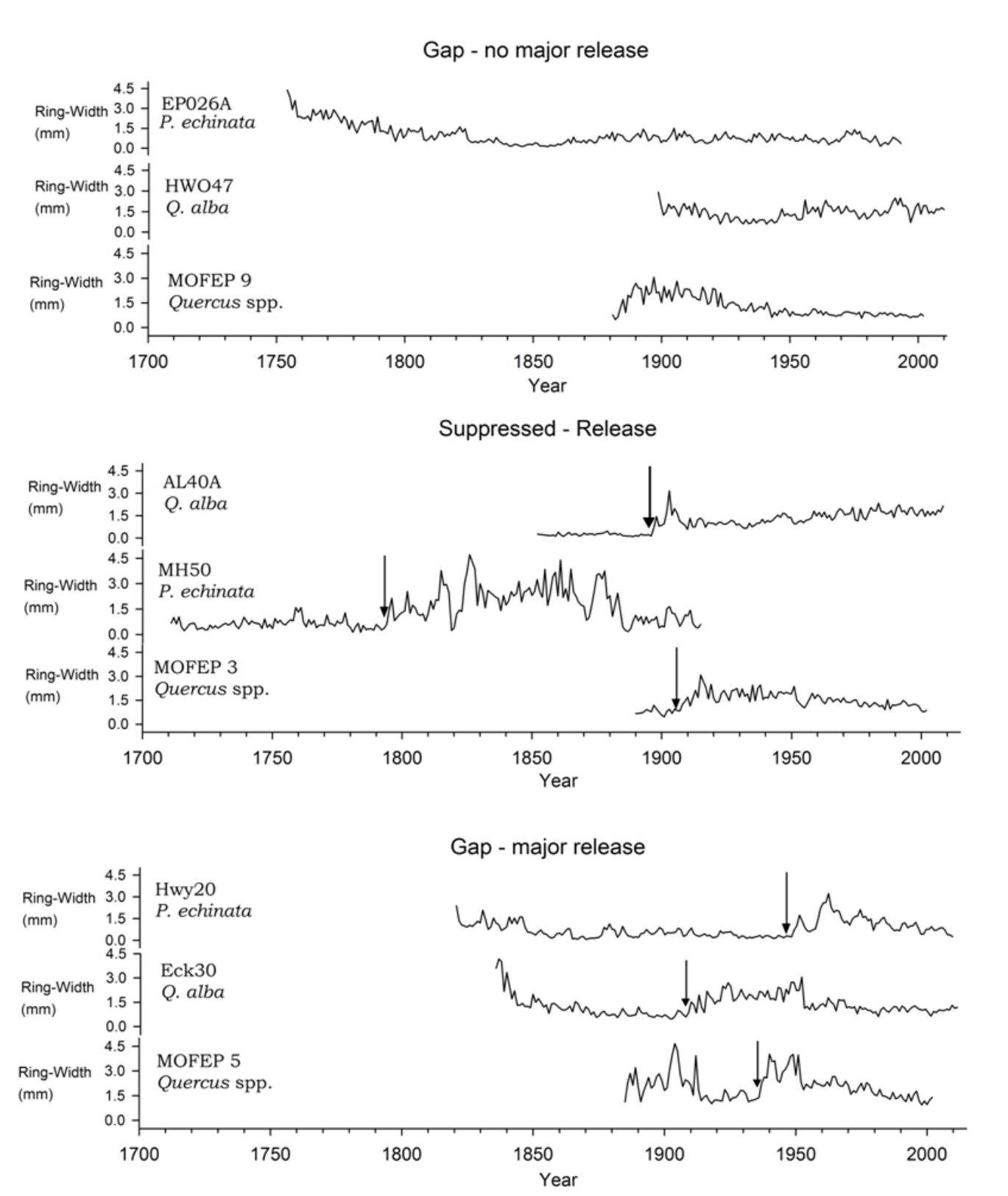

Figure 3.14. Examples of canopy accession identified in pine and oak at sites in Missouri. Measurements indicate the diameter inside bark (dib) at the time of $>100 \%$ growth change for suppressed-release and gap-release strategies. 
Table 3.4. Median understory residence time (years) (MRT) and diameter inside bark $(\mathrm{cm})$ for Pinus and Quercus species. Numbers in parentheses indicate $25^{\text {th }}, 75^{\text {th }}$ percentiles.

\begin{tabular}{lccc}
\hline & & & \\
& MRT (years) & $\begin{array}{c}\text { Diameter (cm) } \\
\text { at MRT }\end{array}$ & $\mathrm{N}$ \\
\hline \hline P. echinata & 60.0 & 11.3 & 106 \\
& $(40.0,85.0)$ & $(7.3,16.0)$ & \\
& 64.0 & 10.2 & 87 \\
Q. alba & $(42.75,89.0)$ & $(5.7,15.3)$ & \\
& & & \\
Q.coccinea/Q.velutina & 47.0 & 9.75 & 46 \\
& $(32.0,56.0)$ & $(6.3,15.4)$ & \\
\hline
\end{tabular}




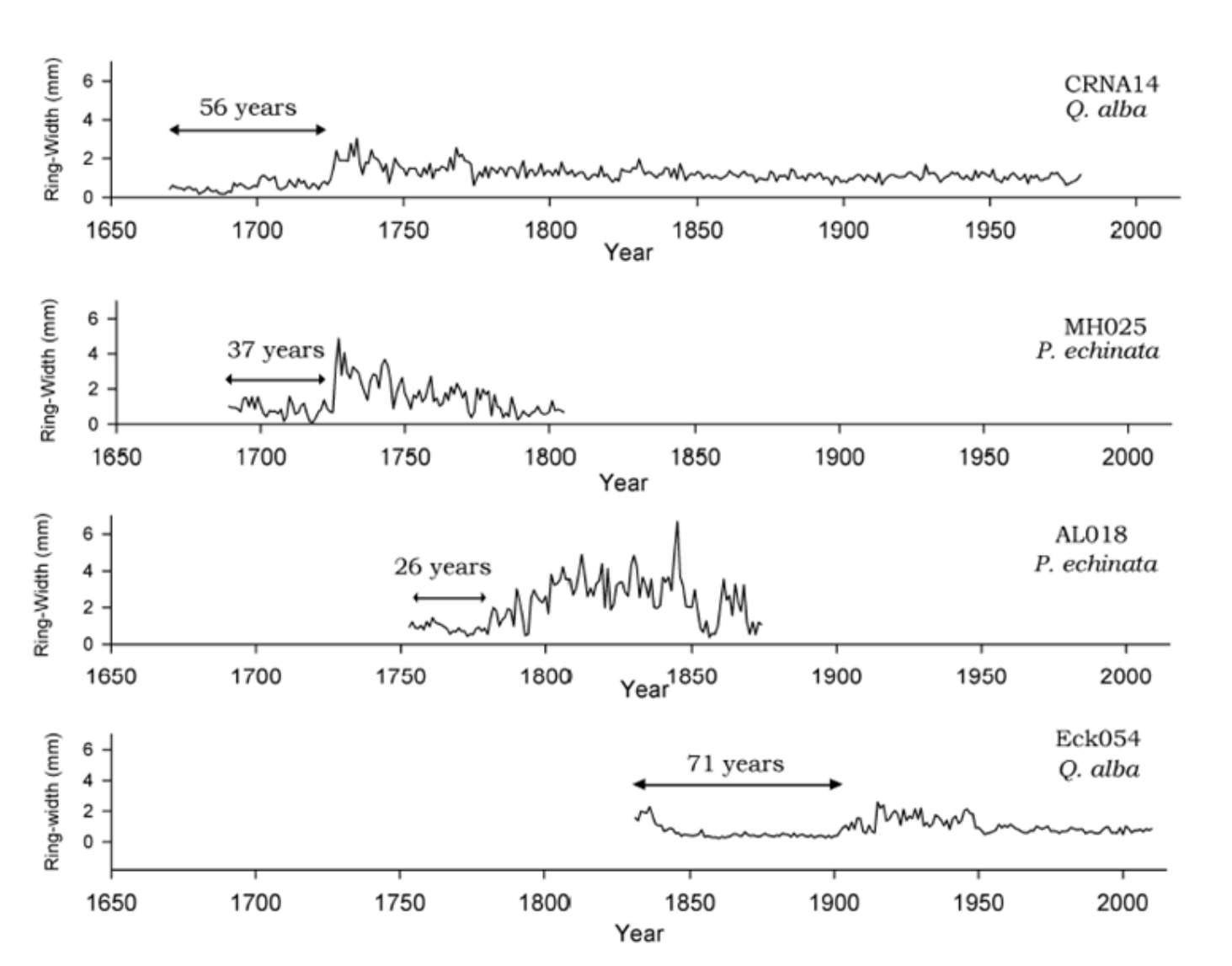

Figure 3.15. Examples of trees that established in the understory and attained the canopy following a release $>100 \%$. Years indicate understory residence time. 

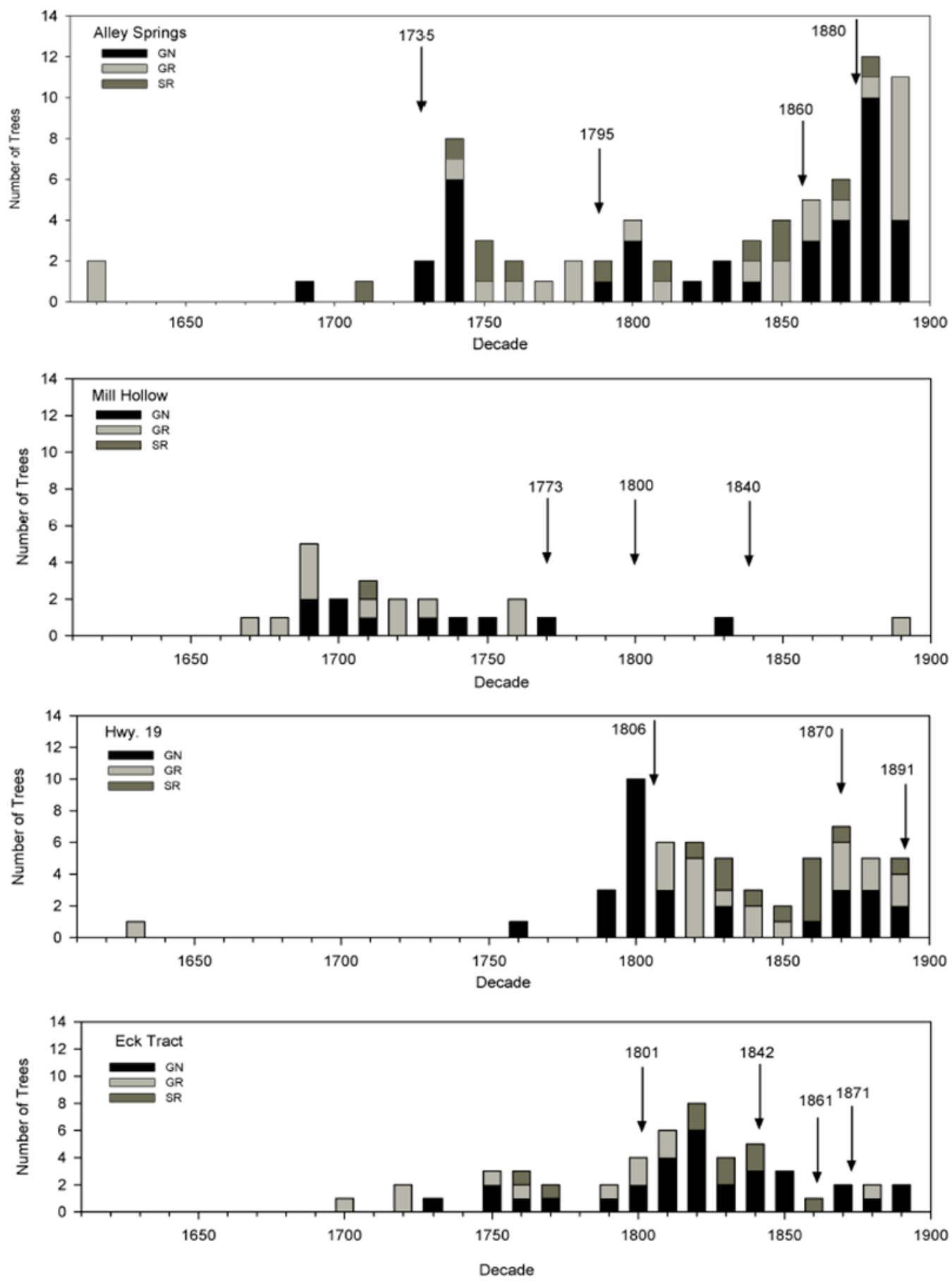

Figure 3.16. Canopy accession by decade at oak-pine sites in Missouri. Years indicate $>25 \%$ trees releasing. GN = Gap-No release; $\mathrm{GR}=$ Gap-Release; $\mathrm{SR}=$ Suppressed-Release Additional analysis is found in Appendix for $Q$. alba and MOFEP sites. 


\section{DISCUSSION}

\section{Historic disturbance patterns at sites in Missouri}

I assessed 19 sites across eastern Missouri for patterns of release and suppression due to canopy disturbance and found that while there were temporal differences among sites there were also common patterns of disturbance. The result was disturbance chronologies that dated from the late 1600's (Current River Natural Area) to the present.

At P. echinata and/or $Q$. alba sites, there were common patterns of establishment of both species. Most recruitment was consistent throughout the disturbance history of the site which suggests that these forests exhibited a multi-aged structure. One exception was Mill Hollow (Fig. 3.6). Mill Hollow had an absence of establishment beginning in the late $18^{\text {th }}$ century to the beginning of the $20^{\text {th }}$ century. One possible explanation for this was high fire frequency that removed regeneration of pine and oak during this time period. In their study of historic fire regimes in the Current River watershed, Guyette and Cutter (1997) noted that Mill Hollow had one of the highest fire frequencies of all sites between $1821-1940(\overline{\mathrm{x}}=1.7$ years, range $=1-3$ years).

Establishment at most sites appeared to correspond with identified years of release. This suggests that, historically, gap dynamics played a role in the establishment of pine and oak similar to other studies in eastern forests. Glitzenstein et al. (1986) found a similar pattern of establishment beginning in the $19^{\text {th }}$ century in an east Texas loblolly pine ( $P$. taeda) forest that exhibited pulses of recruitment following disturbance. Abrams et al. (1997) attributed the correspondence of tree recruitment and release events to canopy disturbances in two Quercus species stands in Virginia. A similar result was determined in an Acer saccharum, Quercus rubra, Tilia americana forest in western Maryland beginning in the late $19^{\text {th }}$ century (McCarthy and Bailey 1996). Bragg and Heitzman (2009) noted continuous recruitment in a second growth Pinus spp. stand during the $20^{\text {th }}$ century in southeast Arkansas rather than pulses of recruitment that indicated a large, infrequent disturbance event. Abrams and Orwig (1996) determined that 
white pine (P. strobus) in western Pennsylvania exhibited historic pulses of recruitment likely due to larger gap openings caused by infrequent disturbance events. These studies are similar to my findings across most sites in which establishment of both pine and oak corresponded to release events and recruitment pulses likely indicated large gap formation.

As with Abrams and Orwig's (1996) assessment of pulse recruitment of P. strobus, there were pulses of $P$. echinata recruitment that corresponded with release events at the Ozark sites. At Eck Tract (1810’s), Hwy. 19 (1800’s, 1930’s, 1950’s), Alley Springs (1750’s, 1880’s, 1930’s), Lower Rock Creek (1780's), and Mill Hollow (1950's) were pulses of $P$. echinata establishment. A similar pattern of $P$. echinata pulses occurred at MOFEP sites including MOFEP 3 (1880's, 1940’s), MOFEP 4 (1890’s, 1940’s), MOFEP 5 (1890’s), MOFEP 6 (1930's), and MOFEP 7 (1920’s). Oak establishment was similar to P. echinata at these sites. These pulses likely indicate disturbance events that created large canopy openings that promoted the establishment of P. echinata, especially during the $20^{\text {th }}$ century logging period. MOFEP 1 and 8 had continuous recruitment of Quercus spp. and P. echinata beginning in the early $20^{\text {th }}$ century until 1940 that suggests periodic logging events, similar to findings from previous research at MOFEP 8 (Guyette and Dey 1997). However, my study suggests that $P$. echinata also likely established following individual tree mortality events in which only a few trees released. Previous research on canopy gap size and $P$. echinata establishment found there was an approximately eight fold increase in the maximum number of pine seedlings that regenerated as canopy gap size increased from $\sim 400 \mathrm{~m}^{2}$ to $\sim 1700 \mathrm{~m}^{2}$ (Stambaugh and Muzika 2004). The historic pulses of P. echinata and Quercus species establishment suggests that gap openings due to natural or anthropogenic causes were likely similar to the large canopy gaps identified by Stambaugh and Muzika (2004). The combination of release events and establishment pulses beginning in the late $19^{\text {th }}$ century likely corresponds with the establishment of large scale logging operations (Cunningham 2007, Lewis 2004) that initially focused on the harvesting of P. echinata and later Q. alba. 
Quercus alba at Current River Natural Area exhibited continuous recruitment beginning in the mid- $17^{\text {th }}$ century to 1800 . There appears a pulse in establishment during the period 1700 to 1720 that corresponds with a release event during the late 1690's. As with the previous sites, establishment of $Q$. alba corresponded with release events at Greasy Creek, Wegener Woods, Jack's Fork, and Babler State Park. Wegener Woods had a pulse of recruitment during the 1720's which likely corresponded with a canopy disturbance event. Jack's Fork exhibited two possible pulses during the 1830's and 1910's. The pulse during the 1910's appears to correspond with a series of releases during the same time period, likely due to logging. However, the pulse during the 1830's does not have a corresponding release event, rather there is suppression. This may indicate a disturbance that resulted in tree-fall injury or a severe fire.

While establishment and release events were common across sites, there were temporal periods with limited establishment even with release events occurring at sites. Periods of limited establishment occurred at Eck Tract (1770-1800, 1850-1870), Hwy. 19 (1840-1860, 1920-1930), Alley Springs (1760-1800), Mill Hollow (1730-1750), MOFEP 1 (1910-1930), and MOFEP 4 (1890-1940). One factor that possibly explains the noticeable decline in establishment based on the time periods of these events may be stand development processes. Prior to the periods of low establishment are periods of higher rates of establishment of trees that may indicate that the sites were going through a stem exclusion phase. There appears to be tremendous variability in the length of time that the stem exclusion phase lasts across forest types. Frelich (2002) notes that for P. strobus and northern hardwoods that the stem exclusion phase may last over a century while in jack pine/aspen stands may only last 20-40 years. In the central hardwoods region, Rentch et al. (2003) noted a 60-100 year period of stem exclusion. Abrams et al. (1997) in Virginia Quercus stands identified an approximately 60 year period of low establishment. While the periods of time for stem exclusion at my sites are shorter than those indicated by the previous studies, Ruffner and Abrams (1997) suggested short stem exclusion phases in a Quercus prinus stand in Pennsylvania ( 20-40 years) that followed recruitment pulses. Shorter periods of stem exclusion 
may be a product of high disturbance frequencies at my sites and other sites across the eastern deciduous forest. Frequent disturbances possibly accelerate the stem exclusion phase of stand development by forcing the thinning of the forest.

Suppressions of $P$. echinata and Quercus species appear to be similar to results found by Guyette et al. (2007) in their assessment of declines in growth of P. echinata. Relationships between drought periods and suppressions include the 1881, 1912, 1952, 1959, and 1977 droughts (Guyette et al. 2007) as droughts with the greatest effect on P. echinata growth. Several other periods of suppression appear to occur simultaneously with releases by other trees. One possible explanation is trees were injured due to a neighboring tree falling that removed a portion of the understory tree's canopy.

Another climatic factor that can cause suppressions to occur is ice storms. Rebertus et al. (1997) analyzed damage to trees in northern Missouri following the 1994 ice storm and determined that $Q$. alba had the least amount of damage relative to other species. They suggest that ice storms in Missouri have a return interval of 20-25 years. For P. echinata, Travis and Meentemeyer (1991) in the southeast United States found that reduced growth due to icing damage was restricted primarily to the growing season following the icing event. Millward and Kraft (2004) determined that the combination of local topography and icing created high variability in the damage caused by an ice storm in the northeast United States and Canada. Based on their results, they suggest that ice storms do not create uniform damage across a landscape, rather the amount of canopy damage is localized. With this knowledge, it is possible that the approaches used to identify disturbance events for this study may not have captured suppressions due to ice storms. If suppressions due to ice storms are restricted to only a few years (Travis and Meentemeyer 1991) and Q. alba damage is restricted, the approaches I used did not account for short-term changes in growth. There were two periods during the 1920's (1924, 1927) of known ice storm events in Missouri. Quercus alba at Wegener Woods and Babler State 
Park demonstrated suppressions in growth during this time period that are not found at other sites and appeared unrelated to drought.

\section{Canopy accession and canopy disturbance}

Tree-ring analysis suggests that the three canopy accession defined by Rentch et al. (2003) are indicated in P. echinata and Quercus species over the historical record in Missouri. Stand-wide disturbances, identified by $25 \%$ of trees releasing (Nowacki and Abrams 1997) corresponded to both Pinus and Quercus exhibiting gap origin-no release canopy accession. Stand-wide disturbances, such as spring wind events, heavy winter snow, or logging likely resulted in large gap formation that promoted increased radial growth rates before canopy closure. Other trees during these stand-wide disturbances exhibited gap origin-major release strategies. These trees had increased radial growth rates during the first 25 years of growth and subsequent declines in radial growth until a major release. These trees likely established in canopy gaps that were subsequently closed by trees already existing in the canopy (Lorimer and Frelich 1989). A subsequent canopy disturbance provided gap origin-major release trees an opportunity to access the canopy.

Understory residence time (MRT, Table 3.4) of Quercus species is similar to those reported by Rentch et al. (2003). Oaks have intermediate shade-tolerance and Q. alba has been shown to survive over 60 years in closed canopy conditions (Burns and Honkala 1990). However, nearly $60 \%$ of $Q$. alba exhibited radial growth rates with no major release possibly indicating that $Q$. alba established in large canopy gaps at all sites prior to 1900 . For red oaks in this study, the median understory residence time was 47 years, slightly less than the 50 years reported by Rentch et al. (2003). Hart et al. (2012) reported Q. velutina having understory residence time up to 80 years in southern Tennessee. Only $37 \%$ of red oaks in this study had an understory residence time $>50$ years. Most of the red oaks in this study established after 1880, a time period in the Missouri Ozarks when logging activity removed most of the Pinus component 
from the overstory. My results suggest that $89 \%$ of red oaks established in a gap that either resulted in no release or a subsequent major release during the 1930's.

Pinus echinata is considered shade-intolerant but may be more tolerant than other southern pines (Burns and Honkala 1990; Shelton and Cain 2000). The results of this study suggest that $P$. echinata had understory residence times (MRT) similar to $Q$. alba (Table 3.4). While most $P$. echinata did not indicate a major release, there appears to be the ability to remain in the understory for several decades prior to a major release. Brose and Waldrop (2012) found similar patterns of canopy accession in Table Mountain pine ( $P$. pungens) and pitch pine $(P$. rigida) at upper slope positions in northern Georgia. They noted that both species established in large gaps without a subsequent release, and small gaps that required a release to attain the canopy prior to 1900 .

Differences in medican understory residence time between $P$. echinata, Q. alba, and $Q$. coccinea/ $Q$. velutina may be explained in two ways. Establishment dates of $P$. echinata and $Q$. alba extended to the $18^{\text {th }}$ century while establishment dates of red oaks largely centered around the late $19^{\text {th }}$ century. The longer median understory residence times of $P$. echinata and $Q$. alba may reflect the effect of smaller canopy disturbance events that resulted in releases of few trees while others remained in the understory. Secondly, shorter median understory residence times of red oaks in the late $19^{\text {th }}$ century likely reflect the role of logging on the landscape. Larger gap formations during the late $19^{\text {th }}$ century may have resulted in shorter understory residence times. 


\section{CONCLUSIONS}

I assessed historic disturbance events using changes in basal area increment growth patterns and canopy accession of $P$. echinata, Q. alba, Q. coccinea, and $Q$. velutina across 19 sites in Missouri. Establishment and subsequent growth of all species suggests large gap formation due to disturbances that affect the forest, such as wind, heavy snow/ice, or logging promoted canopy accession. However, another possible explanation is lower overall stand density at upper slope positions. Partial removal of the existing canopy that was not a stand-wide disturbance may have created large gap openings that promoted radial growth rates that did not require a release to attain the canopy. High fire frequencies during the late 1800's likely reduced understory competition that may have contributed to the high number of trees that did not require a release to attain the canopy. 


\title{
CHAPTER 4
}

\section{DISTURBANCE INTEGRATION: DROUGHT, FIRE, AND GROWTH RELEASE AND THEIR EFFECT ON THE PERSISTENCE OF OAK-PINE FORESTS IN THE MISSOURI \\ OZARKS 1700-1940}

\begin{abstract}
Multiple disturbances have historically affected oak-pine forests in the Missouri Ozarks. This study focuses on the integration of different disturbance regimes to understand the dynamics, the potential interaction between disturbance types, and the effect of disturbance on radial growth. Drought, fire, and canopy disturbances have been documented in these forests and provide an opportunity to consider the likelihood of the effects of one disturbance on other kinds of disturbance. Results indicate that some disturbances preceded others (drought-fire; droughtgrowth release; fire-growth release) but were not consistent across all sites. Significant increases and decreases in radial growth occurred following different fire years at all sites with some trees exhibiting growth releases. Establishment of Pinus echinata (Mill.) and Quercus alba (L.) historically occurred during short intervals when disturbance frequency declined at the study sites. High fire frequencies likely reduced understory competition while frequent canopy disturbance provided $P$. echinata and $Q$. alba the opportunity to persist in these forests.
\end{abstract}




\section{INTRODUCTION}

Most studies of historic disturbance frequency and magnitude generally assess a particular disturbance type and only make reference to other disturbances in a forest (Abrams et al. 1997; Abrams and Copenheaver 1999; Glitzenstein et al. 1986, Hart et al. 2011; McEwan et al. 2007; Rentch et al. 2003). While this can provide invaluable information about the historic stand dynamics of a forest from the standpoint of a single disturbance type, in most cases there are multiple disturbances that occur in a forest with varying frequencies and magnitudes (however, see Hart et al. 2008). In upland oak forests, where fire has been attributed to maintaining these oak systems, the potential exists in studying the relationship between historic fire, growth release, and drought. Incorporating multiple disturbance regimes of forests has the potential of extending our understanding of forest dynamics (Rentch et al. 2002, 2003).

There is some evidence that suggests drought was an antecedent to fires in western forests (DeRose and Long 2012) and severe fire years in eastern forests (Guyette et al. 2006). Changes in radial growth due to fires that result in either increases (Aldrich et al. 2010; Nesbitt 2001; Py et al. 2006) or decreases (Guyette and Kabrick 2003) indicate that fire may act as an antecedent to growth suppressions or releases. Therefore, there is some precedence to incorporating multiple disturbance regimes for an overall analysis of historic disturbance dynamics.

Oak (Quercus spp.) - shortleaf pine (Pinus echinata, Mill.) forests of the Missouri Ozark Highlands provide an opportunity to assess multiple disturbance regimes and their effect on stand dynamics. Previous research has demonstrated that historic fire regimes played a significant role in these forests (Guyette and Cutter 1997; Guyette et al. 2003). Monthly Palmer Drought Severity Index is strongly correlated to radial growth of white oak (Quercus alba, L.) and $P$.

echinata (Chapter 5; Stambaugh and Guyette 2004). Growth release events have been detected in these forests suggesting that trees were responding to canopy disturbance (Chapters 2,3). With 
this knowledge, there appears to be the potential of incorporating multiple lines of disturbance to understand the dynamics of oak-pine forests.

I used dendroecological techniques to explain the disturbance regimes of four $Q$. alba-P. echinata forests in the Missouri Ozark Highlands. The primary objective was to reconstruct disturbance events across multiple oak-pine sites in the Missouri Ozarks and determine if there were previous circumstances that indicate an interactive effect of disturbance. Specifically, I tested: (1) the association between disturbances to address the potential of antecedent disturbance effects, and; (2) radial growth and establishment patterns of $Q$. alba and $P$. echinata subsequent to historic fire years to analyze the effect of fire at multiple sites. 


\section{METHODS}

\section{Field and Laboratory Methods}

Samples of tree-rings from $P$. echinata and $Q$. alba had three sources: increment cores collected at breast height $(1.37 \mathrm{~m})$; cross-sections of remnant wood; and previously collected wood by the Missouri Tree-Ring Laboratory at Eck Tract, Alley Springs, Mill Hollow, and Hwy. 19. At the four sites I established three $500 \mathrm{~m}$ transects $100 \mathrm{~m}$ apart along the prevailing slope contour at upper slope positions (ridge, shoulder, backslope). Remnant P. echinata (stump/snag) wood encountered along each transect was visually inspected for a pith and approximate ring count $>75$ years for cross-dating purposes. Remnant wood collection was not limited to samples that showed fire scars. Increment cores were collected on any P. echinata or Q. alba $\geq 30 \mathrm{~cm}$ diameter at breast height (DBH) and were in a dominant or co-dominant position. Individual increment cores were sampled on the side of the tree that was parallel with the prevailing slope contour. Cross-sections of $P$. echinata remnant wood were collected as close to ground level as possible with a chainsaw.

Samples that were previously collected from Mill Hollow, Alley Springs, and Eck Tract by the MTRL were inspected, and in some cases tree-ring widths were re-measured and used in the analysis. Wood samples were prepared using the methods of Stokes and Smiley (1996). A radius (pith to bark) was chosen for ring-width measurements that avoided the high variability of growth response near an identified injury or fire scar on remnant wood that may bias growth response analysis. Fire scars were identified by the combination presence of charcoal, cambial injury, callus tissue, or traumatic resin canals (Guyette and Cutter 1997) in P. echinata remnant wood. All samples were cross-dated using visual methods and COFECHA (Holmes 1983, Grissino-Mayer 2001a) that assesses the correlation among individual tree-ring series from a site. 


\section{Disturbance Analysis}

I used modified methods of Nowacki and Abrams (1997) to identify growth releases associated with canopy disturbance. To identify a growth release, I used 10-year running medians that resulted in an increase in growth $>50 \%$ that was sustained for a minimum of 10 years. Rubino and McCarthy (2004) analyzed the various methods developed to identify growth releases and concluded that medians are a more robust statistic for growth release analysis due to the non-normality of tree-ring measurements. I restricted the definition of a growth release to trees that exhibited increases in growth $>50 \%$ that were sustained for at least 10 years as a conservative approach to assessing canopy disturbance. Short-term increases in ring-width at xeric sites following drought conditions may indicate growth responses to drought and not canopy disturbances. Therefore, I restricted a growth release due to a canopy disturbance to increases in radial growth $>50 \%$.

Descriptive statistics were calculated of fire events for individual trees and sites using the computer program FHX2 (Grissino-Mayer 2001b). The FHX2 program was originally developed to analyze fire history statistics and graphically display temporal patterns of fire events at sites but has been expanded to analyze other disturbances that affect forests (Hart et al. 2011).

Regional drought conditions were identified using reconstructed Palmer Drought Severity Indices (PDSI) (Cook et al. 2004). Mean reconstructed PDSI was calculated using annual reconstructed PDSI values from locations 201 and 210 in southern Missouri for the time period 1700-1940 for disturbance association analysis (www.ncdc.noaa.gov/paleo/pdsidata.html).

\section{Disturbance Associations}

For each site, I considered the potential antecedent effects of drought and fire, drought and growth release, and fire and growth release using superposed epoch analysis (SEA) (Grissino-Mayer 2001b). Superposed epoch analysis assesses the association between an event and a time-series with the assumption that the two have biological relevance. The program, as 
part of FHX2, was originally designed to analyze associations between fire years and a timeseries. SEA provides the user the opportunity to assess significant associations between event years and time-series prior and subsequent to any event year. Confidence limits are calculated based on 1000 Monte Carlo simulations of the data. For each site SEA analysis, I tested the association between fire year (event) and drought (mean reconstructed PDSI time series), growth release year (event) and drought (mean reconstructed PDSI time series), and fire year (event) and annual proportion of growth releases (time series).

I utilized all fire years identified at each site for SEA of fire and drought. Given that samples were collected at upper slope positions on exposed aspects, the potential exists that increases in growth (release) may occur following a series of drought years. Rather than capturing canopy disturbance due to wind or logging, the releases were possibly drought induced responses. I calculated a time-series for growth releases at each site to assess the association between fire and growth release. The time-series used to compare to fire year was the annual proportion of total releases that demonstrated an increase in radial growth $>50 \%$. I tested the hypothesis that fire years were associated with release events prior to or subsequent to any fire

year. While the percentage of trees that exhibit a release provide some context for historic events, sample depths decline as one goes back in time. I calculated the annual proportion of release events to understand the magnitude of canopy disturbance events over multiple centuries.

\section{Disturbances, Radial Growth, and Establishment Patterns}

I analyzed the radial growth of trees at each site following fire events. Fire events are discrete events in time that may result in changes in growth of trees. However, because of high fire frequencies at most sites in the Missouri Ozarks, a difficulty exists in attributing changes in growth to a specific fire year. With this knowledge, I restricted my analysis of growth to fire years in which $>2$ trees were scarred during the same year. 
Radial growth the year of the fire, two year mean radial growth, and three year mean radial growth following the fire year were compared to radial growth one year prior to the fire year using Wilcoxon signed ranks test to investigate short-term changes in growth. The null hypothesis in all cases is there were no differences in growth prior to a fire and growth subsequent to a fire.

A qualitative assessment was made in comparing the percentage of trees exhibiting growth releases within three years of a fire year. The combination of changes in growth up to three years subsequent to a fire and the percentage of releases may provide some insight into the effect of specific historic fires. I compared multiple disturbance events (release and fire) to establishment dates of P. echinata and $Q$. alba to understand the forest dynamics at each site. Pith dates at breast height were estimated using methods outlined by Duncan (1989). 


\section{RESULTS}

I analyzed 72 samples (32 P. echinata; 40 Q. alba) from Eck Tract, 108 (69 P. echinata; 39 Q. alba) from Alley Springs, 109 from Mill Hollow (54 P. echinata; 55 Q. alba), and 148 from Hwy. 19 (82 P. echinata; 66 Q. alba). Of the 437 samples collected across all sites, $78 \%$ of P. echinata and $48 \%$ of $Q$. alba were growing during periods of fire between 1700 and 1934 (Table 4.1). A high amount of variability existed in the number of fire scars identified among sites, yet mean fire interval among sites $<10$ years. Mean fire interval for Mill Hollow and Alley Springs are similar to that reported by Guyette and Cutter (1997) and Guyette et al. (2003), respectively. Mean release intervals were similar to the mean fire intervals with the greatest discrepancy between the two measurements occurring at Eck Tract (Table 4.1). Guyette (1993) reported four fire years at Eck Tract that I independently verified based on remnant wood collection. In addition to the four fires years previously reported $(1837,1871,1879,1907)$ an additional 10 fire years are reported in this chapter. However, remnant wood at Eck Tract was limited in availability and I was unable to cross-date most remnant wood collected because of low numbers of tree-rings and few fire scars.

\section{Disturbance Associations}

Based on superposed epoch analysis, there was little association between fire year and mean reconstructed PDSI (Fig. 4.1). The exception was at Hwy. 19 where there was a significant 4-5 year lag between drought and any fire year. However, when combining all fire years across all sites, there was no significant association between fire and drought (Fig. 4.1).

Superposed epoch analysis for release year and mean reconstructed PDSI indicated significant 2 year lagged associations between the variables at Mill Hollow and Alley Springs (Fig. 4.2). At Eck Tract and Hwy. 19 there were no significant associations between release year and mean reconstructed PDSI. Analyses of fire year and proportion of releases using superposed 
epoch analysis indicated significant associations prior and subsequent to fires at Mill Hollow and Alley Springs, and prior to any fire year at Hwy. 19 (Fig. 4.3).

\section{Radial Growth Comparisons and Historic Fire Events}

For radial growth comparisons prior and subsequent to discrete fire events in which $>2$ trees were scarred during the same year, 13 years at Hwy. 19, 27 years at Alley Springs, and 31 years at Mill Hollow were identified for use in growth analysis. An exception was made for Eck Tract due to the low number of fires (14 fire years) identified at the site. I therefore used all 14 fire years for growth analysis.

Wilcoxon signed ranks test indicated significant differences in radial growth before and after fire years at all sites (statistical results, Appendix). There was variability in the percentage of trees that exhibited increased or decreased growth based on fire year. While mean growth rates often increased following a fire, there were years in which mean radial growth declined and $>50 \%$ of trees exhibited declining mean radial growth. Significant differences were usually associated with $>60 \%$ of trees following a fire year that demonstrated increasing or decreasing mean growth 1,2 , and 3 years following the fire.

One of the confounding factors in this analysis was the frequency of fire across all sites. Mean radial growth rates often overlapped among sequential years with high fire frequencies (see Mill Hollow beginning in 1882, Table 4.2). Significant increase in mean radial growth was most common among all sites in which 58\% of fire years resulted in sustained increases in mean radial growth up to three years following a fire. Even following fire years which did not show significant differences, $>50 \%$ of trees exhibited increases in mean radial growth. At Mill Hollow, $74 \%$ of fire years saw $>50 \%$ trees increasing in radial growth regardless of significance (Table 4.4). The same pattern was observed at Hwy. 19 (78\%) (Table 4.3) and Alley Springs (67\%) (Table 4.4). The exception was at Eck Tract in which only $43 \%$ of fire years showed an increase in radial growth (Table 4.5). 
Table 4.1. Descriptive fire and release statistics of four sites in the Missouri Ozarks during the temporal range of fire events at the sites. $\mathrm{MFI}=$ mean fire interval; $\mathrm{MRI}=$ mean release interval; $\mathrm{SD}=$ standard deviation. Temporal periods indicate range of years that fires burned at each site.

\begin{tabular}{|c|c|c|c|c|c|c|c|c|c|c|c|}
\hline Site & Years & \multicolumn{2}{|c|}{ \# Trees } & $\begin{array}{l}\text { \# Fire } \\
\text { Scars }\end{array}$ & MFI & SD & Range & $\begin{array}{c}\# \\
\text { Releases }\end{array}$ & MRI & SD & Range \\
\hline Alley Springs & $1706-1915$ & $\begin{array}{c}\text { Shortleaf } \\
64\end{array}$ & $\begin{array}{c}\text { White Oak } \\
29\end{array}$ & 58 & 4.54 & 3.53 & $(1-21)$ & 81 & 5.00 & 5.87 & $(1-31)$ \\
\hline Eck Tract & $1822-1907$ & 44 & 24 & 14 & 9.62 & 9.68 & $(3-30)$ & 114 & 2.48 & 1.38 & $(1-5)$ \\
\hline Hwy 19 & $1806-1930$ & 39 & 30 & 53 & 8.86 & 11.14 & $(3-49)$ & 91 & 4.35 & 3.79 & $(1-16)$ \\
\hline Mill Hollow & $1703-1923$ & 40 & 12 & 130 & 4.63 & 3.54 & $(1-27)$ & 68 & 5.84 & 5.05 & $(1-20)$ \\
\hline
\end{tabular}



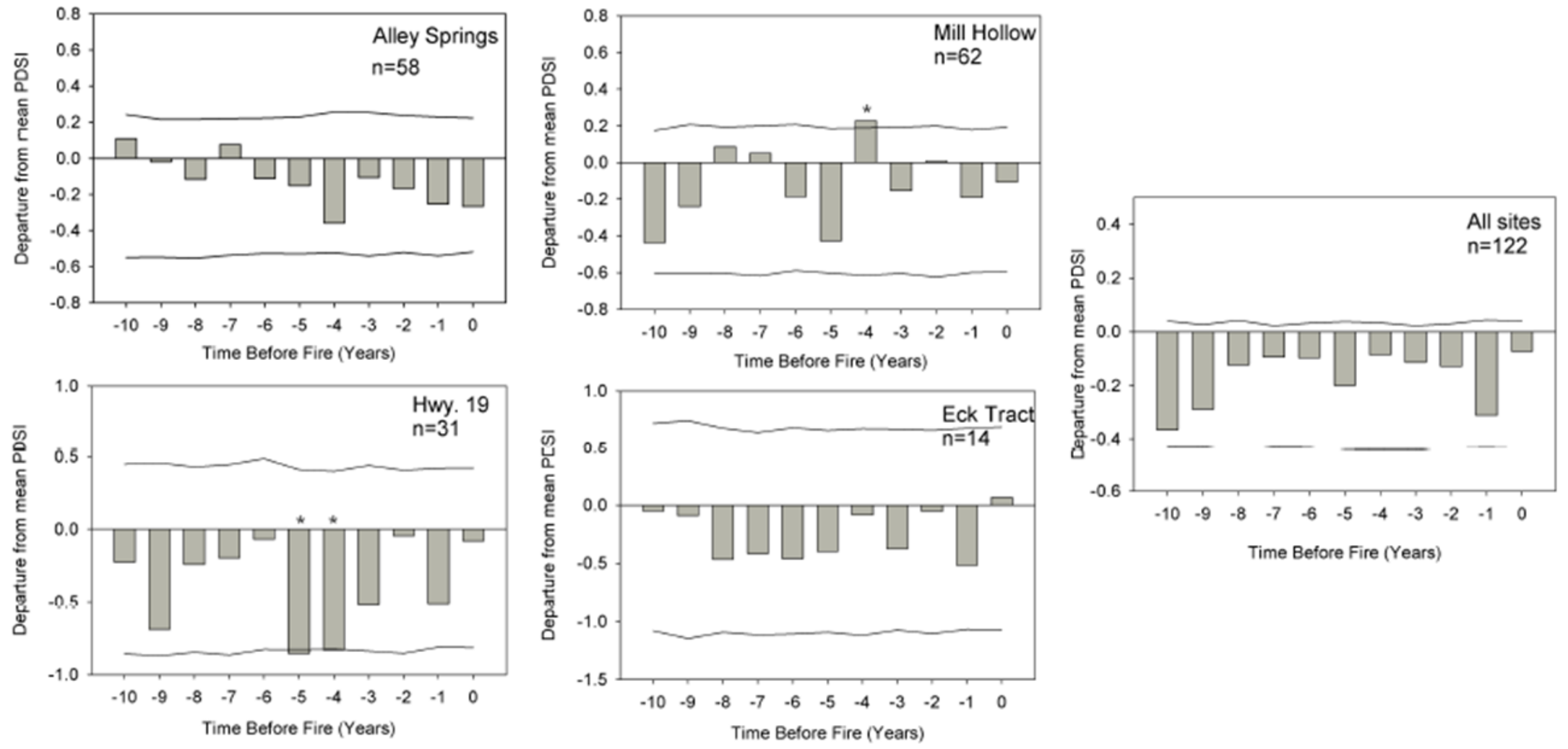

Figure 4.1. Superposed epoch analysis of fire year and mean rconstructed PDSI at four study sites and all sites. Horizontal lines indicate 95\% confidence limits based on 1000 Monte Carlo simulations. Asterisks indicate significant associations between lagged PDSI and fire year. $\mathrm{n}=$ number of fire years. Significant associations occur at Hwy. 19 4-5 years prior to any fire and 4 years prior to any fire year at Mill Hollow. 

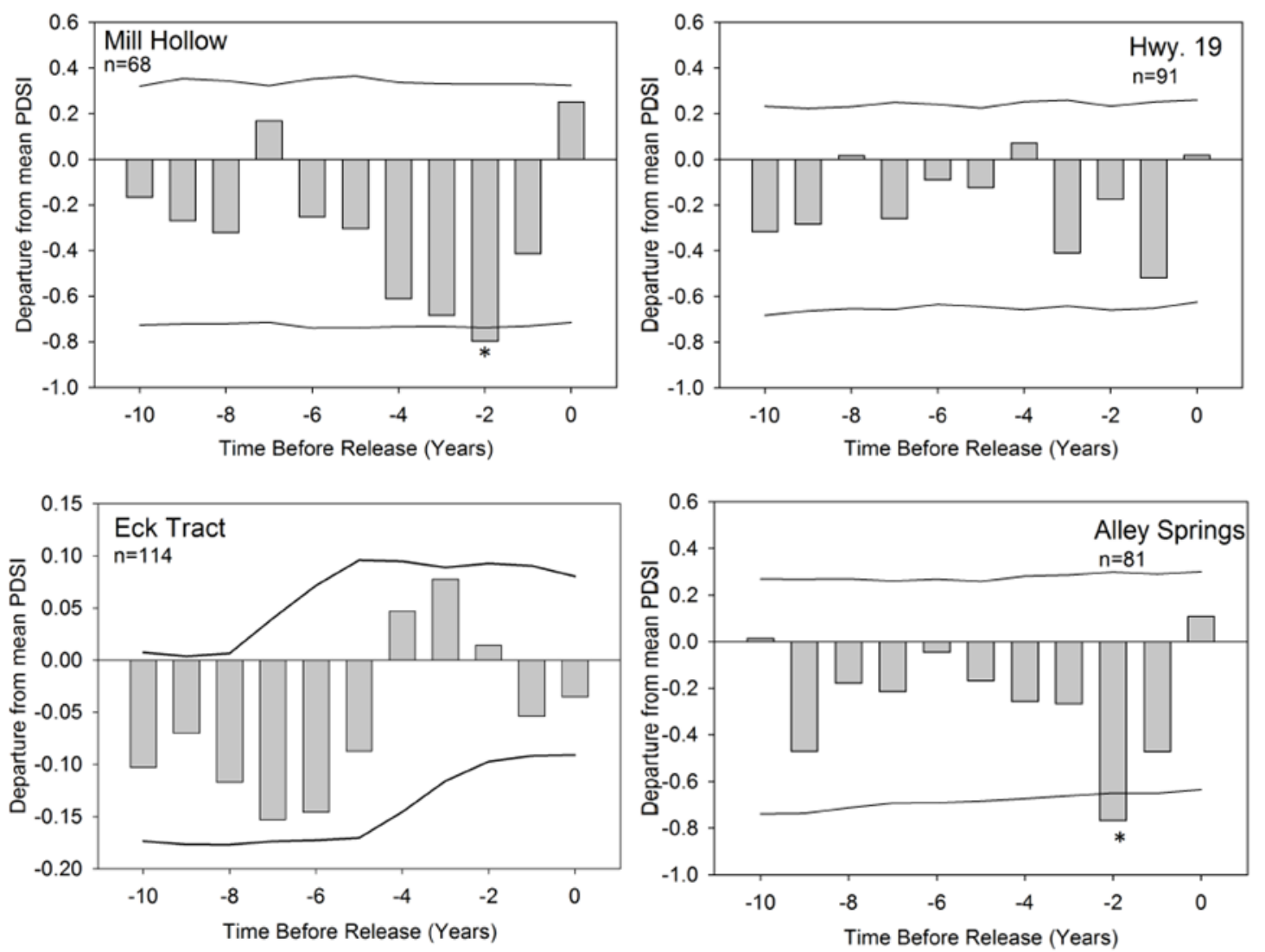

Figure 4.2. Superposed epoch analysis for release year and mean reconstructed PDSI at four study sites. Horizontal lines indicate 95\% confidence limits based on 1000 Monte Carlo simulations.

Asterisks indicate significant associations between lagged PDSI and release year at Mill Hollow and Alley Springs. $\mathrm{n}=$ number of release events. 

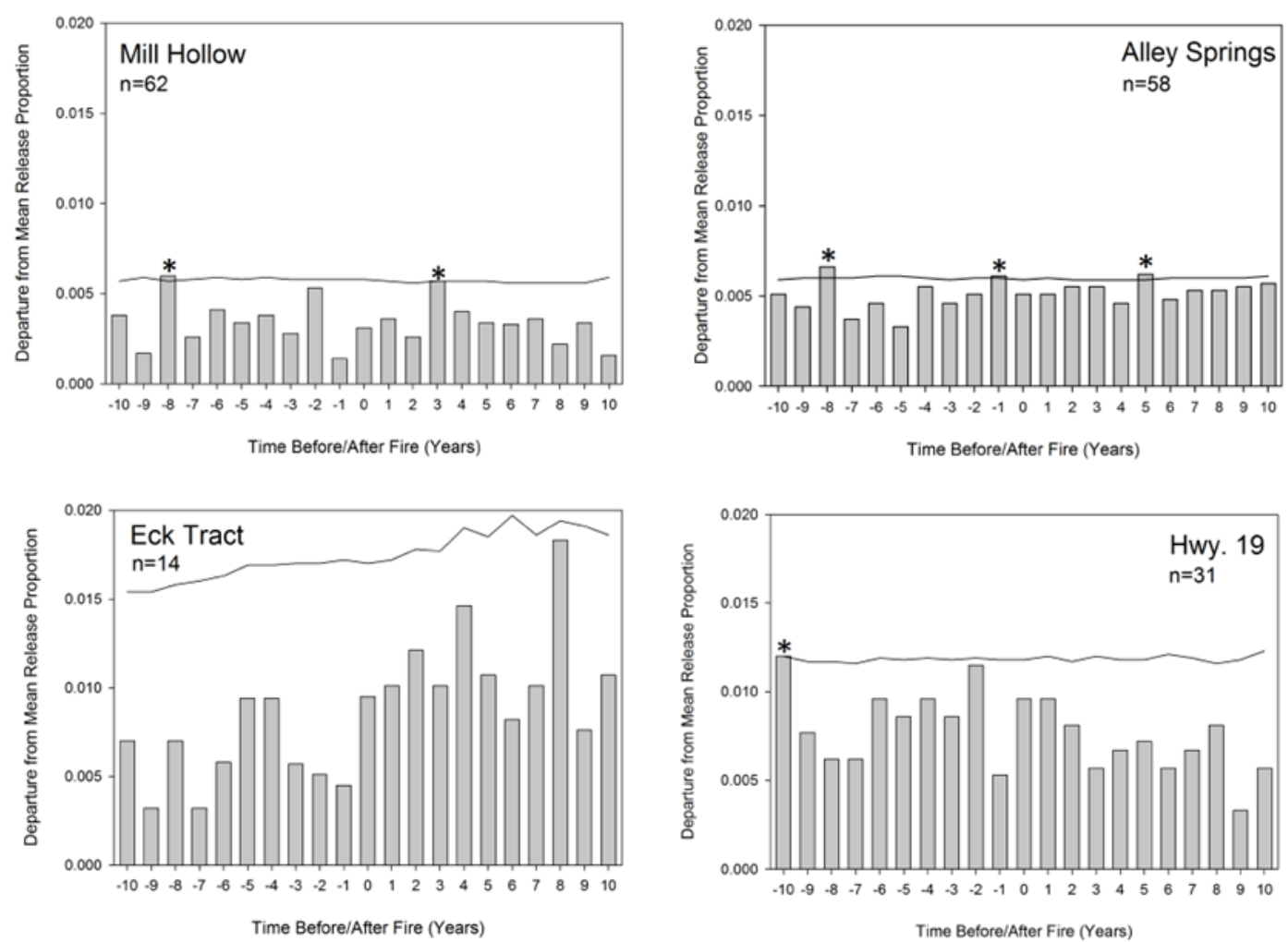

Figure 4.3. Superposed epoch analysis for fire year and release proportion at four study sites. Horizontal lines indicate 95\% confidence limits based on 1000 Monte Carlo simulations. Asterisks indicate significant associations between lagged release proportion and fire year at Mill Hollow, Alley Springs, and Hwy. 19. $\mathrm{n}=$ number of fire years 
Table 4.2 Radial growth differences 1,2, and 3 years following a fire in which $>2$ trees were scarred at Mill Hollow using Wilcoxon sign rank test $(\mathrm{p}<0.05)$. Shaded areas indicate significant differences in radial growth following a fire (grey $=$ increases; black $=$ decreases). Bolded years indicate mean reconstructed PDSI $<-2.0$ one year prior to fire year.

\begin{tabular}{lc}
\hline Mill & Percentage of Trees with \\
Hollow & Growth Increases ${ }^{1}$
\end{tabular}

Fire Year

1726

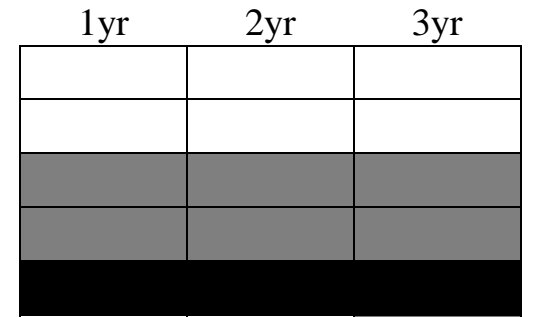

1786

1794

1800

1808

1815

1819

1833

1836

1844

1847

1853

1857

1860

1864

1870

1876
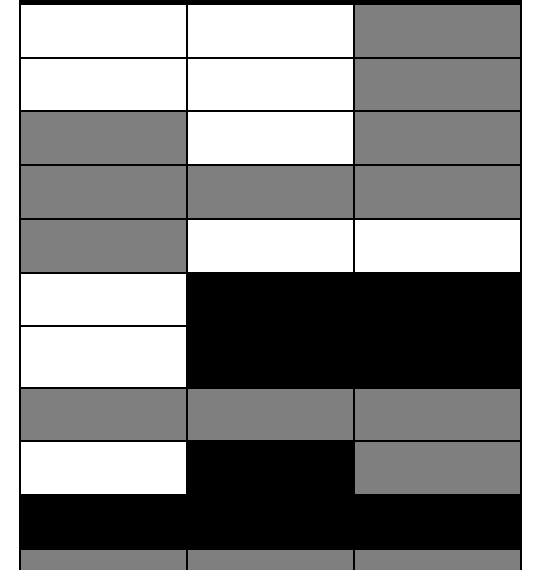

53

29

75

90

0

54

53

80

88

76

38

42

96

54

21

63

33

14

52

68

\section{$2 \mathrm{yr}$}

53

33

57

62

25

43

56

40

68

60

13

13

92

21

13

38

88

62

76

47

100

11

50

82

69

54

25

63

52

50

39
$\%$

$\underline{3 \mathrm{yr}}$

59

Release

5.8

$\underline{\text { Samples }}$

46

17

64

26

93

7.7

28

6.8

29

25

29

57

3.0

28

70

7.1

28

72

33.0

27

64

24.0

25

40

8.0

25

24

21

4.2

24

100

52.2

24

79

8.3

24

24

21

88

61

9.5

21

38

5.0

20

71

11.1

18

89

22.2

18

100

11

76

88

63

43

19

31

52

59

39

16

$\begin{array}{ll}7.0 & 14\end{array}$

$\begin{array}{ll}7.0 & 14\end{array}$

$14.2 \quad 14$

$25.0 \quad 12$
1882

1884

1886

1888

1892

1898

1907

1910

1917

1921

1932

100

22

44

82

69

79

25

63

52

54

46

${ }^{1}$ Indicates percentage of trees with increased mean radial growth 1, 2, 3 years following fire compared to one year prior to fire year.

${ }^{2}$ Indicates the percentage of trees that had a $>50 \%$ growth release within three years of a fire. 
Table 4.3 Radial growth differences 1,2, and 3 years following a fire in which $>2$ trees were scarred at Hwy. 19 using Wilcoxon sign rank test $(\mathrm{p}<0.05)$. Shaded areas indicate significant differences in radial growth following a fire $($ grey $=$ increases; black $=$ decreases $)$. Bolded years indicate mean reconstructed PDSI $<-2.0$ one year prior to fire year.

\begin{tabular}{|c|c|c|c|c|c|c|c|c|}
\hline \multirow[t]{2}{*}{$\begin{array}{l}\text { Hwy. } 19 \\
\text { Fire Year } \\
\end{array}$} & \multicolumn{8}{|c|}{$\begin{array}{l}\text { Percentage of Trees with } \\
\text { Growth Increases }{ }^{1}\end{array}$} \\
\hline & $1 \mathrm{yr}$ & $2 \mathrm{yr}$ & $3 \mathrm{yr}$ & $\underline{1 \mathrm{yr}}$ & $\underline{2 \mathrm{yr}}$ & $\underline{3 \mathrm{yr}}$ & Release $^{\underline{\%}}$ & $\underline{\text { Samples }}$ \\
\hline 1808 & & & & 54.5 & 54.5 & 54.5 & 18.0 & 11 \\
\hline 1818 & & & & 50 & 55 & 35 & 20.0 & 20 \\
\hline 1823 & & & & 52.2 & 65.2 & 52.2 & 13.0 & 23 \\
\hline 1842 & & & & 87.5 & 78.1 & 80.6 & 9.4 & 32 \\
\hline 1844 & & & & 84.4 & 78.1 & 77.4 & 12.5 & 32 \\
\hline 1847 & & & & 15.2 & 21.2 & 31.3 & 3.0 & 33 \\
\hline 1857 & & & & 47.1 & 61.8 & 66.7 & 17.6 & 34 \\
\hline 1878 & & & & 71.1 & 53.5 & 51.2 & 6.7 & 45 \\
\hline 1902 & & & & 69.2 & 82.4 & 82.4 & 21.2 & 52 \\
\hline 1905 & & & & 23.5 & 24 & 28.6 & 15.7 & 51 \\
\hline 1907 & & & & 59.6 & 63.5 & 57.7 & 3.8 & 52 \\
\hline 1912 & & & & 56.6 & 55.8 & 67.3 & 7.5 & 53 \\
\hline 1922 & & & & 45.5 & 50.9 & 56.4 & 3.6 & 55 \\
\hline
\end{tabular}


Table 4.4. Radial growth differences 1,2 , and 3 years following a fire in which $>2$ trees were scarred at Alley Springs using Wilcoxon sign rank test $(\mathrm{p}<0.05)$. Shaded areas indicate significant differences in radial growth following a fire (grey $=$ increases; black $=$ decreases $)$. Bolded years indicate mean reconstructed PDSI $<-2.0$ one year prior to fire year.

\begin{tabular}{cc} 
Alley & Percentage of Trees with \\
Springs & Growth Increases ${ }^{1}$ \\
Fire Year & \\
\hline
\end{tabular}

\begin{tabular}{|c|c|c|c|c|c|c|c|c|}
\hline & $1 \mathrm{yr}$ & $2 \mathrm{yr}$ & $3 \mathrm{yr}$ & $1 \mathrm{yr}$ & $2 \mathrm{yr}$ & $\underline{3 \mathrm{yr}}$ & $\frac{\%}{\text { Release }^{2}}$ & Samples \\
\hline 1753 & & & & 60 & 40 & 46.7 & 18.8 & 16 \\
\hline 1780 & & & & 13.6 & 31.8 & 28.6 & 4.00 & 22 \\
\hline 1784 & & & & 0 & 4.3 & 4.5 & 8.69 & 23 \\
\hline 1793 & & & & 45.8 & 58.3 & 70.8 & 8.33 & 24 \\
\hline 1796 & & & & 50 & 62.5 & 58.3 & 12.5 & 24 \\
\hline 1807 & & & & 50 & 46.4 & 50 & 15.4 & 26 \\
\hline 1819 & & & & 60 & 41.9 & 38.7 & & 30 \\
\hline 1821 & & & & 56.7 & 45.2 & 45.2 & & 30 \\
\hline 1835 & & & & 40 & 48.4 & 35.5 & 3.33 & 30 \\
\hline 1837 & & & & 35.5 & 32.3 & 38.7 & & 30 \\
\hline 1842 & & & & 65.6 & 50 & 59.4 & 25.8 & 31 \\
\hline 1845 & & & & 46.7 & 40 & 36.7 & 10.0 & 30 \\
\hline 1847 & & & & 67.7 & 71 & 76.7 & 3.33 & 30 \\
\hline 1852 & & & & 40.6 & 34.4 & 41.9 & & 31 \\
\hline 1858 & & & & 34.3 & 68.6 & 65.7 & 26.5 & 34 \\
\hline 1861 & & & & 68.6 & 62.9 & 60 & 11.8 & 34 \\
\hline 1865 & & & & 61.1 & 63.9 & 66.7 & 2.90 & 35 \\
\hline 1868 & & & & 61.1 & 63.9 & 62.9 & 13.2 & 36 \\
\hline 1875 & & & & 75 & 77.5 & 72.5 & & 40 \\
\hline 1879 & & & & 25.6 & 23.8 & 12.2 & & 42 \\
\hline 1886 & & & & 51 & 51 & 51 & & 51 \\
\hline 1890 & & & & 39.2 & 37.3 & 37.3 & 7.40 & 53 \\
\hline 1895 & & & & 46.3 & 58.2 & 55.6 & 7.20 & 55 \\
\hline 1907 & & & & 42.6 & 45.9 & 42.6 & 11.7 & 62 \\
\hline 1909 & & & & 52.4 & 53.9 & 38.1 & & 63 \\
\hline 1913 & & & & 35.9 & 34.9 & 44.4 & & 64 \\
\hline 1915 & & & & 81.25 & 69.8 & 70.3 & & 64 \\
\hline
\end{tabular}


Table 4.5. Radial growth differences 1,2 , and 3 years following a fire in which $>2$ trees were scarred at Eck Tract using Wilcoxon sign rank test $(\mathrm{p}<0.05)$. Shaded areas indicate significant differences in trees demonstrating increases or decreases in growth following a fire (grey = increases; black $=$ decreases). Bolded years indicate mean reconstructed PDSI $<-2.0$ one year prior to fire year.

\begin{tabular}{|c|c|c|c|c|c|c|c|c|}
\hline \multirow[t]{2}{*}{$\begin{array}{l}\text { Eck Tract } \\
\text { Fire Year } \\
\end{array}$} & \multicolumn{8}{|c|}{ Percentage of Trees with } \\
\hline & $1 \mathrm{yr}$ & $2 \mathrm{yr}$ & $3 \mathrm{yr}$ & $\underline{1 \mathrm{yr}}$ & $2 \mathrm{yr}$ & $\underline{3 \mathrm{yr}}$ & $\stackrel{\frac{\%}{\text { Release }^{2}}}{{ }^{2}}$ & $\underline{\text { Samples }}$ \\
\hline 1822 & & & & 28 & 28 & 32 & & 25 \\
\hline 1828 & & & & 26.4 & 30.3 & 38.2 & & 34 \\
\hline 1830 & & & & 85.3 & 76.5 & 67.6 & & 34 \\
\hline 1832 & & & & 20 & 42.9 & 45.7 & & 35 \\
\hline 1837 & & & & 37.8 & 24.3 & 29.7 & 2.7 & 37 \\
\hline 1866 & & & & 16.7 & 18.8 & 12.5 & 8.3 & 48 \\
\hline 1869 & & & & 62.5 & 68.8 & 77.1 & 12.5 & 48 \\
\hline 1871 & & & & 64.6 & 72.9 & 62.5 & 12.5 & 48 \\
\hline 1879 & & & & 31.3 & 45.8 & 27.1 & 20.8 & 48 \\
\hline 1898 & & & & 51.9 & 22.2 & 20.4 & 5.6 & 54 \\
\hline 1900 & & & & 70.9 & 60 & 78.2 & 21.8 & 55 \\
\hline 1902 & & & & 92.7 & 96.4 & 98.2 & 38.2 & 55 \\
\hline 1907 & & & & 14.5 & 32.7 & 43.6 & 9.1 & 55 \\
\hline 1934 & & & & 34.4 & 63.9 & 60.7 & 11.5 & 61 \\
\hline
\end{tabular}

\section{Release Events and Fire}

Associations between fire year and proportion of releases were detected at most sites (Fig. 4.3). I also found that the percentage of trees exhibiting a release ( $>50 \%$ increase in median radial growth sustained for at least 10 years) within three years of a fire was closely tied to significant differences in short-term changes in radial growth of $P$. echinata and $Q$. alba at each site (Tables 4.2-4.5). 


\section{Drought, Fire, and Radial Growth}

While mean radial growth increased following fires across the sites, there were notable declines in radial growth following fire years. Drought conditions have the potential of influencing radial growth during and subsequent to the drought. There were fire years in which reconstructed mean PDSI was <-2.0 one year prior to a fire year at all sites (Tables 4.2-4.5). In all but one fire year (Mill Hollow, 1836, Table 4.2) trees showed increased mean radial growth 13 years following the fire.

Decreases in mean radial growth following a fire year ( $>2$ scarred trees) occurred across all sites (Tables 4.2-4.5) even while moisture conditions during these fire years were near normal $(-1.0$ to +1.0 mean reconstructed PDSI) (Figs. 4.4-4.7). Release events were rare within three years of these fire years in which $<20 \%$ of trees exhibited a release.

\section{Establishment Patterns of $P$. echinata and Q. alba}

Establishment of both $P$. echinata and $Q$. alba occurred during or subsequent to at least one disturbance type (fire, release, fire/release) (Figs. 4.4-4.7). The greatest proportion of establishment occurred during temporal periods when there was a lower frequency of disturbances or an absence of disturbances. This was emphasized during the early 1900's at Mill Hollow (Fig. 4.4), 1875-1890 at Alley Springs (Fig. 4.6), and 1820-1840 at Eck Tract (Fig. 4.7). Mill Hollow appeared to be a distinctive site when compared to the other three sites. Based on actual and estimated pith dates for trees at Mill Hollow there was little to no establishment during the $19^{\text {th }}$ century. 


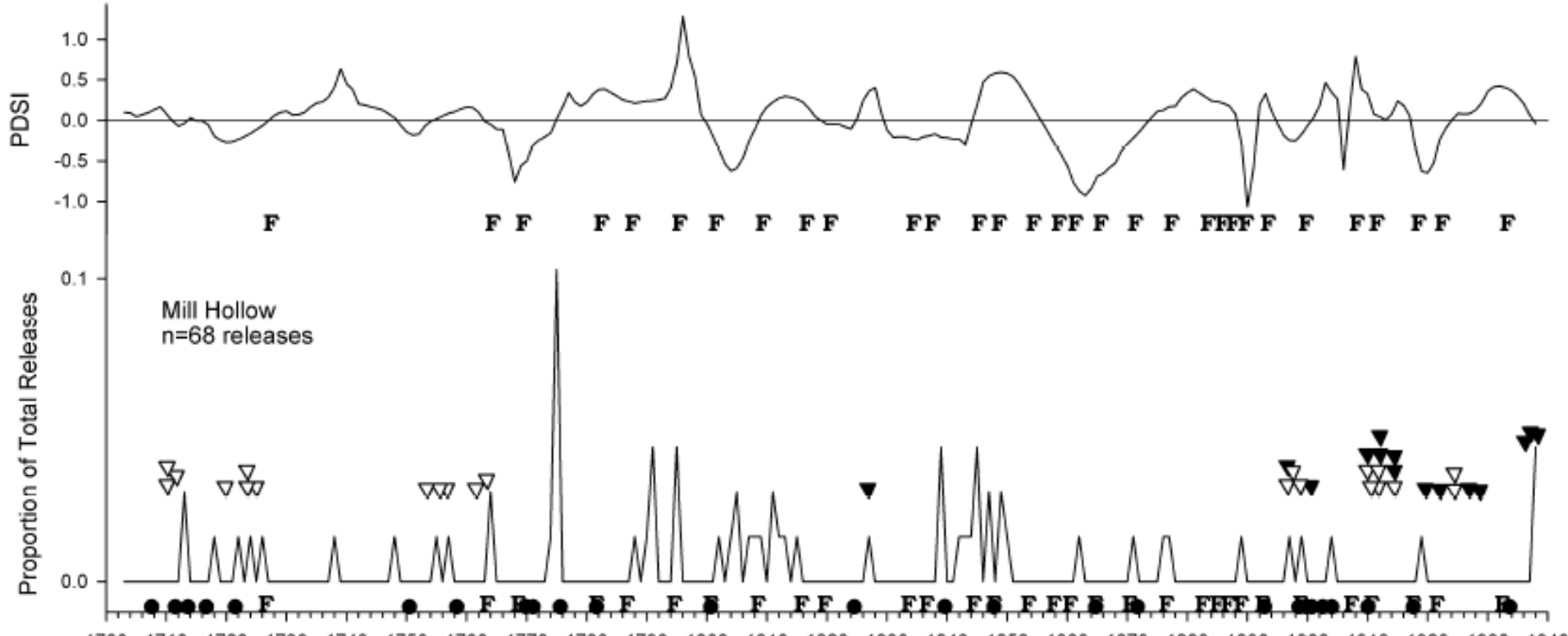

$\begin{array}{llllllllllllllllllllllllll}1700 & 1710 & 1720 & 1730 & 1740 & 1750 & 1760 & 1770 & 1780 & 1790 & 1800 & 1810 & 1820 & 1830 & 1840 & 1850 & 1860 & 1870 & 1880 & 1890 & 1900 & 1910 & 1920 & 1930 & 1940\end{array}$

Year

Figure 4.4. Disturbance events (fire, drought, proportion of releases) at Mill Hollow 1700-1940. Top graph indicates a 3 yr spline of mean reconstructed PDSI. Bottom graph indicates proportion of releases, fire years, and establishment years of P. echinata and Q. alba. Letter (F) indicates fire year $>2$ trees scarred. Closed circles indicate a fire year with one scarred sample. Open triangles indicate $P$. echinata

establishment; closed triangles indicate $Q$. alba establishment. Number of releases is a composite of trees that exhibited a change in growth $>50 \%$ that was sustained for at least 10 years. 


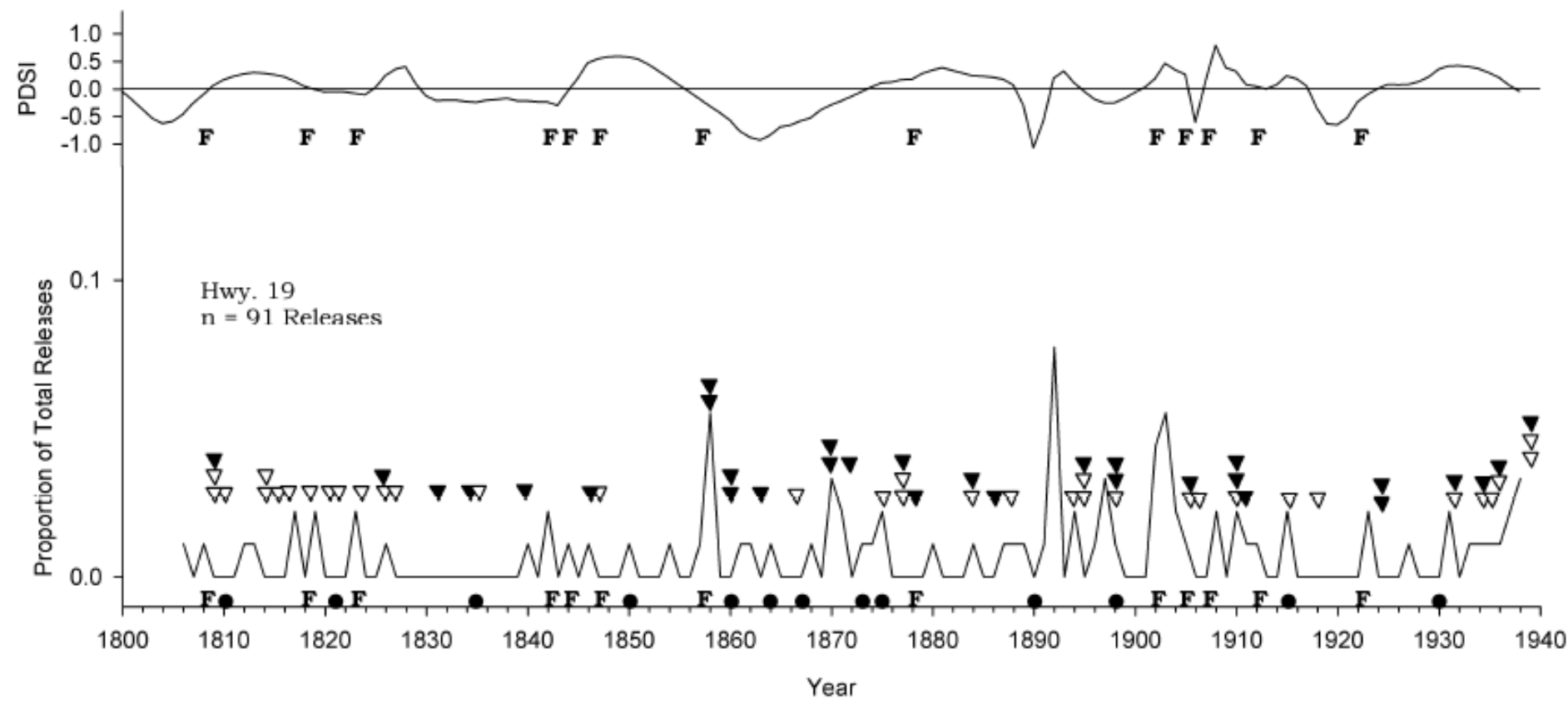

Figure 4.5. Disturbance events (fire, drought, proportion of releases) at Hwy. 19 1800-1940. Top graph indicates a 3 yr spline of mean reconstructed PDSI. Bottom graph indicates proportion of releases, fire years, and establishment years of P. echinata and Q. alba. Letter (F) indicates fire year $>2$ trees scarred. Closed circles indicate a fire year with one scarred sample. Open triangles indicate $P$. echinata establishment; closed triangles indicate $Q$. alba establishment. Number of releases is a composite of trees that exhibited a change in growth $>50 \%$ that was sustained for at least 10 years. 


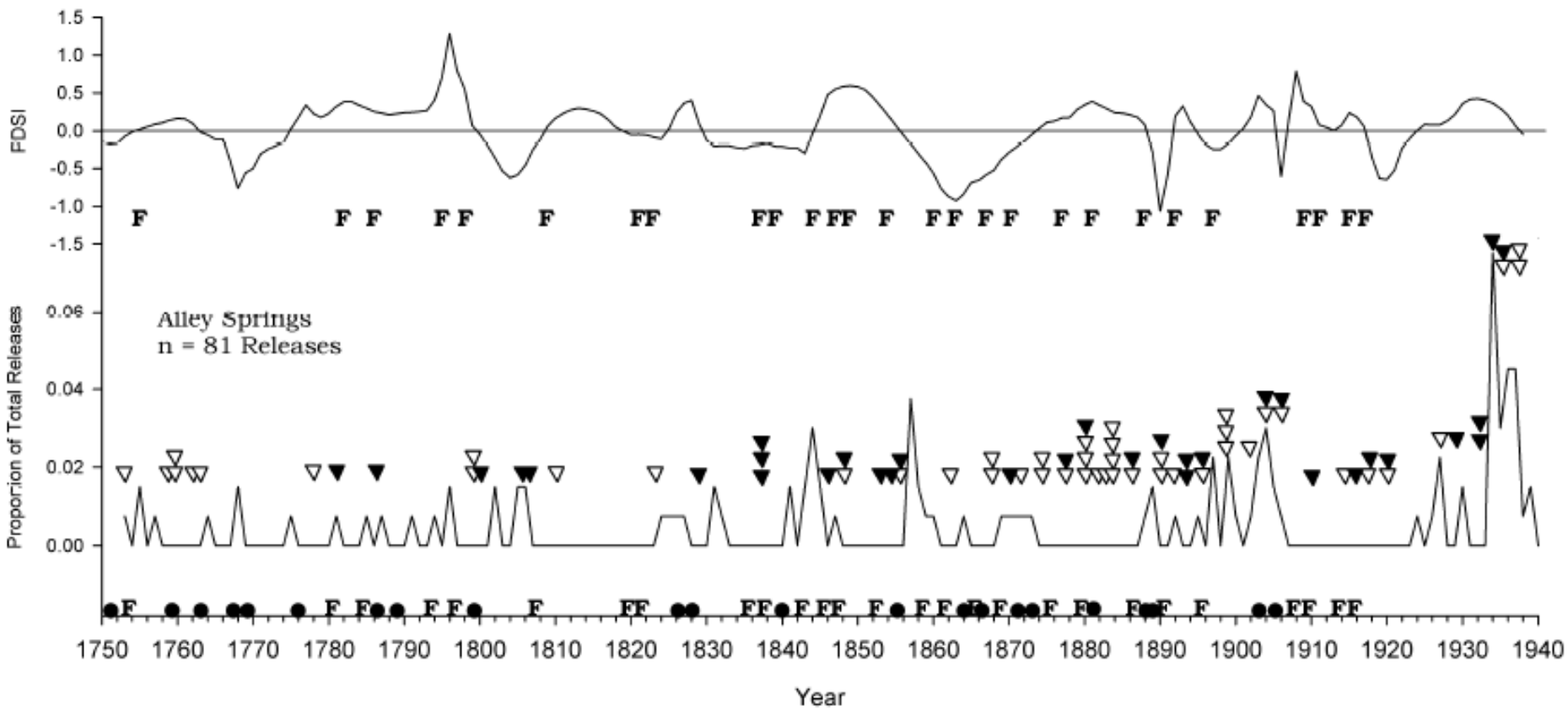

Figure 4.6. Disturbance events (fire, drought, proportion of releases) at Alley Springs 1750-1940. Top graph indicates a 3 yr spline of mean reconstructed PDSI. Bottom graph indicates proportion of releases, fire years, and establishment years of P. echinata and $Q$. alba. Letter (F) indicates fire year $>2$ trees scarred. Closed circles indicate a fire year with one scarred sample. Open triangles indicate $P$. echinata establishment; closed triangles indicate $Q$. alba establishment. Number of releases is a composite of trees that exhibited a change in growth $>50 \%$ that was sustained for at least 10 years. 


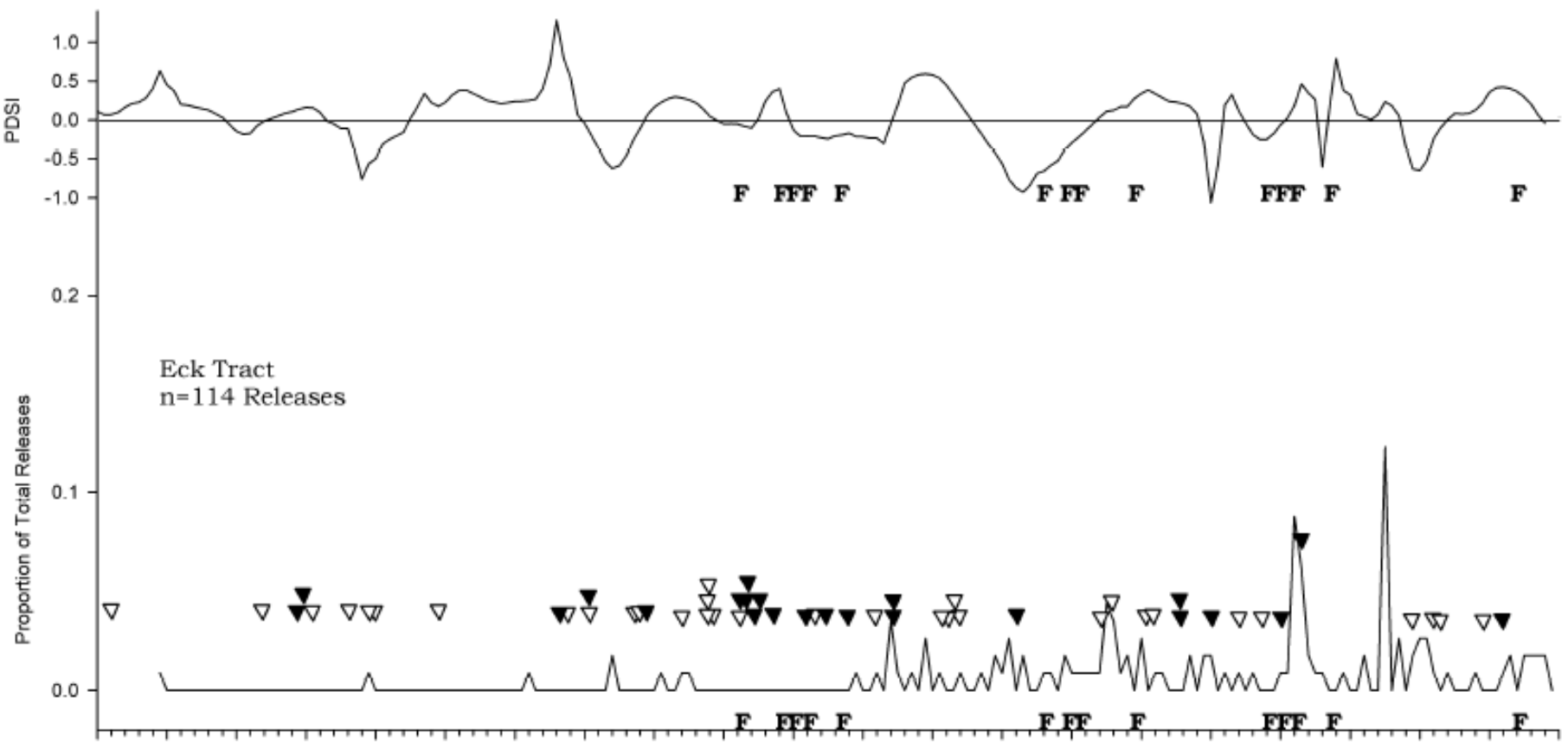

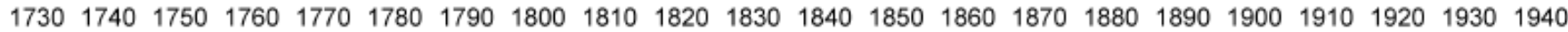

Year

Figure 4.7. Disturbance events (fire, drought, proportion of releases) at Eck Tract 1730-1940. Top graph indicates a 3 yr spline of mean reconstructed PDSI. Bottom graph indicates proportion of releases, fire years, and establishment years of P. echinata and Q. alba. Letter (F) indicates fire year $>2$ trees scarred. Closed circles indicate a fire year with one scarred sample. Open triangles indicate $P$. echinata establishment; closed triangles indicate $Q$. alba establishment. Number of releases is a composite of trees that exhibited a change in growth $>50 \%$ that was sustained for at least 10 years. 


\section{DISCUSSION}

Disturbance during the past three centuries of analysis at the four study sites suggest establishment and radial growth of $P$. echinata and $Q$. alba were tied to individual disturbances and combinations of disturbances. The frequencies of releases indicated in this study are similar to that found by Rentch et al. (2003) at multiple oak-dominated sites in the central hardwoods region. They found a median return interval of 3 years and a combination of varying gap sizes promoted historic oak dominance. The mean return intervals for releases in this study (2-6 years) also likely indicates a frequent disturbance regime that allowed for the persistence of P. echinata and $Q$. alba in the canopy of these forests. Stambaugh and Muzika (2004) demonstrated that $P$. echinata regeneration is directly related to the size of gap opening in Missouri Ozark oak-pine forests. They found an overall mean gap size at their pine sites of $283.6 \mathrm{~m}^{2}$ (range $15 \mathrm{~m}^{2}-$ $1583 \mathrm{~m}^{2}$ ). This high variability in contemporary gap sizes possibly indicates that historically pine and white oak experienced a range of frequent small and large gap openings to attain the overstory canopy.

My independent analysis of fire regimes at these four sites are similar to those reported by Guyette et al. (2003) for Alley Springs, and Guyette and Cutter (1997) at Mill Hollow. At these four sites, there was little evidence that prevailing drought conditions were correlated with fire. Unlike western forests where fires appear to be directly related to prevailing drought conditions (DeRose and Long 2012), fires in eastern deciduous forests have been largely tied to anthropogenic ignition (Guyette et al. 2002; Sutherland 1997; Wade et al. 2000) due to the lack of correlation between drought conditions and fire year.

There appears to be some evidence for an association between fire and release. Two lines of evidence, superposed epoch analysis and mean radial growth subsequent to fires, suggests that canopy disturbance may have provided fine and coarse fuels for historic fires and fires may have supported increases in radial growth with the release of some trees after fires. Logging activity during the late $19^{\text {th }}$ and early $20^{\text {th }}$ century likely increased slash that was subsequently burned at 
the study sites. Natural disturbances, such as wind, may increase surface fuels that increased the opportunity for fire. At all sites, release events and fires at the turn of the $20^{\text {th }}$ century equated to pulses of P. echinata and Q. alba establishment. Establishment occurred during periods in which there was no disturbance or during a period of declining disturbance frequency. A large pulse of establishment occurred at Alley Springs during the 1870's and 1880's following a period of releases and fires that nearly occurred on an annual basis. The same series of events occurred at Mill Hollow during the 1910's.

The second line of evidence suggesting a relationship between fire and release events is the subsequent radial growth of trees following a fire. Both P. echinata and Q. alba exhibited short-term (up to 3 years) increases in mean radial growth following fires, but it should also be noted that some trees during those time periods also had declines in mean radial growth. Nesbitt (2001) in southern British Columbia found that major releases were more common than major suppressions following historic fire. Py et al. (2006) found that growth releases were detected following fire in singleaf pinyon pine (P. monophylla) forests in Nevada. Aldrich et al. (2010) in a pine-oak forest in central Virginia suggested the maintenance of the xeric forests in this region was due to frequent fires and implied that growth releases documented in the late 1800's were most likely due to fires. Lageard et al. (2000) in Pinus sylvestris stands in England found that infrequent historic low to moderate intensity surface fires promoted radial growth. Increases in radial growth following fires at my sites may have been a short-term response to reduced understory competition due to the removal of saplings and herbaceous vegetation.

Most often, trees in this study exhibited increases in growth with $<20 \%$ of trees demonstrating a growth release. Low to moderate intensity fires at these study sites may have removed portions of the mid-story $(\mathrm{dbh} 4 \mathrm{~cm}-11 \mathrm{~cm})$ that promoted releases of trees from competition following a fire. In a study on the effects of high frequency, low to moderate intensity prescribed fire at Chilton Creek (Carter Co. Missouri), Hartman and Huermann (2004) found a $28 \%$ decline in mid-story stem density and $47 \%$ decline in understory $(<4 \mathrm{~cm} \mathrm{dbh})$ stem 
density. Elliott and Vose (2005) analyzed the effect of two summer prescribed fires in southern Appalachian P. echinata stands and found that there was little $P$. echinata regeneration following the fires with prolific hardwood sprouting. In the mixed-species forests at my sites, frequent surface fires likely removed regeneration. However, the reduction in competition was likely short-term with abundant oak sprouting following the fire. This may explain the short-term increases in radial growth with few trees demonstrating long-term releases ( $>10$ years).

While it is difficult to infer that the effects of a few contemporary prescribed fires are similar to centuries of historic fire events, there is some precedence for understanding historic fire. Guyette and Dey (1997) determined that a century of historic burning at high fire frequencies (MFI=3.1) likely resulted in the removal of pine regeneration. The results of this study show that $P$. echinata and $Q$. alba establishment was consistent even with low mean fire intervals. This suggests that most fires that were burning at these sites were likely localized, low intensity surface fires that may have promoted increases in radial growth of approximately $50 \%$ of trees and, in some cases, growth releases of $<20 \%$ of trees. Modelling of historic litter accumulation in oak-pine forests of the Missouri Ozarks suggested that if nearly $100 \%$ litter was consumed by a fire, within two years approximately $50 \%$ of the previous litter load had accumulated (Stambaugh et al. 2006). Stambaugh et al. (2007) modeled fire intervals that would promote $P$. echinata regeneration in Missouri Ozark forests and found that short intervals (1-4 years) promoted $P$. echinata regeneration but that longer intervals (8-15 years) were required for pine survival. My study demonstrated that historic fire intervals at the four sites were short (2-6 years) that would suggest strong potential for P. echinata regeneration with low survival.

However, establishment of P. echinata and Q. alba appeared to occur during temporal periods of low disturbance frequencies that sustained both species in overall high frequency disturbance intervals.

Growth reductions during the three years following a fire and lack of detected releases potentially indicate severe fire years. Of the 20 fire years that indicated at least two years of 
reduced radial growth (Tables 4.2-4.5), 45\% occurred the year following below normal reconstructed PDSI $(<0)$. These fire years were related to subsequent releases and establishment of trees. At Alley Springs, the 1852 fire resulted in 35\% (n=6) of P. echinata samples being scarred. Following this fire, trees established and release events occurred during the late 1850's (Fig. 4.6). The combination of events subsequent to 1852 suggests a severe disturbance or series of severe disturbances. Guyette and Kabrick (2003) attributed radial growth reductions to severe disturbance events at the Missouri Ozark Forest Ecosystem Project as declines in radial growth were associated with below normal Palmer Hydrologic Drought Index. These severe disturbance years likely resulted in crown scorch that effectively reduced radial growth following a severe fire year. The subsequent establishment of trees and increased mean radial growth possibly indicate reduced competition due to a combination of lower stem density and gap formation. A similar pattern of reduced radial growth and subsequent establishment occurred at Eck Tract following the 1822 fire, the 1884 fire at Mill Hollow, and the 1847 fire at Hwy. 19.

This study demonstrates that the combination of high frequency disturbances over multiple centuries at four sites in the Missouri Ozarks promoted the persistence of P. echinata and $Q$. alba prior to 1900 . Based on radial growth changes, fire disturbance was largely low to moderate intensity with infrequent severe fire years. Growth releases were generally associated with fire years. I caution the use of superposed epoch analysis to draw specific conclusions concerning associations between disturbance events. My results suggested there was little association between fire and drought over multiple centuries of high frequency fire. However, when analyzing specific fire years in which $>25 \%$ of samples were scarred, there appeared to be some indication that drought preceded severe fire years indicated by radial growth reductions and subsequent releases and establishment of trees. 


\title{
CHAPTER 5
}

\section{ASSESSMENT OF DISTURBANCE, TOPOGRAPHY, AND CLIMATE ON TREE GROWTH}

\begin{abstract}
Drought is a disturbance that has the potential of mediating radial growth of trees that grow at moisture limiting sites. Following droughts when moisture is less of a limiting factor, trees can increase their radial growth that may be perceived as a lower magnitude growth release. This chapter considers the correlation of climate variables and radial growth, changes in radial growth following droughts, and the combination of drought and growth releases (a proxy for canopy disturbance) at a location with contrasting aspects. Results suggest that droughts significantly affected radial growth of both species. Extreme and severe droughts resulted in most trees having reduced radial growth, but this was not consistently found among all droughts. Growth releases appeared to mitigate the effect of drought on radial growth of both species.
\end{abstract}




\section{INTRODUCTION}

Eastern deciduous forests are prone to various disturbance regimes that function in shaping the forest development and successional trajectory of the forest. Disturbance on forests usually results in tree mortality or injury while providing opportunities for individuals to establish or replace those that have been removed from the forest (Oliver and Larson 1996). In eastern deciduous forests, gap dynamics is the most important disturbance factor that affects forest structure (Runkle 1982). Variations in the size of gap openings can result in heterogeneity of light levels, temperature, and soil moisture gradients that affect survivors within and adjacent to gap openings. In closed canopy forests, light levels at the forest floor can be $<10 \%$ relative to full sunlight (Canham et al. 1990). Therefore, light becomes an important limiting factor for regeneration in forest stands. Gap openings equate to increased resources thereby changing competitive interactions, particularly important for increased light availability for understory trees.

Dendrochronology can effectively document different long-term forest disturbance dynamics including fire (Guyette \& Cutter 1997; Guyette et al. 1995), ice storms (Lafon and Speer 2002), insect abundance and outbreak (Muzika and Guyette 2004; Muzika and Liebhold 1999), and changes in species composition over time (Abrams et al. 1997; Henry and Swan 1974). Analyzing long-term changes in growth can be useful in inferring past canopy disturbance events (Nowacki and Abrams 1997; Rentch 2001) by identifying abrupt increases in growth. This approach is effective in closed-canopy forests where long-term radial growth patterns reflect resource competition. However, even in closed-canopy forests at the edge of a species distribution, climate possibly has a greater effect on radial growth (Fritts 1976).

In Missouri, shortleaf pine (Pinus echinata, Mill) and white oak (Quercus alba, L.) are near the western edge of their distribution, where both competition and climate affect radial growth. Pinus echinata is relatively drought tolerant and often restricted to exposed upper slope and ridge positions in the Missouri Ozarks where thin soils limit soil moisture (Fletcher and 
McDermott 1957). However, pure stands of P. echinata in the Missouri Ozarks were historically rare. Quercus alba has a wider ecological amplitude but is also relatively drought tolerant within its distribution (Abrams 1990). It can be found in mixed-species stands in upper slope and ridge positions with P. echinata in the Missouri Ozarks.

Previous research on climate and growth of these two species in Missouri indicated significant correlations with climate variables such as July precipitation (Guyette and Rabeni 1995), Palmer Drought Severity Index (PDSI), June precipitation, and July temperature (Stambaugh and Guyette 2004), confirming the importance of drought or moisture limitations on radial growth of P. echinata and $Q$. alba in Missouri. Other studies across eastern deciduous forests also indicate that climate influences radial growth of $Q$. alba in closed canopy forests (Rubino and McCarthy 2000; Speer et al. 2009) and P. echinata (Grissino-Mayer and Butler 1993).

Differentiating the effect of climate from competition on radial growth has the potential of complicating historic stand reconstruction. Pederson et al. (2008) analyzed historic longleaf pine (P. palustris, Mill.) stand dynamics in Georgia and found that increases in radial growth associated with canopy disturbance (growth releases) were not related to climate. Nowacki and Abrams (1997) developed a way to assess long-term changes in average radial growth that minimizes the short-term radial growth variability due to climate. Rentch et al. (2002) determined that the percent growth change approach (Nowacki and Abrams 1997) identified growth releases with a 1-3 year lag in most species to a known stand thinning event. However, for species at their distributional limits, radial growth following droughts may show a lower magnitude growth release that is not necessarily due to a canopy disturbance.

The Current River watershed in the Missouri Ozarks is known for its rough topography and steep slopes and local relief exceeding 80 meters. Contrasting aspects, particularly south, west (exposed) and north, east (protected) may exhibit differences in canopy disturbance and small-scale climate that is reflected in growth of P. echinata and Q. alba. One of the study sites 
in this project has distinctive aspects in which $Q$. alba is a canopy co-dominant on the protected aspect while $P$. echinata and $Q$. alba are canopy co-dominants on the exposed aspect of the same ridge. Trees in the Missouri Ozarks are exposed to various wind related disturbance events such as microbursts and downdrafts associated with thunderstorms or derechos. Windflow patterns over a heterogeneous topographic profile can result in discrepancies in canopy damage, tree snapping, or windthrow (Quine and Gardiner 2007) on the windward versus leeward sides of the hill due to turbulence development (Finnegan 2007). Canopy disturbance on opposing slopes may demonstrate differential canopy disturbance regimes due to the effect of natural wind disturbances.

This research occurred at one location that consists of opposing slopes. This study will address the following three objectives:

1) assess canopy disturbance dynamics of $P$. echinata and $Q$. alba in Mill Hollow (west facing slope) and Current River Natural Area (CRNA) (north facing slope);

2) determine the effect of climate variables on radial growth; and

3) determine the effect of drought on radial growth. 


\section{METHODS}

\section{Study Site}

The CRNA is the oldest designated natural area in the state of Missouri, having been established in 1955 . This area was originally identified for its late-successional $Q$. alba trees that have been determined to be 300-400 years old. Tree-ring series for some of these trees are available via the International Tree-Ring Database (ITDRB;

www.ncdc.noaa.gov/paleo/treering.html). CRNA was originally a 4 ha tract that was expanded to include $103 \mathrm{ha}$. This area is located on a protected aspect and is considered a dry-mesic chert forest natural community (Nelson 2005). CRNA is privately owned by the L-A-D Foundation (St. Louis, MO). Canopy dominant and co-dominant species in CRNA include Q. alba, black oak (Quercus velutina, Lam.), and northern red oak (Quercus rubra, L.).

Mill Hollow is located on the same ridge line as CRNA. Elevations range from $335 \mathrm{~m}$ at the top to $220 \mathrm{~m}$ along the lower slope positions. Mill Hollow is located on a south and west aspect. This site is approximately 70 ha in size and is also owned by the L-A-D Foundation (St. Louis, MO). Canopy dominant and co-dominant tree species in Mill Hollow include scarlet oak (Quercus coccinea, Muenchh.), Q. alba, and P. echinata at upper slope positions. Both sites are located approximately $37^{\circ} 24^{\prime} \mathrm{N}, 91^{\circ} 26^{\prime} \mathrm{W}$.

For this study, I collected increment cores of $P$. echinata and $Q$. alba at breast height $(1.37 \mathrm{~m})$ in Mill Hollow. In addition, remnant cross-sections of $P$. echinata were collected from stumps or snags. The Missouri Tree-Ring Laboratory (MTRL) previously collected remnant $P$. echinata cross-sections and some of these cross-sections were used to compliment my collections at Mill Hollow. Previously collected increment cores of $Q$. alba from CRNA had been crossdated and raw ring-width data were downloaded from the International Tree-Ring Database (ITDRB).

Increment cores and cross-sections were sanded with progressively finer sandpaper (up to 1200 grit) in order to differentiate narrow tree-rings (Stokes and Smiley 1996). Tree-ring width 
measurements to the nearest $0.01 \mathrm{~mm}$ for all samples were taken using a Velmex measuring stage (Velmex, Inc., Bloomfield, NY) and binocular microscope. Standard visual cross dating procedures (Yamaguchi 1991) and the COFECHA quality control program (Holmes 1983, Grissino-Mayer 2001) were used to cross-date and verify the appropriate calendar year for each tree-ring.

\section{Tree-ring Series Standardization and Climate Correlations}

The program ARSTAN (Cook 1985, 1986) was used to calculate descriptive statistics and develop standardized series of the ring-width data from both sites and for both species. ARSTAN has several built-in standardization features to remove noise and enhance the timeseries signal of choice, e.g. removing the age-related growth trend. For instance, ARSTAN fits a curve to each tree-ring series, divides the ring-width by the curve value for each year to calculate a standardized series for each ring-width series. A stand-level standardized chronology is calculated based on the average of the standardized series at the site. For most trees, the tree-ring series shows a declining trend (negative exponential) as the age of the tree increases which can be removed with the curve-fitting approach. The resulting standardized chronologies are dimensionless and indicate annual above average growth $(>1)$ and below average growth $(<1)$.

Several descriptive statistics are generated using ARSTAN to explain the growth rates and patterns of trees within their environment. Sensitivity is a measure of the variability between adjacent ring-widths and describes the amount of high-frequency variance in tree-rings. Values range from zero (no difference between adjacent tree-ring width) to 2 (a zero value next to a nonzero value). Higher values indicate more high-frequency variance and the limiting effect of temperature and precipitation on growth (Fritts 1976). A second statistic generated by analyzing tree-ring series is autocorrelation. Autocorrelation is a measure of the association of previous conditions (lag) to current conditions. Higher values indicate a stronger association with previous states or conditions (Fritts 1976). 
I first used a detrending approach to remove age-related growth by applying a negative exponential curve to each tree-ring series. If an exponential curve did not fit the series trend, a linear function was applied to the series. The resulting signals in the tree-ring index were expected to be radial growth due to stand disturbance and climate.

I constructed species ARSTAN chronologies by site (Mill Hollow P. echinata, Mill Hollow $Q$. alba, CRNA $Q . a l b a$ ) and ring-width indices for each sample by site. The ARSTAN chronology is built based on the total detrended series for species ring-width series. The ARSTAN chronology controls or accounts for the autocorrelation component in the time series (Cook 1985).

The ARSTAN chronology was used to assess the correlation of growth and three monthly climate variables (mean PDSI, mean temperature, mean precipitation) during the time period 1895-1981 using divisional climate data (Division 5, Missouri) from the National Climatic Data Center (NCDC). I analyzed the correlations between indices and overall mean monthly climate data beginning in July of the previous year through August of the growing year. I calculated

overall mean monthly correlations between climate variables and growth at $\mathrm{p}<0.05$ using Pearson product moment correlation to determine the role of climate at a species level given the close proximity of these two sites.

\section{Drought and Growth Analysis}

I tested the significance of droughts on growth for each species between 1700 and 1981 using methods similar to Rubino and McCarthy (2000) to test the effect of individual drought events on growth during the drought and subsequent to the drought. Specifically, I looked at severe (-3.0 to -3.9$)$ and extreme $(<-4.0)$ droughts (Palmer 1965) during the time period using reconstructed Palmer Drought Severity Index (PDSI) for 1700-1894 and Division 5 (Missouri) PDSI for 1895-1981. Palmer Drought Severity Index (Palmer 1965) measures the duration and intensity of drought based on temperature and rainfall information. The PDSI is a dimensionless, 
standardized time series with a mean of 0 and negative values indicating below normal (dry) and positive values indicating above normal (wet) conditions.

I identified severe and extreme droughts using divisional mean annual PDSI for years 1895 to 1981 (National Climatic Data Center), and mean reconstructed PDSI from station 201 and 210 in the Missouri Ozarks for years 1700 to 1894 . I conducted two different analyses based on identified droughts and ring-width indices for $P$. echinata and $Q$. alba. To analyze the effect of drought on growth, I investigated the mean ring-width indices one year prior to drought with mean ring-width indices during the year of drought using paired t-tests at $p<0.05$. Based on extreme $(<-4.0$ PDSI) drought years that showed a significant growth decline compared to the year prior to a drought, I tested the 5-year mean ring-width index prior to the drought year to the 5 year mean ring-width index following the drought using paired t-tests to determine if lower growth rates were sustained for longer than the year of extreme drought.

\section{Canopy disturbance}

Growth release methods defined by Nowacki and Abrams (1997) are built into the ARSTAN interface to assess stand dynamics using tree-ring data. I used a $25 \%$ increase threshold by comparing 15 year moving means of radial growth to define a growth release associated with a canopy disturbance. CRNA and Mill Hollow trees were independently assessed for growth releases by year. 


\section{RESULTS}

\section{Descriptive Statistics}

Current River Natural Area (n=33), Mill Hollow P. echinata $(\mathrm{n}=40)$, and Mill Hollow $Q$. alba $(\mathrm{n}=40)$ were analyzed for climate and growth comparisons. Series length was shorter for trees at Mill Hollow than CRNA. However, mean ring-widths were greater for trees in Mill Hollow than CRNA which may be a reflection of juvenile growth given the shorter mean length of tree-ring series. While mean autocorrelation values were high within species, mean sensitivity values were within the range of species in the eastern deciduous forest (Table 5.1).

Table 5.1. Descriptive standardization statistics of $Q$. alba and P. echinata at CRNA and Mill Hollow, respectively. Values in parentheses indicate range.

\begin{tabular}{llll}
\hline \hline & $\begin{array}{l}\text { CRNA } \\
\text { Q. alba }\end{array}$ & $\begin{array}{l}\text { Mill Hollow } \\
\text { P. echinata }\end{array}$ & $\begin{array}{l}\text { Mill Hollow } \\
\text { Q. alba }\end{array}$ \\
Statistics & & & \\
\hline Mean length of series (years) & $239(132-351)$ & $108(44-235)$ & $69(43-109)$ \\
Mean ring width (mm) & 1.052 & 1.484 & 1.782 \\
Mean index & 1.000 & 1.001 & 1.001 \\
SD of ring widths (mm) & 0.322 & 0.712 & 0.545 \\
SD of indices & 0.353 & 0.425 & 0.282 \\
& & & 0.628 \\
Ring-width autocorrelation & 0.785 & 0.666 & 0.500 \\
Indices autocorrelation & 0.623 & 0.576 & \\
& & & 0.202 \\
Mean sensitivity of ring widths & 0.215 & 0.304 & 0.198 \\
Mean sensitivity of indices & 0.214 & 0.301 & \\
\hline
\end{tabular}

\section{Climate Variable Correlation Analysis}

Mean monthly PDSI, temperature, and precipitation with ARSTAN chronologies were analyzed for the time period 1895 to 1981 . I limited analysis to 1981 based on the end year of the CRNA series and to compare climate correlations among species and location. 
All significant correlations between ring-width index and monthly PDSI were positive. Annual ring-width index (RWI) values and monthly PDSI were significantly positive for all months of the growing year for CRNA $Q$. alba and Mill Hollow P. echinata (Table 5.2). Mean monthly correlation coefficients for RWI and growing season monthly PDSI were higher for CRNA $Q$. alba $(\overline{\mathrm{x}}=0.444)$ than Mill Hollow P. echinata $(\overline{\mathrm{x}}=0.241)$ and Mill Hollow $Q$. alba $(\overline{\mathrm{x}}$ $=0.368)$. For both species and sites, PDSI correlations were significant in all months of the growing year. Trees in Mill Hollow had significant positive correlations between RWI and monthly PDSI for August, September, and December of the previous year but not at CRNA (Table 5.2).

As expected, overall mean monthly temperature was inversely related to growth. The exception was a positive correlation during January for Mill Hollow P. echinata. Among species and sites, the significant correlations occurred during the growing year months of June, July, and August. The strongest correlations between temperature and growth were in Mill Hollow Q. alba (Table 5.2).

Correlations of precipitation with growth were strongest for $Q$. alba at CRNA and Mill Hollow. There were no significant correlations between precipitation and growth for P. echinata during the growing year and previous year. The strongest significant correlations occurred during June of the growing year for $Q$. alba at both sites while significant correlations were also detected in February and April for CRNA Q. alba.

\section{Drought and Growth Analysis}

For the time period 1700 to 1981, there were six years of extreme drought (PDSI < -4.0): 1736, 1772, 1801, 1834, 1874, and 1954 and nine years of severe drought (PDSI -3.0 to -3.9) $1708,1737,1767,1773,1800,1839,1856,1953$, and 1955 . The years 1736 and 1954 had the lowest PDSI values $(<-5.0)$. Based on series length, I was limited to analyzing growth and drought in Mill Hollow Q. alba to the years 1952-1955 (Fig. 5.1). 
Table 5.2. Correlation analysis of ring-width index values with current year monthly (January - August) and previous year monthly (July - December) Palmer Drought Severity Index, temperature, and precipitation for years 1895 to 1981. Correlation coefficients are only presented for significant correlations $(\mathrm{p}<0.05)$. Values indicate correlation coefficients based on Pearson product moment correlation analysis.

\begin{tabular}{|c|c|c|c|c|c|c|c|c|c|}
\hline & \multicolumn{3}{|c|}{ CRNA Q. alba } & \multicolumn{3}{|c|}{ Mill Hollow P. echinata } & \multicolumn{3}{|c|}{ Mill Hollow Q. alba } \\
\hline & PDSI & Temp & Precip & PDSI & Temp & Precip & PDSI & Temp & Precip \\
\hline \multicolumn{10}{|c|}{$\begin{array}{c}\text { Growing } \\
\text { Year }\end{array}$} \\
\hline Aug & 0.485 & -0.279 & & 0.214 & & & 0.421 & & \\
\hline Jul & 0.543 & -0.232 & & 0.26 & -0.254 & & 0.466 & -0.354 & \\
\hline Jun & 0.524 & -0.395 & 0.533 & 0.215 & -0.255 & & 0.443 & -0.445 & 0.314 \\
\hline May & 0.44 & & & 0.214 & & & 0.35 & & \\
\hline Apr & 0.417 & & 0.282 & 0.264 & & & 0.332 & & \\
\hline Mar & 0.419 & & & 0.237 & & & 0.342 & & \\
\hline Feb & 0.422 & & 0.291 & 0.265 & & & 0.331 & & \\
\hline Jan & 0.302 & & & 0.256 & 0.237 & & 0.262 & & \\
\hline \multicolumn{10}{|c|}{$\begin{array}{c}\text { Previous } \\
\text { Year }\end{array}$} \\
\hline Dec & & & & 0.213 & & & 0.219 & & \\
\hline \multicolumn{10}{|l|}{ Nov } \\
\hline \multicolumn{10}{|l|}{ Oct } \\
\hline Sep & & & & 0.197 & & & 0.234 & & \\
\hline Aug & & & & & & & 0.244 & & 0.227 \\
\hline Jul & & & & & & & & & \\
\hline
\end{tabular}


Table 5.3. Analysis of differences in growth one year prior to growth during the year of extreme (PDSI < -4.0) and severe (PDSI < -3.0 to $-3.9)$ using paired t-tests. Asterisks indicate significant differences in growth at $\mathrm{p}<0.05$. Grey shaded years indicate positive growth during year of drought compared to the previous year.

\begin{tabular}{|c|c|c|c|c|c|c|c|c|c|c|c|}
\hline CRNA Q. alba & & & & & & $\begin{array}{l}\text { Mil } \\
\text { P.e } \\
\end{array}$ & $\begin{array}{l}\text { llow } \\
\text { zata }\end{array}$ & & & & \\
\hline Year & PDSI & t-statistic & $P$ value & $\begin{array}{c}\text { Difference in } \\
\text { Mean Growth }\end{array}$ & $\begin{array}{c}\% \text { Trees } \\
\text { Declining }\end{array}$ & Year & PDSI & t-statistic & $P$ value & $\begin{array}{c}\text { Difference in } \\
\text { Mean } \\
\text { Growth } \\
\end{array}$ & $\begin{array}{c}\% \text { Trees } \\
\text { Declining }\end{array}$ \\
\hline 1736 & -5.893 & 3.154 & $0.003 *$ & -0.314 & 91.4 & 1736 & -5.893 & 3.812 & $0.003 *$ & -0.393 & 91.7 \\
\hline 1772 & -4.191 & 2.021 & $0.048^{*}$ & -0.140 & 76.3 & 1772 & -4.191 & 4.585 & $<0.001 *$ & -0.500 & 80.0 \\
\hline 1801 & -4.308 & 6.653 & $<0.001 *$ & -0.257 & 91.0 & 1801 & -4.308 & -2.095 & 0.06 & 0.172 & 13.3 \\
\hline 1834 & -4.368 & 2.668 & $0.009 *$ & -0.163 & 70.1 & 1834 & -4.368 & 2.992 & $0.012 *$ & -0.267 & 66.7 \\
\hline 1874 & -4.145 & 1.386 & 0.17 & -0.0695 & 55.9 & 1874 & -4.145 & -2.128 & 0.062 & 0.161 & 30.0 \\
\hline 1954 & -5.943 & 6.151 & $<0.001^{*}$ & -0.213 & 85.3 & 1954 & -5.943 & -1.354 & 0.193 & 0.057 & 33.3 \\
\hline 1708 & -3.195 & 2.408 & $0.023^{*}$ & -0.553 & 88.5 & 1708 & -3.195 & 0.488 & 0.643 & -0.0855 & 71.4 \\
\hline 1737 & -3.798 & -6.146 & $<0.001 *$ & 0.293 & 0.0 & 1737 & -3.798 & 1.661 & 0.125 & -0.0861 & 75.0 \\
\hline 1767 & -3.471 & 3.523 & $<0.001^{*}$ & -0.209 & 84.5 & 1767 & -3.471 & 2.58 & $0.022 *$ & -0.123 & 66.7 \\
\hline 1773 & -3.01 & 1.351 & 0.182 & -0.047 & 66.1 & 1773 & -3.01 & 1.534 & 0.147 & -0.13 & 73.3 \\
\hline 1800 & -3.592 & -4.974 & $<0.001 *$ & 0.168 & 17.9 & 1800 & -3.592 & -0.225 & 0.825 & 0.0171 & 40.0 \\
\hline 1839 & -3.406 & -3.557 & $<0.001 *$ & 0.094 & 29.9 & 1839 & -3.406 & -4.636 & $<0.001 *$ & 0.376 & 0.0 \\
\hline 1856 & -3.203 & -0.118 & 0.907 & 0.003 & 51.5 & 1856 & -3.203 & 9.003 & $<0.001^{*}$ & -0.576 & 100.0 \\
\hline 1953 & -3.791 & 2.125 & $0.041^{*}$ & -0.082 & 67.6 & 1953 & -3.791 & 1.414 & 0.175 & -0.092 & 50.0 \\
\hline 1955 & -3.062 & -4.91 & $<0.001^{*}$ & 0.593 & 0.0 & 1955 & -3.062 & -2.881 & $0.01 *$ & 0.147 & 22.0 \\
\hline
\end{tabular}

Mill Hollow

Q. alba

\begin{tabular}{cccccc}
\hline Year & PDSI & t-statistic & P value & $\begin{array}{c}\text { Difference in } \\
\text { Mean Growth }\end{array}$ & $\begin{array}{c}\text { \% Trees } \\
\text { Declining }\end{array}$ \\
\hline $\mathbf{1 9 5 4}$ & -5.943 & -0.0511 & 0.96 & 0.00164 & 47.2 \\
$\mathbf{1 9 5 3}$ & -3.791 & 6.195 & $<0.001 *$ & -0.316 & 88.2 \\
$\mathbf{1 9 5 5}$ & -3.062 & -3.786 & $<0.001 *$ & 0.279 & 14.7
\end{tabular}




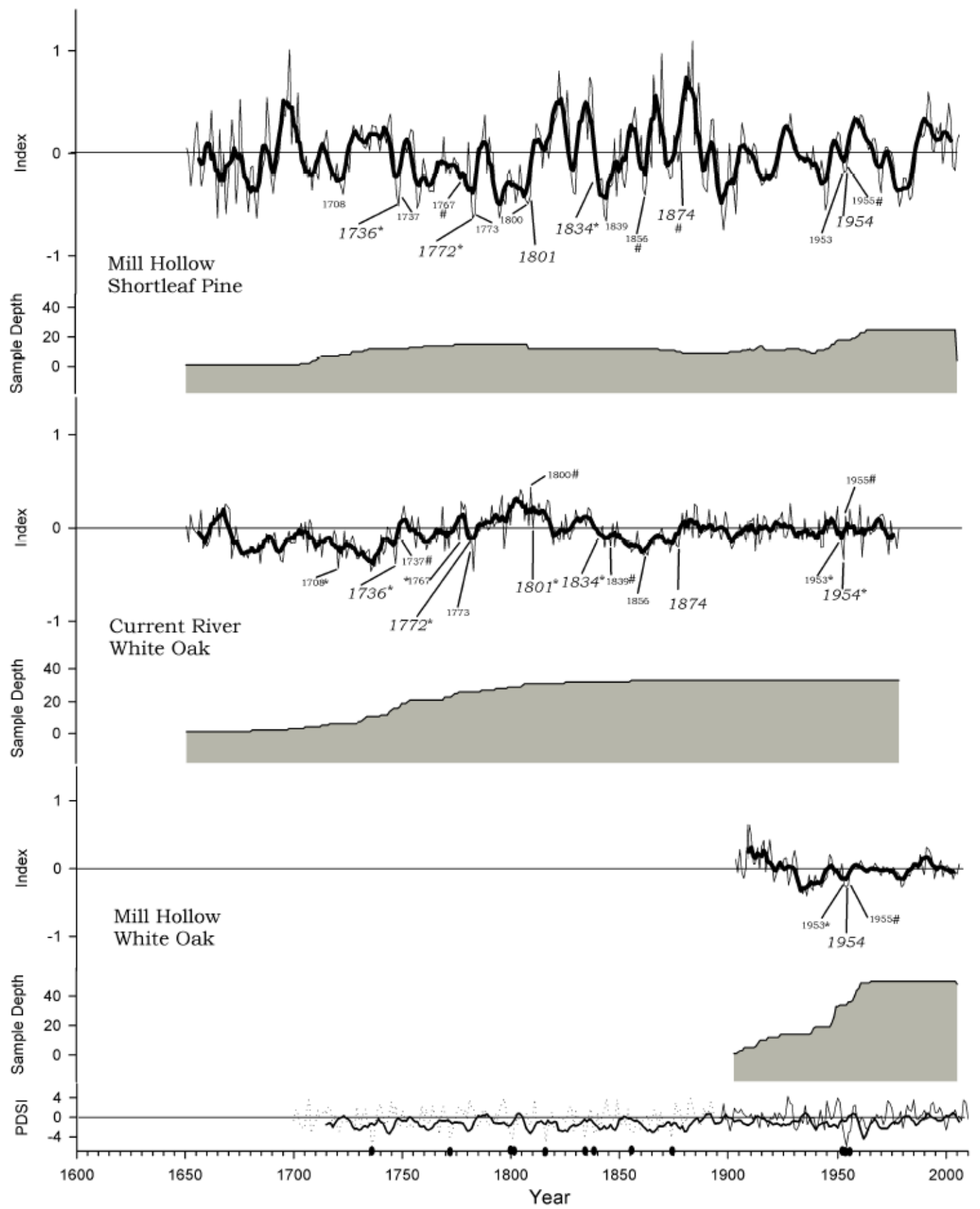

Figure 5.1. ARSTAN chronologies for P. echinata and Q. alba at Mill Hollow and CRNA. Black lines indicate 5 year moving averages. Italicized dates (larger font) indicate years of extreme drought $(<-4.0)$. Smaller dates indicate years of severe drought (-3.0 to -3.9). Years with asterisks indicate significant declines in mean growth (Table 5.3). Years with ampersands indicate significant increases in mean growth (Table 5.3). Bottom graph indicates PDSI (solid line) 1895-2009 and reconstructed PDSI (dashed line) 1700-1894. Dark line in PDSI graph indicates 5 year moving average. 
Significant differences in mean RWI were detected in $83 \%$ of extreme drought years at CRNA and 50\% at Mill Hollow (Table 5.3). Significant differences in mean RWI were detected in $78 \%$ of severe drought years at CRNA and $44 \%$ at Mill Hollow. Overall, $81 \%$ of Current River $Q$. alba and $81 \%$ of $P$. echinata declined in growth during severe and extreme droughts.

Not all drought-related growth effects were decline, and effect of drought might be limited to only one year. For CRNA $Q$. alba, differences in mean growth were positive for the years 1737,1800 , and 1955, each of these is the year following drought. For Mill Hollow $P$. echinata, differences in mean growth were positive for the years 1839 and 1955. A similar pattern was detected for Mill Hollow Q. alba during 1955 (Table 5.3). During these years the range of trees that exhibited declines in growth was between $0 \%$ and $30 \%$. For extreme droughts, there were no increases in growth for CRNA $Q$. alba, while three of the six years indicated positive increases in mean growth for Mill Hollow P. echinata.

Years of extreme drought that indicated significant differences in growth were analyzed to assess if growth declines were sustained longer than the year of drought. Analysis of the 5 year mean growth prior to the drought to the 5 year mean growth after the drought indicated significant differences during drought years 1772, 1801, and 1834 for Current River Q. alba and 1736 and 1834 for Mill Hollow P. echinata (Table 5.4). The percent of trees exhibiting declining growth was consistent for the five years following the drought. However, the exceptions were 1736 and 1954 for Current River Q. alba. For P. echinata following the drought of 1834, the percentage of trees declining in growth actually increased (Tables 5.3, 5.4). 
Table 5.4. Differences in 5 year mean growth prior and subsequent to droughts using paired ttests for Q. alba at CRNA and P. echinata at Mill Hollow. Asterisks indicate significant differences in 5 year mean growth at $\mathrm{p}<0.05$. $(\mathrm{A})=Q$. alba; $(\mathrm{B})=P$. echinata

\begin{tabular}{|c|c|c|c|c|}
\hline Year & $\begin{array}{c}\mathrm{t}- \\
\text { statistic } \\
\end{array}$ & $P$ value & $\begin{array}{c}\text { Difference } \\
\text { in } 5 \text { Yr. } \\
\text { Mean } \\
\text { Growth } \\
\end{array}$ & $\begin{array}{c}\% \text { Trees } \\
\text { Declining }\end{array}$ \\
\hline 1736 & -0.227 & 0.821 & 0.008 & 47.0 \\
\hline 1772 & 6.433 & $<0.001 *$ & -0.216 & 81.0 \\
\hline 1801 & 4.837 & $<0.001 *$ & -0.135 & 75.0 \\
\hline 1834 & 9.041 & $<0.001 *$ & -0.203 & 88.1 \\
\hline 1954 & -0.323 & 0.748 & 0.012 & 58.8 \\
\hline Year & $\begin{array}{c}\mathrm{t}- \\
\text { statistic }\end{array}$ & $P$ value & $\begin{array}{c}\text { Difference } \\
\text { in } 5 \text { Yr. } \\
\text { Mean } \\
\text { Growth }\end{array}$ & $\begin{array}{c}\% \text { Trees } \\
\text { Declining }\end{array}$ \\
\hline 1736 & 2.923 & 0.014* & -0.398 & 91.7 \\
\hline 1772 & 1.452 & 0.169 & -0.096 & 66.7 \\
\hline 1834 & 6.346 & $<0.001 *$ & -0.593 & 100 \\
\hline
\end{tabular}

\section{Growth Release Analysis}

Using growth release analysis (Nowacki and Abrams 1997), 127 releases were detected in Current River Q. alba, 65 releases in Mill Hollow P. echinata, and 26 releases in Mill Hollow Q. alba that demonstrated a $>25 \%$ increase in growth. Time periods in which sample depth $>10$ trees and $>25 \%$ of trees released included 1754-1758, 1774-1780, 1820-1828, 1860-1864, 18741880, 1900-1908, and 1944-1948 at CRNA (Figs. 5.2a-b). Using the same criteria with Mill Hollow data included 1754-1758, 1799-1804, 1840-1844, 1896-1904, 1948-1952, and 1982-1988 (Figs. 5.3a-b, 5.4). There appeared to be some discrepancy in growth release analysis. An example is the release event that occurred in the early 1820's at CRNA that resulted in growth release detection in $42 \%$ of $Q$. alba but only $18 \%$ in P. echinata (Figs. 5.2a-b, 5.3b). Noticeable increases in growth are noted in $P$. echinata but were not identified as growth releases using these methods. This occurred again with releases during the late 1850's, late 1870's, and early 1900's.

The year 1800 saw significant positive growth for $P$. echinata at Mill Hollow in which $83 \%$ of trees exhibited releases while only $12 \%$ of trees at CRNA were releasing. However, an 
additional $48 \%$ of Current River $Q$. alba exhibited positive ring-width index values that were not captured by release analysis (Figs. 5.2a,b). ARSTAN chronologies of Mill Hollow P. echinata and CRNA Q. alba appear to also indicate increases in growth during this drought period (Fig. 5.1). A similar event occurs with the 1839 drought in Mill Hollow P. echinata (Table 5.3).

While not significant at $\mathrm{p}<0.05$, the 1874 drought also indicated a positive difference in growth that is demonstrated in the ARSTAN chronology for P. echinata (Fig. 5.1). 

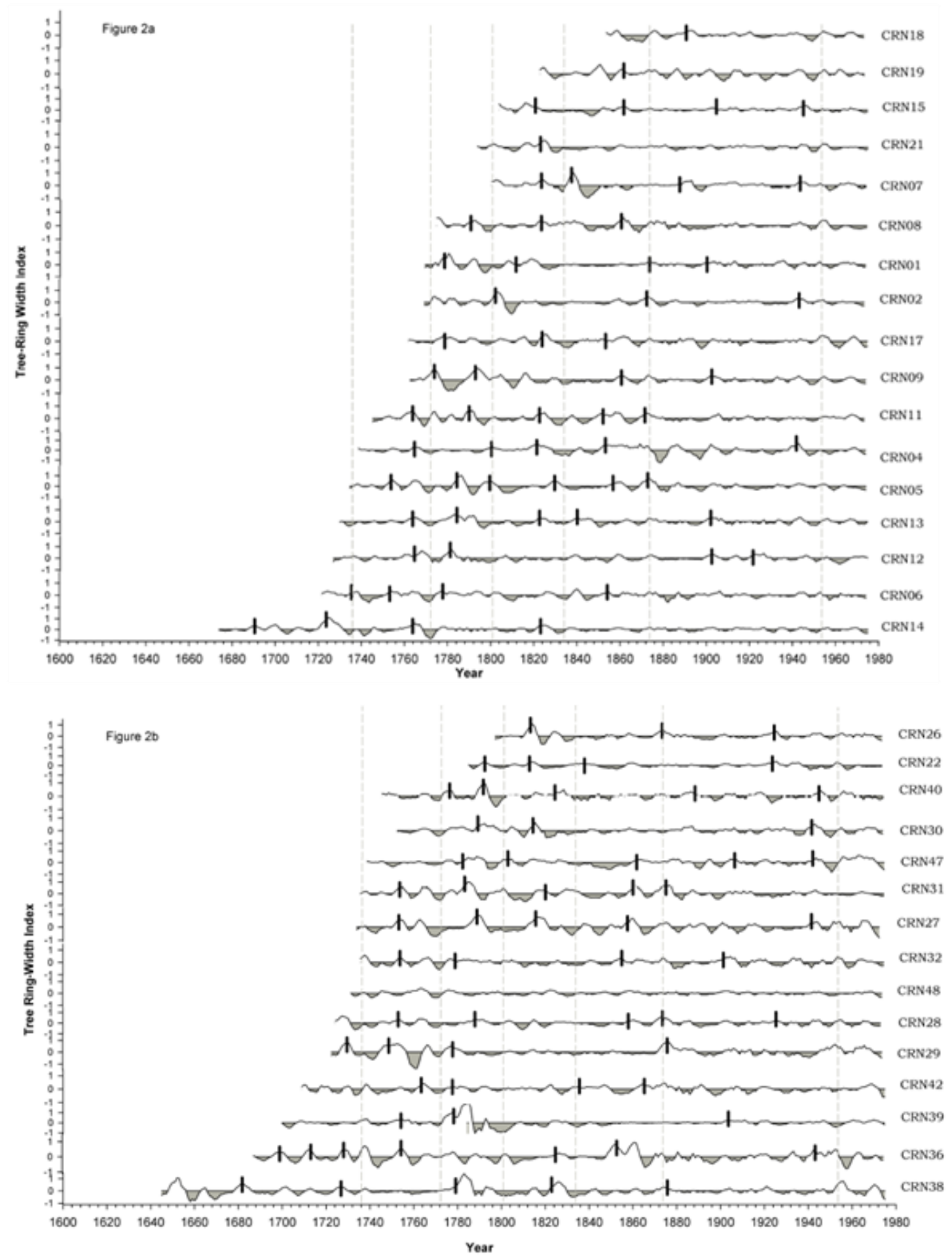

Figures 5.2a-b. Standardized ring-width indices for 33 white oak at Current River Natural Area. Each graph represents a 5 year moving average of ring-width indices. Grey shaded regions indicate below average growth. Vertical black lines show year of growth release based on release criteria in methods. Vertical grey dashed lines indicate years of extreme drought $(<-4.0)$. 

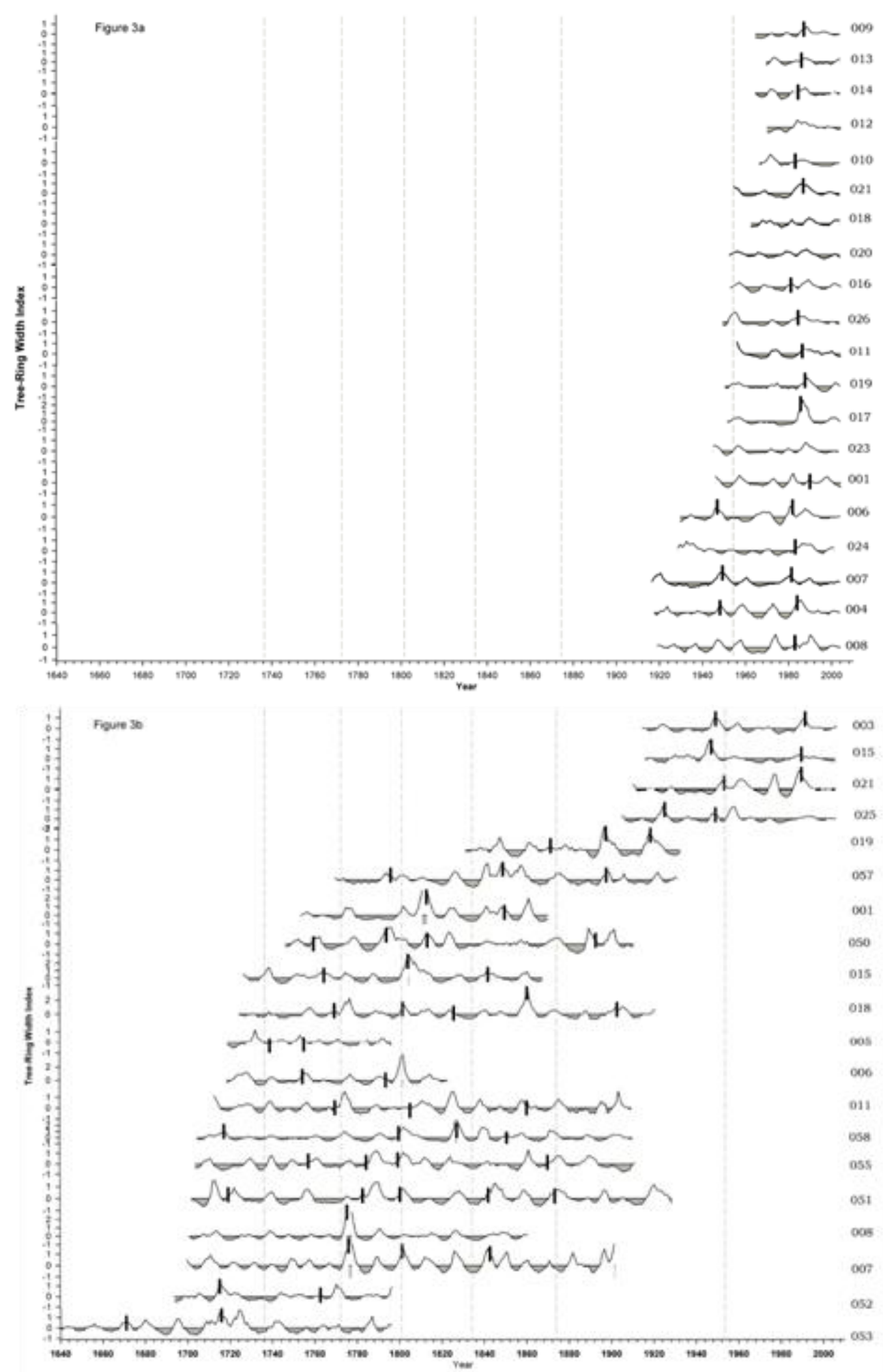

Figures 5.3a-b. Standardized ring-width indices for 40 P. echinata at Mill Hollow. Each graph represents a 5 year moving average of ring-width indices. Grey shaded regions indicate below average growth. Vertical black lines show year of growth release based on release criteria in methods. Vertical grey dashed lines indicate years of extreme drought $(<-4.0)$. 


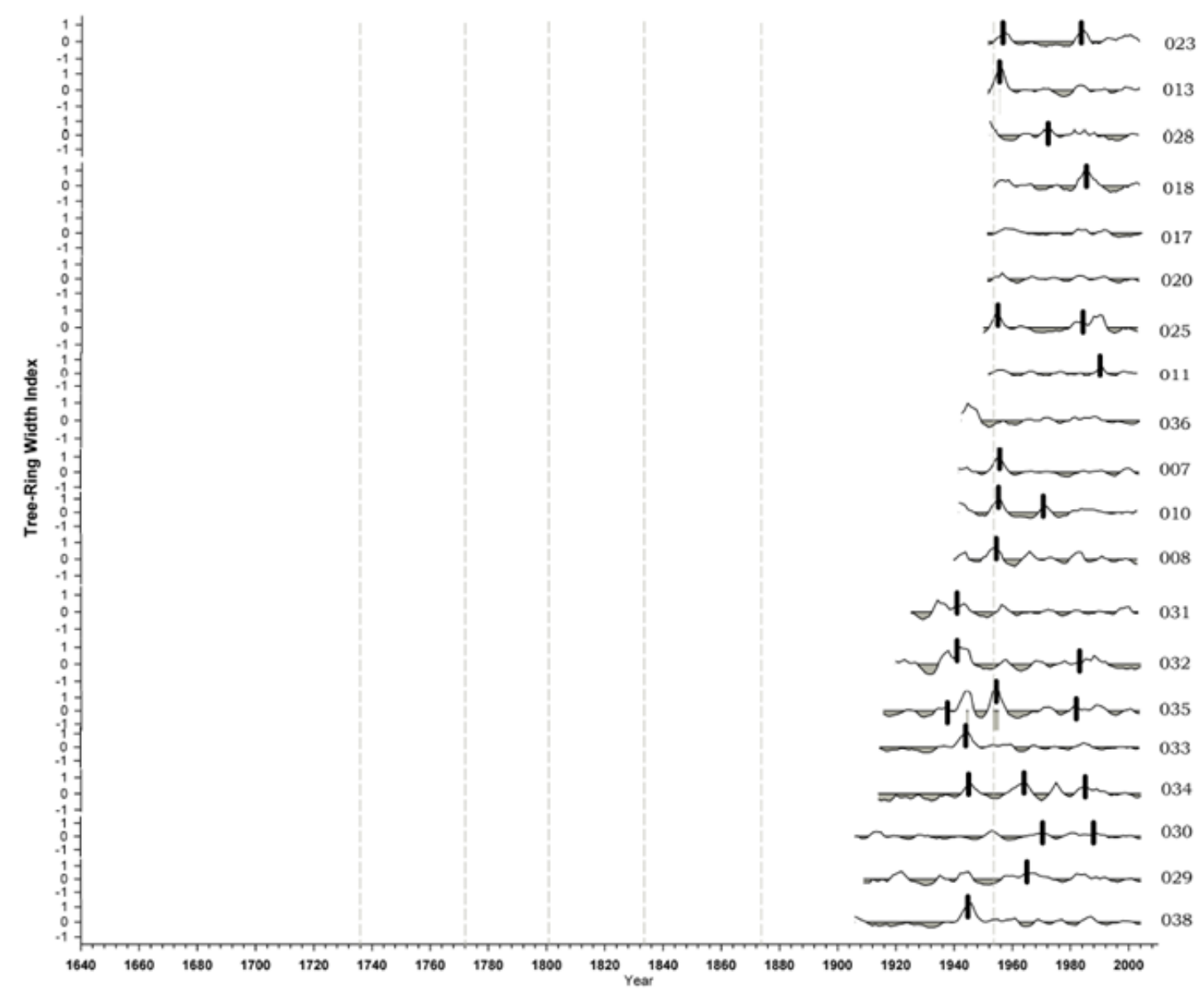

Figure 5.4. Standardized ring-width indices for 20 of the longest $Q$. alba tree-ring series at Mill Hollow. Each graph represents a 5 year moving average of ring-width indices. Grey shaded regions indicate below average growth. Vertical black lines show year of growth release based on release criteria in methods. Vertical grey dashed lines indicate years of extreme drought $(<-4.0)$. 


\section{DISCUSSION}

The mean sensitivity values reported in this study $(0.215,0.202)$ for $Q$. alba are possibly at the lower limit for climate analysis. Tardiff et al. (2006) reported values $>0.3$ for $Q$. alba in Quebec, Canada. My results are similar to those reported by Speer et al. (2009) for Q. alba in the southern Appalachians (0.22) in which they conducted climate analysis. Phipps (1982) suggested that tree growth in eastern deciduous forests may be more influenced by competition rather than

climate. Therefore, the low mean sensitivity values in $Q$. alba may indicate that competition is an important factor in tree growth at this location.

The mean sensitivity value for $P$. echinata reported in the study $(0.3)$ is similar to that reported by Estes (1970) for the Ozarks (0.3) and Speer (2009) for Georgia (0.26). The higher sensitivity values in $P$. echinata than $Q$. alba indicates a higher variability in year-to-year ringwidths and possibly a greater sensitivity to climate than $Q$. alba.

The low mean sensitivity and high first-order autocorrelation values for both species indicates more low-frequency variance and long-term growth departures from the fitted curve (Fritts 1976). This suggests that Q. alba and P. echinata had long-term trends in growth $>10$ years that resulted in possible releases or suppressions that were not related to climate. While the year-to-year variability in growth appears to be affected by climatic variables, long-term trends in growth suggest stand dynamics.

\section{Climate Variables and Growth}

This study reports that climate variables (PDSI, precipitation, temperature) are significantly correlated with growth, yet there is temporal and species variability at a local scale. For both species regardless of aspect, growth and monthly PDSI were significantly correlated between 1895 and 1981. This is somewhat expected, given the influence of regional climate at a local scale. However, stronger monthly PDSI correlations were found for $Q$. alba suggesting that 
annual ring-width was positively associated with moisture availability. Positive PDSI (above normal moisture) was associated with greater annual growth in $Q$. alba. In Ohio, Rubino and McCarthy (2000) reported significant correlations but the associations between monthly PDSI and $Q$. alba growth were weaker ( 0.2). Near the edge of its distribution in Missouri, Q. alba may be more sensitive to annual variation in PDSI. Speer et al. (2009) reported correlation coefficients that were similar to this study for $Q$. alba from several sites in the Appalachian Mountains. Site differences may also explain variation across studies. The approximate elevation for this study was $300 \mathrm{~m}$ and the trees sampled were at upper slope and ridge positions. Speer et al. (2009) reported elevations of their study sites ranging from $300 \mathrm{~m}$ to $1100 \mathrm{~m}$. While Rubino and McCarthy (2000) did not report elevation of their study site, they do reference their study site as in a mixed-mesophytic forest with moist conditions.

Mean monthly temperature was negatively correlated with growth during the months June, July, and August for both species. This suggests that at this site, above normal summer temperatures result in reduced growth for both species. In a study of $P$. echinata at the Missouri Ozark Forest Ecosystem project reported a significant negative correlation between July temperature and P. echinata growth (Stambaugh and Guyette 2004). Grissino-Mayer and Butler (1993) reported negative correlations between June and July mean temperatures and P. echinata growth in Georgia. In contrast, Biermann (2009) reported that summer temperatures were not correlated with growth of P. echinata in the Great Smoky Mountains National Park and attributed this to less extreme high temperatures or greater soil moisture in the area.

While mean monthly temperature and growth correlations were stronger for $Q$. alba than P. echinata, the importance of growing season conditions was apparent for both species. June and July cooler temperatures equate to greater growth of $Q$. alba, a result found in other studies. Jacobi and Tainter (1988) in South Carolina $Q$. alba found cooler temperatures during May through July resulted in wider tree-ring increments. Significant inverse correlations for June 
temperature and growth were also found for Q. alba in Ohio (Rubino and McCarthy 2000) and the southern Appalachians (Speer et al. 2009).

Correlation analysis between mean monthly precipitation and growth was not significant for the months examined in P. echinata at Mill Hollow. At four sites in Missouri, Estes (1970) found strong correlations between monthly average precipitation (Apr-Aug; May-Aug.; Apr.Jun.; May-Jun) and growth. Stambaugh and Guyette (2004) indicated that June precipitation was significantly correlated with growth for P. echinata in Missouri, and Grissino-Mayer and Butler (1993) showed that precipitation was the dominant climatic variable in P. echinata growth in Georgia when looking at monthly combinations of growing season precipitation, similar to Estes (1970). In this study, while not significant, the strongest correlations for precipitation occurred during the months of January, April, June, and July (range 0.137-0.175). The literature suggests that $P$. echinata growth is more associated with sequences of monthly precipitation rather than specific months of precipitation. Therefore, monthly average precipitation likely would have resulted in stronger correlations in P. echinata at this site. Biermann (2009) found results similar to this study in which precipitation and growth were positively correlated though not significant at two of her study sites.

Significant associations were detected between Quercus alba growth and monthly precipitation during the growing year months of February, April, and June. Soil moisture prior to the growing season (February) is important for initial cambial activity at the beginning of the growing season. The combination of cooler temperatures and higher precipitation during June was important for both Mill Hollow and CRNA Q. alba. Estes (1970) also indicated that growing season precipitation (Apr.-Aug.) was highly correlated with growth in Missouri, and Speer et al. (2009) found significant positive correlations for growing season May and June precipitation in the southern Appalachians.

Overall, monthly PDSI, precipitation, and temperature were strongly correlated with growth in $Q$. alba, while monthly PDSI and temperature were the strongest correlations in $P$. 
echinata. Drought conditions at this elevated, xeric to dry-mesic site likely have an influence on the growth of $Q$. alba and P. echinata. However, $Q$. alba is relatively drought tolerant (Abrams 1990) as is P. echinata after the seedling stage (Shelton and Cain 2000). Years of cooler June temperatures and normal or above normal precipitation favor growth in $Q$. alba, while $P$. echinata growth responds to cooler summer temperatures. Significant positive correlations between growth and monthly PDSI reinforce the importance of moisture in annual tree-ring development in both $Q$. alba and P. echinata. However, there was little correlation between previous year, monthly PDSI and growth suggesting that growing year moisture is important for annual tree-ring development.

\section{Drought, Growth, and Canopy Disturbance}

Analysis of the mean difference in growth prior, during, and subsequent to extreme and severe droughts during the past 281 years at Mill Hollow and CRNA can help reveal the response to drought and effect on stand dynamics. During the years of extreme drought $(<-4.0)$ (Table 5.3), Q. alba and P. echinata trees indicated a significant difference in mean growth during droughts. The differences equated to an overall decline in growth with $>60 \%$ of trees exhibiting growth declines. Interestingly, not all years of extreme drought resulted in significant differences in mean growth (e.g. the years 1801, 1874). Severe and extreme droughts in this study were a series of multiple year droughts. In some cases, the first year of the drought sequence resulted in a decline in mean growth while the subsequent year resulted in a mean increase in growth of trees. This could be an artifact of the analysis in that trees with a decline in mean growth during the first year of drought likely responded with a minor increase in growth. Approximately $45 \%$ of $Q$. alba in CRNA and 77\% of P. echinata in Mill Hollow increased growth during 1801. The year 1800 was identified with a severe drought $($ PDSI $=-3.592)$ followed by an extreme drought year in 1801 . However, the year 1800 saw $83 \%$ of Q. alba and $60 \%$ of P. echinata increasing in mean growth compared to the year 1799. A release event was detected during this time period 
(Figs. 5.2a-b, 5.3b) in both stands but was largely focused in Mill Hollow based on the percent of trees exhibiting a growth release. A severe fire (Guyette et al. 2006) was also identified in 1800 (15\% of P. echinata scarred) (Chapter 4) in Mill Hollow. By 1801, approximately $91 \%$ of $Q$. alba exhibited declines in growth. It is possible that the fire of 1800 extended into CRNA that resulted in crown scorch and contributed to the growth declines indicated in this study. Increases in growth during drought years may be explained by other disturbances mitigating the effect of drought at this site. At multiple oak sites in the central hardwoods region, climate was a significant contributor to growth but was less influential than canopy disturbance (Rentch 2001). In comparing control vs. thinned stands, Rentch (2001) indicated that the amount of tree-ring variation due to climate was higher in control stands. During the drought year of 1988 at his sites $($ Jun-Jul PDSI $=-3.9)$, he indicated a decline in growth in oaks, but trees responded to predrought growth the following year. My study and Rentch (2001) indicate that while drought can have effects on radial growth, the effects tend to be short-term.

To further assess the long-term effects of extreme droughts on growth of these two species, I analyzed the 5-year mean growth following extreme drought years (Table 5.4). Following the drought years 1736 and 1834 for P. echinata and 1772, 1801, and 1834 for Q. alba, 5-year mean growth was significantly lower than pre-drought mean growth. Orwig and Abrams (1997) found that following severe droughts, growth reductions in $Q$. alba lasted 2-3 years and up to 6 years in dry-mesic sites, especially for overstory individuals. Rubino and McCarthy (2000) found 5-year mean reductions in growth following an extreme drought. Guyette et al. (2007) noted reductions in growth of $P$. echinata associated with droughts in Missouri that resulted in $75 \%$ growth declines using 10-year averages. However, my study suggests that there were differential effects of drought on growth that were not consistent across all droughts that may indicate mediation of growth by other disturbance factors. 


\section{CONCLUSIONS}

While climatic variables are strongly correlated with growth of $P$. echinata and $Q$. alba, the effect of drought on growth appears to be mostly a short-term effect. Significant positive correlations between growing year monthly PDSI and growth supports the findings that drought appears to influence growth more strongly during the growing season. During sequential years of severe and extreme drought, declines in growth were not continuous for both species. In the situation where a greater percentage of trees responded with increases in growth, they may have been responding to crown dieback or tree mortality due to the long-term drought conditions (Fritts 1976, p. 116). This is reflected in Mill Hollow $Q$. alba that exhibited $\geq 25 \%$ releases following the long-term drought during the early 1950's. Historically, growth releases $\geq 25 \%$ occurred in both P. echinata an $Q$. alba at Mill Hollow and CRNA following sequential drought years or extreme drought years. This suggests that growth release analysis was capturing increases in growth related to mortality due to drought. Increases in moisture following droughts and gap formation possibly explain some of the identified growth releases. These results suggest the possibility of differentiating the causal factor of growth releases at xeric to dry-mesic sites where drought directly influences growth of trees. 


\section{CHAPTER 6}

\section{SYNTHESIS AND CONCLUSIONS}

This study aimed to (1) identify growth releases to understand historic canopy disturbances, (2) assess canopy accession strategies and recruitment patterns to corroborate growth release events, (3) integrate multiple disturbance events and evaluate their effect on radial growth, and (4) analyze the effect of drought on radial growth of P. echinata and Q. alba.

Growth releases (a proxy for canopy disturbance) were frequent events in oak-pine forests of the Missouri Ozarks over the past three centuries. Pinus echinata usually had one major release (\% GC >100\%) during its lifetime, but some individuals had multiple growth releases (\% GC <100\%) indicating that multiple gap openings were common for P. echinata. Growth release chronologies and decadal radial growth patterns of $P$. echinata suggest that canopy disturbance was largely individual tree mortality that resulted in a few trees responding to the canopy opening. Stand-wide canopy disturbance events were historically rare but were detected using multiple lines of evidence: tree establishment patterns, percentage of trees releasing, and decadal median growth of trees $>75^{\text {th }}$ percentile. More recently, stand-wide canopy disturbance events during the 1930's and 1940's are attributable to logging activity.

Assessment of long-term radial growth patterns in P. echinata, Q. alba, and $Q$. coccinea/Q. velutina across 19 sites in Missouri indicated that release events were more common than long-term suppressions. Most of the suppressions occurred in different trees than releasing trees during the same time period suggesting that the disturbance event likely resulted in gap formation for the releasing trees while suppressions are explained as injury due to falling stems that removed portions of a tree's canopy or otherwise damaged the canopy.

The most common canopy accession was gap origin-no major release. Canopy disturbances resulted in large gaps such that trees attained overstory status before canopy closure. Additionally, historically low stand density at upper-slope sites due to high fire frequencies and 
xeric conditions could also generate gap origin trees with no major release. If portions of the overstory were removed due to a canopy disturbance, understory trees may have attained the overstory in large gaps and did not require a major release to reach the overstory. Gap origin-no release strategies most often corresponded to major canopy disturbance events in which $>25 \%$ of trees demonstrated a growth release. Most trees established in gaps and rarely originated in a closed canopy, suppressed position.

Collectively, fire and release events were frequent in oak-pine forests of the Missouri Ozarks with return intervals less than 10 years with differences among sites (fire $=4-10$ years; release $=2-6$ years). The combination of frequent surface fires and canopy disturbances likely promoted the persistence of oak and pine at these sites. Radial growth of $P$. echinata and $Q$. alba following fire years indicated increases in growth up to three years following a fire with release events corresponding to those fire years, therefore fires were important competition release events for $P$. echinata and $Q$. alba that had already established. Evidence suggests that fire and canopy disturbances may have superseded the effect of drought on radial growth. Following a fire that occurred during a drought year (<-2.0 PDSI), radial growth increased for $>50 \%$ of trees. At all sites, there were decreases in radial growth and the lack of releases following specific fire years that did not correspond to drought. These years may indicate severe fire events that resulted in injury due to crown scorch and moreover support a mixed severity disturbance regime in the Missouri Ozarks.

While overall disturbance frequency was high, establishment of P. echinata and Q. alba appeared to correspond to temporal periods of reduced disturbance frequency; a disturbance free period was necessary for establishment, however it often occurred following identified periods of growth release. This, in combination with gap origin canopy accession, indicates that large gap formation was historically important for $P$. echinata and $Q$. alba to eventually access the overstory. 
As expected, severe (PDSI -3.0 to -3.9) and extreme (PDSI < -4.0) droughts often resulted in decreases in radial growth of $P$. echinata and $Q$. alba for periods up to five years following a drought. Unfortunately, our data could not reveal the mortality associated with drought. In comparing these drought events to growth releases, I caution the use of a growth release threshold of $25-49 \%$ used to indicate a minor release for upper slope, xeric sites. Any relative increase in moisture after the drought likely results in increases in radial growth that may be identified as a minor release due to a canopy disturbance. Furthermore, a competitive release from post-drought mortality occurred, but again, was not quantifiable. A $25 \%$ increase in growth that is $<10$ years in length may be a drought-induced response. Future research needs to differentiate between drought-induced growth changes and canopy disturbance responses at sites where moisture is a limiting factor.

High disturbance frequencies likely affected the establishment and eventual overstory succession of both P. echinata and $Q$. alba. Frequent fires reduced understory competition and frequent disturbances resulting in releases provided these species canopy accession. Stand-wide disturbance events due to logging during the early to mid- $20^{\text {th }}$ century resulted in regeneration of both species but in the absence of fire likely resulted in increased competition with more fireintolerant species such as $Q$. coccinea and $Q$. velutina. Consequently, growth dynamics of the $20^{\text {th }}$ century forest contrast dramatically with earlier forest growth.

This research demonstrates the direct and indirect effects of individual and multiple disturbances on the radial growth of trees in Missouri (Fig. 6.1). Two disturbances (drought and fire) have a direct effect on short-term radial growth of pine and oak. (i.e. mean radial growth 1-3 years following the disturbance). Evidence in this research also suggests that drought may have an indirect effect on short-term radial growth by increasing the likelihood of a fire. In turn, fire can have direct effects on short-term radial growth. Analysis indicates that mean radial growth subsequent to fire years resulted in increases in growth even when a fire was associated with a severe or extreme drought year (Chapter 4). 


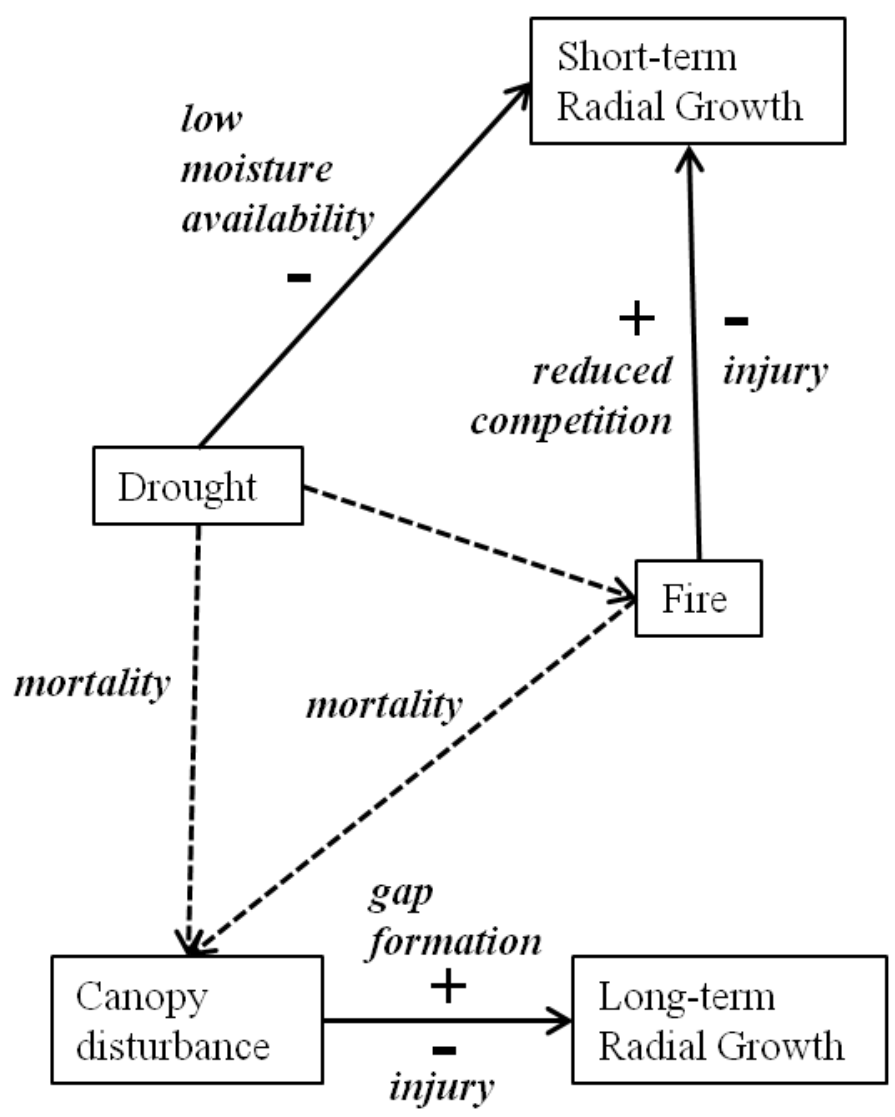

Figure 6.1. Model of direct and indirect effects of multiple disturbances on short-term and longterm radial growth of trees in the Missouri Ozarks. Solid arrows indicate direct effects of disturbance; dashed arrows indicate indirect effects of disturbance. Italicized terms indicate the conditions that directly or indirectly influenced radial growth responses. "+" = positive response following disturbance; " $"$ " $=$ negative response following disturbance. Mortality of overstory trees due to drought and/or fire can create canopy gaps that result in long-term increases $(+)$ in radial growth of surviving understory trees in the gap or long-term decreases (--) in radial growth in surviving understory trees due to falling trees.

Disturbances that result in gap formation in the overstory canopy have a direct effect on the long-term radial growth (i.e. increases in mean radial growth lasting $>10$ years) of pine and oak in the Missouri Ozarks that survive the disturbance. However, increases in radial growth (releases) in some trees occurred simultaneously with suppressions in other trees during the same time period (Chapter 3) reflecting the differential response of surviving trees.

Evidence suggests that drought and/or fire may have indirect effects on long-term radial growth of pine and oak by affecting gap dynamics via canopy disturbance events. Drought events may result in mortality of overstory trees that provide gap formation for 


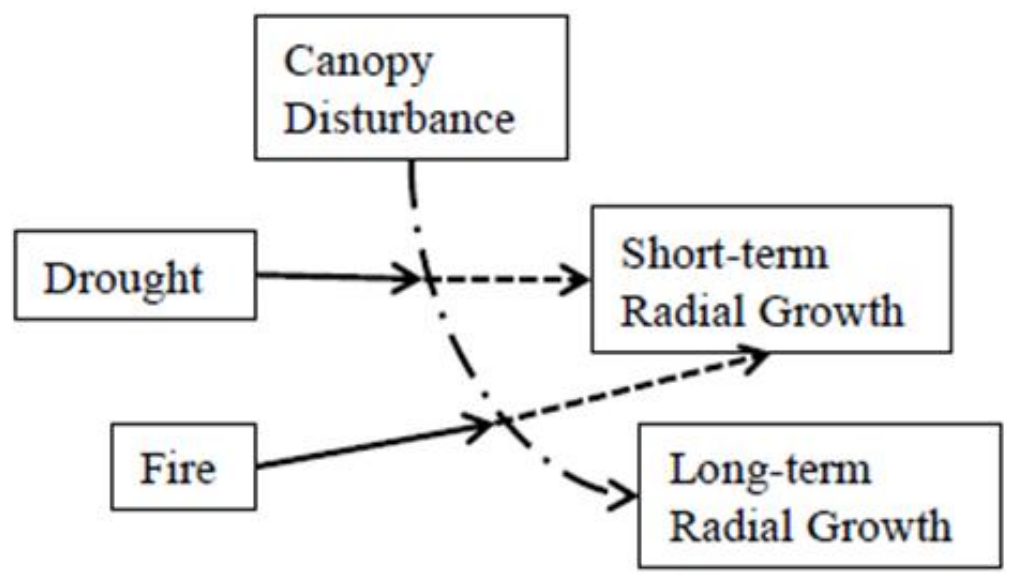

Figure 6.2. Model demonstrating the effect of an independent canopy disturbance event superseding the effect of drought or fire on short-term radial growth. Dashed lines for drought and fire indicate these disturbances would have an effect on short term growth of trees in the absence of canopy disturbance. However, canopy disturbance overrides the effect of drought or fire on radial growth. The result is short-term effects becoming long-term effects on radial growth.

understory trees. Evidence also indicates that increases in radial growth following droughts may be interpreted as releases associated with canopy disturbance, but minor increases in radial growth may actually be an artifact following reduced growth during a drought (Chapter 5). Fires that result in partial overstory canopy removal through crown scorch may afford surviving trees the opportunity to access the canopy.

This research has also demonstrated that the effect of one disturbance may surpass the effects of other disturbances resulting in a different growth response by trees (Fig. 6.2). The studies in this dissertation have demonstrated the short-term effects of drought and fire on the radial growth of pine and oak. However, there is evidence that canopy disturbances may supersede the short-term effects of drought or fire.

Figure 6.2 provides a conceptual framework for the effect of canopy disturbance in overriding the short-term effects of drought or fire based on research in this dissertation. In the absence of canopy disturbance, drought or fire were demonstrated to have short-term effects on the radial growth of pine and oak. Drought and fire have the potential of causing overstory 
canopy gap formation, and therefore growth releases would be evident in understory trees. While there is evidence that disturbances likely occurred together, there appears to be differential effects of disturbances and an overriding response to canopy gap formation.

Overall, this research emphasized the growth responses of $P$. echinata and oaks to different disturbances in Missouri over the past 300 years. During the $18^{\text {th }}$ and $19^{\text {th }}$ century, stand-wide canopy disturbances were rare, yet the persistence of oak-pine forests was sustained by frequent fire and canopy disturbances that may have resulted in frequent gap formation. The combination of disturbances at the study sites appeared to be frequent, yet disturbance type was important for the radial growth response of oak and pine. Future research should consider the spatial attributes of growth releases as a possible approach to understanding the severity of historic canopy disturbances. Accounting for the spatial location of trees and the identification of growth releases could corroborate the suggested canopy disturbance dynamics in my research. Further research is needed to differentiate growth releases due to small gap formation (gap size $<250 \mathrm{~m}^{2}$ ) from increases in radial growth following droughts at xeric oak sites. Initial growth release analysis in this research suggested that oak and pine had minor (\% growth change $<50 \%)$ increases in radial growth following droughts. While these "releases" were short-term $(<10$ years), it was not possible to determine if the growth response was an artifact of drought or small gap formation. I recommend that future research in growth release analysis at xeric oak sites use $\%$ growth changes $<50 \%$ cautiously to identify years of historic canopy disturbance. Additionally, dendroecological analysis of all tree species at sites will likely provide a more complete understanding of historic stand dynamics in oak-pine forests in the Missouri Ozarks. 


\section{LITERATURE CITED}

Abell, C.A. 1934. Influence of glaze storms upon hardwood forests in the Southern Appalachians. Journal of Forestry. 32: 35-37.

Abrams, M.D. 1990. Adaptations and responses to drought in Quercus species of North America. Tree Physiology 7: 227-238.

Abrams, M.D. 1996. Distribution, historical development and ecophysiological attributes of oak species in the eastern United States. Annals of Forest Science. 53: 487-512.

Abrams, M.D. and D.A. Orwig. 1996. A 300-year history of disturbance and canopy recruitment for co-occurring white pine and hemlock on the Allegheny Plateau, USA. Journal of Ecology 84: 353-363.

Abrams, M.D., D.A. Orwig, M.J. Dockry. 1997. Dendroecology and successional status of two contrasting old-growth oak forests in the Blue Ridge Mountains, USA. Canadian Journal of Forest Research 27: 994-1002.

Abrams, M.D. and C.A. Copenheaver. 1999. Temporal variation in species recruitment and dendroecology of an old-growth white oak forest in the Virginia Piedmont, USA. Forest Ecology and Management 124: 275-284.

Albrecht, M.A. and McCarthy, B.C. 2006. Effects of prescribed fire and thinning on tree recruitment patterns in central hardwood forests. Forest Ecology and Management. 226: 88103.

Aldrich, S.R., Lafon, C.W., Grissino-Mayer, H.D., G.G. DeWeese, and J.A. Hoss. 2010. Three centuries of fire in montane pine-oak stands on a temperate forest landscape. Applied Vegetation Science 13: 36-46.

Alexander, H.D., Arthur, M.A., Loftis, D.L., and Green, S.R. 2008. Survival and growth of upland oak and co-occurring competitor species following single and repeated prescribed fires. Forest Ecology and Management. 256: 1021-1030.

Aubrey, D.P., Coleman, M.D., and Coyle, D.R. 2007. Ice damage in loblolly pine: understanding the factors that influence susceptibility. Forest Science. 53: 580-589.

Batek, M.J., A.J. Rebertus, W.A. Schroeder, T.L. Haithcoat, E. Compas, R.P. Guyette. 1999. Reconstruction of early nineteenth-century vegetation and fire regimes in the Missouri Ozarks. Journal of Biogeography 26: 397-412.

Battaglia, L.L., Sharitz, R., and Minchin, P.R. 1999. Patterns of seedling and overstory composition along a gradient of hurricane disturbance in an old-growth bottomland hardwood community. Canadian Journal of Forest Research. 29: 144-156.

Bebber, D.P., S.C. Thomas, W.G. Cole, D. Balsille. 2004. Diameter increment in mature eastern white pine Pinus strobus L. following partial harvest of old-growth stands in Ontario, Canada. 
Bekker, M.F. and Taylor, A.H. 2010. Fire disturbance, forest structure, and stand dynamics in montane forests of the Southern Cascades, Thousand Lakes Wilderness, California, USA. Ecoscience. 17: 59-72.

Biermann, C.P. 2009. Twentieth century changes in the climate response of yellow pines in Great Smoky Mountains National Park, Tennessee, U.S.A. M.S. Thesis, University of Tennessee, Knoxville. 171 pp.

Black, B.A. and Abrams, M.D. 2003. A boundary-line approach to establishing release criteria in old-growth hemlock. Ecological Applications. 13: 1733-1749.

Black, B.A. and Abrams, M.D. 2004. Development and application of boundary line release criteria. Dendrochronologia. 22: 31-42.

Black, B.A. and M.D. Abrams. 2005. Disturbance history and climate response in an old-growth hemlock-white pine forest, central Pennsylvania. Journal of the Torrey Botanical Society 132: 103-114.

Boerner, R.E.J., Lord, T.R., and Peterson, J.C. 1988. Prescribed burning in the oak-pine forest of the New Jersey Pine Barrens: effects on growth and nutrient dynamics of two Quercus species. American Midland Naturalist. 120: 108-119.

Boerner, R.E.J., Runge, S.D., Cho, D.S., and Kooser, J.G. 1988. Localized ice storm damage in an Appalachian Plateau watershed. American Midland Naturalist. 119: 199-208.

Bragg, D.C. and E. Heitzman. 2009. Composition, structure, and dynamics of a mature, unmanaged, pine-dominated old-field stand in southeastern Arkansas. Southeastern Naturalist 3: 445-470.

Bragg, D.C., Shelton, M.G., and Zeide, B. 2003. Impacts and management implications of ice storms on forests in the southern United States. Forest Ecology and Management. 186: 99123.

Brommit, A.G., Charbonneau, N., Contreras, T.A., and Fahrig, L. 2004. Crown loss and subsequent branch sprouting of forest trees in response to a major ice storm. Journal of the Torrey Botanical Society. 131: 169-176.

Brookshire, B.L. and D.C. Dey. 2000. Establishment and data collection of vegetation-related studies on the Missouri Ozark Forest Ecosystem Project study sites. In: Missouri Ozark Forest Ecosystem Project: site history, soils, landforms, woody and herbaceous vegetation, down wood, and inventory methods for the landscape experiment. S.R. Shifley and B.L. Brookshire, editors. USDA, Forest Service, Northern Research Station. 1-18.

Brown, P.M. 2006. Climate effects on fire regimes and tree recruitment in Black Hills ponderosa pine forests. Ecology. 87: 2500-2510.

Campbell, E.M., Alfaro, R.I., and Hawkes, B. 2007. Spatial distribution of mountain pine beetle outbreaks in relation to climate and stand characteristics: a dendroecological analysis. Journal of Integrative Plant Biology 49: 168-178. 
Carter, M.C. and Foster, C.D. 2004. Prescribed burning and productivity in southern pine forests: a review. Forest Ecology and Management. 191: 93-109.

Canham,C.D., Denslow, J.S., Platt, W.J., Runkle, J.R., Spies, T.A., and White, P.S. 1990. Light regimes beneath closed canopies and tree-fall gaps in temperate and tropical forests. Canadian Journal of Forest Research 20: 620-631.

Cook, E.R. 1985. A time series approach to tree-ring standardization. PhD Dissertation. University of Arizona, Tucson. 171pp.

Cook, E.R., and Holmes, R.L. 1986. Guide to computer program ARSTAN. In: Holmes, R.L., Adams, R.K., and Fritts, H.C. eds. Tree-ring chronologies of western North America: California, eastern Oregon and northern Great Basin. Laboratory of Tree-Ring Research, University of Arizona, Tucson, AZ.

Cook, E.R., D.M. Meko, D.W. Stahle, and M.K. Cleaveland. 2004. North American summer PDSI reconstructions. World Data Center for Paleoclimatology Data Contribution Series \#2004-045. Accessed 28 January 2013.

Coulson, R.N. 1979. Population dynamics of bark beetles. Annual Review of Entomology. 24: 417-447.

Cunningham, R.J. 2007. Historical and social factors affecting pine management in the Ozarks during the late 1800's through 1940. In Proceedings of the Shortleaf Pine Restoration and Ecology in the Ozarks Symposium. Edited by John M. Kabrick, Daniel C. Dey, David Gwaze. 7-9 November 2006 Springfield, MO. Gen. Tech. Rep. NRS-P-15. U.S. Department of Agriculture, Forest Service, Northern Research Station, Newtown Square, PA. pp. 1-7.

Cunningham, R.J. and C. Hauser. 1989. The decline of Missouri Ozark forest between 1880 and 1920. In: T.A. Waldrop ed., Proceedings of pine-hardwood mixtures: a symposium on the management and ecology of the type. Atlanta, GA. pp. 34-37.

Cutter, B.E. and Guyette, R.P. 1994. Fire history of an oak-hickory ridgetop in the Missouri Ozarks. American Midland Naturalist. 132: 393-398.

DeRose, R.J. and J.N. Long. 2012. Drought-driven disturbance history characterizes a southern Rocky Mountain subalpine forest. Canadian Journal of Forest Research 42: 1649-1660.

Drever, C.R., Drever, M.C., Messier, C., Bergeron, Y., and Flannigan, M. 2008. Fire and the relative roles of weather, climate and landscape characteristics in the Great Lakes-St. Lawrence forest of Canada. Journal of Vegetation Science. 19: 57-66.

Druckenbrod, D.L. 2005. Dendroecological reconstructions of forest disturbance history using time-series analysis with intervention detection. Canadian Journal of Forest Research. 35: 868-876.

Duncan, R.P. 1989. An evaluation of error in tree age estimates based on increment cores in Kahikatea (Dacrycarpus dacrydioides). New Zealand Natural Sciences. 16: 31-37. 
Elliott, G.P. 2011. Influences of $20^{\text {th }}$-century warming at the upper tree line contingent on localscale interactions: evidence from a latitudinal gradient in the Rocky Mountains, USA. Global Ecology and Biogeography 20: 46-57.

Elliott, K.J. and J.M. Vose. 2005. Effects of understory prescribed burning on shortleaf pine (Pinus echinata Mill.)/mixed-hardwood forests. Journal of the Torrey Botanical Society 132: 236-251.

Engbring, B.L., Heitzman, E., and Spetich, M.A. 2008. Ridgetop fire history of an oak-pine forest in the Ozark Mountains of Arkansas. Southeastern Naturalist. 7: 49-60.

Estes, E.T. 1970. Dendrochronology of black oak (Quercus velutina Lam.), white oak (Quercus alba L.) and shortleaf pine (Pinus echinata Mill.) in the Central Mississippi Valley. Ecological Monographs 40: 295-316.

Fauria, M.M. 2007. Climate and wildfires in the North American boreal forest. Philosophical Transactions of the Royal Society Bulletin. 363: 2317-2329.

Finnegan, J.J. The turbulent wind in plant and forest canopies. In: Plant Disturbance Ecology. Eds. Johnson, E.A. and Miyanishi, K. Elsevier, Amsterdam. pp. 15-58.

Fletcher, P.W. and R.E. McDermott. 1957. Influence of geologic parent material and climate on distribution of shortleaf pine in Missouri. University of Missouri Agricultural Experiment Station. Research Bulletin 625. 42 pp.

Foley, J.A., Coe, M.T., Scheffer, M., and Wang, G. 2003. Regime shifts in the Sahara and Sahel: interactions between ecological and climatic systems in Northern Africa. Ecosystems 6: 524539.

Folke, C., Carpenter, S., Walker, B., Scheffer, M., Elmqvist, T., Gunderson, L., and Holling, C.S. 2004. Regime shifts, resilience, and biodiversity in ecosystem management. Annual Review of Ecological and Evolutionary Systematics 35:557-581.

Foster, D.R. 1988. Disturbance history, community organization and vegetation dynamics of the old-growth Pisgah Forest, South-Western New Hampshire, U.S.A. Journal of Ecology 76: 105-134.

Foster, D.R., Zebryk, T., Schoonmaker, P., Lezberg, A. 1992. Post-settlement history of human land-use and vegetation dynamics of a Tsuga canadensis (hemlock) woodlot in Central New England. Journal of Ecology. 80: 773-786.

Fraver, S. and White, A.S. 2005a. Disturbance dynamics of old-growth Picea rubens forests of northern Maine. Journal of Vegetation Science. 16: 597-610.

Fraver S. and White, A.S. 2005b. Identifying growth releases in dendrochronological studies of forest disturbance. Canadian Journal of Forest Research. 35: 1648-1656.

Frelich, L.E. 2002. Forest Dynamics and Disturbance Regimes: Studies from Temperate Evergreen-Deciduous Forests. Cambridge University Press, Cambridge, U.K. 266pp. 
Frelich, L.E. and Lorimer, C.G. 1991. Natural disturbance regimes in hemlock-hardwood forests of the Upper Great Lakes Region. Ecological Monographs, 61: 145-164.

Frelich, L.E. and Reich, P.B. 1995. Neighborhood effects, disturbance, and succession in forests of the western Great Lakes Region. Ecoscience 2: 148-158.

Frelich, L.E. and Reich, P.B. 1999. Neighborhood effects, disturbance severity, and community stability in forests. Ecosystems 2: 151-166.

Fritts, H.C. 1976. Tree Rings and Climate. Academic Press, New York. 567pp.

Fujita, T.T. 1981. Tornadoes and downbursts in the context of generalized planetary scales. Journal of the Atmospheric Sciences. 38: 1511-1534.

Glitzenstein, J.S., P.A. Harcombe, and D.R. Streng. 1986. Disturbance, succession, and maintenance of species diversity in an East Texas forest. Ecological Monographs 56: 243258.

Gray, R.W., Riccius, E., and Wong, C. 2004. Comparison of current and historical stand structure in two interior Douglas-fir sites in the Rocky Mountain Trench, British Columbia, Canada. $I n$ : Proceedings of the $22^{\text {nd }}$ Tall Timbers Fire Ecology Conference: Fire in Temperate, Boreal, and Montane Ecosystems. eds: Engstrom, R.T., Galley, K.E.M., and de Groot, W.J. Tall Timbers Research Station, Tallahasee, FL. pp. 23-35.

Gilliam, F.S. and Platt, W.J. 1999. Effects of long-term fire exclusion on tree species composition and stand structure in an old-growth Pinus palustris (Longleaf pine) forest. Plant Ecology. 140: $15-26$.

Greene, D.F., Jones, K.F., and Proulx, O.J. 2007. The effect of icing events on the death and regeneration of North American trees. In: Plant Disturbance Ecology. Eds. Johnson, E.A. and Miyanishi, K. Elsevier, Amsterdam. pp. 181-213.

Grissino-Mayer, H.D. and Butler, D.R. 1993. Effects of climate on growth of shortleaf pine (Pinus echinata, Mill.) in northern Georgia: A dendroclimatic study. Southeastern Geographer 3: 65-81.

Grissino-Mayer, H.D. 2001a. Evaluating crossdating accuracy: A manual and tutorial for the computer program COFECHA. Tree-Ring Research 57: 205-221.

Grissino-Mayer, H.D. 2001b. FHX2 - software for analyzing temporal and spatial patterns in fire regimes from tree rings. Tree-Ring Research 57: 115-124.

Gutsell, S.L. and Johnson, E.A. 2007. Wildfire and tree population processes. In: Plant Disturbance Ecology. Eds. Johnson, E.A. and Miyanishi, K. Elsevier, Amsterdam. pp. 441486.

Guyette, R. 1993. Fire history of the Eck Tract, on the Big Piney River. Report for Missouri Department of Conservation, National Park Service, and the Mark Twain National Forest. 8pp. 
Guyette, R.P. and B.E. Cutter, 1997. Fire history, population, and calcium cycling in the Current River watershed. In Proceedings $11^{\text {th }}$ Central Hardwoods Conference, Columbia, MO 23-26 March 1997. S.G. Pallardy, R.A. Cecich, H.E. Garrett, and P.S. Johnson, editors. St. Paul, MN: United States Department of Agriculture, Forest Service, North Central Experiment Station, Gen. Tech. Rep. NC-188. 354-372.

Guyette, R.P. and Dey, D.C. 1997a. Fire and logging history at Huckleberry Hollow, Shannon County, Missouri. Forest Research Report No. 1. Missouri Department of Conservation. Jefferson City, MO. 1-14.

Guyette, R.P. and D.C. Dey. 1997b. Historic shortleaf pine (Pinus echinata Mill.) abundance and fire frequency in a mixed oak-pine forest (MOFEP, Site 8). In Proceedings of the Missouri Ozark Forest Ecosystem Project Symposium. B.L. Brookshire and S.R. Shifley. 3-5 June 1997 St. Louis, MO. GTR-NC-193. St. Paul, MN: USDA, Forest Service, North Central Forest Experimental Station. 136-149.

Guyette, R.P., Dey, D.C., and McDonell, C. 1995. Determining fire history from old white pine stumps in an oak-pine forest in Bracebridge, Ontario. Forest Research Report No. 133. Ontario Ministry of Natural Resources, Ontario Forest Research Institute. 15pp.

Guyette, R.P. and J. Kabrick. 2003. The legacy of forest disturbance, succession, and species at the MOFEP sites. In: Shifley, S. ed. Proceedings of the second Missouri Ozark forest ecosystem project symposium. General Technical Report NC-227. St. Paul, MN: USDA Forest Service, North Central Research Station. 26-44.

Guyette, R.P. and D. Larsen. 2000. A history of anthropogenic and natural disturbances in the area of the Missouri Ozark Forest Ecosystem Project. In: S.R. Shifley and B.L. Brookshire, eds. Missouri Ozark Forest Ecosystem Project: Site history, soils, landforms, woody and herbaceous vegetation, down wood, and inventory methods for the landscape experiment. USDA, Forest Service, North Central Research Station, GTR NC-208: 19-40.

Guyette, R.P., R.M. Muzika, and D.C. Dey. 2002. Dynamics of an anthropogenic fire regime. Ecosystems. 5: 472-486.

Guyette, R.P., Muzika, R.M. and Voelker, S.L. 2007. The historical ecology of fire, climate, and the decline of shortleaf pine in the Missour Ozarks. In: Kabrick, J.M, Dey, D.C., Gwaze, D. eds. Shortleaf pine restoration and ecology in the Ozarks: proceedings of a symposium. 7-9 November 2006. Springfield, MO. GTR-P-15. Newtown Square, PA. USDA, Forest Service, Northern Research Station: 8-18.

Guyette, R.P. and Rabeni, C.F. 1995. Climate response among growth increments of fish and trees. Oecologia 104: 272-279.

Guyette, R.P., Stambaugh, M.C., and Dey, D.C. 2003. Fire history in the riparian corridor of the Ozark National Scenic Riverways. A report to the National Park Service, Ozark National Scenic Riverways, Van Buren, Missouri.

Guyette, R.P., Dey, D.C., Stambaugh, M.C., and Muzika, R.M. 2006. Fire scars reveal variability and dynamics of eastern fire regimes. In: Fire in Eastern Oak Forests: Delivering Science to Land Managers, Proceedings of a Conference. 2005 November 15-17, Columbus, OH. Ed. 
Dickinson, M.B. Gen. Tech. Rep. NRS-P-1, Newtown Square, PA. USDA, Forest Service, Northern Research Station. pp.20-39.

Guyette, R.P., Muzika, R.M., and Voelker, S.L. 2007. The historical ecology of fire, climate, and the decline of shortleaf pine in the Missouri Ozarks. In: Proceedings of the Shortleaf Pine Restoration and Ecology in the Ozarks Symposium. eds. John M. Kabrick, Daniel C. Dey, David Gwaze. 7-9 November 2006 Springfield, MO. Gen. Tech. Rep. NRS-P-15. U.S. Department of Agriculture, Forest Service, Northern Research Station, Newtown Square, PA. pp. 8-18.

Guyette, R.P. and Spetich, M.A. 2003. Fire history of oak-pine forests in the Lower Boston Mountains, Arkansas, USA. Forest Ecology and Management. 180: 463-474.

Guyette, R.P., M.C. Stambaugh, and D.C. Dey. 2003. Fire history in the riparian corridor of the Ozark National Scenic Riverways. Report for the Ozark National Scenic Riverways. USDI NPS PO \#6640010030, 2003. 31pp.

Harrod, J.C. and White, R.D. 1999. Age structure and radial growth in xeric pine-oak forests in Western Great Smoky Mountains National Park. Journal of the Torrey Botanical Society 126: 139-146.

Hart, J.L., A.A.R. Bhuta, R.M. Schneider. 2011. Canopy disturbance patterns in secondary hardwood stands on the Highland Rim of Alabama. Castanea 76: 55-63.

Hart, J.L., S.L. Clark, S.J. Torreano, M.L. Buchanan. 2012. Composition, structure, and dendroecology of an old-growth Quercus forest on the tablelands of the Cumberland Plateau, USA. Forest Ecology and Management 266: 11-24.

Hart, J.L., S.L. van de Gevel, and H.D. Grissino-Mayer. 2008. Forest dynamics in a natural area of the Southern Ridge and Valley, Tennessee. Natural Areas Journal 28: 275-289.

Hartman, G.W. and B. Heumann. 2004. Prescribed fire effects in the Ozarks of Missouri: the Chilton Creek project 1996-2001. In: Proceedings, $2^{\text {nd }}$ Interational Wildland Fire Ecology and Fire Management Congress. Orlando, FL. 2003 November 16-20; Orlando, Fl.

Henry, J.D. and Swan, J.M.A. 1974. Reconstructing forest history from live and dead plant material - an approach to the study of forest succession in southwest New Hampshire. Ecology 55: 772-783.

Heyerdahl, E.K., Lertzman, K., and Wong, C.M. 2012. Mixed-severity fire regimes in dry forests of southern interior British Columbia, Canada. Canadian Journal of Forest Research. 42: 8898.

Hibbs, D.E. 1982. Gap dynamics in a hemlock-hardwood forest. Canadian Journal of Forest Research. 12: 522-527.

Hicke, J.A., Johnson, M.C., Hayes, J.L., and Preisler, H.K. 2012. Effects of bark beetle-caused tree mortality on wildfire. Forest Ecology and Management. 271: 81-90.

Hjemfelt, M.R. 2007. Microbursts and macrobursts: windstorms and blowdowns. In: Plant Disturbance Ecology. Eds. Johnson, E.A. and Miyanishi, K. Elsevier, Amsterdam. pp. 59102. 
Holling, C.S. 1973. Resilience and stability of ecological systems. Annual Review of Ecology and Systematics. 4: 1-23.

Holling, C.S. and Gunderson, L.H. 2002. Resilience and adaptive cycles. In: Panarchy. eds. Gunderson, L.H. and Holling, C.S. Island Books. pp. 25-62.

Holmes, R.L. 1983. Computer-assisted quality control in tree-ring dating and measurement. TreeRing Bull. 43: 69-78.

Hutchinson, T.F., Sutherland, E.K., and Yaussey, D.A. 2005. Effects of repeated prescribed fires on the structure, composition, and regeneration of mixed-oak forests in Ohio. Forest Ecology and Management. 218: 210-228.

Iffrig, G.F., Trammel, C.E., and Cunningham, T. 2004. Pioneer Forest: a case study in sustainable forest management. In: Flader, S.L. ed. Toward sustainability for Missouri forests. GTR NC-239. St. Paul, MN. USDA, Forest Service, North Central Research Station. 193-204.

Iniguez, J.M., Swetnam, T.W., and Yool, S.R. 2008. Topography affected landscape fire history patterns in southern Arizona, USA. Forest Ecology and Management. 256: 295-303.

Jacobi, J.C. and Tainter, F.H. 1988. Dendroclimatic examination of white oak along an environmental gradient in the Piedmont of South Carolina. Castanea 53: 252-262.

Jenkins, M.J., Page, W.G., Hebertson, E.G., and Alexander, M.E. 2012. Fuels and fire behavior dynamics in bark beetle-attacked forests in Western North America and the implications for fire management. Forest Ecology and Management. 275: 23-34.

Johnson, S.E. and M.D. Abrams. 2009. Basal area increment trends across age classes for two long-lived tree species in the eastern U.S. In: TRACE - Tree Rings in Archaeology, Climatology, and Ecology, Vol. 7. Kaczka, R, Malik, I, Owczarek, P., Gartner, H., Helle, G., Heinrich, I. (eds.). GFZ Potsdam, Scientific Technical Report STR 09/03, Postdam. 127-134.

Jones, K., Thorkildson, R., and Lott, N. 2002. The development of a U.S. climatology of extreme ice loads. National Climatic Data Center, U.S. Department of Commerce. Technical Report 2002-01. Asheville, N.C. 24pp.

Kabrick, J.M., D.C. Dey, and D. Gwaze. 2007. Shortleaf pine restoration and ecology in the Ozarks: Proceedings of a symposium. USDA, Forest Service, Northern Research Station. General Technical Report NRS-P-15.

Kitzberger, T., Brown, P.M., Heyerdahl, E.K., Swetnam, T.W., and Veblen, T.T. 2007. Contingent Pacific-Atlantic Ocean influence on multicentury wildfire synchrony over western North America. Proceedings of the National Academy of Sciences of the United States of America. 104: 543-548.

Kulakowski, D. and Veblen, T.T. 2002. Influences of fire history and topography on the pattern of a severe wind blowdown in a Colorado subalpine forest. Journal of Ecology 90: 806-819. 
Lafon, C.W. 2004. Stand dynamics of a yellow-poplar (Liriodendron tulipifera L.) forest in the Appalachian Mountains, Virginia, USA. Dendrochronologia. 22: 43-52.

Lafon, C.W. 2006. Forest disturbance by ice storms in Quercus forests of the southern Appalachian Mountains, USA. Ecoscience. 13: 30-43.

Lafon, C.W. and Kutac, M.J. 2003. Effects of ice storms, southern pine beetle infestation, and fire on Table Mountain pine forests of southwestern Virginia. Physical Geography. 24: 502-519.

Lafon, C.W. and J.H. Speer. 2002. Using dendrochronology to identify major ice storm events in oak forests of southwestern Virginia. Climate Research 20: 41-54.

Lageard, J.G.A., P.A. Thomas, F.M. Chambers. 2000. Using fire scars and growth release in subfossil Scots pine to reconstruct prehistoric fires. Palaeogeography, Palaeoclimatology, Palaeoecology 164: 87-99.

Land, A.D. and Rieske, L.K. 2006. Interactions among prescribed fire, herbivore pressure and shortleaf pine (Pinus echinata) regeneration following southern pine beetle (Dendroctonus frontalis) mortality. Forest Ecology and Management, 235: 260-269.

Lewis, D.A. 2004. Nineteenth century Shannon County, Vol. 2. 189pp.

Liming, F.G. 1946. The range and distribution of shortleaf pine in Missouri. Technical Paper 106. Columbus, OH. USDA, Forest Service, Central States Experiment Station. 4p.

Lorente, M., Parsons, W.F.J., McIntire, E.J.B., and Munson, A.D. 2012. Wildfire and forest harvest disturbances in the boreal forest leave different long-lasting spatial signatures. Plant Soil. Published online: http://www.springerlink.com/content/250220h557548123/. Accessed: 1 July 2012.

Lorimer, C.G. and Frelich, L.E. 1989. A methodology for estimating canopy disturbance frequency and intensity in dense temperate forests. Canadian Journal of Forest Research. 19: 651-663.

McCarthy, B.C. and D.R. Bailey. 1996. Composition, structure, and disturbance history of Crabtree Woods: an old-growth forest of western Maryland. Bulletin of the Torrey Botanical Club 123: 350-365.

McEwan, R.W., T.F. Hutchinson, R.P. Long, D.R. Ford, B.C. McCarthy. 2007. Temporal and spatial patterns in fire occurrence during the establishment of mixed-oak forests in eastern North America. Journal of Vegetation Science 18: 655-664.

Millward, A.A. and Kraft, C.E. 2004. Physical influences of landscape on a large-extent ecological disturbance: the northeastern North American ice storm of 1998. Landscape Ecology. 19: 99-111.

Morin, H., Laprise, D. and Bergeron, Y. 1993. Chronology of spruce budworm outbreaks near Lake Duparquet, Abitibi region, Quebec. Canadian Journal of Forest Research 23: 14971506. 
Morrow, L. 2008. Piney sawmillers at Gasconade mills. Old Settlers Gazette newspaper. pp. 3042.

Moser, W.K., C.H. Barnett, M.H. Hansen, C.M. Kurtz, T.B. Treiman. 2011. Missouri's forest resources, 2010. Res. Note NRS-117. Newtown Square, PA: U.S. Department of Agriculture, Forest Service, Northern Research Station.

Muzika, R.M. and Guyette, R.P. 2004. A dendrochronological analysis of red oak borer abundance. In: Spetich, M.A. ed. Upland oak ecology symposium: history, current conditions, and sustainability. GTR SRS-73. Asheville, NC. USDA, Forest Service, Southern Research Station. 102-105.

Muzika, R.M. and Liebhold, A.M. 1999. Changes in radial increment of host and nonhost tree species with gypsy moth defoliation. Canadian Journal of Forest Research. 29: 1365-1373.

National Climatic Data Center. 2012. Climatic data publications [online]. Available from http://www7.ncdc.noaa.gov/IPS/cd/cd.html [accessed 24 May 2012].

Nelson, P.W. 2005. The Terrestrial Natural Communities of Missouri. Missouri Natural Areas Committee. 550pp.

Nesbitt, J.H. 2001. Quantifying forest fire variability using tree rings, Nelson, British Columbia. M.S. Thesis. Middlebury College. 113pp.

Nigh, T.A. and W.A. Schroeder. Atlas of Missouri ecoregions. Missouri Department of Conservation, Jefferson City, MO. 212pp.

Nowacki, G.J. and Abrams, M.D. 1997. Radial-growth averaging criteria for reconstructing disturbance histories from presettlement-origin oaks. Ecological Monographs. 67: 225-249.

Nowacki, G.J. and Abrams, M.D. The demise of fire and "mesophication" of forests in the eastern United States. Bioscience. 58: 123-138.

Oliver, C.D. and Larson, B.C. 1996. Forest Stand Dynamics. Jon Wiley and Sons, New York, N.Y. 520pp.

Orwig, D.A. and M.D. Abrams. 1997. Variation in radial growth responses to drought among species, site, and canopy strata. Trees 11: 474-484.

Pan, C., S.J. Taichman, J.N. Kochenderfer. 1997. Dendroclimatological analysis of major forest species of the central Appalachians. Forest Ecology and Management 98: 77-87.

Palmer, W.C. 1965. Meteorological drought. U.S. Department of Commerce, Weather Bureau Research Paper No. 45, Washington, D.C. 58pp.

Parker, T.J., Clancy, K.M., and Mathiasen, R.L. 2006. Interactions among fire, insects and pathogens in coniferous forests of the interior western United States and Canada. Agricultural and Forest Entomology, 8: 167-189.

Pascual, M. and Guichard, F. 2005. Criticality and disturbance in spatial ecological systems. Trends in Ecology and Evolution 20: 88-95. 
Pedersen, B.S. 1998. The role of stress in the mortality of Midwestern oaks as indicated by growth prior to death. Ecology 79: 79-93.

Pederson, C.J. 2007. Consistent influence of tree diameter and species on damage in nine eastern North America tornado blowdowns. Forest Ecology and Management. 250: 96-108.

Pederson, N., A.R. Bell, T.A. Knight, C. Leland, N. Malcomb, K.J. Anchukaitis, K. Tackett, J. Scheff, A. Brice, B. Catron, W. Blozan, and J. Riddle. 2012. A long-term perspective on a modern drought in the American Southeast. Environmental Research Letters 7: 1-12.

Pederson, N., Varner III, J.M., and Palik, B.J. 2008. Canopy disturbance and tree recruitment over two centuries in a managed longlead pine landscape. Forest Ecology and Management. 254: 85-95.

Perry, D.A. and Amaranthus, M.P. 1997. Disturbance, recovery, and stability. In: Creating a Forestry for the $21^{\text {st }}$ Century. eds. Kohm, K.A. and Franklin, J.F. Island Press, Washington, D.C. pp. 31-56.

Peterson, C.J. 2000. Damage and recovery of tree species after two different tornadoes in the same old growth forest: a comparison of infrequent wind disturbances. Forest Ecology and Management. 135: 237-252.

Pickett, S.T.A. and White, P.S. 1985. The Ecology of Natural Disturbance and Patch Dynamics. Academic Press, Orlando.

Pickett, S.T.A., Kolasa, J., Armesto, J., and Collins, S.L. 1989. The ecological concept of disturbance and its expression at various hierarchical levels. Oikos. 54: 129-136

Pisaric, M.F.J., King, D.J., MacIntosh, A.J.M., and Bemrose, R. 2008. Impact of the 1998 ice storm on the health and growth of sugar maple (Acer saccharum Marsh.) dominated forests in Gatineau Park, Quebec. Journal of the Torrey Botanical Society. 135: 530-539.

Pohl, K.A., Hadley, K.S., and Arabas, K.B. 2006. Decoupling tree-ring signatures of climate variation, fire, and insect outbreaks in central Oregon. Tree-Ring Research. 62: 37-50.

Predmore, S.A., McDaniel, J., and Kush, J.S. 2007. Presettlement forests and fire in southern Alabama. Canadian Journal of Forest Research. 37: 1723-1736.

Proulx, O.J. and Greene, D.F. 2001. The relationship between ice thickness and northern hardwood tree damage during ice storms. Canadian Journal of Forest Research. 31: 17581767.

Py, C., J. Bauer, P.J. Weisberg, F. Biondi. 2006. Radial growth responses of singleaf pinyon (Pinus monophylla) to wildfire. Dendrochronologia 24: 39-46.

Quine, C.P. and Gardiner, B.A. 2007. Understanding how the interaction of wind and trees results in windthrow, stem breakage, and canopy gap formation. In: Plant Disturbance Ecology: The Process and Response. eds. Johnson, E.A. and Miyanishi, K. Elsevier, Amsterdam. pp. 103153. 
Rauchfuss, J. 2009. Dynamics of old-growth forests of Minnesota. PhD Dissertation, University of Minnesota. $182 \mathrm{pp}$.

Rebertus, A.J., Shifley, S.R., Richards, R.H., and Roovers, L.M. 1997. Ice storm damage to an old-growth oak-hickory forest in Missouri. American Midland Naturalist. 137: 48-61.

Rebertus, A.J. and Meier, A.J. 2001. Blowdown dynamics in oak-hickory forests of the Missouri Ozarks. Journal of the Torrey Botanical Society. 128: 362-369.

Record, S.J. 1910. Forest conditions of the Ozark region of Missouri. Agricultural Experiment Station, USDA, Forest Service Bull. No. 89. pp. 149-289.

Rentch, J.S. 2001. Stand dynamics and disturbance history of five oak-dominated old-growth stands in the unglaciated Appalachian Plateau. PhD Dissertation. West Virginia University, Morgantown, WV. 238 pp.

Rentch, J.S., Desta, F., and Miller, G.W. 2002. Climate, canopy disturbance, and radial growth averaging in a second-growth mixed-oak forest in West Virginia, U.S.A. Canadian Journal of Forest Research 32: 915-927.

Rentch, J.S., M.A. Fajvan, and R.R. Hicks, Jr. 2003. Spatial and temporal disturbance characteristics of oak-dominated old-growth stands in the central hardwood forest region. Forest Science 49: 778-789.

Rodionov, S.N. 2004. A sequential algorithm for testing climate regime shifts. Geophysical Research Letters 31, L09204.

Rodionov, S.N. 2005. Application of a sequential regime shift detection method to the Bering Sea ecosystem. ICES Journal of Marine Science 62: 328-332.

Rodionov, S.N. and J.E. Overland. 2005. Application of a sequential regime shift detection method to the Bering Sea ecosystem. ICES Journal of Marine Science 62: 328-332.

Rodionov, S.N. 2006. Use of prewhitening in climate regime shift detection. Geophysical Research Letters 33: 1-4.

Romme, W.H. and Knight, D.H. 1981. Fire frequency and subalpine forest succession along a topographic gradient in Wyoming. Ecology. 62: 319-326.

Romme, W.H. 1982. Fire and landscape diversity in subalpine forests of Yellowstone National Park. Ecological Monographs. 52: 199-221.

Romme, W.H., Everham, E.H., Frelich, L.E., Moritz, M.A., and Sparks, R.E. 1998. Are large, infrequent disturbances qualitatively different from small, frequent disturbances? Ecosystems 1: $524-534$.

Romme, W.H., Allen, C.D., Bailey, J.D., Baker, W.L., Bestelmeyer, B.T., Brown, P.M., Eisenhart, K.S., Floyd, M.L., Huffman, D.W., Jacobs, B.F., Miller, R.F., Muldavin, E.H., Swetnam, T.W., Tausch, R.J., and Weisenberg, P.J. 2009. Historical and modern disturbance regimes, stand structures, and landscape dynamics in pinon-juniper vegetation of the western United States. Rangeland Ecology and Management. 62: 203-222. 
Rubino, D.L. and B.C. McCarthy. 2000. Dendroclimatological analysis of white oak (Quercus alba L., Fagaceae) from an old-growth forest of southeastern Ohio, USA. Journal of the Torrey Botanical Society 127: 240-250.

Rubino, D.L. and McCarthy, B.C. 2004. Comparative analysis of dendroecological methods used to assess disturbance events. Dendrochronologia. 21: 97-115.

Runkle, J.R. 1982. Patterns of disturbance in some old-growth mesic forests of eastern North America. Ecology. 63: 1533-1546.

Runkle, J.R. 1985. Disturbance regimes in temperate forests. In: Natural Disturbance and Patch Dynamics. eds. Pickett, S.T.A. and White, P.S. Academic Press, San Diego. pp. 17-33.

Rykiel, Jr., E.J. 1985. Towards a definition of ecological disturbance. Australian Journal of Ecology. 10: 361-365.

SAS. 2011. SAS version 9.3. SAS Institute, Cary, N.C.

Scheffer, M., Carpenter, S., Foley, J.A., Folke, C., and Walker, B. 2001. Catastrophic shifts in ecosystems. Nature 413: 591-596.

Scheffer, M. and Carpenter, S.R. 2003. Catastrophic regime shifts in ecosystems: linking theory to observation. Trends in Ecology and Evolution 18: 648-656.

Schoennagel, T., Veblen, T.T., Negron, J.F., and Smith J.M. 2012. Effects of mountain pine beetle on fuels and expected fire behavior in lodgepole pine forests, Colorado, USA. PLoS ONE. 7:e30002. doi: 10.1371/journal/pone.0030002.

Schowalter, T.D. 1985. Adaptations of insects to disturbance. In: Natural Disturbance and Patch Dynamics. eds. Pickett, S.T.A. and White P.S. pp. 235-252.

Shelton, M.G. and M.D. Cain. 2000. Regenerating uneven-aged stands of loblolly and shortleaf pines: the current state of knowledge. Forest Ecology and Management 129: 177-193.

Shirakura, F., Sasaki, K., Arevelo, J.R., Palmer, M.W. 2006. Tornado damage of Quercus stellata and Quercus marilandica in the Cross Timbers, Oklanhoma, USA. Journal of Vegetation Science. 17: 347-352.

Sibold, J.S. and Veblen, T.T. 2006. Relationships of subalpine forest fires in the Colorado Front Range with interannual and multidecadal-scale climatic variation. Journal of Biogeography. 33: 833-842.

Sigmaplot. 2008. Sigmaplot version 11.0. Systat Software Inc. Chicago, IL.

Smith, G.F., Nicholas, N.S., and Zedaker, S.M. 1997. Succession dynamics in a maritime forest following Hurricane Hugo and fuel reduction burns. Forest Ecology and Management. 95: 275-283.

Smolnik, M., Hessl, A., and Colbert, J.J. 2006. Species-specific effects of a 1994 ice storm on radial tree growth in Delaware. Journal of the Torrey Botanical Society. 133: 577-584. 
Sousa, W.P. 1984. The role of disturbance in natural communities. Annual Review of Ecology and Systematics. 15: 353-391.

Speer, J.H. 2010. Fundamentals of Tree-Ring Research. The University of Arizona Press, Tucson, AZ. 333pp.

Speer, J.H., Grissino-Mayer, H.D., Orvis, K.H., and Greenberg, C.H. 2009. Climate response of five oak species in the eastern deciduous forest of the southern Appalachian Mountains, USA. Canadian Journal of Forest Research 39: 507-518.

Speer, J.H., Swetnam, T.W., Wickman, B.E., and Youngblood, A. 2001. Changes in Pandora moth outbreak dynamics during the past 622 years. Ecology 82: 679-697.

Stambaugh, M.C. 2001. Forest canopy gap dynamics in shortleaf pine forests of the Ozark Highlands. University of Missouri. M.S. Thesis. 186pp.

Stambaugh, M.C. and R.P. Guyette. 2004. Long-term growth and climate response of shortleaf pine at the Missouri Ozark Forest Ecosystem Project. In Proceedings $14^{\text {th }}$ Central Hardwoods Conference, Wooster, OH, 16-19 March 2004. D.A. Yaussey, D.M. Hix, R.P. Long, and P. Charles Goebel, editors. Newtown Square, PA: USDA Forest Service, GTR-NE-316. pp. 448-458.

Stambaugh, M.C., R.P. Guyette, K.W. Grabner, and J. Kolaks. 2006. Understanding Ozark forest litter variability through a synthesis of accumulation rates and fire events. In: Andrews, P.L., Butler, B.W. eds. Fuels management - how to measure success: conference proceedings. 28-30 March 2006; Portland, OR. Proceedings RMRS-P-41. Fort Collins, CO: USDA Forest Service, Rocky Mountain Research Station. 321-332.

Stambaugh, M.C., Guyette, R.P., and Putnam, C. 2005. Fire in the pines: a 341-year history of wildland fire at Big Spring Pines Natural Area, Ozark National Scenic Riverways. Park Science. 23: 43-47.

Stambaugh, M.C. and R. Muzika. 2004. Promoting shortleaf pine: canopy openness and pine regeneration in closed canopy forests. Forestry Research Note, Report \#7. Jefferson, City, MO: Missouri Department of Conservation. 2p.

Stambaugh, M.C. and Muzika, R.M. 2007. Successional trends of six mature shortleaf pine forests in Missouri. In: Shortleaf Pine Restoration and Ecology, Proceedings of a Symposium. eds. Kabrick, J.M., Dey, D.C., Gwaze, D. 2006 November 7-9, Springfield, MO. Gen. Tech. Rep. NRS-P-15. Newtown Square, PA: USDA, Forest Service, Northern Research Station. pp.59-67.

Stambaugh, M.C., Guyette, R.P., Godfrey, R., McMurry, E.R., and Marschall, J.M. 2009. Fire, drought, and human history near the western terminus of the Cross Timbers, Wichita Mountains, Oklahoma, USA. Fire Ecology. 5: 51-65.

Stambaugh, M.C., Guyette, R.P., and Marschall, J.M. 2011. Longleaf pine (Pinus palustris Mill.) fire scars reveal new details of a frequent fire regime. Journal of Vegetation Science. 22: 1094-1104. 
Steele, J.H. 1998. Regime shifts in marine ecosystems. Ecological Applications 8: S33-S36.

Stevens, Jr., D.L. 1991. A homeland and hinterland: the Current and Jacks Fork Riverways. Historic Resource Study, Ozark National Scenic Riverways. U.S. National Park Service. Midwest Regional Office. Omaha, NE.

Stoffel, M., Bollschweiler, B., Butler, D.R., Luckman, B.H. 2010. Tree Rings and Natural Hazards: A State of the Art. Springer, New York, N.Y. 505 p.

Stokes, M.A. and T.L. Smiley. 1996. An introduction to tree-ring dating. Reprint of 1968. University of Chicago Press ed. University of Arizona Press, Tucson, AZ. 73pp.

Sutherland, E.K. 1997. History of fire in a southern Ohio second-growth mixed oak forest. In: Proceedings of $11^{\text {th }}$ Central Hardwood Forest Conference. Pallardy, S.G. ed. USDA Forest Service General Technical Report NC-188 pp. 172-183.

Swetnam, T.W., Wickman, B.E., Paul, H.G., and Baisan, C.H. 1995. Historical patterns of western spruce budworm and Douglas-fir tussock moth outbreaks in the northern Blue Mountains, Oregon, since AD 1700. Research Papter PNW-RP-484. Portland, OR: USDA Forest Service, Pacific Northwest Research Station. 27p.

Swetnam, T.W. and Baisan, C.H. 1996. Historical fire regime patterns in the southwestern United States since AD 1700. In: Fire Effects in Southwestern Forests, Proceedings of the $2^{\text {nd }} \mathrm{La}$ Mesa Fire Symposium. ed: Allen, C.D. Tech. Rep. RM-GTR-286. USDA Forest Service, Rocky Mountain Research Station. pp. 11-32.

Travis, D.J. and Meentemeyer, V. 1991. Influence of glaze ice storms on growth rates of loblolly pine (Pinus taeda) and shortleaf pine (P. echinata) in the Southern Appalachian Piedmont. Climate Research. 1: 199-205.

Turcotte, R.M., Elliott, T.R., Fajvan, M.A., Park, Y.L., Snider, D.A., Tobin, P.C. 2012. Effects of ice storm damage on hardwood survival and growth in Ohio. Northern Journal of Applied Forestry. 29: 53-59.

Turner, M.G., Baker, W.L., Peterson, C.J., and Peet, R.K. 1998. Factors influencing succession: lessons from large, infrequent natural disturbances. Ecosystems. 1: 511-523.

Turner, M.G., Gardner, R.H., and O’Neill, R.V. 2001. The critical concept of scale. In: Landscape Ecology: In Theory and Practice. Springer-Verlag, Inc. New York, NY. pp. 2745 .

Turner, M.G. 2010. Disturbance and landscape dynamics in a changing world. Ecology 91: 28332849.

Veblen, T.T., Hadley, K.S., Nel, E.M., Kitzberger, T., Reid, M., and Villalba, R. 1994. Disturbance regime and disturbance interactions in a Rocky Mountain subalpine forest. Journal of Ecology 82: 125-135.

Veblen, T.T., Kitzberger, T., and Donnegan, J. 2000. Climatic and human influences on fire regimes in ponderosa pine forests in the Colorado Front Range. Ecological Applications. 10: $1178-1195$. 
Visser, H. 1995. Note on the relation between ring widths and basal area increments. Forest Science 41: 297-304.

Voelker, S.L. 2004. Causes of forest decline and consequences for oak-pine stand dynamics in southeastern Missouri. M.S. Thesis, Department of Forestry, University of Missouri, Columbia, MO.

Voelker, S.L., R.M. Muzika, R.P. Guyette, M.C. Stambaugh. 2006. Historical CO2 growth enhancement declines with age in Quercus and Pinus. Ecological Monographs 76: 549-564.

Volney, W.J.A. 1988. Analysis of historic jack pine budworm outbreaks in the prairie provinces of Canada. Canadian Journal of Forest Research. 18: 1152-1158.

Wade, D.D., B.L. Brock, P.H. Brose, J.B. Grace, G.A. Hock, and W.A. Patterson III. 2000. Fire in eastern ecosystems. In: Wildland Fire in Ecosystems: Effects of Fire on Flora. Brown, J.K. and J.K. Smith, eds. USDA Forest Service General Technical Report RMRS-42 Vol. 2. Pp. 53-96.

Warrillow, M. and Mou, P. 1999. Ice storm damage to forest tree species in the ridge and valley region of southwestern Virginia. Journal of the Torrey Botanical Society. 126: 147-158.

Westerling, A.L. and Swetnam, T.W. 2003. Interannual to decadal drought and wildlife in the western United States. EOS 84: 545, 554-5.

Whitney, H.E., and Johnson, W.C. 1984. Ice storms and forest succession in southwestern Virginia. Bulletin of the Torrey Botanical Club. 111: 429-437.

Yamaguchi, D.K. 1991. A simple method for cross-dating increment cores from living trees. Can. J. For. Res. 21(3): 414-416.

Yorks, T.E. and Adams, K.B. 2005. Ice storm impact and management implications for jack pine and pitch pine stands in New York, USA. Forestry Chronicle. 81: 502-515.

Xi, W., Peet, R.K., Decoster, J.K., and Urban, D.L. 2008. Tree damage risk factors associated with large, infrequent wind disturbances of Carolina forests. Forestry. 81: 317-334.

Zhang, Q.B. and Alfaro, R.I. 2003. Spatial synchrony of the two-year cycle budworm outbreaks in central British Columbia, Canada. Oikos. 102: 146-154. 


\section{APPENDIX A}

The following figures and tables are part of additional disturbance analysis for Chapter 3.

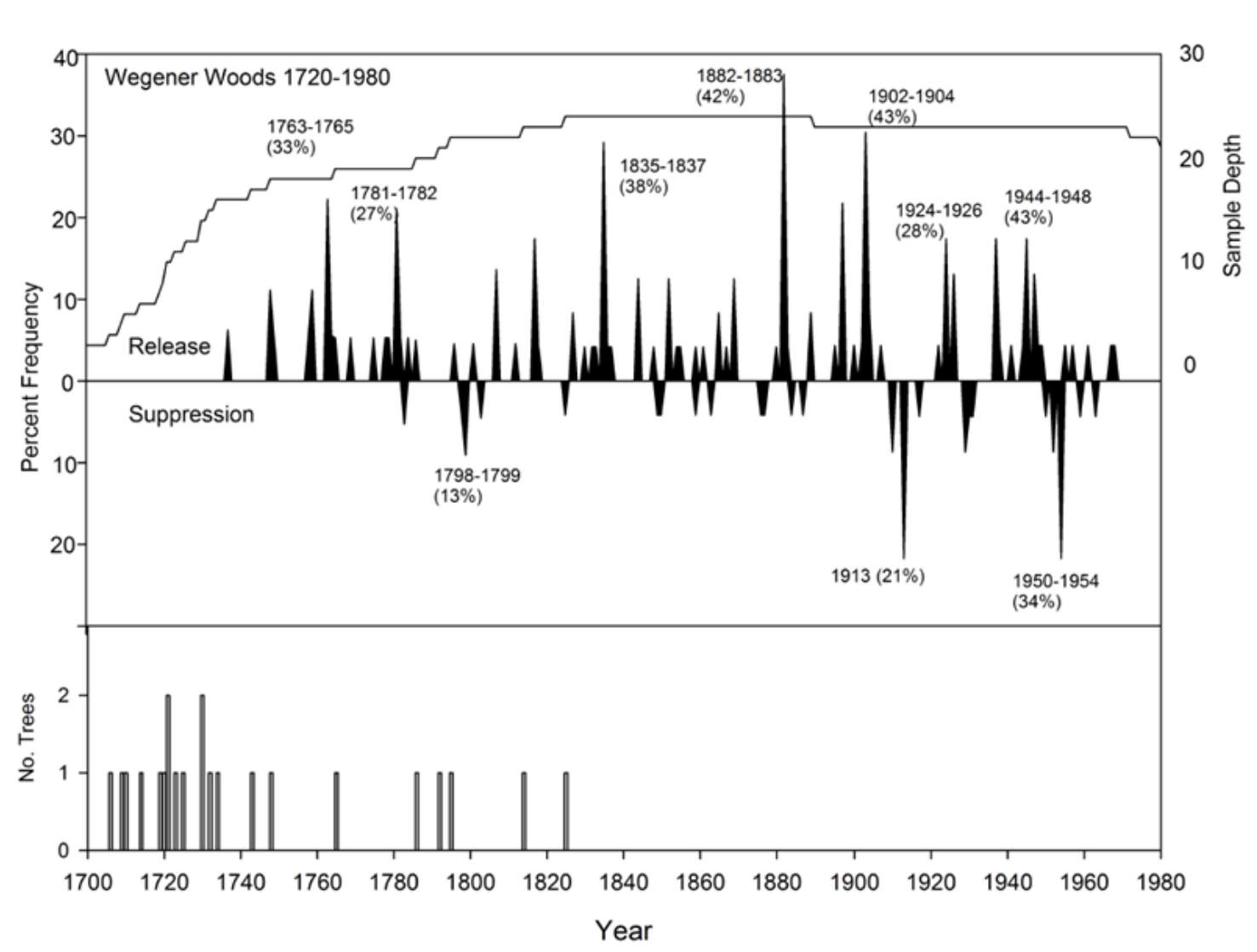

Figure 3.17. Frequency of abrupt increases and decreases in growth of trees at Wegener Woods, Warren County, Missouri 1650-1980. Periods of time are highlighted that include a sample depth $>20$ trees and $>10 \%$ of trees released or suppressed based on mean BAI. Horizontal line indicates the annual number of trees alive in each year (sample depth). White bars indicate inside ring/pith dates of $Q$. alba. 


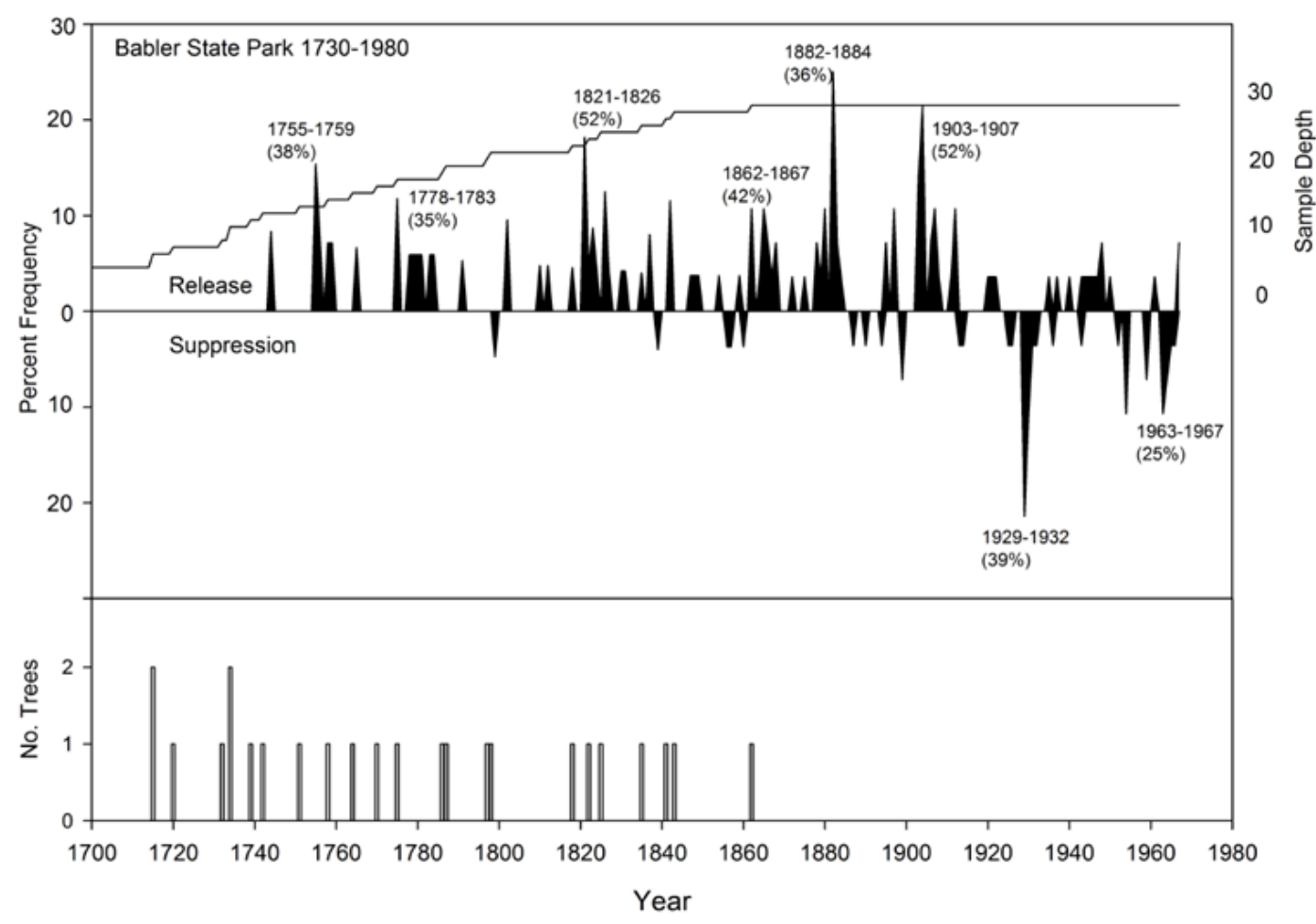

Figure 3.18. Frequency of abrupt increases and decreases in growth of trees at Babler State Park, St. Louis County, Missouri 1650-1980. Periods of time are highlighted that include a sample depth $>20$ trees and $>10 \%$ of trees released or suppressed based on mean BAI. Horizontal line indicates the annual number of trees alive in each year (sample depth). White bars indicate inside ring/pith dates of $Q$. alba. 


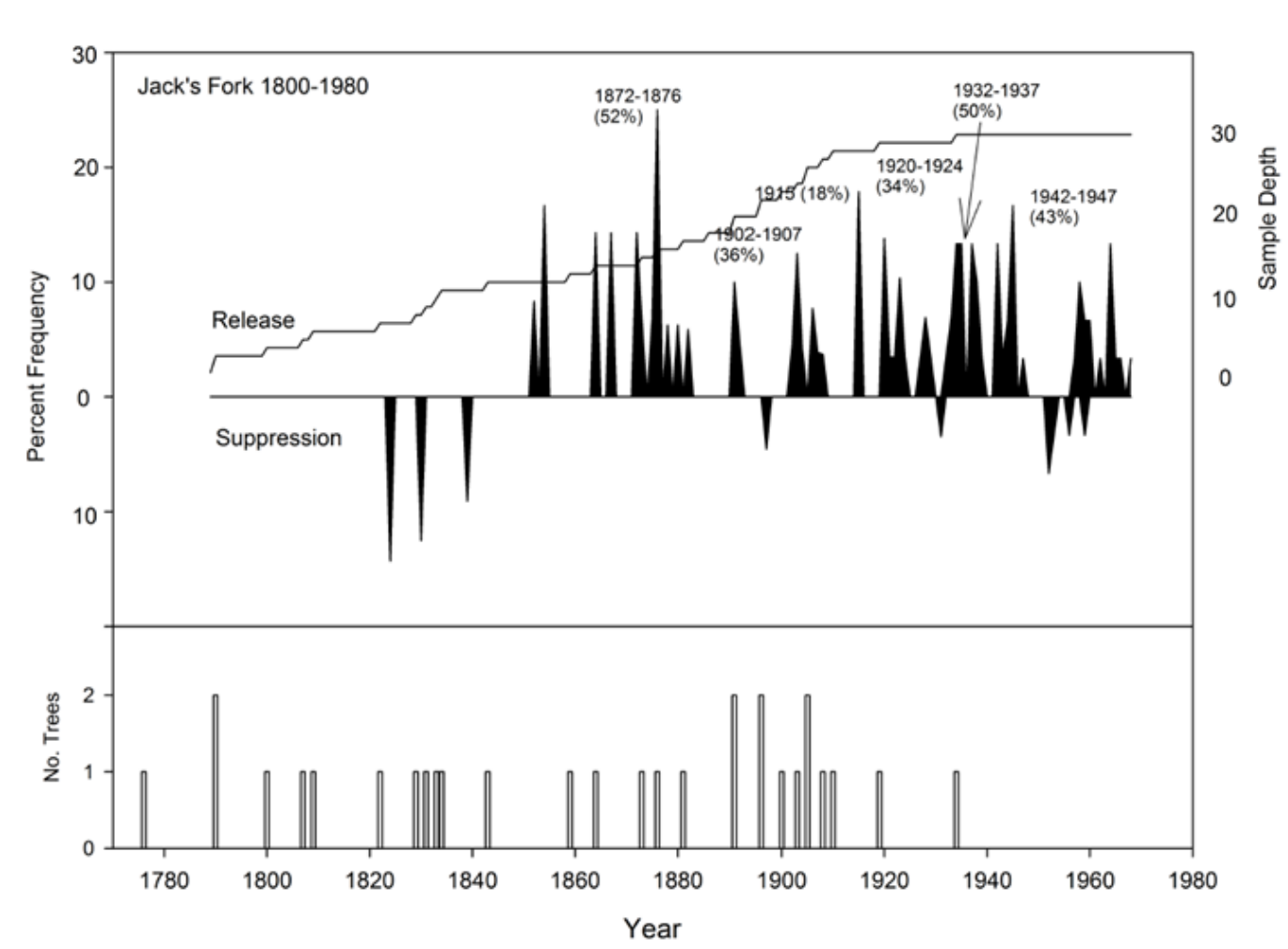

Figure 3.19. Frequency of abrupt increases and decreases in growth of trees at Jack's Fork Site, Shannon County, Missouri 1800-1980. Periods of time are highlighted that include a sample depth $>20$ trees and $>10 \%$ of trees released or suppressed based on mean BAI. Horizontal line indicates the annual number of trees alive in each year (sample depth). White bars indicate inside ring/pith dates of $Q$. alba. 


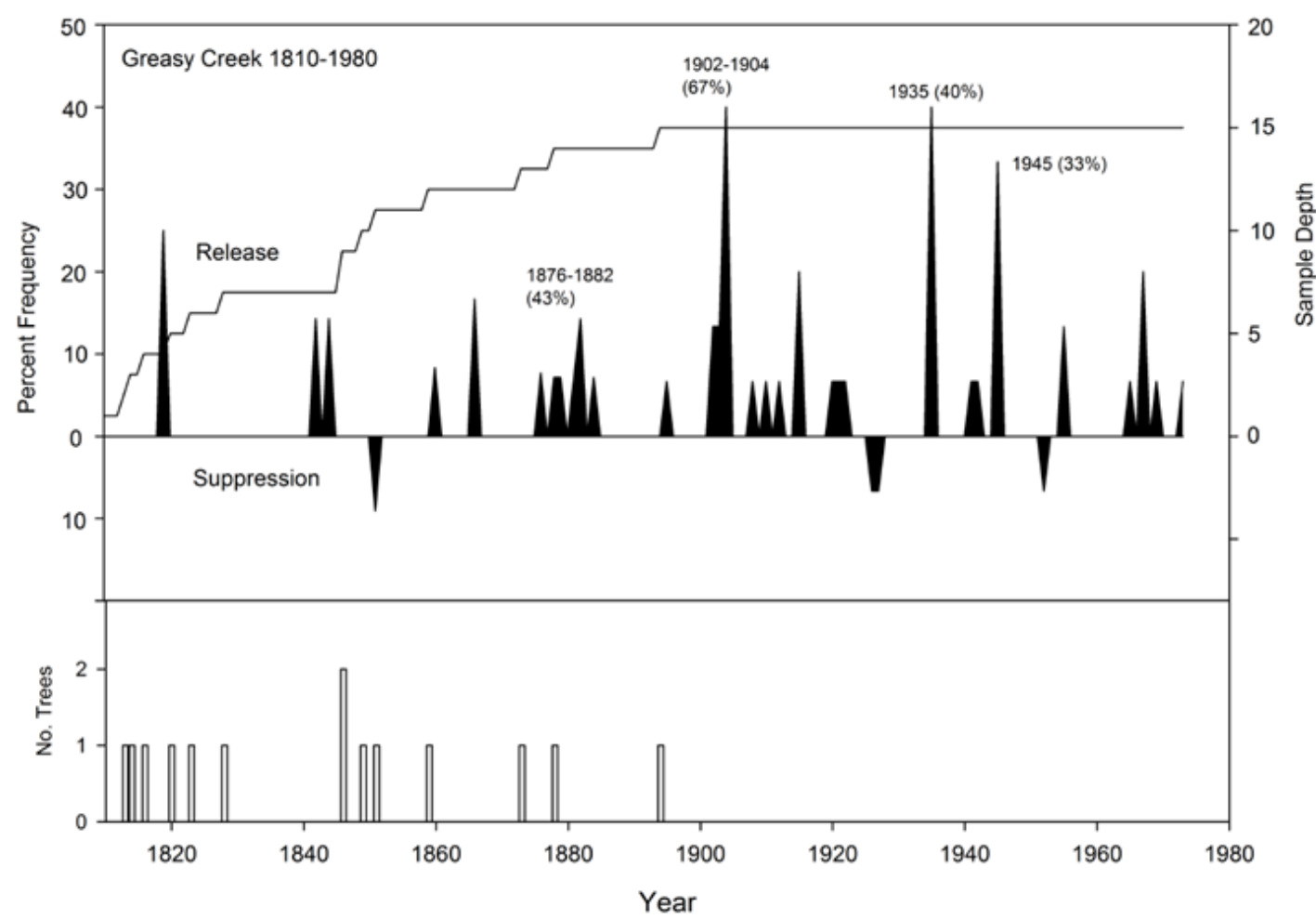

Figure 3.20. Frequency of abrupt increases and decreases in growth of trees at Greasy Creek, Ste. Genevieve County, Missouri 1800-1980. Periods of time are highlighted that include a sample depth $>20$ trees and $>10 \%$ of trees released or suppressed based on mean BAI. Horizontal line indicates the annual number of trees alive in each year (sample depth). White bars indicate inside ring/pith dates of $Q$. alba. 


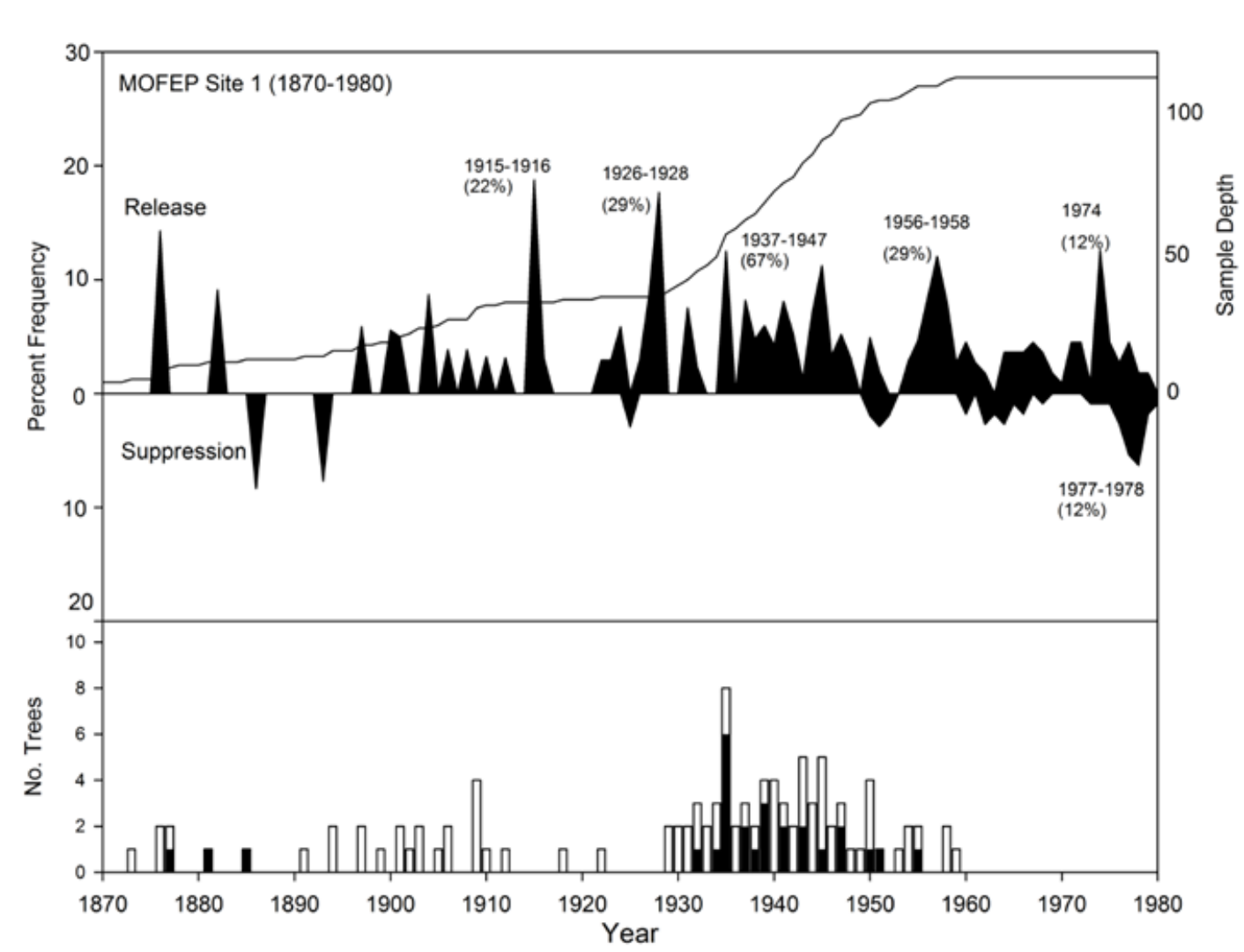

Figure 3.21. Frequency of releases and suppressions in growth of trees at MOFEP 1, Missouri 1870-1980. Periods of time are highlighted that include a sample depth $>20$ trees and $>10 \%$ of trees released or suppressed based on mean BAI. Horizontal line indicates the annual number of trees alive in each year (sample depth). Black bars indicate inside ring/pith dates of $P$. echinata; white bars indicate inside ring/pith dates of $Q$. coccinea/ $Q$. velutina. 


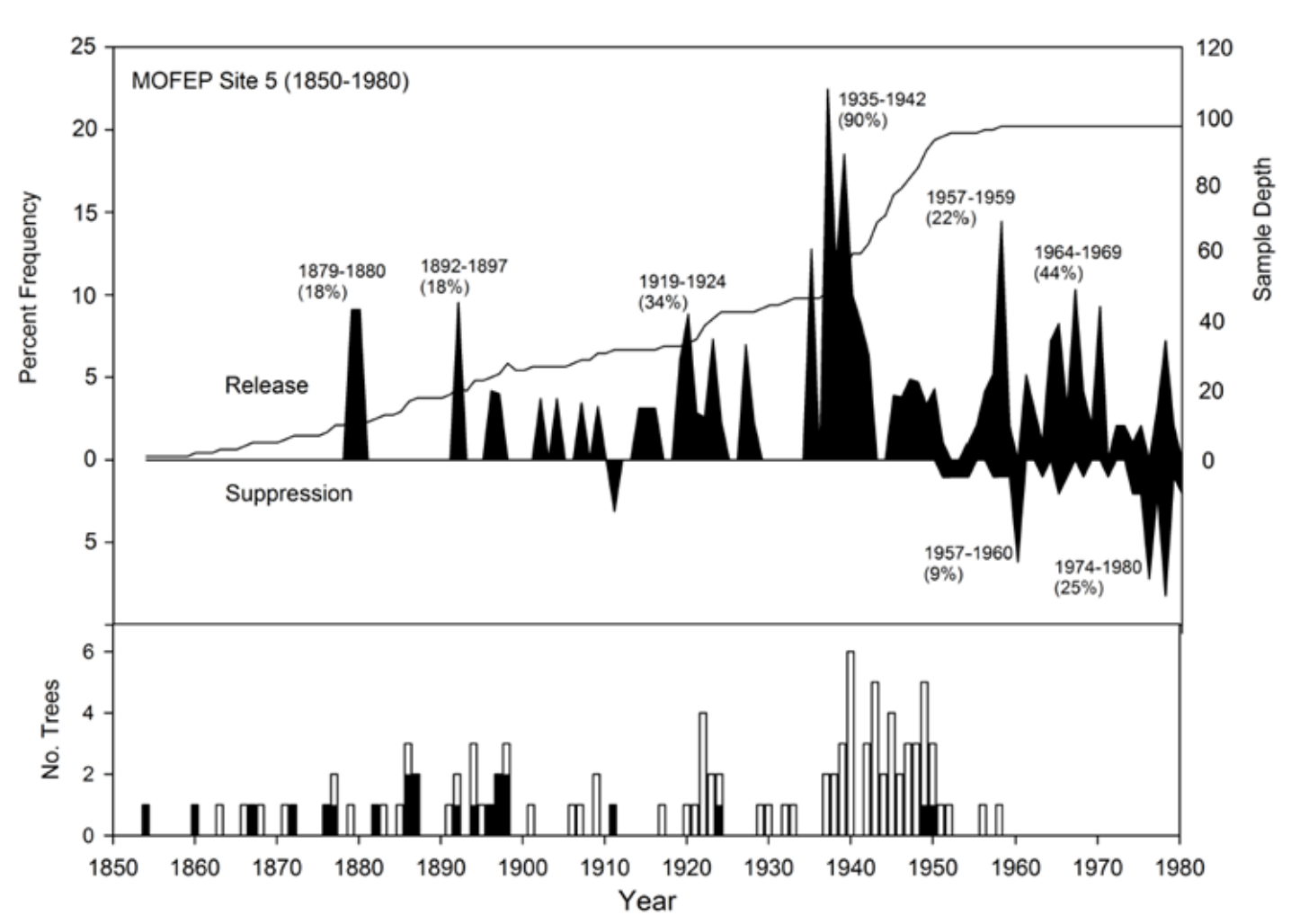

Figure 3.22. Frequency of releases and suppressions in growth of trees at MOFEP 5, Missouri 1850-1980. Periods of time are highlighted that include a sample depth $>20$ trees and $>10 \%$ of trees released or suppressed based on mean BAI. Horizontal line indicates the annual number of trees alive in each year (sample depth).Black bars indicate inside ring/pith dates of $P$. echinata; white bars indicate inside ring/pith dates of $Q$. coccinea/Q. velutina. 


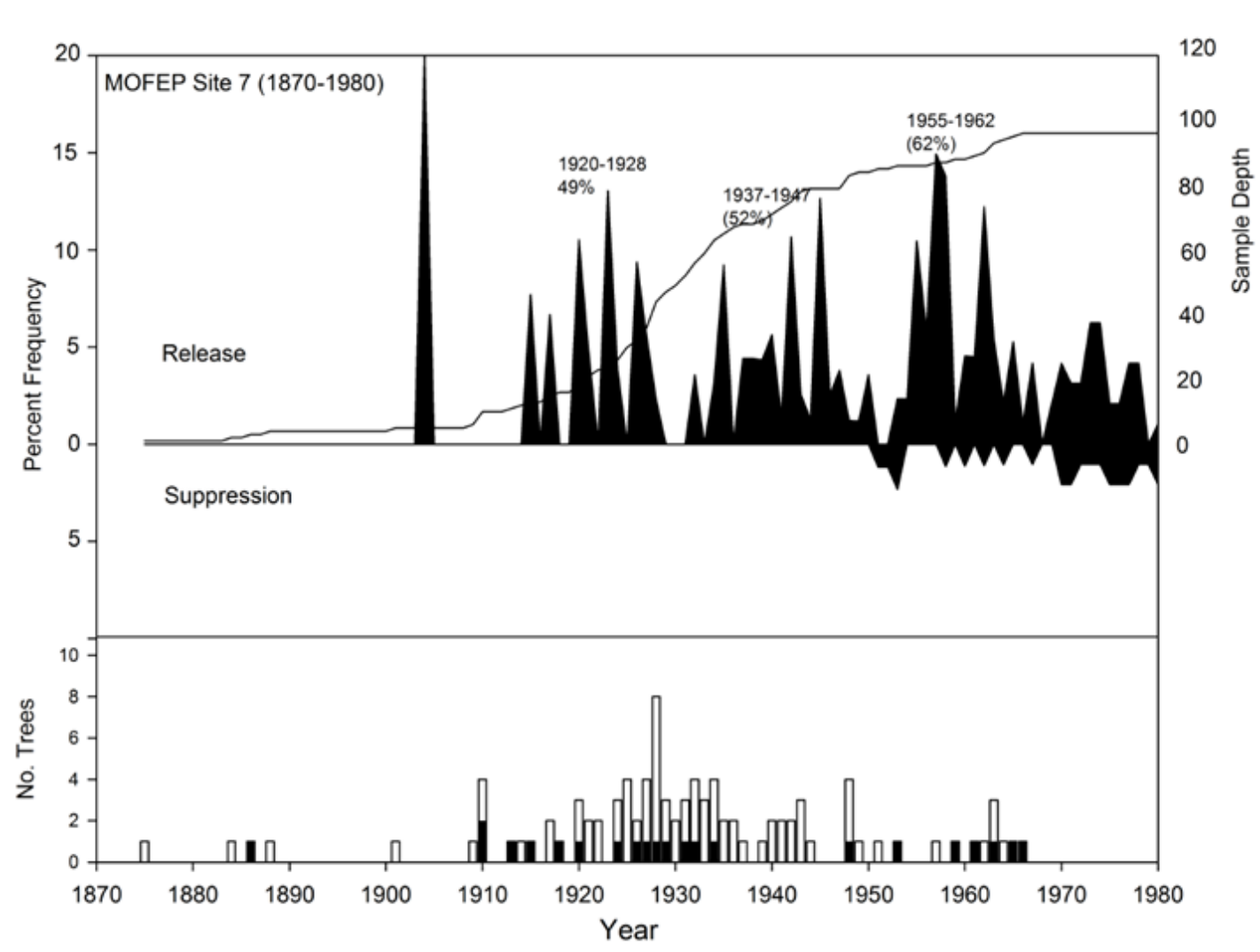

Figure 3.23. Frequency of releases and suppressions in growth of trees at MOFEP 7, Missouri 1870-1980. Periods of time are highlighted that include a sample depth $>20$ trees and $>10 \%$ of trees released or suppressed based on mean BAI. Horizontal line indicates the annual number of trees alive in each year (sample depth). Black bars indicate inside ring/pith dates of $P$. echinata; white bars indicate inside ring/pith dates of $Q$. coccinea/Q. velutina. 


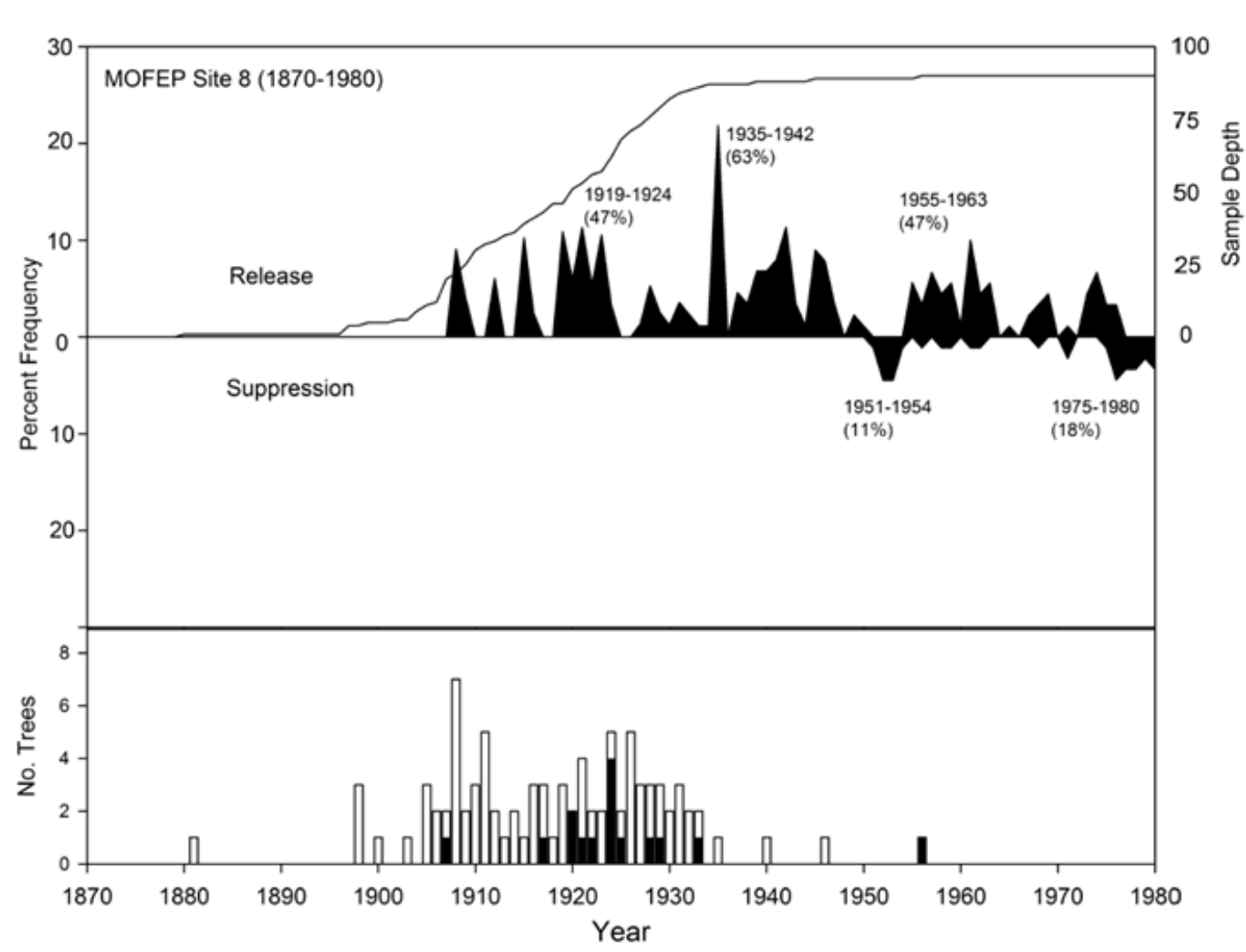

Figure 3.24. Frequency of releases and suppressions in growth of trees at MOFEP 8, Missouri 1870-1980. Periods of time are highlighted that include a sample depth $>20$ trees and $>10 \%$ of trees released or suppressed based on mean BAI. Horizontal line indicates the annual number of trees alive in each year (sample depth). Black bars indicate inside ring/pith dates of $P$. echinata; white bars indicate inside ring/pith dates of $Q$. coccinea/ $Q$. velutina. 


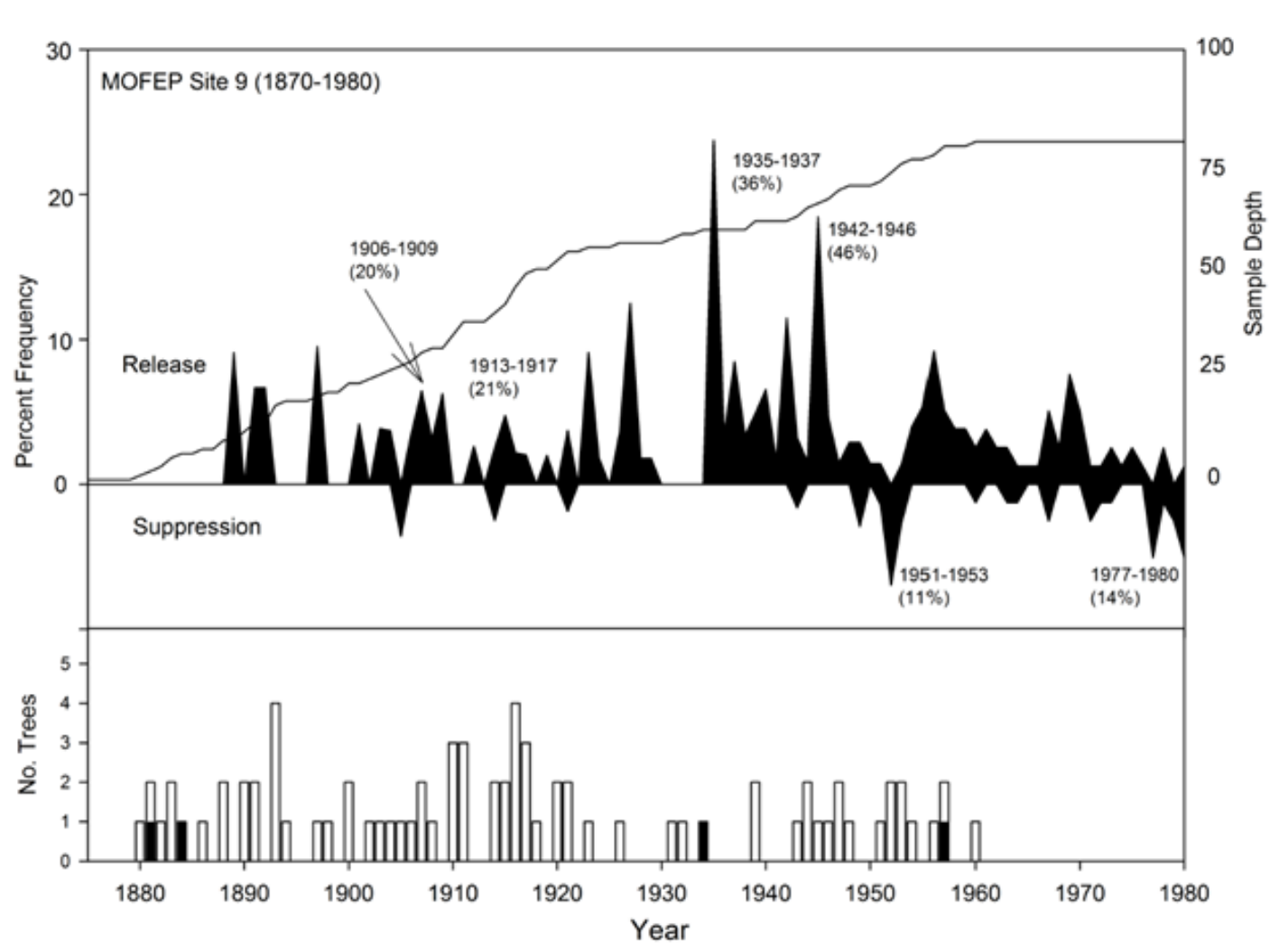

Figure 3.25. Frequency of releases and suppressions in growth of trees at MOFEP 9, Missouri 1870-1980. Periods of time are highlighted that include a sample depth $>20$ trees and $>10 \%$ of trees released or suppressed based on mean BAI. Horizontal line indicates the annual number of trees alive in each year (sample depth).Black bars indicate inside ring/pith dates of $P$. echinata; white bars indicate inside ring/pith dates of $Q$. coccinea/Q. velutina. 
Table 3.5. Decadal analysis of the percentage of $P$. echinata and $Q$. alba trees that exhibited releases and suppressions 1780-1980 at sites with both pine and white oak. Sample depths include trees alive during the decade of analysis. MH = Mill Hollow; LRC = Lower Rock Creek; ECK = Eck Tract; ALS $=$ Alley Springs.

\begin{tabular}{|c|c|c|c|c|c|c|c|c|c|c|c|c|c|c|c|c|c|c|c|c|c|c|c|}
\hline & & & 1780 & 1790 & 1800 & 1810 & 1820 & 1830 & 1840 & 1850 & 1860 & 1870 & 1880 & 1890 & 1900 & 1910 & 1920 & 1930 & 1940 & 1950 & 1960 & 1970 & 1980 \\
\hline \multirow[t]{3}{*}{$\begin{array}{c}\text { Hwy. } \\
19\end{array}$} & Release & $\begin{array}{l}\text { Pine } \\
\text { Oak }\end{array}$ & & 50.0 & 40.0 & $\begin{array}{c}28.6 \\
50\end{array}$ & 10.0 & & $\begin{array}{l}12.5 \\
12.5\end{array}$ & 20.0 & 16.7 & $\begin{array}{l}25 \\
5.9\end{array}$ & 15.0 & $\begin{array}{l}20.8 \\
26.1\end{array}$ & $\begin{array}{l}17.9 \\
26.9\end{array}$ & $\begin{array}{c}3.9 \\
11.1\end{array}$ & 6.7 & $\begin{array}{l}13.0 \\
12.5\end{array}$ & $\begin{array}{l}13.8 \\
58.3\end{array}$ & $\begin{array}{l}67.7 \\
69.8\end{array}$ & $\begin{array}{l}11.9 \\
26.7\end{array}$ & $\begin{array}{c}8.2 \\
39.4\end{array}$ & $\begin{array}{l}29.5 \\
56.1\end{array}$ \\
\hline & Suppress & $\begin{array}{l}\text { Pine } \\
\text { Oak }\end{array}$ & & & & & 5.0 & 8.3 & 16.7 & & 8.3 & & 16.7 & & 3.6 & & & 8.7 & 2.8 & & $\begin{array}{l}1.7 \\
1.7\end{array}$ & $\begin{array}{l}13.1 \\
10.6\end{array}$ & $\begin{array}{l}3.3 \\
4.5\end{array}$ \\
\hline & Depth & $\begin{array}{l}\text { Pine } \\
\text { Oak }\end{array}$ & 2 & 2 & $\begin{array}{l}5 \\
1\end{array}$ & $\begin{array}{c}13 \\
2\end{array}$ & $\begin{array}{c}20 \\
2\end{array}$ & $\begin{array}{c}24 \\
4\end{array}$ & $\begin{array}{c}24 \\
8\end{array}$ & $\begin{array}{l}25 \\
10\end{array}$ & $\begin{array}{l}24 \\
13\end{array}$ & $\begin{array}{l}25 \\
17\end{array}$ & $\begin{array}{l}24 \\
20\end{array}$ & $\begin{array}{l}24 \\
23\end{array}$ & $\begin{array}{l}28 \\
26\end{array}$ & $\begin{array}{l}26 \\
27\end{array}$ & $\begin{array}{l}23 \\
30\end{array}$ & $\begin{array}{l}23 \\
32\end{array}$ & $\begin{array}{l}29 \\
36\end{array}$ & $\begin{array}{l}34 \\
43\end{array}$ & $\begin{array}{l}59 \\
60\end{array}$ & $\begin{array}{l}61 \\
66\end{array}$ & $\begin{array}{l}61 \\
66\end{array}$ \\
\hline \multirow[t]{3}{*}{$\mathrm{MH}$} & Release & $\begin{array}{l}\text { Pine } \\
\text { Oak }\end{array}$ & 6.9 & 14.3 & 35.7 & 20.0 & 16.0 & 8.3 & 62.5 & 8.7 & 4.4 & 20.0 & 5.9 & & 7.1 & $\begin{array}{c}7.7 \\
33.3\end{array}$ & 11.1 & 9.1 & $\begin{array}{c}40 \\
33.3\end{array}$ & $\begin{array}{l}16.7 \\
18.2\end{array}$ & 9.6 & 5.5 & $\begin{array}{l}65.4 \\
21.8\end{array}$ \\
\hline & Suppress & $\begin{array}{l}\text { Pine } \\
\text { Oak }\end{array}$ & 13.8 & 10.7 & & & & 29.2 & & & 21.7 & & 29.1 & 12.5 & 7.1 & 7.7 & & 7.7 & & & $\begin{array}{l}4.8 \\
1.9\end{array}$ & 3.9 & 5.5 \\
\hline & Depth & $\begin{array}{l}\text { Pine } \\
\text { Oak }\end{array}$ & 29 & 28 & 28 & 25 & 25 & $\begin{array}{c}24 \\
1\end{array}$ & $\begin{array}{c}24 \\
1\end{array}$ & $\begin{array}{c}23 \\
1\end{array}$ & $\begin{array}{c}23 \\
1\end{array}$ & $\begin{array}{c}20 \\
1\end{array}$ & $\begin{array}{c}17 \\
1\end{array}$ & $\begin{array}{c}16 \\
1\end{array}$ & $\begin{array}{c}14 \\
2\end{array}$ & $\begin{array}{c}13 \\
3\end{array}$ & $\begin{array}{c}13 \\
9\end{array}$ & $\begin{array}{l}13 \\
11\end{array}$ & $\begin{array}{l}10 \\
15\end{array}$ & $\begin{array}{l}18 \\
33\end{array}$ & $\begin{array}{l}21 \\
52\end{array}$ & $\begin{array}{l}26 \\
55\end{array}$ & $\begin{array}{l}26 \\
55\end{array}$ \\
\hline \multirow[t]{3}{*}{ LRC } & Release & $\begin{array}{l}\text { Pine } \\
\text { Oak }\end{array}$ & 0.0 & $\begin{array}{c}0 \\
22.2\end{array}$ & $\begin{array}{c}0 \\
20\end{array}$ & & $\begin{array}{c}0 \\
15.4\end{array}$ & $\begin{array}{c}20 \\
33.3\end{array}$ & $\begin{array}{l}33.3 \\
12.5\end{array}$ & $\begin{array}{c}50 \\
29.4\end{array}$ & $\begin{array}{l}22.2 \\
17.6\end{array}$ & $\begin{array}{l}18.2 \\
29.4\end{array}$ & $\begin{array}{c}0 \\
47.1\end{array}$ & $\begin{array}{l}14.3 \\
29.4\end{array}$ & $\begin{array}{c}26.67 \\
23.5\end{array}$ & $\begin{array}{c}46.67 \\
58.8\end{array}$ & $\begin{array}{c}13.33 \\
52.9\end{array}$ & $\begin{array}{l}6.67 \\
23.5\end{array}$ & $\begin{array}{l}6.67 \\
58.8\end{array}$ & $\begin{array}{c}0 \\
5.9\end{array}$ & $\begin{array}{c}6.7 \\
23.5\end{array}$ & & \\
\hline & Suppress & $\begin{array}{l}\text { Pine } \\
\text { Oak }\end{array}$ & & & & & $\begin{array}{c}0 \\
7.7\end{array}$ & $\begin{array}{c}0 \\
6.7\end{array}$ & & & & & $\begin{array}{c}0 \\
5.9\end{array}$ & $\begin{array}{c}7.1 \\
11.8\end{array}$ & & 13.3 & $\begin{array}{c}6.7 \\
11.8\end{array}$ & $\begin{array}{l}26.7 \\
17.6\end{array}$ & & $\begin{array}{c}6.7 \\
23.5\end{array}$ & 40.0 & & \\
\hline & Depth & $\begin{array}{l}\text { Pine } \\
\text { Oak }\end{array}$ & $\begin{array}{l}3 \\
8\end{array}$ & $\begin{array}{l}4 \\
9\end{array}$ & $\begin{array}{c}5 \\
10\end{array}$ & $\begin{array}{c}5 \\
13\end{array}$ & $\begin{array}{c}5 \\
13\end{array}$ & $\begin{array}{c}5 \\
15\end{array}$ & $\begin{array}{c}6 \\
16\end{array}$ & $\begin{array}{c}6 \\
17\end{array}$ & $\begin{array}{c}9 \\
17\end{array}$ & $\begin{array}{l}11 \\
17\end{array}$ & $\begin{array}{l}12 \\
17\end{array}$ & $\begin{array}{l}14 \\
17\end{array}$ & $\begin{array}{l}15 \\
17\end{array}$ & $\begin{array}{l}15 \\
17\end{array}$ & $\begin{array}{l}15 \\
17\end{array}$ & $\begin{array}{l}15 \\
17\end{array}$ & $\begin{array}{l}15 \\
17\end{array}$ & $\begin{array}{l}15 \\
17\end{array}$ & $\begin{array}{l}15 \\
17\end{array}$ & & \\
\hline \multirow[t]{3}{*}{ ECK } & Release & $\begin{array}{l}\text { Pine } \\
\text { Oak }\end{array}$ & 10.0 & & $\begin{array}{c}18.2 \\
25\end{array}$ & 21.4 & 5.3 & 5.0 & $\begin{array}{l}19.0 \\
21.4\end{array}$ & $\begin{array}{l}3.6 \\
6.3\end{array}$ & $\begin{array}{l}13.3 \\
18.8\end{array}$ & $\begin{array}{l}40.6 \\
35.3\end{array}$ & $\begin{array}{c}9.4 \\
17.6\end{array}$ & $\begin{array}{c}12.1 \\
15\end{array}$ & $\begin{array}{l}33.3 \\
57.1\end{array}$ & $\begin{array}{l}16.7 \\
65.2\end{array}$ & $\begin{array}{c}8.1 \\
17.4\end{array}$ & $\begin{array}{c}2.5 \\
42.8\end{array}$ & $\begin{array}{c}35 \\
37.5\end{array}$ & $\begin{array}{c}2.5 \\
10.3\end{array}$ & $\begin{array}{c}25 \\
54.8\end{array}$ & $\begin{array}{c}5 \\
12.9\end{array}$ & $\begin{array}{c}5 \\
46.7\end{array}$ \\
\hline & Suppress & $\begin{array}{l}\text { Pine } \\
\text { Oak }\end{array}$ & & & & & 10.5 & & 4.8 & & & & 9.4 & & & $\begin{array}{l}8.3 \\
8.7\end{array}$ & $\begin{array}{l}13.5 \\
21.7\end{array}$ & 2.5 & $\begin{array}{c}15 \\
8.3\end{array}$ & $\begin{array}{c}25 \\
24.1\end{array}$ & 15.0 & $\begin{array}{c}15 \\
6.5\end{array}$ & 5.0 \\
\hline & Depth & $\begin{array}{l}\text { Pine } \\
\text { Oak }\end{array}$ & $\begin{array}{c}10 \\
2\end{array}$ & $\begin{array}{c}10 \\
2\end{array}$ & $\begin{array}{c}11 \\
4\end{array}$ & $\begin{array}{c}14 \\
5\end{array}$ & $\begin{array}{c}19 \\
5\end{array}$ & $\begin{array}{l}20 \\
11\end{array}$ & $\begin{array}{l}21 \\
14\end{array}$ & $\begin{array}{l}28 \\
16\end{array}$ & $\begin{array}{l}30 \\
16\end{array}$ & $\begin{array}{l}32 \\
17\end{array}$ & $\begin{array}{l}32 \\
17\end{array}$ & $\begin{array}{l}33 \\
20\end{array}$ & $\begin{array}{l}36 \\
21\end{array}$ & $\begin{array}{l}36 \\
23\end{array}$ & $\begin{array}{l}37 \\
23\end{array}$ & $\begin{array}{l}40 \\
23\end{array}$ & $\begin{array}{l}40 \\
24\end{array}$ & $\begin{array}{l}40 \\
29\end{array}$ & $\begin{array}{l}40 \\
31\end{array}$ & $\begin{array}{l}40 \\
30\end{array}$ & $\begin{array}{l}40 \\
30\end{array}$ \\
\hline \multirow[t]{3}{*}{ ALS } & Release & $\begin{array}{l}\text { Pine } \\
\text { Oak }\end{array}$ & 23.8 & 14.3 & $\begin{array}{l}8.7 \\
25\end{array}$ & & $\begin{array}{c}8.7 \\
42.9\end{array}$ & $\begin{array}{c}4.2 \\
12.5\end{array}$ & $\begin{array}{c}21.7 \\
20\end{array}$ & 41.7 & $\begin{array}{l}15 \\
20\end{array}$ & $\begin{array}{c}4.5 \\
31.3\end{array}$ & $\begin{array}{l}8.3 \\
10\end{array}$ & $\begin{array}{c}9.4 \\
18.2\end{array}$ & $\begin{array}{l}8.8 \\
32\end{array}$ & 17.2 & $\begin{array}{l}11.1 \\
21.9\end{array}$ & $\begin{array}{l}22.2 \\
57.6\end{array}$ & $\begin{array}{l}12.2 \\
48.2\end{array}$ & $\begin{array}{c}9.3 \\
51.4\end{array}$ & $\begin{array}{l}13.9 \\
41.0\end{array}$ & 15.4 & $\begin{array}{l}20.9 \\
51.3\end{array}$ \\
\hline & Suppress & $\begin{array}{l}\text { Pine } \\
\text { Oak }\end{array}$ & 19.0 & 9.5 & 13.0 & 13.0 & 21.7 & 33.3 & 8.7 & & 6.7 & 4.5 & $\begin{array}{c}16.7 \\
5.0\end{array}$ & 15.6 & $\begin{array}{l}5.9 \\
4.0\end{array}$ & $\begin{array}{c}22.9 \\
6.9\end{array}$ & 19.4 & 2.8 & $\begin{array}{l}4.9 \\
3.0\end{array}$ & $\begin{array}{c}16.3 \\
8.1\end{array}$ & 4.7 & $\begin{array}{l}47.3 \\
17.9\end{array}$ & $\begin{array}{c}0 \\
2.6\end{array}$ \\
\hline & Depth & $\begin{array}{l}\text { Pine } \\
\text { Oak }\end{array}$ & 21 & 21 & $\begin{array}{c}23 \\
4\end{array}$ & $\begin{array}{c}23 \\
6\end{array}$ & $\begin{array}{c}23 \\
7\end{array}$ & $\begin{array}{c}24 \\
8\end{array}$ & $\begin{array}{l}23 \\
10\end{array}$ & $\begin{array}{l}20 \\
12\end{array}$ & $\begin{array}{l}20 \\
15\end{array}$ & $\begin{array}{l}22 \\
16\end{array}$ & $\begin{array}{l}24 \\
20\end{array}$ & $\begin{array}{l}32 \\
22\end{array}$ & $\begin{array}{l}34 \\
25\end{array}$ & $\begin{array}{l}35 \\
29\end{array}$ & $\begin{array}{l}36 \\
32\end{array}$ & $\begin{array}{l}36 \\
33\end{array}$ & $\begin{array}{l}41 \\
33\end{array}$ & $\begin{array}{l}43 \\
37\end{array}$ & $\begin{array}{l}43 \\
39\end{array}$ & $\begin{array}{l}44 \\
39\end{array}$ & $\begin{array}{l}43 \\
39\end{array}$ \\
\hline
\end{tabular}


Table 3.6. Decadal analysis of the percentage of $Q$. alba trees that exhibited releases and suppressions 1780-1980 at sites. Sample depths include trees alive during the decade of analysis.

\begin{tabular}{|c|c|c|c|c|c|c|c|c|c|c|c|c|c|c|c|c|c|c|c|c|c|c|}
\hline & & 1780 & 1790 & 1800 & 1810 & 1820 & 1830 & 1840 & 1850 & 1860 & 1870 & 1880 & 1890 & 1900 & 1910 & 1920 & 1930 & 1940 & 1950 & 1960 & 1970 & 1980 \\
\hline \multirow[t]{3}{*}{$\begin{array}{l}\text { Jacks } \\
\text { Fork } \\
\end{array}$} & Release & & & & & & & 25.0 & 8.3 & & 21.4 & 26.7 & 58.8 & 5.3 & 12.5 & 37.9 & 30.0 & 33.3 & 50.0 & 43.3 & 26.7 & 26.7 \\
\hline & Suppress & & & & & & & & & & & & & & 4.2 & & & & 3.3 & & 16.7 & \\
\hline & Depth & 1 & 1 & 3 & 4 & 6 & 6 & 8 & 12 & 13 & 14 & 15 & 17 & 19 & 24 & 29 & 30 & 30 & 30 & 30 & 30 & 30 \\
\hline \multirow[t]{3}{*}{$\begin{array}{l}\text { Wegen. } \\
\text { Woods } \\
\end{array}$} & Release & 15.8 & 36.8 & 5.0 & 18.2 & 27.3 & 8.7 & 50.0 & 12.5 & 25.0 & 25.0 & & 54.2 & 26.1 & 52.2 & & 34.8 & 21.7 & 47.8 & 8.7 & 13.0 & \\
\hline & Suppress & & 5.3 & 15.0 & 4.5 & & 4.3 & & 4.2 & 8.3 & 4.2 & 8.3 & 8.3 & & & 30.4 & 8.7 & 8.7 & & 30.4 & 4.3 & \\
\hline & Depth & 19 & 19 & 20 & 22 & 22 & 23 & 24 & 24 & 24 & 24 & 24 & 24 & 23 & 23 & 23 & 23 & 23 & 23 & 23 & 23 & \\
\hline \multirow[t]{3}{*}{$\begin{array}{l}\text { Greasy } \\
\text { Creek }\end{array}$} & Release & $\begin{array}{c}100 . \\
0\end{array}$ & & $\begin{array}{c}100 . \\
0\end{array}$ & & & 28.6 & 10.0 & 16.7 & 25.0 & 28.6 & 7.1 & 80.0 & 33.3 & 13.3 & 40.0 & 46.7 & 13.3 & 33.3 & 6.7 & 0.0 & \\
\hline & Suppress & & & & & & & 10.0 & & & & & & & 13.3 & & & 6.7 & & & & \\
\hline & Depth & 1 & 1 & 1 & 1 & 1 & 5 & 7 & 7 & 10 & 12 & 12 & 14 & 14 & 15 & 15 & 15 & 15 & 15 & 15 & 15 & \\
\hline \multirow[t]{3}{*}{$\begin{array}{c}\text { Babler } \\
\text { St. Park }\end{array}$} & Release & 33.3 & 18.8 & 5.9 & 15.8 & 10.5 & 61.9 & 18.2 & 24.0 & 8.0 & 46.2 & 30.8 & 38.5 & 19.2 & 61.5 & 19.2 & 7.7 & 11.5 & 30.8 & & 11.5 & \\
\hline & Suppress & & & 5.9 & & & & 4.5 & & 12.0 & & & 7.7 & 11.5 & & 7.7 & 42.3 & 11.5 & 3.8 & 23.1 & 26.9 & \\
\hline & Depth & 15 & 16 & 17 & 19 & 19 & 21 & 22 & 25 & 25 & 26 & 26 & 26 & 26 & 26 & 26 & 26 & 26 & 26 & 26 & 26 & \\
\hline & & & & & & & & & & & & & & & & & & & & & & \\
\hline \multirow[t]{3}{*}{$\begin{array}{l}\text { Current } \\
\text { River } \\
\text { N.A. }\end{array}$} & Release & 35.6 & 37.7 & 35.4 & 16.2 & 16.2 & 41.2 & 8.7 & 7.4 & 18.8 & 23.2 & 52.2 & 10.1 & 7.2 & 31.9 & 18.8 & 24.6 & 4.4 & 58.8 & 20.6 & 29.4 & 9.1 \\
\hline & Suppress & & 1.6 & & 2.9 & 13.2 & & 17.4 & 10.3 & 8.7 & 1.4 & & 10.1 & 18.8 & 1.4 & 2.9 & 14.5 & 4.4 & & 14.7 & 2.9 & 3.0 \\
\hline & Depth & 59 & 61 & 65 & 68 & 68 & 68 & 69 & 68 & 69 & 69 & 69 & 69 & 69 & 69 & 69 & 69 & 68 & 34 & 34 & 34 & 33 \\
\hline
\end{tabular}


Table 3.7. Decadal analysis of the percentage of $P$. echinata and $Q$. coccinea/Q. velutina trees that exhibited releases and suppressions $1800-1980$ at MOFEP sites. Sample depths include trees alive during the decade of analysis. Site numbers correspond to MOFEP compartments. Blank areas indicate no detection of releases or suppressions.

\begin{tabular}{|c|c|c|c|c|c|c|c|c|c|c|c|c|c|c|c|c|c|c|c|c|c|}
\hline Site & & & 1800 & 1810 & 1820 & 1830 & 1840 & 1850 & 1860 & 1870 & 1880 & 1890 & 1900 & 1910 & 1920 & 1930 & 1940 & 1950 & 1960 & 1970 & 1980 \\
\hline \multirow[t]{3}{*}{1} & Release & $\begin{array}{l}\text { Pine } \\
\text { Oak }\end{array}$ & & & & & & & $\begin{array}{c}100 . \\
0\end{array}$ & 50.0 & $\begin{array}{l}14.3 \\
33.3\end{array}$ & 14.3 & $\begin{array}{c}23.1 \\
60\end{array}$ & $\begin{array}{c}23.1 \\
60\end{array}$ & $\begin{array}{c}46.4 \\
20\end{array}$ & $\begin{array}{l}39.4 \\
52.6\end{array}$ & $\begin{array}{l}46.2 \\
62.9\end{array}$ & $\begin{array}{l}54.7 \\
27.6\end{array}$ & $\begin{array}{l}34.1 \\
20.7\end{array}$ & $\begin{array}{c}51.2 \\
3.4\end{array}$ & $\begin{array}{l}35.4 \\
51.7\end{array}$ \\
\hline & Suppress & $\begin{array}{l}\text { Pine } \\
\text { Oak }\end{array}$ & & & & & & & & & 33.3 & 14.3 & & & 3.6 & & & $\begin{array}{c}2.7 \\
17.2\end{array}$ & $\begin{array}{c}2.4 \\
41.4\end{array}$ & $\begin{array}{c}7.3 \\
51.7\end{array}$ & $\begin{array}{l}7.3 \\
3.4\end{array}$ \\
\hline & Depth & $\begin{array}{l}\text { Pine } \\
\text { Oak }\end{array}$ & & & 1 & 1 & 1 & 1 & $\begin{array}{l}1 \\
1\end{array}$ & $\begin{array}{l}2 \\
2\end{array}$ & $\begin{array}{l}7 \\
3\end{array}$ & $\begin{array}{l}7 \\
5\end{array}$ & $\begin{array}{c}13 \\
5\end{array}$ & $\begin{array}{c}26 \\
5\end{array}$ & $\begin{array}{c}28 \\
5\end{array}$ & $\begin{array}{l}33 \\
19\end{array}$ & $\begin{array}{l}52 \\
27\end{array}$ & $\begin{array}{l}75 \\
29\end{array}$ & $\begin{array}{l}82 \\
29\end{array}$ & $\begin{array}{l}82 \\
29\end{array}$ & $\begin{array}{l}82 \\
29\end{array}$ \\
\hline \multirow[t]{3}{*}{2} & Release & $\begin{array}{l}\text { Pine } \\
\text { Oak }\end{array}$ & $\begin{array}{c}11.11 \\
1\end{array}$ & & $\begin{array}{c}11.11 \\
1\end{array}$ & 20 & 40 & $\begin{array}{c}10 \\
100\end{array}$ & & $\begin{array}{c}33.3 \\
50\end{array}$ & $\begin{array}{c}13.3 \\
0\end{array}$ & $\begin{array}{c}18.8 \\
75\end{array}$ & $\begin{array}{l}13.3 \\
28.6\end{array}$ & $\begin{array}{c}7.7 \\
22.2\end{array}$ & $\begin{array}{c}6.7 \\
60\end{array}$ & $\begin{array}{c}55.6 \\
50\end{array}$ & $\begin{array}{l}45.8 \\
42.1\end{array}$ & $\begin{array}{l}27.6 \\
41.7\end{array}$ & $\begin{array}{l}16.7 \\
20.8\end{array}$ & $\begin{array}{l}16.7 \\
20.8\end{array}$ & $\begin{array}{l}23.3 \\
33.3\end{array}$ \\
\hline & Suppress & $\begin{array}{l}\text { Pine } \\
\text { Oak }\end{array}$ & & & $\begin{array}{c}11.11 \\
1\end{array}$ & & & & $\begin{array}{c}14.3 \\
0\end{array}$ & & $\begin{array}{c}20 \\
0\end{array}$ & $\begin{array}{c}12.5 \\
0\end{array}$ & & $\begin{array}{c}7.7 \\
11.1\end{array}$ & $\begin{array}{c}6.7 \\
0\end{array}$ & & $\begin{array}{c}4.2 \\
0\end{array}$ & $\begin{array}{l}3.4 \\
8.3\end{array}$ & $\begin{array}{c}20 \\
0\end{array}$ & $\begin{array}{l}33.3 \\
29.2\end{array}$ & $\begin{array}{c}13.3 \\
0\end{array}$ \\
\hline & Depth & $\begin{array}{l}\text { Pine } \\
\text { Oak }\end{array}$ & 9 & 10 & 9 & 10 & 10 & $\begin{array}{c}10 \\
1\end{array}$ & $\begin{array}{c}14 \\
1\end{array}$ & $\begin{array}{c}15 \\
2\end{array}$ & $\begin{array}{c}15 \\
4\end{array}$ & $\begin{array}{c}16 \\
4\end{array}$ & $\begin{array}{c}15 \\
7\end{array}$ & $\begin{array}{c}13 \\
9\end{array}$ & $\begin{array}{l}15 \\
10\end{array}$ & $\begin{array}{l}18 \\
10\end{array}$ & $\begin{array}{l}24 \\
19\end{array}$ & $\begin{array}{l}29 \\
24\end{array}$ & $\begin{array}{l}30 \\
24\end{array}$ & $\begin{array}{l}30 \\
24\end{array}$ & $\begin{array}{l}30 \\
24\end{array}$ \\
\hline \multirow[t]{3}{*}{3} & Release & $\begin{array}{l}\text { Pine } \\
\text { Oak }\end{array}$ & 36.4 & & 7.7 & 28.6 & 38.5 & 15.4 & 7.1 & $\begin{array}{c}33.3 \\
20\end{array}$ & 5 & & $\begin{array}{l}36.6 \\
11.1\end{array}$ & $\begin{array}{c}4.8 \\
15.8\end{array}$ & $\begin{array}{c}15 \\
34.5\end{array}$ & $\begin{array}{l}44.4 \\
63.2\end{array}$ & $\begin{array}{l}61.9 \\
24.3\end{array}$ & $\begin{array}{l}26.7 \\
39.3\end{array}$ & $\begin{array}{c}3.3 \\
47.8\end{array}$ & $\begin{array}{c}3.3 \\
36.7\end{array}$ & $\begin{array}{l}23.3 \\
42.2\end{array}$ \\
\hline & Suppress & $\begin{array}{l}\text { Pine } \\
\text { Oak }\end{array}$ & & & & & & 7.7 & 21.4 & 6.7 & 25 & & & & & & & $\begin{array}{l}10 \\
5.6\end{array}$ & $\begin{array}{c}23.3 \\
8.9\end{array}$ & $\begin{array}{c}53.3 \\
8.9\end{array}$ & $\begin{array}{l}3.3 \\
10\end{array}$ \\
\hline & Depth & $\begin{array}{l}\text { Pine } \\
\text { Oak }\end{array}$ & 11 & 12 & 13 & 14 & 13 & 13 & 14 & $\begin{array}{c}15 \\
5\end{array}$ & $\begin{array}{c}20 \\
7\end{array}$ & $\begin{array}{l}21 \\
12\end{array}$ & $\begin{array}{l}22 \\
18\end{array}$ & $\begin{array}{l}21 \\
19\end{array}$ & $\begin{array}{l}22 \\
29\end{array}$ & $\begin{array}{l}21 \\
38\end{array}$ & $\begin{array}{l}20 \\
74\end{array}$ & $\begin{array}{l}30 \\
89\end{array}$ & $\begin{array}{l}30 \\
90\end{array}$ & $\begin{array}{l}30 \\
90\end{array}$ & $\begin{array}{l}30 \\
90\end{array}$ \\
\hline \multirow[t]{3}{*}{4} & Release & $\begin{array}{l}\text { Pine } \\
\text { Oak }\end{array}$ & 57.1 & 11.1 & & 12.5 & 25 & 37.5 & 12.5 & 33.3 & 18.2 & 20 & $\begin{array}{c}13.3 \\
50\end{array}$ & $\begin{array}{c}7.1 \\
0\end{array}$ & $\begin{array}{c}9.1 \\
0\end{array}$ & $\begin{array}{l}43.8 \\
100\end{array}$ & $\begin{array}{c}17.4 \\
0\end{array}$ & $\begin{array}{l}26.1 \\
41.3\end{array}$ & $\begin{array}{c}13.0 \\
75\end{array}$ & $\begin{array}{c}4.3 \\
40.9\end{array}$ & $\begin{array}{l}26.1 \\
68.2\end{array}$ \\
\hline & Suppress & $\begin{array}{l}\text { Pine } \\
\text { Oak }\end{array}$ & & & 11.1 & & & & 12.5 & & & & & & & & & $\begin{array}{c}17.4 \\
0\end{array}$ & $\begin{array}{c}4.3 \\
0\end{array}$ & $\begin{array}{c}78.2 \\
0\end{array}$ & 0 \\
\hline & Depth & $\begin{array}{l}\text { Pine } \\
\text { Oak }\end{array}$ & 7 & 9 & 9 & 8 & 8 & 8 & 8 & 9 & 11 & 15 & 2 & 2 & 2 & 2 & 3 & 17 & 20 & 22 & 22 \\
\hline \multirow[t]{3}{*}{5} & Release & $\begin{array}{l}\text { Pine } \\
\text { Oak }\end{array}$ & & & & & & & & 33.3 & 16.7 & $\begin{array}{c}7.7 \\
33.3\end{array}$ & 26.7 & $\begin{array}{c}17.6 \\
10\end{array}$ & $\begin{array}{l}33.3 \\
31.8\end{array}$ & $\begin{array}{l}61.1 \\
68.8\end{array}$ & $\begin{array}{l}42.1 \\
51.1\end{array}$ & $\begin{array}{c}5 \\
46.2\end{array}$ & $\begin{array}{l}10 \\
50\end{array}$ & 35.3 & $\begin{array}{c}15 \\
37.8\end{array}$ \\
\hline & Suppress & $\begin{array}{l}\text { Pine } \\
\text { Oak }\end{array}$ & & & & & & & & 0 & 0 & 0 & 0 & $\begin{array}{c}5.9 \\
0\end{array}$ & 0 & 0 & 0 & $\begin{array}{l}20 \\
3.8\end{array}$ & $\begin{array}{l}40 \\
3.7\end{array}$ & $\begin{array}{l}75 \\
6.1\end{array}$ & 7.3 \\
\hline & Depth & $\begin{array}{l}\text { Pine } \\
\text { Oak }\end{array}$ & & & & & & & & 3 & 6 & $\begin{array}{c}13 \\
9\end{array}$ & $\begin{array}{l}16 \\
15\end{array}$ & $\begin{array}{l}17 \\
20\end{array}$ & $\begin{array}{l}18 \\
22\end{array}$ & $\begin{array}{l}19 \\
32\end{array}$ & $\begin{array}{l}20 \\
47\end{array}$ & $\begin{array}{l}20 \\
78\end{array}$ & $\begin{array}{l}20 \\
82\end{array}$ & $\begin{array}{l}20 \\
82\end{array}$ & $\begin{array}{l}20 \\
82\end{array}$ \\
\hline
\end{tabular}




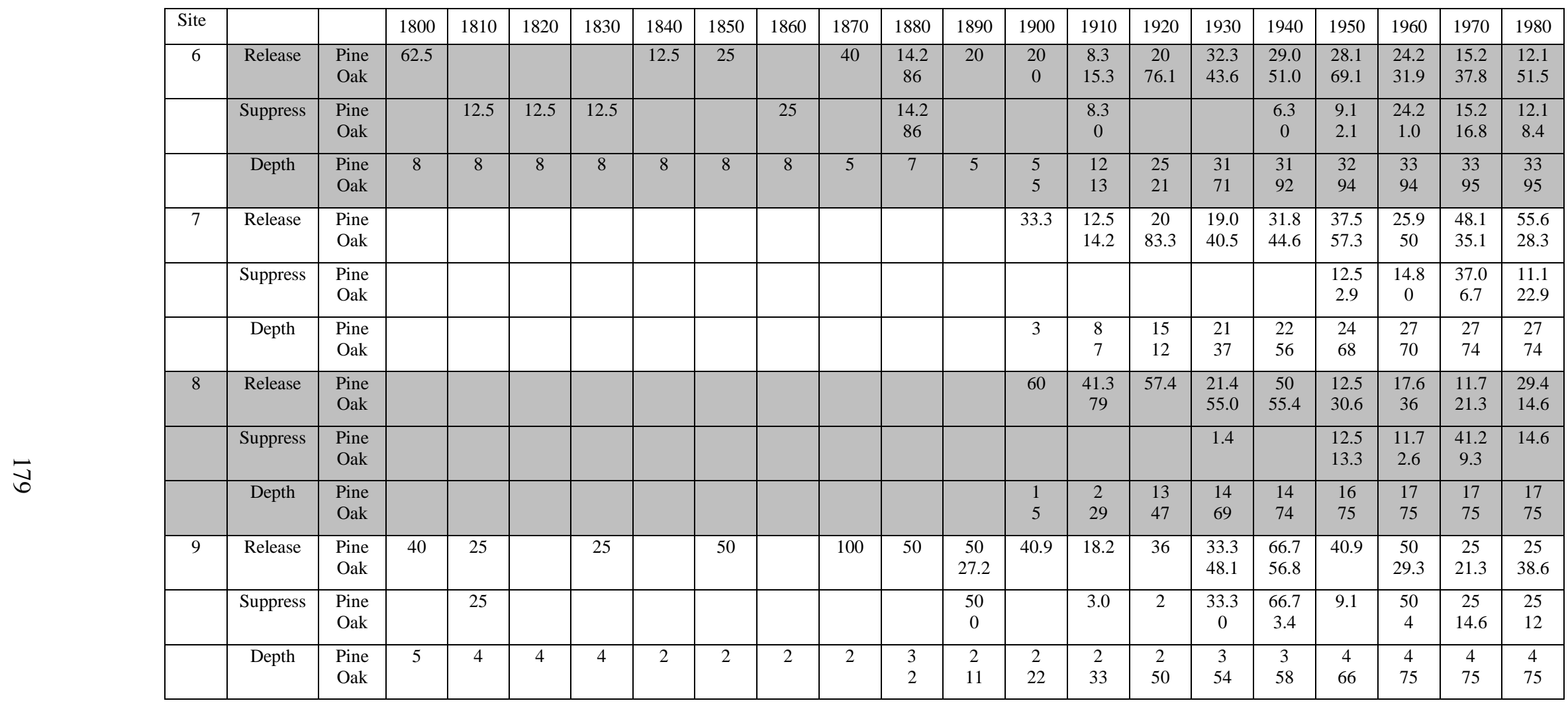


Table 3.8. Canopy accession of $Q$. alba five sites in Missouri. Tree-ring series was accessed via the International Tree-Ring Database (National Climatic Data Center).

\begin{tabular}{|c|c|c|c|c|c|}
\hline $\begin{array}{c}\text { Canopy } \\
\text { Accession }\end{array}$ & $\begin{array}{c}\text { Jack's } \\
\text { Fork } \\
\text { Q. alba } \\
\end{array}$ & $\begin{array}{c}\text { Wegener } \\
\text { Woods } \\
\text { Q. alba }\end{array}$ & $\begin{array}{c}\text { Greasy } \\
\text { Crk } \\
\text { Q. alba } \\
\end{array}$ & $\begin{array}{c}\text { Babler } \\
\text { St. Park } \\
\text { Q. alba }\end{array}$ & $\begin{array}{l}\text { CRNA } \\
Q \text { alba } \\
\end{array}$ \\
\hline $\begin{array}{l}\text { Gap - No } \\
\text { Release }\end{array}$ & 13 & 15 & 7 & 20 & 10 \\
\hline Gap - Release & 4 & 9 & 6 & 8 & 2 \\
\hline $\begin{array}{l}\text { Suppressed - } \\
\text { Release }\end{array}$ & 0 & 0 & 1 & 3 & 5 \\
\hline Total & 17 & 24 & 14 & 31 & 17 \\
\hline
\end{tabular}


Table 3.9. Canopy accession of P. echinata and Quercus species at the nine Missouri Ozark Forest Ecosystem Project (MOFEP) sites. Quercus spp. indicates $Q$. coccinea and $Q$. velutina.

\begin{tabular}{ccc}
\hline Canopy & & \\
Accession & P. echinata & Quercus spp. \\
\hline \hline $\begin{array}{c}\text { Gap - No } \\
\text { Release }\end{array}$ & 60 & 32 \\
Gap - & & \\
Release & 31 & 36 \\
Suppressed - \\
Release & & \\
Total & 8 & 8 \\
\hline
\end{tabular}



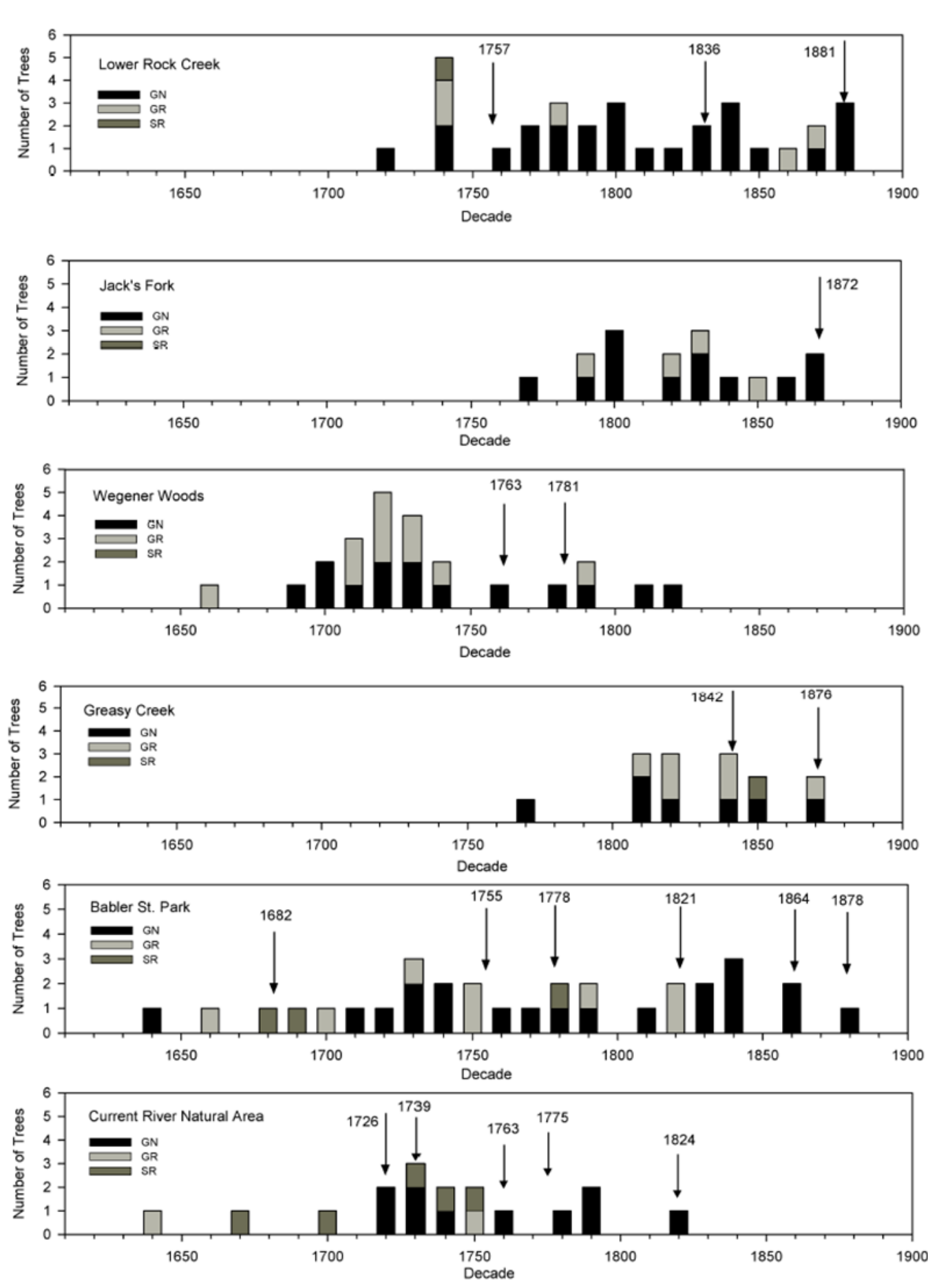

Figure 3.26. Canopy accession strategies by decade at oak sites in Missouri. Years indicate $>25 \%$ trees releasing. $\mathrm{GN}=$ Gap-No release; $\mathrm{GR}=$ Gap-Release; $\mathrm{SR}=$ Suppressed-Release. 

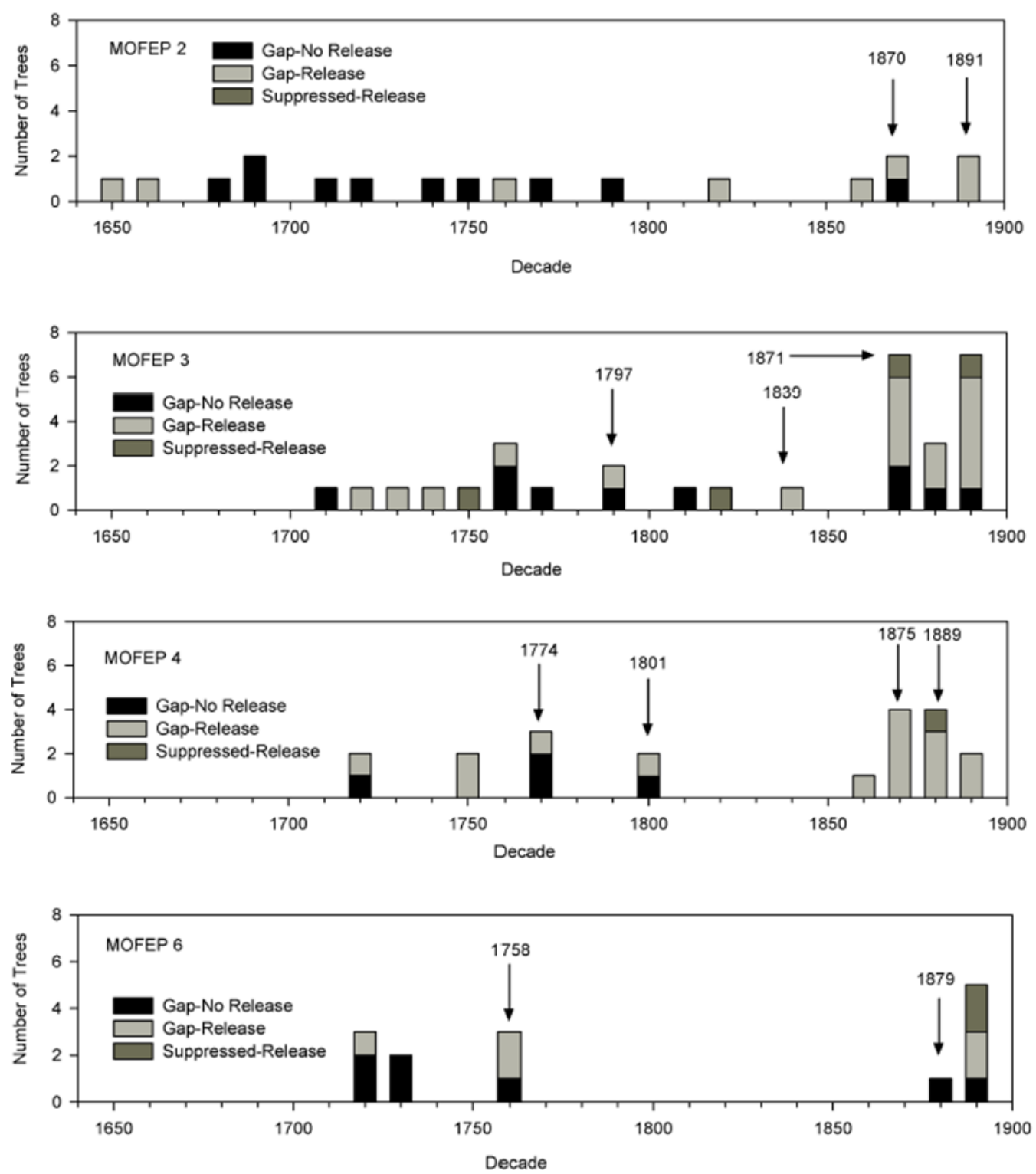

Figure 3.27. Canopy accession strategies by decade at select MOFEP sites in Missouri. Years indicate $>25 \%$ trees releasing. $\mathrm{GN}=$ Gap-No release; $\mathrm{GR}=$ Gap-Release; $\mathrm{SR}=$ Suppressed-Release. 


\section{APPENDIX B}

Statistical results of differences in radial growth prior and subsequent to fire years for Chapter 4. 
Results of Wilcoxon signed ranks test (Chapter 4) to assess differences in radial growth prior and subsequent to fire years with $>2$ scarred trees. All tests were conducted at $\mathrm{p}<0.05$.

Increase/Decrease indicates the greater number of trees that demonstrated increases or decreases in radial growth. Asterisks indicate significance at $p=0.05$. Bolded fire years indicate reconstructed PDSI was $<-2.0$ one year prior to fire.

\begin{tabular}{|c|c|c|c|c|c|c|c|c|c|}
\hline $\begin{array}{c}\text { Mill } \\
\text { Hollow }\end{array}$ & & $\begin{array}{c}1 \mathrm{yr} \\
\text { Growth }\end{array}$ & & & $\begin{array}{l}2 \mathrm{yr} \\
\text { Gror }\end{array}$ & & & $\begin{array}{c}3 \mathrm{yr} \\
\text { Growth }\end{array}$ & \\
\hline & Increase/ & & & Increase/ & & & Increase/ & & \\
\hline Fire Year & Decrease & P-value & & Decrease & $\mathrm{P}$-value & & Decrease & P-value & \\
\hline 1726 & I & 0.404 & & I & 0.611 & & I & 0.854 & \\
\hline 1763 & D & 0.091 & & I & 0.171 & & I & 0.357 & \\
\hline 1768 & I & 0.001 & $*$ & I & 0.008 & $*$ & I & 0.045 & $*$ \\
\hline 1781 & I & $<0.001$ & $*$ & I & $<0.001$ & $*$ & I & $<0.001$ & $*$ \\
\hline 1786 & D & $<0.001$ & $*$ & D & 0.002 & $*$ & $\mathrm{D}$ & 0.002 & $*$ \\
\hline 1794 & I & 0.674 & & I & 0.838 & & I & 0.046 & $*$ \\
\hline 1800 & I & 0.683 & & I & 0.199 & & I & 0.007 & $*$ \\
\hline 1808 & I & 0.001 & $*$ & $\mathrm{D}$ & 0.706 & & I & 0.014 & $*$ \\
\hline 1815 & I & $<0.001$ & $*$ & I & 0.002 & $*$ & I & 0.021 & $*$ \\
\hline 1819 & I & 0.021 & $*$ & I & 0.389 & & D & 0.184 & \\
\hline 1833 & $\mathrm{D}$ & 0.315 & & D & $<0.001$ & $*$ & D & 0.01 & $*$ \\
\hline 1836 & $\mathrm{D}$ & 0.465 & & D & $<0.001$ & $*$ & D & 0.001 & $*$ \\
\hline 1844 & I & $<0.001$ & $*$ & I & $<0.001$ & $*$ & I & $<0.001$ & $*$ \\
\hline 1847 & D & 0.966 & & D & 0.005 & $*$ & I & 0.006 & $*$ \\
\hline 1853 & D & 0.001 & $*$ & D & $<0.001$ & $*$ & $\mathrm{D}$ & 0.002 & $*$ \\
\hline 1857 & I & 0.036 & $*$ & I & 0.002 & $*$ & I & $<0.001$ & $*$ \\
\hline 1860 & $\mathrm{D}$ & 0.007 & $*$ & I & $<0.001$ & $*$ & I & 0.166 & \\
\hline 1864 & $\mathrm{D}$ & $<0.001$ & $*$ & I & 0.281 & & $\mathrm{D}$ & 0.532 & \\
\hline 1870 & I & 0.159 & & I & 0.003 & * & I & 0.009 & $*$ \\
\hline 1876 & I & 0.036 & $*$ & I & 0.465 & & I & 0.001 & $*$ \\
\hline 1882 & I & $<0.001$ & $*$ & I & $<0.001$ & $*$ & I & $<0.001$ & $*$ \\
\hline 1884 & D & 0.004 & $*$ & D & $<0.001$ & $*$ & D & $<0.001$ & $*$ \\
\hline 1886 & $\mathrm{D}$ & 0.609 & & I & 0.966 & & I & 0.065 & \\
\hline 1888 & I & $<0.001$ & $*$ & I & $<0.001$ & $*$ & I & $<0.001$ & $*$ \\
\hline 1892 & I & 0.274 & & I & 0.175 & & I & 0.268 & \\
\hline 1898 & I & 0.057 & & I & 0.95 & & D & 0.502 & \\
\hline 1907 & D & 0.058 & & D & 0.074 & & D & 0.083 & \\
\hline 1910 & I & 0.632 & & I & 0.821 & & D & 0.323 & \\
\hline 1917 & D & 0.768 & & D & 0.715 & & D & 0.578 & \\
\hline 1921 & I & 0.299 & & I & 0.108 & & I & 0.135 & \\
\hline 1932 & $\mathrm{D}$ & 0.647 & & $\mathrm{D}$ & 0.186 & & $\mathrm{D}$ & 0.085 & \\
\hline
\end{tabular}




\begin{tabular}{|c|c|c|c|c|c|c|c|c|c|}
\hline $\begin{array}{l}\text { Alley } \\
\text { Springs }\end{array}$ & & $\begin{array}{l}1 \mathrm{yr} \\
\text { growth }\end{array}$ & & & $\begin{array}{c}2 \mathrm{yr} \\
\text { growth }\end{array}$ & & & $\begin{array}{l}3 \mathrm{yr} \\
\text { growth }\end{array}$ & \\
\hline $\begin{array}{c}\text { Fire Year } \\
\mathbf{1 7 5 3}\end{array}$ & $\begin{array}{c}\text { Increase/ } \\
\text { Decrease } \\
\text { I }\end{array}$ & $\begin{array}{c}\mathrm{P} \text { value } \\
0.391\end{array}$ & & $\begin{array}{c}\text { Increase/ } \\
\text { Decrease } \\
\text { D }\end{array}$ & $\begin{array}{c}P \text { value } \\
0.978\end{array}$ & & $\begin{array}{c}\text { Increase/ } \\
\text { Decrease } \\
\text { I }\end{array}$ & $\begin{array}{c}\mathrm{P} \text { value } \\
0.808\end{array}$ & \\
\hline 1780 & D & 0.002 & $*$ & $\mathrm{D}$ & 0.048 & $*$ & $\mathrm{D}$ & 0.018 & $*$ \\
\hline 1784 & $\mathrm{D}$ & $<0.001$ & $*$ & $\mathrm{D}$ & $<0.001$ & $*$ & $\mathrm{D}$ & $<0.001$ & $*$ \\
\hline 1793 & $\mathrm{D}$ & 0.424 & & I & 0.376 & & I & 0.144 & \\
\hline 1796 & I & 0.310 & & I & 0.265 & & I & 0.449 & \\
\hline 1807 & $\mathrm{D}$ & 0.220 & & $\mathrm{D}$ & 0.449 & & $\mathrm{D}$ & 0.086 & \\
\hline 1819 & I & 0.003 & $*$ & $\mathrm{D}$ & 0.659 & & $\mathrm{D}$ & 0.252 & \\
\hline 1821 & I & 0.447 & & $\mathrm{D}$ & 0.59 & & $\mathrm{D}$ & 0.383 & \\
\hline 1835 & $\mathrm{D}$ & 0.484 & & $\mathrm{D}$ & 0.899 & & $\mathrm{D}$ & 0.203 & \\
\hline 1837 & $\mathrm{D}$ & 0.016 & $*$ & $\mathrm{D}$ & 0.009 & $*$ & $\mathrm{D}$ & 0.079 & \\
\hline 1842 & I & 0.021 & $*$ & $\mathrm{D}$ & 0.472 & & I & 0.158 & \\
\hline 1845 & I & 0.345 & & $\mathrm{D}$ & 0.118 & & $\mathrm{D}$ & 0.039 & $*$ \\
\hline 1847 & I & 0.100 & & I & 0.07 & & I & 0.021 & $*$ \\
\hline 1852 & $\mathrm{D}$ & 0.08 & & $\mathrm{D}$ & 0.016 & $*$ & $\mathrm{D}$ & 0.015 & $*$ \\
\hline 1858 & $\mathrm{D}$ & 0.374 & & I & 0.017 & $*$ & I & 0.026 & $*$ \\
\hline 1861 & I & 0.004 & $*$ & I & 0.037 & $*$ & I & 0.076 & \\
\hline 1865 & I & 0.005 & $*$ & I & 0.002 & $*$ & I & 0.011 & $*$ \\
\hline 1868 & I & 0.04 & $*$ & I & 0.045 & $*$ & I & 0.056 & \\
\hline 1875 & I & 0.003 & $*$ & I & 0.001 & $*$ & I & 0.007 & $*$ \\
\hline 1879 & $\mathrm{D}$ & 0.008 & $*$ & $\mathrm{D}$ & $<0.001$ & $*$ & $\mathrm{D}$ & $<0.001$ & $*$ \\
\hline 1886 & D & 0.508 & & D & 0.605 & & D & 0.754 & \\
\hline 1890 & $\mathrm{D}$ & 0.107 & & D & 0.009 & $*$ & $\mathrm{D}$ & 0.048 & $*$ \\
\hline 1895 & $\mathrm{D}$ & 0.577 & & I & 0.424 & & I & 0.54 & \\
\hline 1907 & $\mathrm{D}$ & 0.061 & & D & 0.296 & & $\mathrm{D}$ & 0.409 & \\
\hline 1909 & $\mathrm{D}$ & 0.727 & & $\mathrm{D}$ & 0.918 & & $\mathrm{D}$ & 0.015 & $*$ \\
\hline 1913 & $\mathrm{D}$ & 0.007 & $*$ & $\mathrm{D}$ & 0.01 & $*$ & $\mathrm{D}$ & 0.445 & \\
\hline 1915 & I & $<0.001$ & $*$ & $\mathrm{I}$ & $<0.001$ & $*$ & I & $<0.001$ & \\
\hline
\end{tabular}




\begin{tabular}{|c|c|c|c|c|c|c|c|c|c|}
\hline $\begin{array}{c}\text { Eck } \\
\text { Tract }\end{array}$ & & $\begin{array}{c}1 \mathrm{yr} \\
\text { Growth }\end{array}$ & & & $\begin{array}{c}2 \mathrm{yr} \\
\text { Growth }\end{array}$ & & & $\begin{array}{c}3 \mathrm{yr} \\
\text { Growth }\end{array}$ & \\
\hline Fire & Increase/ & & & Increase/ & & & Increase/ & & \\
\hline Year & Decrease & $P$ value & & Decrease & $P$ value & & Decrease & $\mathrm{P}$ value & \\
\hline 1822 & D & 0.048 & $*$ & $\mathrm{D}$ & 0.007 & $*$ & D & 0.009 & $*$ \\
\hline 1828 & $\mathrm{D}$ & 0.023 & $*$ & $\mathrm{D}$ & 0.007 & $*$ & $\mathrm{D}$ & 0.2 & \\
\hline 1830 & I & $<0.001$ & $*$ & I & 0.01 & $*$ & I & 0.039 & $*$ \\
\hline 1832 & $\mathrm{D}$ & 0.006 & $*$ & $\mathrm{D}$ & 0.412 & & $\mathrm{D}$ & 0.437 & \\
\hline 1837 & $\mathrm{D}$ & 0.053 & & $\mathrm{D}$ & $<0.001$ & $*$ & $\mathrm{D}$ & 0.002 & $*$ \\
\hline 1866 & $\mathrm{D}$ & $<0.001$ & $*$ & $\mathrm{D}$ & $<0.001$ & $*$ & $\mathrm{D}$ & $<0.001$ & $*$ \\
\hline 1869 & I & 0.042 & $*$ & I & 0.003 & $*$ & I & $<0.001$ & $*$ \\
\hline 1871 & I & $<0.001$ & $*$ & I & 0.002 & $*$ & I & 0.027 & $*$ \\
\hline 1879 & $\mathrm{D}$ & $<0.001$ & $*$ & $\mathrm{D}$ & 0.2 & & $\mathrm{D}$ & $<0.001$ & $*$ \\
\hline 1898 & I & 0.676 & & $\mathrm{D}$ & $<0.001$ & * & $\mathrm{D}$ & $<0.001$ & $*$ \\
\hline 1900 & I & $<0.001$ & * & I & 0.028 & $*$ & I & $<0.001$ & $*$ \\
\hline 1902 & I & $<0.001$ & $*$ & I & $<0.001$ & $*$ & I & $<0.001$ & $*$ \\
\hline 1907 & $\mathrm{D}$ & $<0.001$ & $*$ & $\mathrm{D}$ & 0.002 & $*$ & $\mathrm{D}$ & 0.256 & \\
\hline 1934 & $\mathrm{D}$ & 0.043 & $*$ & $\mathrm{I}$ & 0.004 & $*$ & $\mathrm{I}$ & 0.016 & $*$ \\
\hline
\end{tabular}

\begin{tabular}{|c|c|c|c|c|c|c|c|c|}
\hline $\begin{array}{c}\text { Hwy. } \\
19\end{array}$ & & $\begin{array}{c}1 \mathrm{yr} \\
\text { Growth }\end{array}$ & & & $\begin{array}{c}2 \mathrm{yr} \\
\text { Growth }\end{array}$ & & $\begin{array}{c}3 \mathrm{yr} \\
\text { Growth }\end{array}$ & \\
\hline Fire & Increase/ & & & Increase/ & & Increase/ & & \\
\hline Year & Decrease & $P$ value & & Decrease & $P$ value & Decrease & $P$ value & \\
\hline 1808 & I & 0.765 & & I & 0.638 & I & 0.365 & \\
\hline 1818 & D & 0.922 & & I & 0.349 & $\mathrm{D}$ & 0.143 & \\
\hline 1823 & I & 0.927 & & I & 0.308 & I & 1.000 & \\
\hline 1842 & I & $<0.001$ & $*$ & I & $<0.001$ & I & $<0.001$ & $*$ \\
\hline 1844 & I & $<0.001$ & $*$ & I & $<0.001$ & I & $<0.001$ & $*$ \\
\hline 1847 & D & $<0.001$ & $*$ & D & $<0.001$ & $\mathrm{D}$ & 0.005 & $*$ \\
\hline 1857 & I & 0.957 & & I & 0.054 & I & 0.008 & $*$ \\
\hline 1878 & I & 0.002 & $*$ & I & 0.731 & I & 0.822 & \\
\hline 1902 & I & 0.003 & $*$ & I & $<0.001$ & I & $<0.001$ & * \\
\hline 1905 & $\mathrm{D}$ & $<0.001$ & $*$ & D & $<0.001$ & $\mathrm{D}$ & $<0.001$ & $*$ \\
\hline 1907 & I & 0.442 & & I & 0.15 & I & 0.189 & \\
\hline 1912 & I & 0.119 & & I & 0.231 & I & 0.097 & \\
\hline 1922 & $\mathrm{D}$ & 0.671 & & I & 0.933 & I & 0.544 & \\
\hline
\end{tabular}




\section{APPENDIX C}

Appendix C includes samples of shortleaf pine and white oak that I collected or measured.

Release and suppression dates are based on the regime shift detection program (Rodionov 2004, 2005, 2006). 


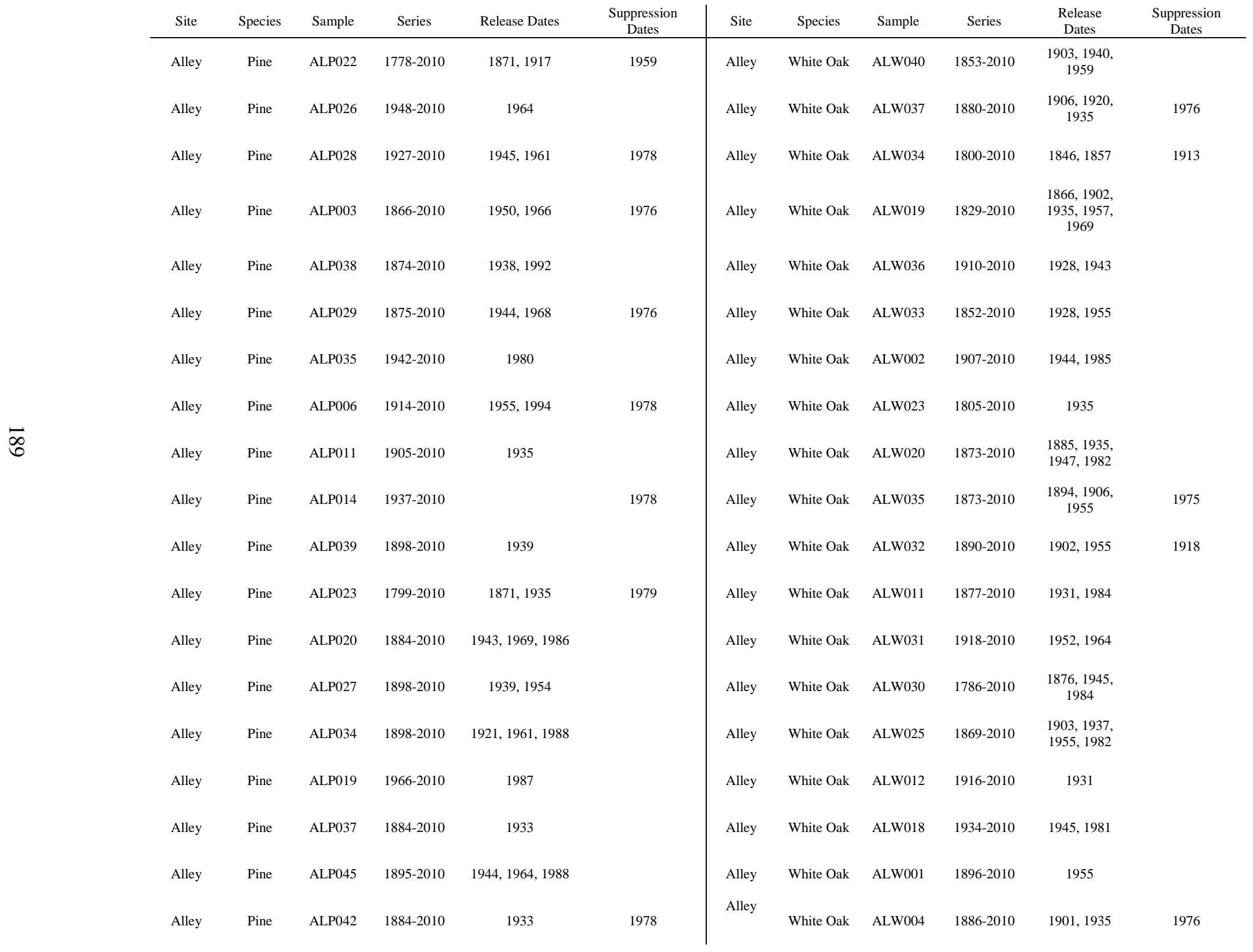




\begin{tabular}{|c|c|c|c|c|c|c|c|c|c|c|c|}
\hline Alley & Pine & ALP021 & $1917-2010$ & 1943, 1986 & & Alley & White Oak & ALW017 & $1932-2010$ & 1981 & \\
\hline Alley & Pine & ALP012 & $1890-2010$ & 1946, 1961 & 1978 & Alley & White Oak & ALW028 & $1814-2010$ & $\begin{array}{c}1857,1965 \\
1979\end{array}$ & \\
\hline Alley & Pine & ALP030 & $1882-2010$ & 1954, 1987 & & Alley & White Oak & ALW024 & $1781-2010$ & $\begin{array}{c}1863,1946 \\
1982\end{array}$ & \\
\hline Alley & Pine & ALP043 & $1868-2010$ & 1953, 1988 & 1977 & Alley & White Oak & ALW015 & 1929-2010 & 1941,1958 & \\
\hline Alley & Pine & ALP018 & $1887-2010$ & 1902,1954 & 1978 & Alley & White Oak & ALW026 & 1919-2010 & $\begin{array}{c}1939,1955 \\
1982\end{array}$ & \\
\hline Alley & Pine & ALP017 & $1881-2010$ & 1928, 1992 & 1949 & Alley & White Oak & ALW022 & 1730-1999 & $\begin{array}{c}1804,1825 \\
1924\end{array}$ & 1861 \\
\hline Alley & Pine & ALP032 & $1890-2010$ & $1945,1961,1990$ & & Alley & White Oak & ALW014 & $1935-2010$ & 1946, 1981 & \\
\hline Alley & Pine & ALP007 & $1877-2010$ & 1935 & 1958,1978 & Alley & White Oak & ALW010 & $1837-2010$ & $\begin{array}{c}1849,1911 \\
1927\end{array}$ & 1955 \\
\hline Alley & Pine & ALP008 & $1902-2010$ & 1934 & & Alley & White Oak & ALW039 & $1893-2010$ & 1950 & \\
\hline Alley & Pine & ALP001 & $1883-2010$ & & 1927,1976 & Alley & White Oak & ALW006 & 1903-2010 & 1975 & \\
\hline Alley & Pine & ALP025 & $1907-2010$ & 1922 & 1980 & Alley & White Oak & ALW005 & $1954-2010$ & 1963 & 1975 \\
\hline Alley & Pine & ALP002 & $1892-2010$ & 1964 & 1978 & Alley & White Oak & ALW003 & 1893-2010 & 1935,1957 & 1976 \\
\hline Alley & Pine & ALP031 & $1881-2010$ & $\begin{array}{c}1898,1956 \\
1969,1989\end{array}$ & & Alley & White Oak & ALW027 & $1845-2010$ & $\begin{array}{c}1859,1875 \\
1958\end{array}$ & \\
\hline Alley & Pine & ALP036 & $1938-2010$ & 1952,1987 & & Alley & White Oak & ALW007 & 1906-2010 & $\begin{array}{c}1920,1935 \\
1962,1984\end{array}$ & \\
\hline Alley & Pine & ALP044 & $1862-2010$ & 1904, 1968 & 1925 & Alley & White Oak & ALW029 & $1854-2010$ & 1900,1936 & \\
\hline Alley & Pine & ALP040 & $1849-2010$ & 1870,1981 & 1896 & Alley & White Oak & ALW013 & $1848-2010$ & $\begin{array}{c}1919,1931 \\
1981\end{array}$ & 1952 \\
\hline Alley & Pine & ALP009 & $1885-2010$ & 1937,1985 & & Alley & White Oak & ALW008 & $1837-2010$ & $\begin{array}{l}1858,1940 \\
1955,1984\end{array}$ & 1885 \\
\hline Alley & Pine & ALP016 & $1937-2010$ & 1951 & 1978 & Alley & White Oak & ALW048 & $1806-2010$ & $\begin{array}{l}1821,1838 \\
1886,1980\end{array}$ & \\
\hline Alley & Pine & ALP013 & $1935-2010$ & 1945 & & Alley & White Oak & ALW009 & $1932-2010$ & 1949 & 1974 \\
\hline Alley & Pine & ALP041 & $1920-2010$ & 1937,1987 & & Alley & White Oak & ALW016 & $1956-2010$ & & \\
\hline
\end{tabular}




\begin{tabular}{|c|c|c|c|c|c|}
\hline Alley & Pine & ALP004 & $1880-2010$ & $1919,1934,1987$ & 1958 \\
\hline Alley & Pine & ALP010 & 1869-2010 & 1941, 1986 & \\
\hline Alley & Pine & ALP005 & $1872-2010$ & 1903, 1969 & \\
\hline Alley & Pine & ALS016 & 1624-1831 & $1669,1738,1772$ & 1805 \\
\hline Alley & Pine & ALS013 & 1745-1869 & 1761 & 1820 \\
\hline Alley & Pine & ALS017 & $1762-1853$ & 1795,1840 & \\
\hline Alley & Pine & ALS002 & 1741-1896 & $1781,1830,1868$ & 1884 \\
\hline Alley & Pine & ALS003 & $1750-1848$ & 1790,1806 & 1832 \\
\hline Alley & Pine & ALS005 & $1758-1913$ & $1848,1868,1889$ & \\
\hline Alley & Pine & ALS007 & 1749-1901 & $1815,1871,1889$ & \\
\hline Alley & Pine & ALS010 & $1716-1827$ & 1753 & 1766 \\
\hline Alley & Pine & ALS009 & 1798-1928 & 1845 & \\
\hline Alley & Pine & ALS008 & $1747-1879$ & $1775,1804,1844$ & 1820 \\
\hline Alley & Pine & ALS012 & 1691-1844 & 1711 & 1820 \\
\hline Alley & Pine & ALS006 & $1763-1880$ & $\begin{array}{l}1829,1844, \\
1857,1868\end{array}$ & \\
\hline Alley & Pine & ALS015 & $1857-1973$ & 1874, 1937, 1961 & 1895 \\
\hline Alley & Pine & ALS001 & 1814-1918 & 1874,1889 & 1909 \\
\hline Alley & Pine & ALS018 & 1753-1874 & 1802,1829 & 1852 \\
\hline Alley & Pine & ALS009 & $1625-1800$ & $1680,1764,1789$ & 1720 \\
\hline Alley & Pine & ALY012 & 1823-1885 & $1844,1859,1872$ & \\
\hline
\end{tabular}




$\begin{array}{lccccc}\text { Alley } & \text { Pine } & \text { ALY005 } & 1746-1841 & 1783,1794 & 1820 \\ \text { Alley } & \text { Pine } & \text { ALY017 } & 1760-1844 & 1800,1828 & \\ \text { Alley } & \text { Pine } & \text { ALY003 } & 1748-1893 & 1804,1840,1871 & \\ \text { Alley } & \text { Pine } & \text { ALY004 } & 1745-1883 & & \\ \text { Alley } & \text { Pine } & \text { ALY002 } & 1759-1874 & 1842,1857 & \\ \text { Alley } & \text { Pine } & \text { ALY006 } & 1741-1894 & 1829 & 1864 \\ \text { Alley } & \text { Pine } & \text { ALY009 } & 1799-1918 & 1845,1870 & 1912\end{array}$




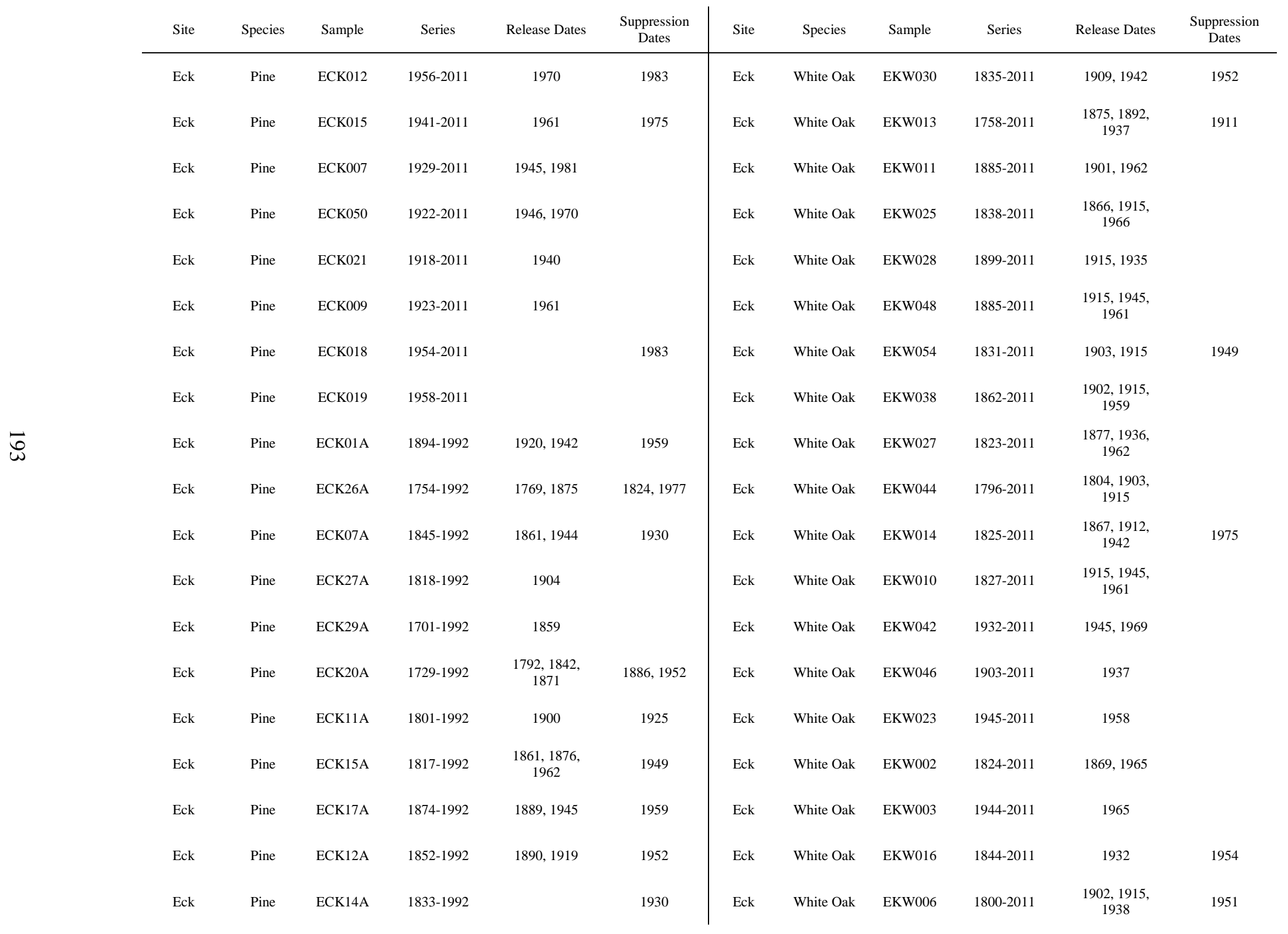




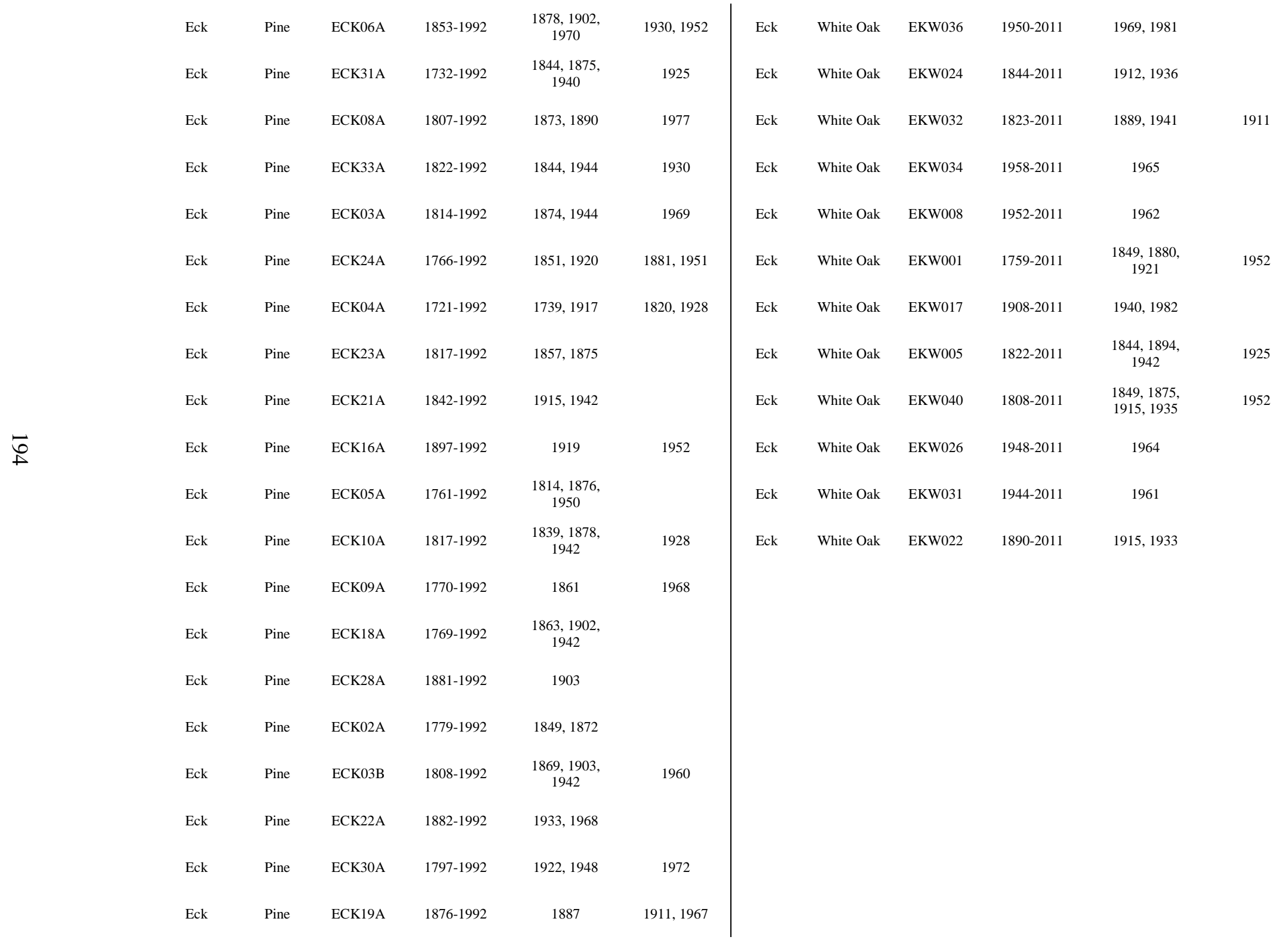




$\begin{array}{lcccc}\text { Eck } & \text { Pine } & \text { ECK25A } & 1851-1992 & 1880,1942 \\ \text { Eck } & \text { Pine } & \text { EKS003 } & 1823-1874 & 1845 \\ \text { Eck } & \text { Pine } & \text { EKS005 } & 1842-1886 & 1863 \\ \text { Eck } & \text { Pine } & \text { EKS018 } & 1955-2008 & 1972 \\ \text { Eck } & \text { Pine } & \text { EKS007 } & 1822-1878 & 1847 \\ \text { Eck } & \text { Pine } & \text { EKS002 } & 1844-1905 & 1860 \\ \text { Eck } & \text { Pine } & \text { EKS014 } & 1852-1952 & 1905\end{array}$




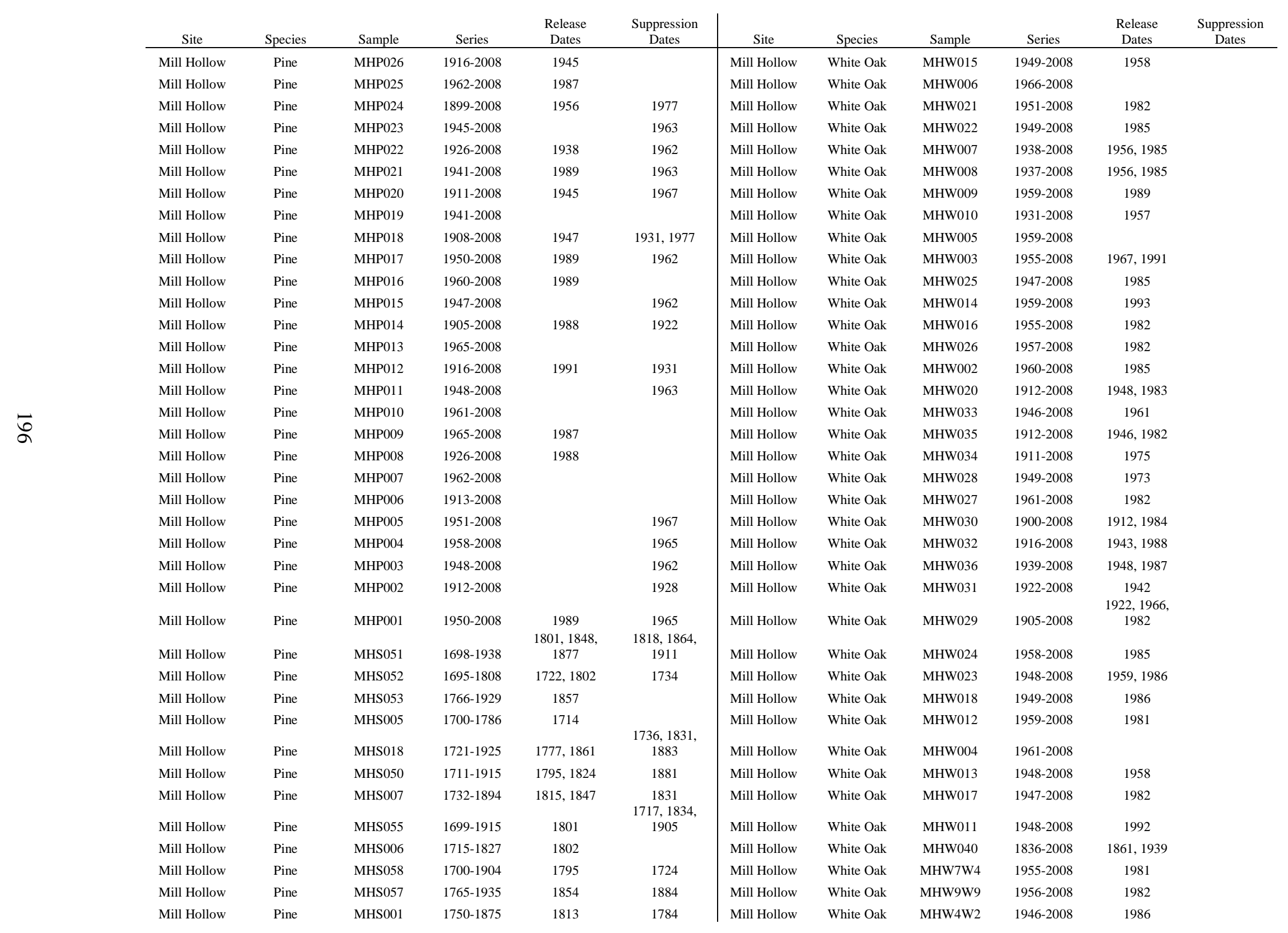




\begin{tabular}{|c|c|c|c|c|c|c|c|c|c|c|}
\hline Mill Hollow & Pine & MHS019 & 1754-1863 & & 1780 & Mill Hollow & White Oak & MHW9W1 & 1953-2008 & 1989 \\
\hline Mill Hollow & Pine & MHS011 & $1709-1914$ & & 1751 & Mill Hollow & White Oak & MH11W1 & $1947-2008$ & 1986 \\
\hline Mill Hollow & Pine & MHS056 & $1670-1800$ & 1764,1792 & & Mill Hollow & White Oak & MHW3W2 & $1957-2008$ & 1986 \\
\hline Mill Hollow & Pine & MHS015 & $1723-1872$ & 1808 & 1745 & Mill Hollow & White Oak & MHW4W3 & $1945-2008$ & 1982 \\
\hline Mill Hollow & Pine & MHS034 & $1695-1908$ & 1904 & 1727 & Mill Hollow & White Oak & MHW5W3 & 1949-2008 & 1983 \\
\hline Mill Hollow & Pine & MHS014 & $1749-1877$ & 1805 & 1782,1820 & Mill Hollow & White Oak & MHW7W1 & $1950-2009$ & 1985 \\
\hline Mill Hollow & Pine & MHS008 & $1696-1864$ & 1776 & 1835 & Mill Hollow & White Oak & MHW8W2 & 1943-2009 & 1992 \\
\hline Mill Hollow & Pine & MHS007 & $1754-1891$ & & & Mill Hollow & White Oak & MHW7W3 & 1954-2009 & 1967,1987 \\
\hline Mill Hollow & Pine & MHS013 & 1763-1914 & 1802,1849 & 1881 & Mill Hollow & White Oak & MHW3W3 & 1959-2009 & 1988 \\
\hline Mill Hollow & Pine & MHS012 & 1732-1894 & 1842 & & Mill Hollow & White Oak & MHW5W1 & $1948-2008$ & 1967, 1984 \\
\hline Mill Hollow & Pine & MHS002 & $1760-1898$ & 1802,1845 & & Mill Hollow & White Oak & MHW038 & 1948-2009 & 1967,1982 \\
\hline Mill Hollow & Pine & MHS021 & $1731-1861$ & 1813 & & Mill Hollow & White Oak & MHW039 & 1929-2009 & 1945 \\
\hline Mill Hollow & Pine & MHS022 & $1721-1841$ & 1804 & 1832 & Mill Hollow & White Oak & MH11W2 & $1954-2009$ & 1965,1982 \\
\hline Mill Hollow & Pine & MHS024 & $1720-1904$ & 1813 & 1746,1866 & Mill Hollow & White Oak & MHW5W6 & 1959-2009 & 1983 \\
\hline Mill Hollow & Pine & MHS020 & 1771-1931 & 1839,1889 & 1872 & Mill Hollow & White Oak & MHW2W7 & 1919-2009 & 1957, 1987 \\
\hline Mill Hollow & Pine & MHS023 & $1712-1889$ & 1841 & 1867 & Mill Hollow & White Oak & MHW5W4 & 1953-2009 & 1978 \\
\hline Mill Hollow & Pine & MHS025 & 1689-1805 & 1726 & & Mill Hollow & White Oak & MHW041 & 1915-2009 & 1945 \\
\hline
\end{tabular}




\begin{tabular}{|c|c|c|c|c|c|c|c|c|c|c|c|c|}
\hline & Site & Species & Sample & Series & $\begin{array}{l}\text { Release } \\
\text { Dates }\end{array}$ & $\begin{array}{l}\text { Suppression } \\
\text { Dates }\end{array}$ & Site & Species & Sample & Series & $\begin{array}{l}\text { Release } \\
\text { Dates }\end{array}$ & $\begin{array}{l}\text { Suppression } \\
\text { Dates }\end{array}$ \\
\hline & Hwy.19 & Pine & HWY036 & 1884-1942 & & 1895,1912 & Hwy.19 & White Oak & HWY004 & $1952-2010$ & 1976 & \\
\hline & Hwy. 19 & Pine & HWY035 & $1814-1878$ & 1875 & & Hwy. 19 & White Oak & HWY002 & $1945-2010$ & 1978 & \\
\hline & Hwy.19 & Pine & HWY014 & $1808-1888$ & 1870 & 1820 & Hwy.19 & White Oak & HWY003 & $1957-2010$ & 1977 & \\
\hline & Hwy.19 & Pine & HWY065 & $1807-1900$ & & 1820 & Hwy.19 & White Oak & HWY014 & $1960-2010$ & 1976 & \\
\hline & Hwy.19 & Pine & HWY057 & $1800-1887$ & & 1837 & Hwy.19 & White Oak & HWY016 & $1960-2010$ & 1973 & \\
\hline & Hwy.19 & Pine & HWY006 & 1821-1905 & 1861 & 1836 & Hwy.19 & White Oak & HWY022 & $1952-2010$ & 1967,1982 & \\
\hline & Hwy.19 & Pine & HWY026 & $1638-1720$ & & & Hwy.19 & White Oak & HWY001 & $1941-2010$ & 1977 & \\
\hline & Hwy.19 & Pine & HWY029 & $1630-1740$ & & 1647 & Hwy.19 & White Oak & HWY008 & $1951-2010$ & 1964 & \\
\hline & Hwy.19 & Pine & HWY083 & 1809-1879 & 1862 & & Hwy.19 & White Oak & HWY018 & $1928-2010$ & 1948 & \\
\hline & Hwy.19 & Pine & HWY082 & $1752-1833$ & 1806 & 1768 & Hwy.19 & White Oak & HWY027 & $1907-2010$ & 1945 & 1987 \\
\hline & Hwy.19 & Pine & HWY002 & $1803-1855$ & & 1817 & Hwy.19 & White Oak & HWY024 & $1953-2010$ & 1975 & \\
\hline & Hwy.19 & Pine & HWY044 & 1804-1869 & & & Hwy.19 & White Oak & HWY028 & $1834-2010$ & 1948,1982 & \\
\hline & Hwy.19 & Pine & HWY030 & 1809-1912 & & 1836 & Hwy.19 & White Oak & HWY047 & $1951-2010$ & 1963, 1981 & \\
\hline & Hwy.19 & Pine & HWY048 & $1810-1910$ & 1858,1901 & 1820 & Hwy.19 & White Oak & HWY049 & $1863-2010$ & 1945 & \\
\hline & Hwy.19 & Pine & HWY019 & $1816-1902$ & 1855 & 1879 & Hwy.19 & White Oak & HWY031 & $1870-2010$ & 1902,1942 & 1977 \\
\hline & Hwy.19 & Pine & HWY004 & $1815-1901$ & 1871 & 1832 & Hwy.19 & White Oak & HWY048 & $1881-2010$ & 1903, 1957 & \\
\hline & Hwy.19 & Pine & & & 1870,1900 & & & & & & $\begin{array}{c}1897,1945, \\
1974\end{array}$ & \\
\hline & $\begin{array}{l}\text { Hwy.19 } \\
\text { Hwy.19 }\end{array}$ & Pine & $\begin{array}{l}\text { HWY025 } \\
\text { HWY095 }\end{array}$ & $\begin{array}{l}1818-1906 \\
1806-1910\end{array}$ & $18 / 0,1900$ & $\begin{array}{l}1832 \\
1820\end{array}$ & $\begin{array}{l}\text { Hwy.19 } \\
\text { Hwy.19 }\end{array}$ & $\begin{array}{l}\text { White Oak } \\
\text { White Oak }\end{array}$ & $\begin{array}{l}\text { HWY032 } \\
\text { HWY072 }\end{array}$ & $\begin{array}{l}1860-2010 \\
1887-2010\end{array}$ & $\begin{array}{c}1974 \\
1957,1981\end{array}$ & \\
\hline & & & & 1806-1910 & & & Hwy.19 & White Oak & HWY072 & $1887-2010$ & $\begin{array}{c}1957,1981 \\
1894,1908\end{array}$ & \\
\hline & Hwy.19 & Pine & HWY016 & 1804-1918 & & 1818 & Hwy.19 & White Oak & HWY063 & $1846-2010$ & 1947 & \\
\hline & Hwy.19 & Pine & HWY043 & 1814-1917 & 1858 & 1831 & Hwy.19 & White Oak & HWY054 & $1831-2010$ & 1955,1985 & \\
\hline & & & & & & & & & & & 1902,1945 & \\
\hline & Hwy.19 & Pine & HWY001 & $1799-1878$ & & 1823 & Hwy.19 & White Oak & HWY064 & $1795-2010$ & 1982 & \\
\hline & Hwy.19 & Pine & HWY069 & $1943-2010$ & 1955 & 1978 & Hwy.19 & White Oak & HWY046 & $1898-2010$ & 1945,1986 & \\
\hline & Hwy.19 & Pine & HWY061 & $1947-2010$ & 1992 & & Hwy.19 & White Oak & HWY057 & $1857-2010$ & 1887,1955 & \\
\hline & Hwy.19 & Pine & HWY062 & $1915-2010$ & & 1978 & Hwy.19 & White Oak & HWY052 & $1863-2010$ & 1945,1955 & 1975 \\
\hline & & Pine & & & & & & & & & $\begin{array}{c}1892,1945 \\
1955\end{array}$ & \\
\hline & $\begin{array}{l}\text { Hwy.19 } \\
\text { Hwy.19 }\end{array}$ & $\begin{array}{l}\text { Pine } \\
\text { Pine }\end{array}$ & $\begin{array}{l}\text { HWY063 } \\
\text { HWY064 }\end{array}$ & $\begin{array}{l}1934-2010 \\
1906-2010\end{array}$ & $\begin{array}{l}1960 \\
1960\end{array}$ & $\begin{array}{l}1978 \\
1978\end{array}$ & $\begin{array}{l}\text { Hwy.19 } \\
\text { Hwy.19 }\end{array}$ & $\begin{array}{l}\text { White Oak } \\
\text { White Oak }\end{array}$ & $\begin{array}{l}\text { HWY050 } \\
\text { HWY051 }\end{array}$ & $\begin{array}{l}1839-2010 \\
1895-2010\end{array}$ & $\begin{array}{c}1955 \\
1945,1956\end{array}$ & 1976 \\
\hline & $\begin{array}{l}\text { Hwy.19 } \\
\text { Hwy.19 }\end{array}$ & Pine & HWY065 & $1960-2010$ & & 1975 & Hwy.19 & White Oak & $\begin{array}{l}\text { HWY058 } \\
\text { HWY }\end{array}$ & $1879-2010$ & 1936,1957 & \\
\hline & Hwy.19 & Pine & HWY066 & $1939-2010$ & 1955 & 1974 & Hwy.19 & White Oak & HWY055 & 1826-2010 & 1935,1955 & 1978 \\
\hline & & & & & & & & & & & 1889, 1945, & \\
\hline & Hwy.19 & Pine & HWY067 & 1932-2010 & 1967 & 1946 & Hwy.19 & White Oak & HWY073 & 1837-2010 & 1955 & \\
\hline & Hwy.19 & Pine & HWY072 & $1939-2010$ & 1956 & 1978 & Hwy.19 & White Oak & HWY061 & $1939-2010$ & 1960 & \\
\hline & Hwy.19 & Pine & HWY071 & $1895-2010$ & 1966 & & Hwy.19 & White Oak & HWY053 & 1911-2010 & 1956, 1982 & \\
\hline & Hwy.19 & Pine & HWY073 & $1905-2010$ & 1952 & 1968 & Hwy.19 & White Oak & HWY065 & 1913-2010 & 1938,1955 & 1978 \\
\hline & Hwy.19 & Pine & HWY076 & $1952-2010$ & & 1993 & Hwy.19 & White Oak & HWY068 & $1937-2010$ & 1957 & \\
\hline & Hwy.19 & Pine & HWY077 & $1935-2010$ & & 1965 & Hwy.19 & White Oak & HWY070 & $1946-2010$ & 1959, 1987 & \\
\hline & Hwy.19 & Pine & HWY070 & $1765-2009$ & 1790 & 1833 & Hwy.19 & White Oak & HWY042 & $1912-2010$ & 1945, 1958 & 1975 \\
\hline & Hwy.19 & Pine & HWY048 & $1877-2010$ & 1903 & 1887 & Hwy.19 & White Oak & HWY044 & $1951-2010$ & 1981 & \\
\hline & Hwy.19 & Pine & HWY029 & $1794-2010$ & & 1817,1864 & Hwy.19 & White Oak & HWY075 & $1953-2010$ & 1963 & \\
\hline & Hwy.19 & Pine & HWY059 & $1887-2010$ & 1954 & 1978 & Hwy.19 & White Oak & HWY071 & $1886-2010$ & 1945,1955 & \\
\hline & Hwy.19 & Pine & HWY049 & $1895-2010$ & 1950 & 1925 & Hwy.19 & White Oak & HWY083 & $1934-2010$ & 1958,1981 & \\
\hline & Hwy.19 & Pine & HWY047 & $1936-2010$ & & & Hwy.19 & White Oak & HWY056 & $1942-2010$ & 1957,1982 & \\
\hline & Hwy.19 & Pine & HWY045 & $1958-2010$ & & & Hwy.19 & White Oak & HWY066 & $1962-2010$ & 1981 & \\
\hline & Hwy.19 & Pine & HWY060 & $1957-2010$ & & & Hwy.19 & White Oak & HWY045 & $1949-2010$ & 1981 & \\
\hline & Hwy.19 & Pine & HWY041 & 1949-2010 & & & Hwy.19 & White Oak & HWY077 & $1966-2010$ & 1979 & \\
\hline & Hwy.19 & Pine & HWY042 & $1960-2010$ & & 1977 & Hwy.19 & White Oak & HWY062 & $1933-2010$ & 1960 & \\
\hline & Hwy.19 & Pine & HWY044 & 1949-2010 & & 1975 & Hwy.19 & White Oak & HWY069 & $1962-2010$ & 1979 & \\
\hline & Hwy.19 & Pine & HWY046 & $1955-2010$ & & 1975 & Hwy.19 & White Oak & HWY036 & $1928-2010$ & 1986 & \\
\hline & Hwy.19 & Pine & HWY057 & $1900-2010$ & 1963 & 1929 & Hwy.19 & White Oak & HWY043 & $1950-2010$ & 1988 & \\
\hline
\end{tabular}




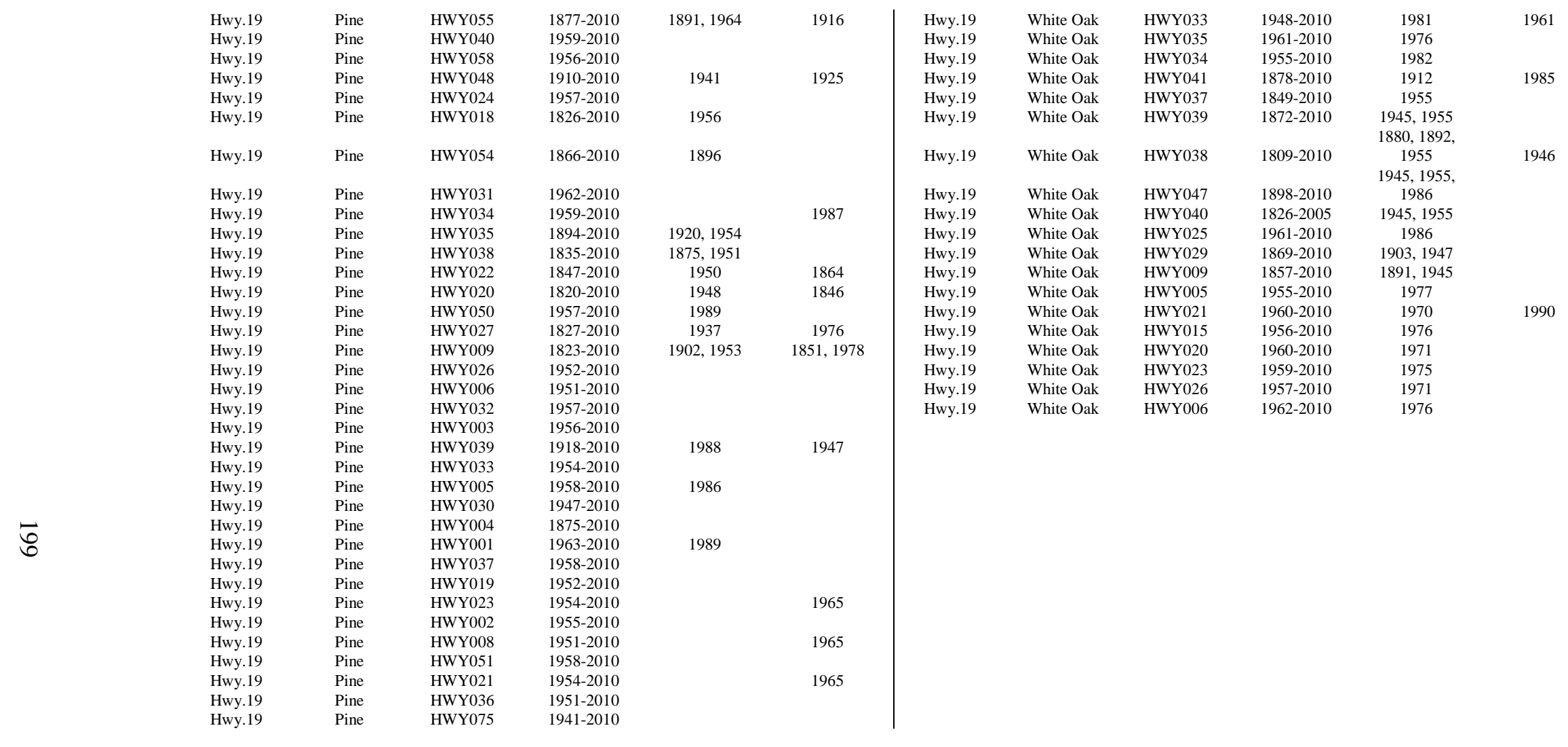




\section{APPENDIX D}

Composite fire scar chronologies based on remnant wood samples that I collected or measured. 


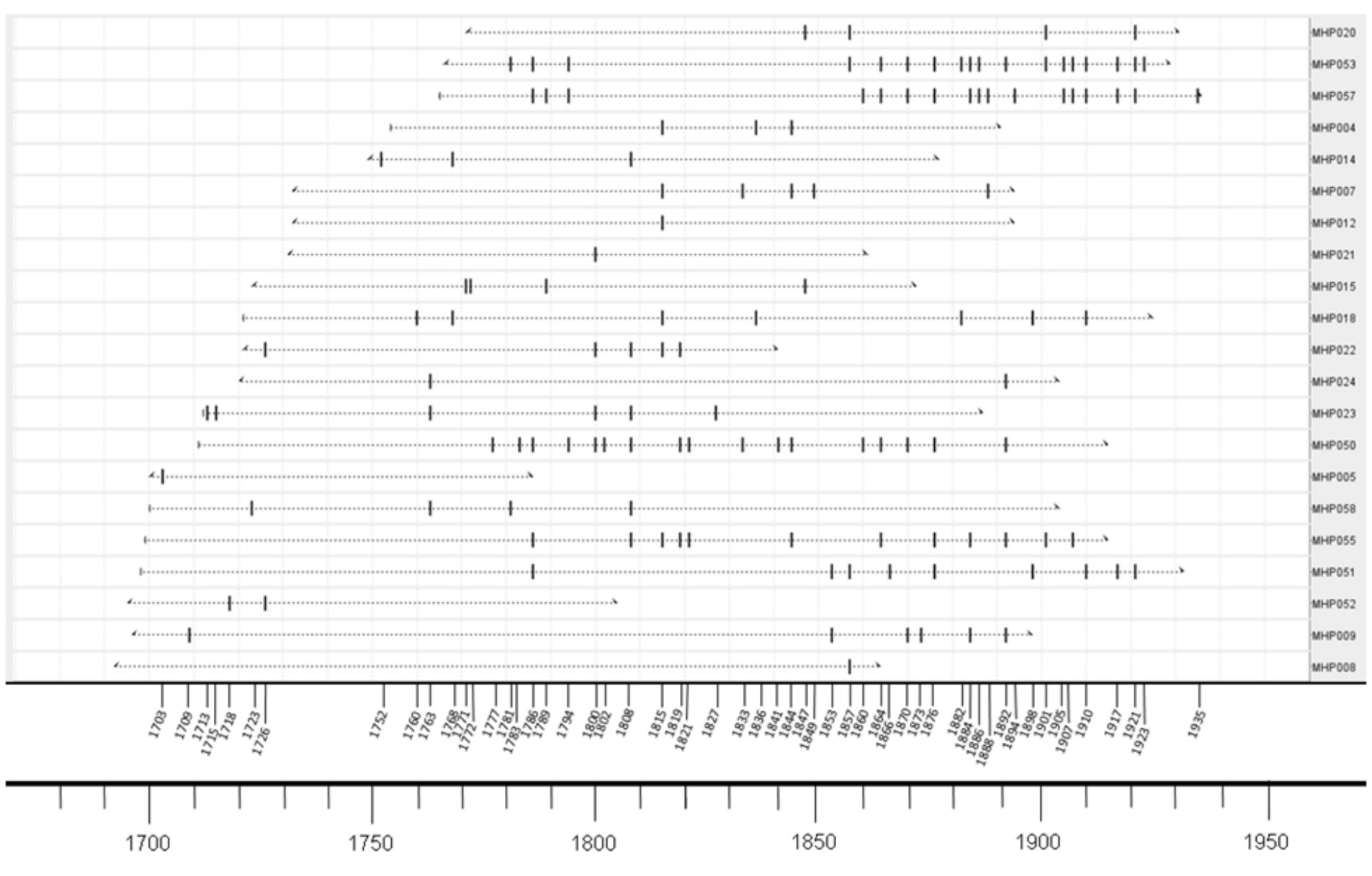

Mill Hollow fire chronology showing fire scar dates from individual trees and fire scar composite chronology for the site. Horizontal lines indicate length of the tree-ring series for individual trees. Vertical dashes indicate the year the tree was scarred by a fire. The composite fire scar chronology is shown at the bottom of the figure. 


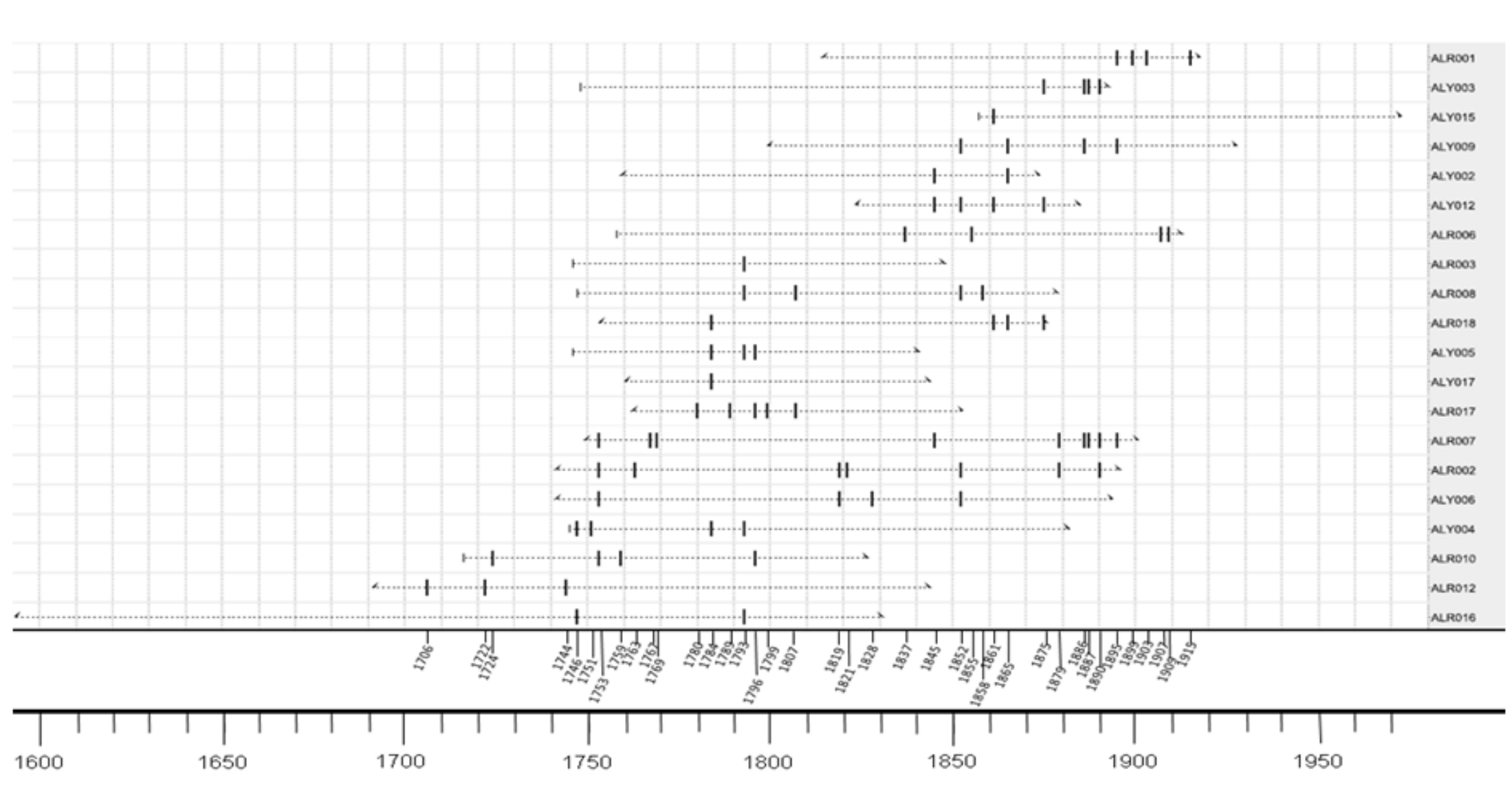

Alley Springs fire chronology showing fire scar dates from individual trees and fire scar composite chronology for the site. Horizontal lines indicate length of the tree-ring series for individual trees. Vertical dashes indicate the year the tree was scarred by a fire. The composite fire scar chronology is shown at the bottom of the figure. 


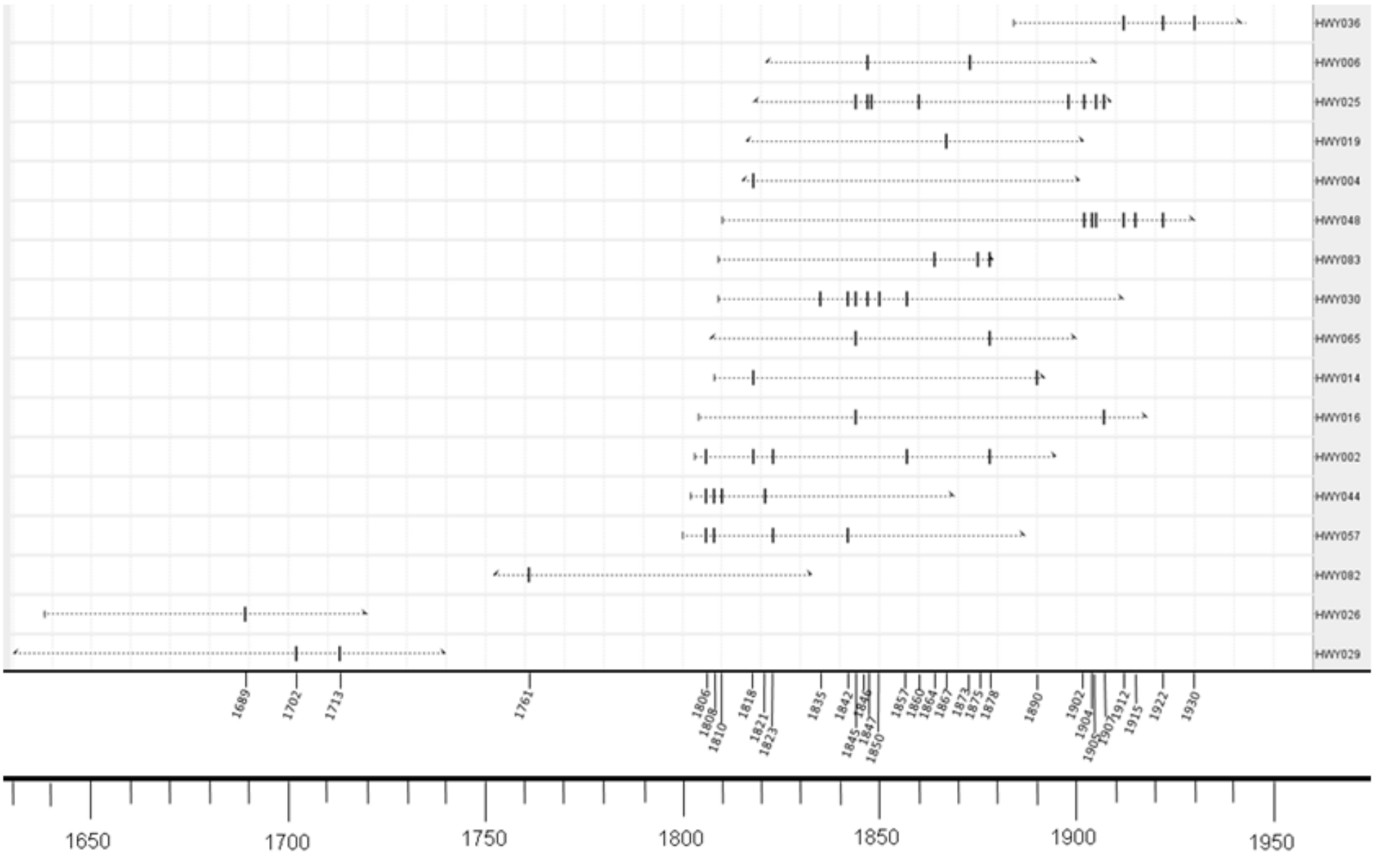

Hwy. 19 fire chronology showing fire scar dates from individual trees and fire scar composite chronology for the site. Horizontal lines indicate length of the tree-ring series for individual trees. Vertical dashes indicate the year the tree was scarred by a fire. The composite fire scar chronology is shown at the bottom of the figure. 


\section{VITA}

Chad King is a native of Nebraska. He grew up in a time when there were only three television stations and there was an expectation of exploring and playing in the outdoors. While he did not know it at the time, his childhood likely influenced his interest in science later in life. He graduated from Lexington High School in Lexington, Nebraska in 1990. Chad received a Bachelor's Degree in Biology from Wayne State College in Wayne, Nebraska and a Master of Arts Degree in Biology from the University of South Dakota in Vermillion, South Dakota. His interest in science stemmed from a college class he took on vertebrate biology with Mr. Schock at Wayne State College. Since that time, Chad has pursued activities and interests in the biological and ecological sciences. Chad has been part of research projects in California, Colorado, Pennsylvania, Wyoming, South Dakota, and Missouri. He spent four years teaching high school science in Texas and seven years as an instructor at the University of Central Missouri in Warrensburg, Missouri prior to returning to the doctoral program at the University of Missouri.

Chad enjoys spending time exploring the outdoors and gardening. He especially likes spending downtime with his wife and son as well as traveling with them. He likes doing outreach activities with people ranging from elementary age to adults. His interests lie in communicating with the general public about science and the amazing world in which we live. 